UNIVERSIDAD NACIONAL DE LA PLATA

FACULTAD DE HUMANIDADES Y CIENCIAS DE LA EDUCACIÓN DOCTORADO EN GEOGRAFÍA

Tesis para optar por el grado de Doctor en Geografía

\title{
PELIGROSIDAD Y VULNERABILIDAD DE ÁREAS COSTERAS URBANAS DEL LAGO NAHUEL HUAPI FRENTE A EVENTOS VOLCÁNICOS Y TSUNAMIGÉNICOS
}

Autor
Lic. Agustín Delménico
Dr. Gustavocción Villarosa
Dra. Débora Beigt
$\frac{\text { Co-Dirección }}{\text { Dra. María Isabel Andrade }}$

San Carlos de Bariloche, 31 de Octubre de 2018 


\section{ÍNDICE}

1.1 Fundamentación del tema de investigación 7

1.2 Antecedentes sobre la temática

1.3 Caída de ceniza volcánica y tsunamis lacustres: definiciones conceptuales 11

1.4 Peligrosidad y vulnerabilidad: aproximaciones teóricas 13

1.5 Hacia una perspectiva geográfica en la concepción de la vulnerabilidad y los riesgos $\quad 17$

1.6 Enfoques teórico-metodológicos actuales en materia de Riesgo, Vulnerabilidad y Desastres en Latinoamérica

1.6.1 Red de Estudios Sociales en Prevención de Desastres en América Latina (La RED)

1.6.2 La Teoría Social del Riesgo 21

1.6.3 Modelo de Presión y Liberación de los Desastres (PAR) 22

1.6.4 Investigación Forénsica de Desastres (FORIN) 23

1.7 Riesgo, vulnerabilidad y desastres en perspectiva teórica: una discusión abierta $\quad 25$

1.8 Bibliografía del capítulo 30

CAPÍTULO II: FORMULACIÓN DEL PROBLEMA DE INVESTIGACIÓN 38

2.1 Formulación del problema 39

2.2 Objetivos 40

2.3 Hipótesis $\quad 41$

2.3.1 Hipótesis específica relacionada a eventos volcánicos 41

2.3.2 Hipótesis específica relacionada a fenómenos tsunamigénicos lacustres $\quad 42$

2.4 Fuentes de información $\quad 43$

2.5 Limitaciones en el proceso de investigación $\quad 45$

2.6 Bibliografía del capítulo 47

CAPÍTULO III: LA REGIÓN DEL NAHUEL HUAPI $\quad 48$

3.1 Historia de la región del Nahuel Huapi $\quad 49$

3.2 Aspectos físicos del territorio

3.3 Principales actividades económicas de la región $\quad 56$

3.4 La población de la región según los censos: crecimiento acelerado y urbanización $\quad 56$

3.4.1 La población de los departamentos de la región del Nahuel Huapi $\quad 57$

3.4.2 La población de las localidades costeras del lago Nahuel Huapi 58

3.4.3 Los aspectos demográficos y su vinculación con el riesgo

3.4.4 Departamentos Bariloche y Pilcaniyeu (Provincia de Río Negro) 60

3.4.5 Departamento Los Lagos (Provincia de Neuquén) 62 
4.1.1 Cronología de eventos: Modelos bayesianos con OxCal

4.2 Erupciones recientes en Norpatagonia Andina: la experiencia del Cordón Caulle en 2011

4.2.1 Efectos en la actividad turística

4.2.2 El turismo en San Carlos de Bariloche

4.2.3 El turismo en Villa La Angostura

4.4 Aspectos metodológicos: indicadores censales y estimación de la vulnerabilidad

4.4.1 El rol de las condiciones demográficas y habitacionales en la vulnerabilidad frente a la caída de ceniza volcánica

4.4.2 Mapas de vulnerabilidad social para las localidades costeras del lago Nahuel Huapi

4.5 Bibliografía del capítulo

CAPÍTULO V: VULNERABILIDAD FRENTE A PROCESOS TSUNAMIGÉNICOS EN EL LAGO NAHUEL HUAPI

5.2 El tsunami lacustre de 1960 en el Lago Nahuel Huapi

5.2.1 Bariloche en 1960

5.2.2 El sismo de Valdivia del 22 de Mayo de 1960 136

5.2.3 El tsunami del lago Nahuel Huapi 137

5.2.4 Las erupciones del Cordón Caulle y Calbuco 139

5.2.5 Conclusiones de las entrevistas

5.3 Aspectos regionales relevantes en relación a la vulnerabilidad frente a tsunamis

5.3.1 San Carlos de Bariloche-Dina Huapi 
PELIGROSIDAD Y VULNERABILIDAD DE ÁREAS COSTERAS URBANAS DEL LAGO NAHUEL HUAPI FRENTE A EVENTOS VOLCÁNICOS Y TSUNAMIGÉNICOS

Lic. Agustín Delménico

5.4 .1 Sismicidad 144

5.4 .2 Deslizamientos subacuáticos y corrientes de densidad 146

5.5 Factores precondicionantes de impactos de una ola de tsunami en el lago Nahuel Huapi 163

5.5 .1 Vegetación

5.5 .2 Morfología costera

5.5 .3 Litología 167

$5.5 .4 \quad$ Nivel del lago 170

5.5 .5 Pendientes 171

$5.5 .6 \quad$ Accesibilidad 173

5.5 .7 Muelles y puertos 176

5.5.8 Playas públicas

5.5.9 Densidad de población 179

5.6 Ponderación de variables 180

5.7 Resultados y conclusiones 184

5.8 Bibliografía del capítulo 187

CAPÍTULO VI: CONCLUSIONES

AGRADECIMIENTOS

ANEXO 


\section{RESUMEN}

El objetivo de la investigación consistió en establecer bases metodológicas para la identificación y análisis de la peligrosidad y la vulnerabilidad de las áreas urbanizadas en grandes lagos de Patagonia Norte ante erupciones volcánicas y olas extraordinarias (olas tipo tsunami), basado en el análisis de indicadores referidos a los factores naturales desencadenantes y precondicionantes de estos fenómenos, e indicadores relacionados con la vulnerabilidad de las localidades costeras.

La Norpatagonia andina se encuentra bajo la influencia de las erupciones explosivas de los volcanes cordilleranos de la Zona Volcánica Sur, con alta exposición a recurrentes caídas de cenizas volcánicas generadas en las erupciones explosivas y transportadas por los vientos dominantes del oeste. Se ha sugerido además que los niveles de tefra ubicados a distintas profundidades en el lecho del lago Nahuel Huapi pueden constituir potenciales planos de deslizamiento de los sedimentos suprayacentes. El sistema de subducción es responsable además de una marcada sismicidad, a la que se han asociado fenómenos de remoción en masa subaéreos y subacuáticos que introducen y/o movilizan grandes volúmenes de sedimentos en los lechos lacustres, pudiendo generar olas extraordinarias.

Un fenómeno natural potencialmente peligroso se convierte en amenaza para un grupo humano solamente cuando éste es vulnerable. La vulnerabilidad social remite a las condiciones o procesos de diversa índole que anteceden a una amenaza natural y determinan los impactos.

En primer lugar, a partir de los impactos inherentes a una caída de ceniza volcánica, se analizaron indicadores censales que permitieran construir una metodología específica para evaluar la vulnerabilidad frente a la caída de material piroclástico. Como resultado, el material predominante de la cubierta exterior del techo, la procedencia del agua de beber y cocinar, las viviendas inconvenientes, el hacinamiento, la desocupación, la presencia de hogares con Jefe de hogar femenino, el analfabetismo y la leña y/o carbón como combustible usado principalmente para cocinar, emergieron como los indicadores censales apropiados para analizar la vulnerabilidad social. Posteriormente, se ponderaron las variables a partir de diferentes metodologías para elaborar mapas de vulnerabilidad social.

En segundo lugar, en lo que respecta a los impactos de un tsunami lacustre, se procedió a su evaluación a través de distintos factores -condicionantes y precondicionantesque permitieran reconocer grados de vulnerabilidad social. Las variables que determinan los impactos de una ola extraordinaria, tales como la densidad de población, la infraestructura costera (muelles y puertos), la vegetación, los deslizamientos subacuáticos (incluyendo sectores deslizados y aún sin deslizar), la presencia de playas públicas, las pendientes, las formas costeras, los accesos y la litología, fueron ponderadas para finalmente elaborar mapas de vulnerabilidad social.

Entre los resultados y aportes sobresale el enfoque dedicado a dos fenómenos naturales poco estudiados y muy relevantes en la región, así como la especificidad de cada peligro, lo cual derivó en la necesidad de construir diferentes metodologías para determinar grados de vulnerabilidad social frente a cada una de ellos. Amplias áreas urbanas, sobre todo en torno a la localidad de San Carlos de Bariloche, muestran valores de vulnerabilidad altos tanto frente a caída de ceniza volcánica como a los impactos de tsunamis lacustres. El desafío a superar en materia de gestión de riesgos se encuentra en el aspecto político/administrativo. Las múltiples jurisdicciones que conforman las poblaciones urbanas de la región del Nahuel Huapi dificultan la gestión integrada de riesgos.

\section{PALABRAS CLAVE}

Riesgos - Vulnerabilidad - Peligrosidad natural - Ceniza volcánica - Tsunamis lacustres 


\section{CAPÍTULO I}

\section{INTRODUCCIÓN}

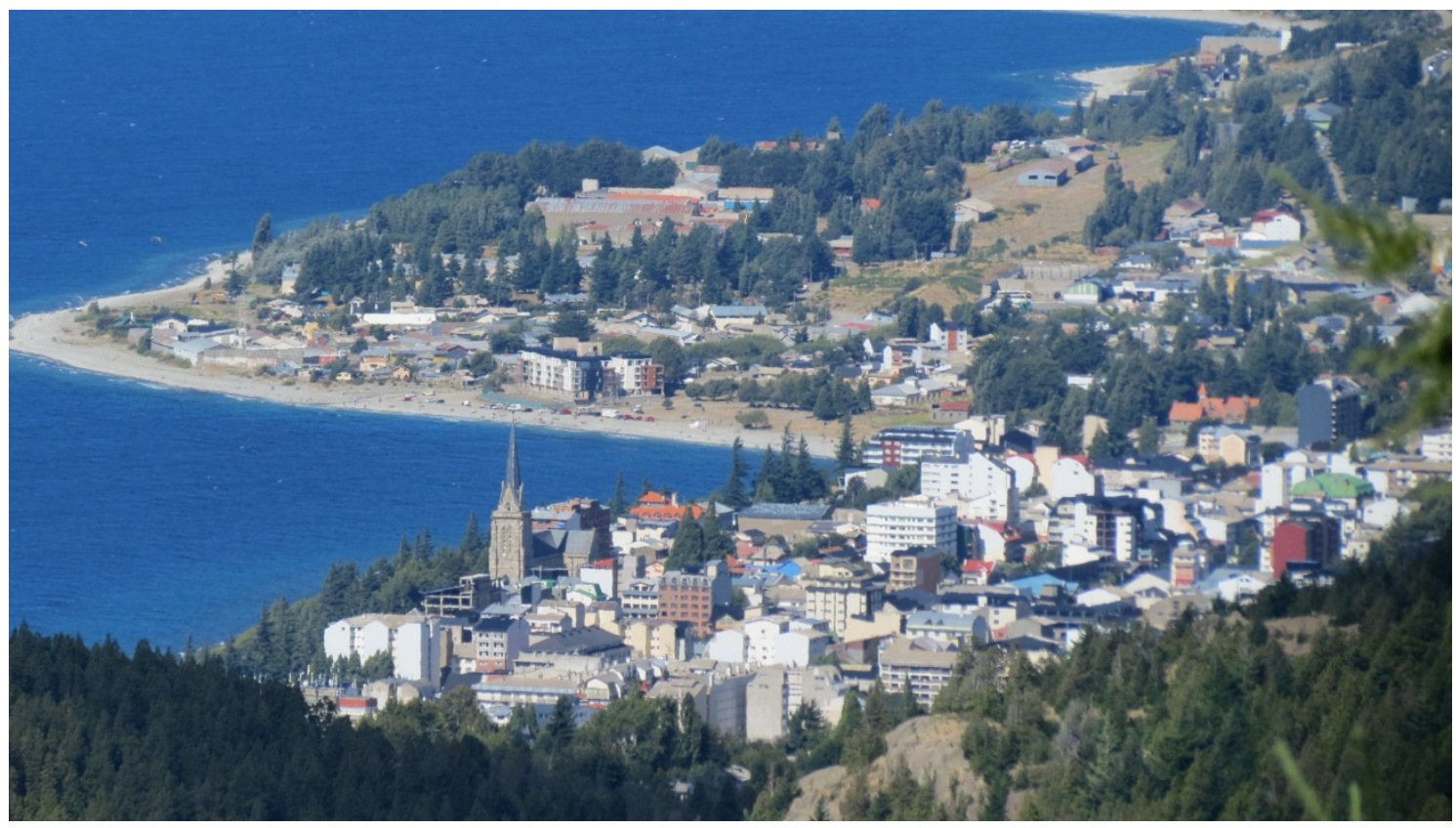

Vista de la ciudad de San Carlos de Bariloche desde el Cerro Otto. Esta ciudad, la más grande de la región del Nahuel Huapi, vivió el tsunami de 1960 y presenta una alta exposición a la caída de ceniza volcánica. San Carlos de Bariloche, 26 de enero de 2014. Foto del autor. 


\subsection{Fundamentación del tema de investigación}

En las últimas décadas, la literatura académica ha mostrado que, en algún aspecto, todas las sociedades son vulnerables frente a eventos de diversa naturaleza y, por ende, están propensas a sufrir profundas alteraciones cuando algún fenómeno extremo de orden natural se materializa en el tiempo y el espacio.

Cuando un espacio urbano crece aceleradamente sin una planificación previa que incluya un conocimiento acabado del ambiente físico, se pueden ocupar espacios altamente susceptibles de ser afectados por eventos de origen natural que pueden ocasionar daños irreversibles y alterar la estructura social y económica del lugar. Este es el caso de varias poblaciones costeras del lago Nahuel Huapi en Río Negro y Neuquén, donde fenómenos de diverso orden como erupciones volcánicas, inundaciones, temporales de nieve, entre otros, la afectan en forma recurrente.

Existen otros fenómenos naturales peligrosos en la región, poco conocidos y en general subestimados; son los tsunamis lacustres (Villarosa et al. 2009). Un evento de este tipo ocurrió en el lago Nahuel Huapi en el año 1960, concomitantemente al terremoto de Valdivia (9.5 de magnitud).

Gran parte del espacio urbano de San Carlos de Bariloche se ha extendido sobre la margen sur del lago conformando un continuo urbano con la localidad de Dina Huapi, ocupando el ambiente litoral y quedando ambas localidades expuestas a estos eventos potencialmente peligrosos.

El Grupo de Estudios Ambientales (GEA) del Instituto Andino Patagónico de Tecnologías Biológicas y Geoambientales (IPATEC - CONICET/UNCo) trabaja en proyectos de investigación y transferencia que abordan la problemática desde el punto de vista de la peligrosidad que los eventos volcánicos y tsunamigénicos representan para las poblaciones de la Norpatagonia Andina. Los avances en estudios científicos relacionados a los procesos físicos condujeron a la necesidad de desarrollar una vinculación con la producción de insumos útiles para la generación de herramientas de gestión. En paralelo, fue emergiendo la necesidad de incorporar a estos trabajos el estudio de la vulnerabilidad que presentan las localidades costeras e investigar las consecuencias sociales y económicas generadas por la caída de cenizas y el grado de exposición que presentan las costas urbanizadas frente a tsunamis lacustres evaluando la preparación de la población ante eventos volcánicos y tsunamigénicos.

En la actualidad pueden encontrarse un gran número de estudios sobre riesgo y vulnerabilidad social en Argentina relacionados con las problemáticas que giran en torno al 
recurso agua, principalmente las inundaciones, como fenómeno recurrente en diferentes lugares del territorio nacional (Caputo et al., 1985; Herzer y Gurevich, 1996b; Natenzon, 1998, 2003; González, 2001; Andrade et al., 2003; por citar algunos ejemplos), siendo escasos los trabajos en materia de vulnerabilidad volcánica (en particular ante la caída de ceniza) y frente a los tsunamis lacustres (como se verá más adelante en este capítulo).

Por último, la localización estratégica es otro de los componentes que justifican los estudios en materia de riesgos. En este sentido, antecedentes únicos como el tsunami reportado en el lago Nahuel Huapi en 1960 sumado a la posibilidad de estudiar recurrencia del volcanismo explosivo en la región (incluyendo eventos recientes ocurridos durante el desarrollo de esta tesis) ofrecen bases sólidas y una oportunidad excepcional para desarrollar diversas investigaciones en materia de riesgo sobre estas temáticas.

\subsection{Antecedentes sobre la temática}

Los acontecimientos registrados señalan que, en los últimos 100 años, seis eventos de caída de cenizas han afectado la región del Nahuel Huapi: en los años 1921, 1960 y 20112012 se produjeron las erupciones generadas por el Complejo Volcánico Puyehue-Cordón Caulle, en 1961 y 2015 se vieron las erupciones originadas por el volcán Calbuco y en 20082009 la región fue afectada por la erupción del Volcán Chaitén.

En los registros sedimentarios de la laguna El Trébol, localizada a unos 20 kilómetros del centro de San Carlos de Bariloche, han quedado preservados al menos 47 niveles de tefras $^{1}$ macroscópicas, indicadoras de erupciones relevantes en un lapso de 15.000 años, indicando la ocurrencia de una erupción de importancia cada 320 años, con 14 eventos de gran magnitud ocurridos en los últimos 2000 años, equivalente a una erupción significativa cada 140 años (Outes y Villarosa, 2007, p. 19). Esto es clave para valorar la exposición de estas poblaciones a los peligros derivados de erupciones explosivas.

Los registros sedimentarios lacustres resultan muy aptos para el estudio de eventos naturales episódicos como las erupciones explosivas o la ocurrencia de grandes sismos y procesos asociados (deslizamientos subacuáticos y tsunamis) ya que cualquier evento de disturbio importante ocurrido en la cuenca hidrográfica se verá reflejado en su sistema sedimentario. Las secuencias sedimentarias lacustres constituyen excelentes registros de la historia ambiental de una cuenca y documentan con alta resolución (decadal a anual en algunos casos) la ocurrencia de eventos volcánicos explosivos (Villarosa et al., 2006,

\footnotetext{
${ }^{1}$ Depósitos no consolidados de material piroclástico.
} 
Ariztegui et al., 2007 y 2008, Haberzettl et al., 2008) y de episodios sísmicos, incluyendo tsunamis, flujos y seiches asociados (Chapron et al., 2006, Villarosa et al., 2007 y 2009).

Fenómenos de este tipo ya afectaron a la ciudad de San Carlos de Bariloche y nuevas evidencias indican que pueden repetirse en ésta y otras poblaciones ubicadas en ambientes litorales de los grandes lagos proglaciares de la zona, de características similares y con importantes poblaciones turísticas ubicadas en sus costas (lagos Lácar, Traful y Aluminé, entre otros).

Por su parte, los deslizamientos subacuáticos han sido estudiados en la cuenca distal del lago Nahuel Huapi, a orillas de la cual se asientan las localidades de San Carlos de Bariloche y Dina Huapi (Villarosa et al., 2009, Beigt et al., 2010, 2014, 2016), y en ambientes deltaicos ubicados en cercanías de Villa La Angostura (Beigt et al., 2012a, b y 2013). Los resultados indican que los deltas son ambientes particularmente propensos a sufrir deslizamientos, dadas las altas tasas de sedimentación que los caracterizan -en especial durante eventos eruptivos donde el material piroclástico es removilizado a lo largo de las cuencas hídricas hacia los deltas- y las elevadas pendientes que presentan los frentes deltaicos.

Algunos de estos deltas -arroyos Ñireco, Ñirihuau y Gutiérrez- han sido incorporados al ejido urbano de San Carlos de Bariloche y Dina Huapi, por lo cual se podría considerar que estas costas están especialmente expuestas frente a la ocurrencia de deslizamientos subacuáticos y la consecuente ola extraordinaria. El análisis de los datos batimétricos ha permitido, entre otras cosas, estimar las dimensiones de estos eventos de remoción en masa, los volúmenes de sedimentos desplazados e identificar y caracterizar distintos subambientes deltaicos (planicie subaérea, terraza lacustre, frente y prodelta) y establecer el tipo de delta que predomina en los principales arroyos que desembocan en el lago Nahuel Huapi (delta de Gilbert retrabajado por olas de tormenta) (Beigt et al., 2014, p. 258).

Resultantes de este complejo escenario, los sedimentos que caracterizan el lecho del lago Nahuel Huapi están constituidos por materiales de diverso origen -glacigénico, lacustre, fluvial, de remoción en masa y piroclástico- depositados desde la deglaciación y a lo largo del Período Holoceno, en tiempos posglaciales (Villarosa et al., 2009; Chapron et al., 2006).

Desde el Grupo de Estudios Ambientales se viene estudiando la morfología, estratigrafía y sedimentología del lecho del lago Nahuel Huapi y otros lagos de la región. Principalmente estas temáticas se abordan desde el punto de vista de la peligrosidad geológica en la cuenca del Lago Nahuel Huapi y otros lagos cordilleranos. Entre los resultados obtenidos de estas investigaciones, se cuentan los trabajos de Villarosa et al., 
(2007, 2009) acerca del origen del tsunami producido en el lago Nahuel Huapi en el año 1960, simultáneo al terremoto de Valdivia (9.5 MW). Mediante la aplicación de técnicas batimétricas, sísmicas y la extracción de testigos de fondo, se identificó un amplio deslizamiento subacuático por debajo de los 70 metros de profundidad frente al Puerto San Carlos (en el centro de la ciudad de San Carlos de Bariloche), desencadenado por los movimientos sísmicos registrados el 22 de mayo de 1960. Esta movilización de sedimentos en profundidad provocó el desplazamiento de un volumen de agua y generó la ola que golpeó las costas de Bariloche. El deslizamiento del sustrato donde se hallaba fundado el antiguo muelle de Puerto San Carlos a su vez provocó el colapso de éste y el hundimiento de varias embarcaciones que se hallaban amarradas al muelle. Esta serie de eventos se cobró dos vidas humanas. Se estima que el fallo pudo haber sido inducido además por la presencia de una superficie poco cohesionada, probablemente una capa de ceniza volcánica, que actuó como plano de deslizamiento, dada la existencia de estratos de tefra a diferentes profundidades en la cuenca distal del lago (Chapron et al., 2006; Villarosa et al., 2009).

Las investigaciones limnogeológicas tendientes a identificar morfologías subacuáticas vinculadas o probablemente vinculadas a la ocurrencia de un tsunami, han sido llevadas a cabo principalmente en lagos europeos (Fanetti et al., 2008, Monecke et al., 2004; Schnellmann et al., 2002, 2006; Girardclos et al., 2007; Strasser et al., 2007, etc.) y más recientemente en lagos chilenos (Moernaut, 2014; van Daele et al., 2015). En el lago Nahuel Huapi y en otros lagos de la región (Huechulafquen, Futalaufquen) se han efectuado relevamientos batimétricos y sísmicos que permitieron identificar morfologías asociadas a procesos de remoción en masa subacuáticos (Beigt et al., 2010, 2012a, b, 2013).

El carácter regional de este tipo de fenómenos de deslizamientos y tsunamis en los lagos de Patagonia Norte puede verificarse en estudios realizados en el lago Frías. El terremoto de 1960 generó una inusual capa rica en materia orgánica (hallada en el sector central de la cuenca), que pudo haber resultado de (1) deslizamientos que afectaron el lago, (2) una ola extraordinaria generada por deslizamientos, que erosionó el área costera del lago u (3) oscilaciones en el nivel de las aguas del lago (efecto seiche) que retrabajaron depósitos costeros ricos en materia orgánica (Chapron et al., 2006, p. 67).

Paralelamente, además del antecedente de 1960, deben destacarse los reportes recientes de oscilaciones de baja frecuencia en el nivel de las aguas del lago Nahuel Huapi registradas en varias oportunidades, simultáneamente a la ocurrencia de movimientos sísmicos en la región (mayo de 2011, simultáneo al registro de actividad sísmica en el 
Complejo Volcánico Puyehue-Cordón Caulle; 11 de Julio de 2011, paralelamente al registro de actividad sísmica y volcánica en el mencionado complejo, entre otros). También caben mencionar las oscilaciones de nivel reportadas como una "ola" observada en el sector mediodistal del lago Nahuel Huapi simultáneamente al sismo de magnitud 8,8 ML (27 de Febrero de 2010), con epicentro a 115 km NNE de Concepción. No se conoce la naturaleza de estas oscilaciones, aunque se estima que puede tratarse de ondas tipo seiche (originadas directamente por los movimientos sísmicos) o de movimientos de remoción en masa subacuáticos inducidos por los terremotos, que generan ondas en la superficie del lago.

\subsection{Caída de ceniza volcánica y tsunamis lacustres: definiciones conceptuales}

Norpatagonia se encuentra bajo la influencia de las erupciones explosivas de los volcanes de la Zona Volcánica Sur (ZVS). Estos volcanes en particular, cuando entran en actividad, pueden desarrollar una columna eruptiva que se compone de diferentes elementos: fragmentos de magma solidificado, de rocas del volcán y gases calientes. En esta región, los vientos dominantes del cuadrante O-NO movilizan gran parte de estos componentes hacia territorio argentino afectando a las zonas aledañas e incluso a aquellas localizadas a distancias medias y ambientes distales del foco de emisión.

Los materiales eruptados por un volcán pueden presentar diversos tamaños. Se consideran cenizas si el tamaño de las partículas no supera los $4 \mathrm{~mm}$, lapilli si su tamaño está comprendido entre los 4 y los $64 \mathrm{~mm}$ y bombas si superan este último valor (Llambías, 2009:41). En función de esta clasificación y la distancia al punto de emisión se pueden reconocer a priori diferentes niveles de peligrosidad. En distancias próximas, las bombas tienen una gran capacidad de generar daños a las personas, las viviendas, la ganadería y las infraestructuras en general (redes viales, telecomunicaciones, servicios básicos, etc.). En cambio, a distancias medias donde las bombas no se hacen presentes, la depositación de tefras de lapilli y ceniza gruesa pueden convertirse en el origen de los problemas para la población siendo, en lugares distantes, sólo las cenizas finas las que pueden ocasionar inconvenientes de diverso orden, especialmente a la salud por su fácil resuspensión o removilización eólica.

La erupción del complejo volcánico Puyehue-Cordón Caulle iniciada el 4 de Junio de 2011, constituye un antecedente importante y reciente en materia de peligrosidad por caída de cenizas. Una de las características más notables de esta erupción ha sido la removilización generalizada de los depósitos de tefra por los vientos predominantes de la región, afectando la calidad del aire (Wilson et al., 2013, p. 46). Las consecuencias 
económicas han sido numerosas incluso en el sector de la meseta, alejada del foco de emisión de cenizas, con una importante mortandad de animales en los espacios rurales en torno a las localidades de Pilcaniyeu, Comallo e Ing. Jacobacci, entre otras.

En términos generales, esta erupción presentó a las poblaciones diversos tipos de peligros asociados a la ceniza en suspensión, al agua potable, a las actividades ganaderas, a los servicios básicos, al tratamiento de aguas residuales/domiciliarias, al transporte y las comunicaciones (Wilson et al., 2013, pp. 53-65).

La escasa consolidación del material depositado también facilita la remoción por parte del agua. La movilización posterior de los depósitos mostró disminuciones de espesor esperables en ambientes expuestos a vientos con depósitos de grano fino y aumentos de espesor en algunos ambientes de bosque húmedo dominados por depósitos gruesos, presumiblemente atribuible a procesos de ladera y removilización hídrica desde ambientes altos hacia los fondos de valle (Villarosa et al., 2013, p. 3). Intensas precipitaciones sumadas al material volcánico depositado no consolidado -conocido genéricamente como tefrapueden provocar aluviones de dimensiones importantes (Córdoba et al., 2015), y el riesgo que representan se puede identificar tanto en las áreas montañosas como en la zona mesetaria.

A una semana de iniciada la erupción de 2011, la ruta que conecta Argentina con Chile a través del paso internacional Cardenal Zamoré quedó destruida por una avalancha de cenizas y arena volcánica, provocada por las fuertes lluvias que afectaron la región (Los Andes, edición digital, 11 de Junio de 2011). Incluso los riesgos de flujos se pueden mantener por un largo tiempo con posterioridad a la erupción dependiendo, entre otros factores, por el volumen de tefra depositado. Villa Llanquín, por ejemplo, sufrió los efectos de un temporal donde la prolongada sequía y el fino material volcánico que cubre la zona contribuyó en la formación de los flujos que invadieron las viviendas de los pobladores depositando unos 10 centímetros de barros (Río Negro, edición digital, 2 de febrero de 2013). En Corralito, una persona falleció en su casa al quedar atrapada por un flujo provocado tras el desborde de un arroyo (ANB, 9 de marzo de 2012).

Para el caso de Villa La Angostura, población argentina más cercana al Complejo Volcánico Puyehue-Cordón Caulle, se ha realizado un modelado de lahares secundarios que permitió determinar de manera preliminar la peligrosidad asociada a este fenómeno (Córdoba et al., 2011). Este estudio mostró que, concomitantemente a la caída de cenizas, se han producido intensas nevadas, lo que ha producido una intercalación de depósitos de cenizas y nieve que, en las cabeceras de los ríos y cuencas en torno a la villa turística, 
pueden alcanzar varios metros de espesor. A ello se suma que la presencia de ceniza superficial puede modificar sensiblemente el albedo de la nieve, pudiendo acelerar la velocidad de derretimiento del manto níveo (Córdoba et al., 2011, pp. 2-3). Este conjunto de factores y procesos deben ser tenidos en cuenta para tomar conocimiento de la peligrosidad derivada de la caída de cenizas considerando las condiciones climáticas, el relieve y la hidrografía.

Las cenizas se acumulan en el lecho lacustre, principalmente en ambientes deltaicos donde la removilización fluvial favorece este proceso, formando depósitos potencialmente inestables, susceptibles de deslizar. Se ha sugerido además que los niveles de tefra ubicados a distintas profundidades en el lecho del lago Nahuel Huapi (Chapron et al., 2006, p. 63) podrían constituir potenciales planos de deslizamiento de los sedimentos suprayacentes (Villarosa et al., 2009; Beigt et al., 2016). Los deslizamientos subacuáticos pueden, en algunos casos, desplazar grandes volúmenes de agua, lo que permite conectar estos eventos de caída de cenizas con la generación de tsunamis lacustres.

Un tsunami lacustre se puede producir por diferentes causas. Además de los deslizamientos subacuáticos, puede ser la consecuencia de la caída de grandes volúmenes de rocas o hielo en el cuerpo de agua, la inestabilidad de edificios volcánicos o el movimiento de fallas en el lecho lacustre. Este tipo de fenómenos afecta la morfología del fondo lacustre y puede desplazar importantes masas de agua, y consecuentemente, inducir la formación de una o más olas en la superficie (Beigt et al., 2013, p. 53).

La ocurrencia de deslizamientos subacuáticos en las cuencas lacustres podría generar olas extraordinarias y afectar a ambientes costeros vulnerables, ya sea por su elevación, pendiente o cercanía a un sector potencialmente inestable. Evaluar la peligrosidad geológica y la vulnerabilidad que presentan dichas áreas es de suma importancia, si se considera que las costas de estos grandes lagos generalmente albergan núcleos urbanos donde se concentra la mayor densidad de población e infraestructura urbana.

\subsection{Peligrosidad y vulnerabilidad: aproximaciones teóricas}

El origen de los estudios sociales en materia de riesgos y desastres se remonta a la década de 1940 con los trabajos pioneros de Gilbert White, pero no va a ser hasta los años 60 que las ciencias sociales se ocupen con mayor dedicación a esta problemática. (Maskrey, 1993, p. 3). Hasta entonces, disciplinas ligadas a las ciencias naturales como la geología marcaron fuertemente el desarrollo de las investigaciones durante gran parte del siglo XX. Los trabajos desarrollados presentaban el sello distintivo de las ciencias duras, aunque ello 
no implicaba necesariamente una exclusión absoluta de la sociedad, sus problemáticas y sus relaciones con el medio natural.

Peligrosidad y susceptibilidad: diferentes pero complementarios.

Peligrosidad es la cualidad de peligroso, y peligroso según la Real Academia Española (RAE), significa que tiene riesgo o puede ocasionar daño. La noción de Peligro se asocia también con Amenaza que proviene del lat. vulg. minacia, y este deriva del lat. Mina y significa acción de amenazar. Por lo cual, tanto Peligro como Amenaza están asociados a un daño o mal. La peligrosidad se entiende como el potencial de peligro de ocurrencia de una amenaza (Natenzon, 1995; Barrenechea et al., 2000; Andrade et al., 2003 y 2012; entre otros).

En cambio, la RAE define susceptibilidad como cualidad de susceptible, término que deriva del lat. tardío susceptibrilis, que significa capaz de recibir la acción o el efecto que se expresan a continuación. Un plan susceptible de modificación. La susceptibilidad sería la capacidad de recibir una acción o un efecto. Por esta razón, la susceptibilidad muchas veces se asocia con la peligrosidad, en el sentido de capacidad de recibir daño que significa la peligrosidad. La susceptibilidad, en este caso, como probabilidad de ocurrencia de un daño o mal.

En otros términos, un fenómeno natural puede generar impactos o efectos en una sociedad (susceptibilidad), aunque ellos no necesariamente pueden ser dañinos (peligrosidad).

En el caso de América Latina, la situación no ha sido muy diferente a la descripta anteriormente. Lavell (1993) sostiene que el dominio que ejercen las ciencias naturales y básicas sobre la problemática de los desastres es casi total (p. 111). En buena medida, los grandes desastres ocurridos en el subcontinente durante la década de 1980, como el Fenómeno del Niño de 1982 y el terremoto de México de 1985, impulsaron la investigación social de los desastres (Maskrey, 1993, p. 3).

Gellert de Pinto (2012) complementa esta perspectiva agregando que las ciencias sociales se ocuparon crecientemente de esta problemática desde 1980, centrándose en el estudio de la vulnerabilidad como factor determinante en la causa de los desastres o la conformación de riesgos (p. 14).

Hacia la década de 1990 fue cobrando cada vez mayor relevancia la idea de que los desastres no son naturales sino que, por el contrario, son una construcción social. La relevancia a nivel mundial de esta temática adquirió tal magnitud que la Asamblea General de la Naciones Unidas declaró a esta década como el "Decenio Internacional para la Reducción de Desastres". Según Oliver-Smith los desastres son socialmente construidos, a la vez que diferencialmente experimentados por individuos y grupos diversos que generan múltiples interpretaciones tanto del proceso como del evento (Oliver-Smith, 2002, p.25, en García Acosta, 2005, p. 23). Es importante remarcar esta visión ya que le otorga a la percepción un lugar relevante por medio del reconocimiento de interpretaciones diferenciales del evento catastrófico. 
Los peligros, ya sean de origen natural o antrópico, constituyen uno de los componentes más relevantes en las diferentes concepciones sobre el riesgo que se erigen en la actualidad (Giddens, 1993; Maskrey, 1993; Natenzon, 1995; Blaikie et al., 1996; Beck, 1999). En un sentido más profundo, para autores como Beck y Giddens los riesgos constituyen un producto de la sociedad moderna. Dado que se pensaba en los desastres como eventos fortuitos o castigo divino, Giddens (1990) retoma a Luhmann agregando que el término riesgo reemplaza lo que con anterioridad se pensó como fortuna -fatalidad- (p. 40) presentando un importante quiebre en la manera de abordar el tema de las catástrofes.
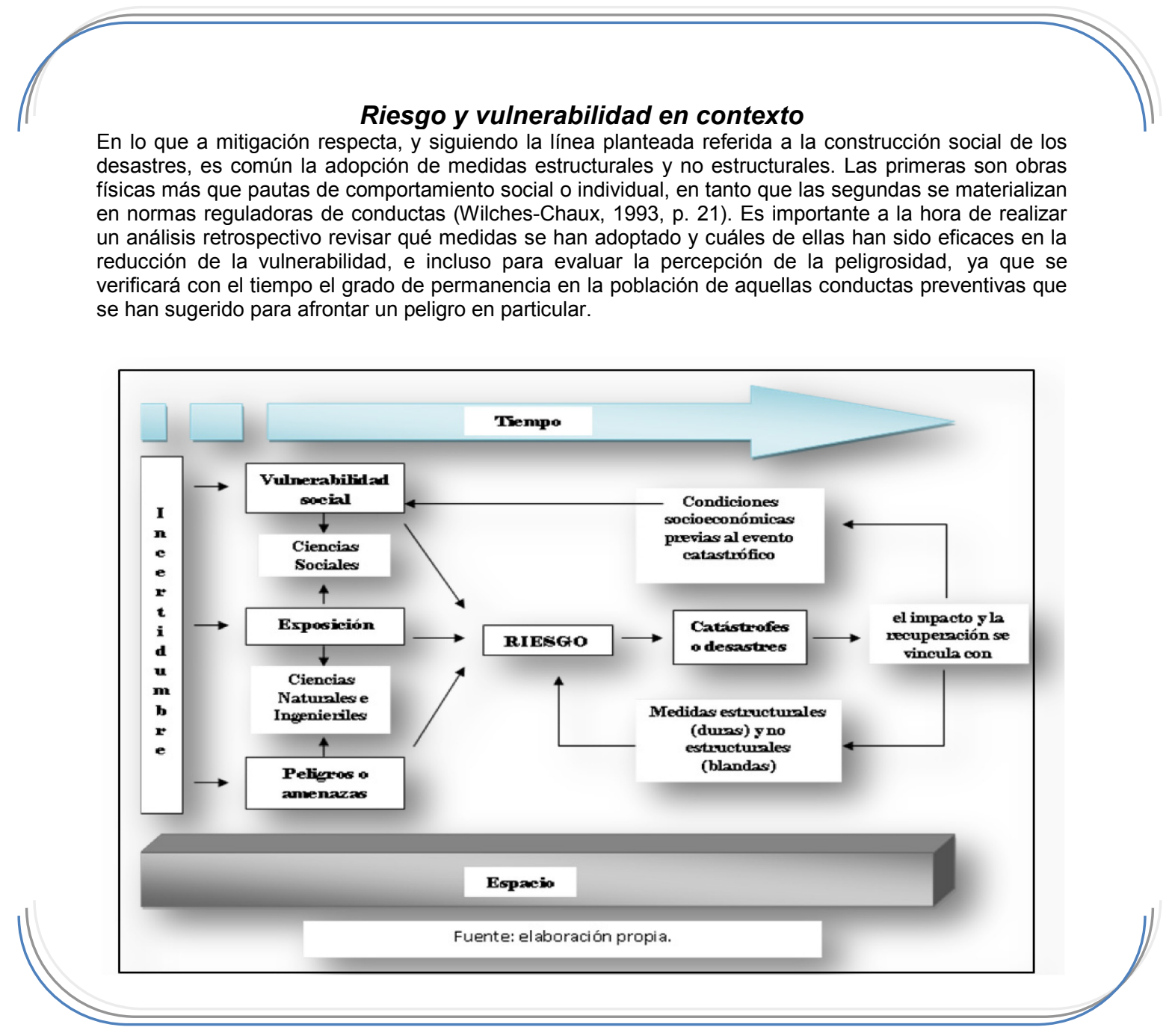

Las nociones de amenaza y peligro aparecen con fuerza en las distintas concepciones teóricas sobre riesgo. Un fenómeno natural potencialmente peligroso se convierte en 
amenaza para un grupo humano solamente cuando éste es vulnerable (Gellert de Pinto, 2012, p. 14). Según Beck (2007), los riesgos globales tienen dos caras: por un lado, la probabilidad de posibles catástrofes y, por otro, la vulnerabilidad social a través de las catástrofes (p. 21). Este autor sugiere que el riesgo no significa catástrofe sino su anticipación y agrega que en el momento en el que los riesgos se convierten en reales dejan de ser riesgos para convertirse en catástrofes (Beck, 2007, p. 10).

Es evidente que la vulnerabilidad adquiere un lugar notable en la comprensión de los riesgos. Un aporte clave de este concepto es que permite superar caracterizaciones dicotómicas (pobre-no pobre) y reconocer las diversas configuraciones socioeconómicas de los distintos grupos sociales (Natenzon y González, 2010, p.196). Si bien existen diferentes acepciones para el término vulnerabilidad, a grandes rasgos se pueden distinguir tres perspectivas vinculadas entre sí. Por un lado, aquella que pone énfasis en la propensión de un grupo social a sufrir daños (Cardona, 1993; Lavell, 1996; Herzer y Gurevich, 1996a). Por otro, la que considera a la vulnerabilidad en términos de la capacidad de un grupo social de adaptarse a los cambios en el ambiente (Wilches-Chaux, 1993; Blaikie et al., 1996), aproximándose esta concepción a la noción de resiliencia. Por último, muy vinculada a la primera, se encuentra la perspectiva que considera un conjunto de condiciones o procesos de diversa índole que anteceden a una amenaza natural y determinan los impactos (Blaikie et al., 1996; Natenzon, 1995 y 2003; Barrenechea et al., 2000; EIRD/ONU, 2004).

En términos generales y en línea con la última acepción, se acuerda con Barrenechea et al. (2000) cuando sostienen que la vulnerabilidad está definida por las condiciones socioeconómicas previas a la ocurrencia del evento catastrófico, en tanto que constituye una "capacidad diferenciada" de hacerle frente (p. 2). Ello involucra numerosos aspectos que van desde la percepción del riesgo hasta las condiciones económicas, sociales e institucionales, que implica la preparación ante la emergencia. Esta concepción otorga particular relevancia a la vulnerabilidad institucional, donde se encuadra en buena medida lo que en la actualidad se conoce como gestión de riesgos de desastres.

Es importante insistir en la complejidad que subyace al concepto de vulnerabilidad. En este sentido, entre los distintos ángulos que la conforman, Wilches-Chaux (1993) reconoce a la vulnerabilidad natural, física, económica, social, política, técnica, ideológica, cultural, educativa, ecológica e institucional (pp. 24-39). Se pueden reconocer otros ángulos de la vulnerabilidad, como el demográfico, cuya relevancia es trabajada por Filgueira y Peri (2004). Si bien en Argentina se carece de trabajos en materia de vulnerabilidad social frente a la problemática de la caída de ceniza volcánica, se deben destacar los aportes generados por 
recientes trabajos que se han desarrollado en materia de vulnerabilidad física a partir de experiencias registradas por diversas erupciones en diferentes lugares del mundo y que sirven de marco general para analizar este ángulo de la vulnerabilidad de gran trascendencia por la importancia que representan las denominadas infraestructuras críticas (redes de agua potable, electricidad, aguas residuales, transportes y comunicaciones, entre otras) (Wilson et al., 2014, Jenkins et al., 2014).

\subsection{Hacia una perspectiva geográfica en la concepción de la vulnerabilidad y los riesgos}

Gellert de Pinto (2012) sostiene que, a partir de la década de 1990, el problema ya no se enfoca tanto en el evento de ocurrencia del desastre y la respuesta (administración del desastre) sino en el riesgo que predispone el desastre, el cual es construido socialmente ( $p$. 13). Aquí, las condiciones de vulnerabilidad adquieren un rol sumamente relevante y son las ciencias sociales las que pueden aportar conocimientos sobre la vulnerabilidad (Barrenechea et al., 2000, p. 2). Desde las ciencias sociales, los aportes deben dirigirse en la dirección de comprender la vulnerabilidad y sus diferenciaciones espaciales.

En materia de abordaje de la problemática de los riesgos en general y de la vulnerabilidad en particular, se puede asegurar que la faceta territorial está siempre presente y es por este motivo que Lavell (2009) respalda la distinción entre territorios causales y de impacto (p. 23), diferenciación que permite enmarcarnos territorialmente en la problemática dado que la dimensión local adquirió gran importancia en los estudios recientes sobre la gestión de los riesgos. En este sentido, el riesgo no solamente se manifiesta a través de desastres mayores con altas pérdidas, sino ante todo en múltiples y numerosos desastres a escala local (Gellert de Pinto, 2012, p. 16).

Como se mencionó con anterioridad, las causas naturales de la caída de cenizas y los fenómenos tsunamigénicos no siempre encuentran su origen en el mismo lugar donde impactan. Por ello, si conjuntamente con introducir la noción de vulnerabilidad, se introduce también el de territorialidad, se permite un acercamiento al análisis que comprende los niveles regional, metropolitano, urbano, local, comunitario y hasta familiar (Lavell, 1993, p. 123).

Este enfoque, al comprender múltiples escalas, permite aportar una perspectiva geográfica, radicando aquí aportes interesantes de esta disciplina a la concepción de los problemas asociados a los riesgos. Puyol et al. (1992) sostienen que según autores como 
Hagget o Harvey, los geógrafos han tendido a organizar su pensamiento en torno a cinco grandes temas (pp. 9-10):

- El tema de la diferenciación espacial, para el que sigue siendo fundamental el concepto de región.

- El tema del paisaje (natural o cultural), desarrollado inicialmente en Alemania.

- El tema de la relación hombre-entorno, iniciado por el determinismo y continuado por el posibilismo.

- El tema de la distribución espacial, describiendo y explicando la localización de los fenómenos en la superficie terrestre.

- El tema geométrico, ligado al análisis locacional y los enfoques teóricos-cuantitativos.

Dentro de este planteo sobresalen dos líneas relevantes para su discusión. La diferenciación espacial, por un lado, puede referir a las diferentes condiciones regionales que se observan también en el área de estudio, como el volcanismo explosivo, características climáticas, diferentes peligrosidades naturales presentes, entre otros aspectos que caracterizan a la Norpatagonia Andina. En otras palabras, estas condiciones constituyen el marco general en el cual se contextualizan los riesgos.

La distribución espacial, por otro lado, da cuenta de cómo se extienden los fenómenos sobre la superficie y es fundamental, en materia de vulnerabilidad, diferenciar espacialmente las comunidades más vulnerables dentro de un área geográfica específica.

Las diferenciaciones y distribuciones espaciales pueden analizarse a diferentes escalas -interior de un país, región, provincia, departamento-, aunque resulta más adecuado reconocer las variaciones dentro de cada localidad independientemente del número de habitantes lo cual, en concordancia con las actuales tendencias en materia de gestión local de riesgos, redundará en la adopción de medidas más específicas y concretas para la reducción de la vulnerabilidad.

En coincidencia con Chiozza y Carballo (2006), es preciso aceptar que no existen recetas establecidas para todo el universo social-espacial, sino más bien metodologías y resignificaciones conceptuales que se pueden adaptar a nuestro objetivo central, la comprensión de la realidad social y su expresión en el espacio geográfico (p. 49). En términos de Funtowicz y Ravetz (1993), la nueva ciencia paradigmática ya no puede permitir que sus explicaciones no se relacionen con el espacio, el tiempo y el proceso (p.3).

Por este motivo, los actuales enfoques teórico-metodológicos en materia de riesgos deben analizarse en virtud de identificar aquellos aportes relevantes para la construcción de metodologías acordes a cada problemática de estudio. 


\subsection{Enfoques teórico-metodológicos actuales en materia de Riesgo, Vulnerabilidad y Desastres en Latinoamérica}

En la actualidad, diferentes concepciones epistemológicas emergen en el análisis de los riesgos y los desastres en el contexto de una corriente denominada alternativa (también conocida como de la vulnerabilidad), es decir, distinta a las anteriores que presentaban una visión más tecnocrática. Siguiendo a Lavell (1993), el dominio del paradigma dominante tecnocrático ha sido paulatinamente erosionado a lo largo de los últimos treinta años en los países del norte, particularmente en los Estados Unidos y las ciencias sociales han aparecido con cierta fuerza en la investigación y acción relacionada con los desastres ( $p$. 114)

Como se mencionó con anterioridad, en Latinoamérica surge con fuerza en los años 80 a partir de los grandes desastres entre los que se cuentan las inundaciones de 1982 y el terremoto de México de 1985, especialmente a partir de estudios de caso de investigadores como Herzer, Caputo, Hardoy (Maskrey, 1993, p. 4).

Dentro de esta corriente, se pueden reconocer determinados enfoques teóricometodológicos en materia de riesgo, vulnerabilidad y desastres, algunos de los cuales se analizan en este apartado con el objeto de destacar aquellos puntos en común como así también tomar en consideración diferentes herramientas que posibiliten la construcción de un enfoque propio para el estudio de la vulnerabilidad social frente a los tsunamis lacustres y la caída de ceniza volcánica en comunidades de Norpatagonia Andina.

\subsubsection{Red de Estudios Sociales en Prevención de Desastres en América Latina (La RED)}

En 1992 se reunieron representantes de diferentes instituciones dedicados a la promoción de un enfoque social hacia el estudio de los desastres, con el fin de constituir una red de colaboración interinstitucional e interdisciplinaria (Maskrey, 1993, p. 4). Una de las publicaciones más reconocidas es "Los Desastres no son naturales" (Maskrey -Comp.-, 1993), que marca una concepción de los riesgos con una fuerte impronta social y con la vulnerabilidad como uno de los pilares fundamentales.

Diversas maneras de analizar los riesgos y la vulnerabilidad pueden reconocerse a partir de diversos autores. La vulnerabilidad es analizada desde la relación entre sistema natural y social a través de Fernández (1996), quien sostiene que los recursos y fenómenos naturales pasan a ser amenazas cuando su potencial para desequilibrar un sistema social aumenta. Cuando un sistema natural produce un evento necesario para mantener su 
equilibrio, pero que afecta el funcionamiento normal de un sistema social, se considera dicho evento como peligroso y sus consecuencias como un desastre. Si, por el contrario, es un sistema social el que desequilibra un ecosistema, usualmente las consecuencias diarias no son vistas como micro-desastres hasta que estas pequeñas, pero permanentes fuerzas desequilibradoras, se acumulan y se manifiestan en un evento catastrófico, y entonces se percibe el desastre (p. 10). Si bien no parte de la vulnerabilidad, esta concepción tiene la particularidad de centrar su atención en la peligrosidad aportando una visión desde el proceso, otorgando a la temporalidad un lugar distinguido.

Según Romero y Maskrey (1993), la vulnerabilidad de los pueblos se da 1) cuando la gente ha ido poblando terrenos que no son buenos para vivienda, por el tipo de suelo, por su ubicación inconveniente respecto a avalanchas, deslizamientos, inundaciones, etc. 2) cuando ha construido casas muy precarias 3) cuando no existe condiciones económicas que permitan satisfacer las necesidades humanas (p. 8). Este aporte es valioso en el abordaje de fenómenos como los tsunamis lacustres y los efectos indirectos de la caída de ceniza volcánica, particularmente los lahares secundarios. La localización en lugares inadecuados sumado al tipo de construcción generan condiciones de vulnerabilidad per se.

Wilches-Chaux (1993), denota por vulnerabilidad la incapacidad de una comunidad para "absorber", mediante el autoajuste, los efectos de un determinado cambio en su medio ambiente, o sea su "inflexibilidad" o incapacidad para adaptarse a ese cambio, que para la comunidad constituye un riesgo. La vulnerabilidad determina la intensidad de los daños que produzca la ocurrencia efectiva del riesgo sobre la comunidad (p. 17), visión que en este caso se aproxima a la noción de resiliencia.

\begin{tabular}{|c|c|c|c|c|}
\hline $\begin{array}{l}\text { Línea teórico- } \\
\text { metodológica }\end{array}$ & Representantes & $\begin{array}{c}\text { Concepción } \\
\text { de riesgo }\end{array}$ & Concepción de vulnerabilidad & $\begin{array}{c}\text { Concepción del } \\
\text { desastre }\end{array}$ \\
\hline $\begin{array}{l}\text { LA RED } \\
\text { (1992) }\end{array}$ & $\begin{array}{l}\text { Lavell, Maskrey, } \\
\text { Wilches-Chaux, } \\
\text { Cardona. }\end{array}$ & $\begin{array}{l}\text { El riesgo es } \\
\text { una } \\
\text { construcción } \\
\text { social. }\end{array}$ & $\begin{array}{l}\text {-"Agente activo" de los desastres. } \\
\text {-Determinada por procesos sociales, } \\
\text { económicos y políticos. } \\
\text {-Incapacidad de una comunidad para } \\
\text { "absorber", mediante el autoajuste, los efectos de } \\
\text { un determinado cambio en su medio ambiente. } \\
\text {-Predisposición intrínseca de un sujeto o } \\
\text { elemento a sufrir daño debido a posibles acciones } \\
\text { externas, y por lo tanto su evaluación contribuye en } \\
\text { forma fundamental al conocimiento del riesgo } \\
\text { mediante interacciones del elemento susceptible } \\
\text { con el ambiente peligroso. }\end{array}$ & $\begin{array}{l}\text { Los desastres no } \\
\text { son naturales. } \\
\text { Hay un alto riesgo } \\
\text { de desastre si uno } \\
\text { o más fenómenos } \\
\text { naturales } \\
\text { peligrosos } \\
\text { ocurrieran en } \\
\text { situaciones } \\
\text { vulnerables. }\end{array}$ \\
\hline
\end{tabular}

Cuadro $N^{\circ} 1$. Síntesis del enfoque presentado por La Red. Fuente: elaboración propia. 


\subsubsection{La Teoría Social del Riesgo}

Desde la Teoría Social del Riesgo, cuyo origen puede remontarse al año 1995, la conceptualización del riesgo en términos de una teoría social del mismo, permite incorporar otras dimensiones, cuya consideración apuntaría a la disminución de las consecuencias catastróficas. Estas dimensiones son peligrosidad, vulnerabilidad, exposición e incertidumbre (Natenzon, 1995):

Peligrosidad. Se refiere al potencial peligroso que tienen los fenómenos naturales (espontáneos o manipulados técnicamente), potencial inherente al fenómeno mismo, sea cual sea su grado de artificialidad (Barrenechea et al., 2000, p. 2). Al distinguir la peligrosidad de un evento de otros factores constitutivos del riesgo (la exposición y la vulnerabilidad), se establece un recorte conceptual consistente en el tipo de abordaje de las disciplinas que estudian los "fenómenos naturales" catastróficos: climatología, volcanología, geomorfología, oceanografía, geofísica, geografía física (Natenzon, 1995, p. 5).

Vulnerabilidad. Pone el énfasis en cuál es la estructura social previa a la ocurrencia del fenómeno ya que es dicha configuración la que determinará, en gran medida, las consecuencias catastróficas (Natenzon, 1995, p. 9). En similares términos, Barrenechea et al. (2000) sostienen que está definida por las características (sociales, económicas, culturales, etc.) de un grupo social previas a la ocurrencia del evento catastrófico, que otorgan una 'capacidad diferenciada' de hacerle frente (p. 2).

Exposición. Se refiere a la distribución de lo que es potencialmente afectable, la población y los medios materiales 'expuestos' al fenómeno peligroso. Es una consecuencia de la interrelación entre peligrosidad y vulnerabilidad y -a la vez- incide sobre ambas (Barrenechea et al., 2000, p. 2). Siguiendo a Natenzon (1995), interesa conocer la distribución territorial de lo "potencialmente afectable", lo "expuesto" al fenómeno natural peligroso (p. 8).

Incertidumbre. Se relaciona con las limitaciones en el estado del conocimiento (incertidumbre científica) y las indeterminaciones en cuanto a competencias institucionales y aspectos normativos (incertidumbre política); al mismo tiempo, estas limitaciones y la complejidad del fenómeno en cuestión impide el manejo de la totalidad de las variables involucradas, impregnando de incertidumbre los procesos de toma de decisiones (Barrenechea et al., 2000, p. 2). Para mayor desarrollo de la incertidumbre, véase apartado en este capítulo. 
Si a nivel técnico no hay respuestas contundentes, a nivel político impone una resolución por la magnitud de los intereses en conflicto. La incertidumbre, en este caso, sólo puede ser manejada a través del consenso público (Natenzon, 1995, p. 15).

\begin{tabular}{|c|c|c|c|c|}
\hline $\begin{array}{l}\text { Línea teórico- } \\
\text { metodológica }\end{array}$ & Representantes & Concepción de riesgo & $\begin{array}{l}\text { Concepción de } \\
\text { vulnerabilidad }\end{array}$ & $\begin{array}{c}\text { Concepción del } \\
\text { desastre }\end{array}$ \\
\hline $\begin{array}{c}\text { TEORÍA SOCIAL DEL } \\
\text { RIESGO } \\
(1995)\end{array}$ & $\begin{array}{l}\text { PIRNA }^{2} \text { (UBA) } \\
\text { Natenzon, } \\
\text { González, } \\
\text { Barrenechea, } \\
\text { Gentile }\end{array}$ & $\begin{array}{l}\text { Conjunción cuatro } \\
\text { dimensiones: } \\
\text { Vulnerabilidad. Dimensión del } \\
\text { riesgo, amplificadora de la } \\
\text { pobreza y las catástrofes. } \\
\text { Peligrosidad. Lo peligroso de } \\
\text { un fenómeno corresponde a una } \\
\text { definición específica de una } \\
\text { determinada sociedad, en un } \\
\text { momento dado y para un lugar } \\
\text { determinado. } \\
\text { Exposición. Considera los } \\
\text { resultados concretos que } \\
\text { surgirían si el si el potencial } \\
\text { peligro se torna realidad. } \\
\text { Incertidumbre. Cuando el } \\
\text { riesgo no es cuantificable se } \\
\text { convierte en incertidumbre. }\end{array}$ & $\begin{array}{l}\text { La vulnerabilidad } \\
\text { está definida por las } \\
\text { condiciones } \\
\text { socioeconómicas } \\
\text { previas a la } \\
\text { ocurrencia del evento } \\
\text { catastrófico, en tanto } \\
\text { que constituye una } \\
\text { "capacidad } \\
\text { diferenciada" de } \\
\text { hacerle frente. }\end{array}$ & $\begin{array}{l}\text { El desastre es una } \\
\begin{array}{l}\text { actualización del } \\
\text { riesgo. }\end{array} \\
\begin{array}{l}\text { Interrupción en el } \\
\text { proceso } \\
\text { desarrollo. }\end{array} \\
\begin{array}{l}\text { Algo } \\
\text { extraordinario en } \\
\text { lo ordinario. }\end{array}\end{array}$ \\
\hline
\end{tabular}

Cuadro $N^{\circ} 2$. Síntesis del enfoque presentado por la Teoría Social del Riesgo. Fuente: elaboración propia.

\subsubsection{Modelo de Presión y Liberación de los Desastres (PAR)}

Dada la complejidad de causas que interactúan en el estudio de la vulnerabilidad, Blaikie et al. (1996) presentan el Modelo de Presión y Liberación de los Desastres ${ }^{3}$, donde la progresión de la vulnerabilidad ocupa un lugar significativo a través de un análisis de las causas de fondo, las presiones dinámicas, las condiciones inseguras y en forma separada las amenazas o peligros.

Causas de fondo. Procesos extensos, bien establecidos dentro de una sociedad y la economía mundial. Las más importantes que dan origen a la vulnerabilidad son procesos económicos, demográficos y políticos (Blaikie et al., 1996, p. 29).

Presiones dinámicas. Son procesos y actividades que "traducen" los efectos de las causas de fondo en vulnerabilidad de condiciones inseguras. Estos incluyen el reducido acceso a los recursos como un resultado de la forma en que presiones regionales o globales (crecimiento rápido de la población, enfermedad epidémica, urbanización rápida, guerra,

\footnotetext{
${ }^{2}$ Programa de Investigaciones en Recursos Naturales y Ambiente, Facultad de Filosofía y Letras, Universidad Nacional de Buenos Aires (UBA).

${ }^{3}$ PAR (Pressure And Release, por sus siglas en inglés). Si bien es una publicación de la Red, se optó por asignarle un tratamiento por separado a este modelo en particular.
} 
deuda externa y ajuste estructural, promoción de la exportación, minería, desarrollo hidroenergético y deforestación) se manifiestan en localidades específicas. La migración rural-urbana es otra presión dinámica presente en muchas partes del Tercer Mundo como respuesta a la estructura económica inherente a las causas de fondo (Blaikie et al., 1996, p. 30).

Condiciones inseguras. Son las formas específicas en las cuales la vulnerabilidad de una población se expresa en el tiempo y espacio junto con una amenaza. Por ejemplo, la población que tiene que vivir en lugares peligrosos, sin posibilidad de hacer construcciones seguras, que carece de protección efectiva por parte del Estado (por ejemplo, desde el punto de vista de códigos de construcción), que tiene que comprometerse en medios de vida arriesgados o que tienen mínimos recursos de alimentos o beneficios que están propensos a rápida interrupción (Blaikie et al., 1996, pp. 30-31).

Es en este contexto en el que el riesgo afrontado por la gente tiene que considerarse como una combinación compleja de vulnerabilidad y amenaza o peligro. Los desastres son el resultado de la interacción de ambas cosas (Blaikie et al., 1996, p. 2).

\begin{tabular}{|c|c|c|c|c|}
\hline $\begin{array}{l}\text { Línea teórico- } \\
\text { metodológica }\end{array}$ & Representantes & $\begin{array}{c}\text { Concepción de } \\
\text { riesgo }\end{array}$ & Concepción de vulnerabilidad & $\begin{array}{c}\text { Concepción del } \\
\text { desastre }\end{array}$ \\
\hline $\begin{array}{l}\text { MODELO DE PRESIÓN } \\
\text { Y LIBERACIÓN DE LOS } \\
\text { DESASTRES. (1996) }\end{array}$ & $\begin{array}{l}\text { Blaikie, Cannon, } \\
\text { David, Wisner }\end{array}$ & $\begin{array}{l}\text { El riesgo } \\
\text { afrontado por la } \\
\text { gente tiene que } \\
\text { considerarse } \\
\text { como una } \\
\text { combinación } \\
\text { compleja de } \\
\text { vulnerabilidad y } \\
\text { amenaza o } \\
\text { peligro. }\end{array}$ & $\begin{array}{l}\text { Progresión de la vulnerabilidad: } \\
\text { Análisis de las causas de fondo } \\
\text { (estructuras de poder, sistemas } \\
\text { políticos o económicos). } \\
\text { Las presiones dinámicas } \\
\text { (ausencia de instituciones, } \\
\text { capacitación, libertad de prensa, } \\
\text { explosión demográfica, } \\
\text { urbanización, deforestación). } \\
\text { Las condiciones inseguras } \\
\text { (entorno físico frágil, sociedad } \\
\text { vulnerable, acciones públicas } \\
\text { como falta de preparación ante } \\
\text { desastres). }\end{array}$ & $\begin{array}{lll}\text { Los desastres son } & \text { el } \\
\text { resultado de la la } \\
\text { interacción de } & \text { la } \\
\text { vulnerabilidad y la } & \text { la } \\
\text { amenaza o peligro. }\end{array}$ \\
\hline
\end{tabular}

Cuadro N⒊ Síntesis del Modelo de Presión y Liberación de los Desastres. Fuente: elaboración propia.

\subsubsection{Investigación Forénsica de Desastres (FORIN)}

En la actualidad, está emergiendo con cierta fuerza la Metodología FORIN (Investigaciones Forénsicas de Desastres), cuyas líneas de trabajo son el análisis de causas críticas, el meta-análisis, el análisis longitudinal y los escenarios de desastres (Burton, 2010).

Análisis de causas críticas. Identifica las causas fundamentales de los eventos de desastre y tiene como premisa la creencia de que los problemas se resuelven mejor al tratar 
de corregir o eliminar las causas fundamentales, en lugar de simplemente abordar los síntomas inmediatamente obvios (Burton, 2010, p. 37; IRDR, 2011, p. 16).

Meta-análisis. Constituyen críticas sistemáticas de la literatura disponible que son usadas para identificar y evaluar resultados consistentes a través de diversos estudios. Los resultados de los estudios de caso u observaciones de investigación son codificadas y estadísticamente analizadas para buscar relaciones causales, la fuerza de la relación entre los factores (variables dependiente o independiente) y la eficacia de las intervenciones (Burton, 2010, p. 38; IRDR, 2011, p. 16).

Análisis longitudinal. La reconstrucción longitudinal permite repetir observaciones de algunos lugares y puede ser comparada geográficamente (dos lugares diferentes pero esencialmente comparables con un evento de similares características, donde la secuencia de acciones, decisiones, políticas, etc., guían el riesgo de desastre y los efectos particulares son estudiados en forma comparativa). La importancia de las reconstrucciones longitudinales es que proveen un entendimiento en profundidad de las causas y consecuencias de los desastres y la evolución de la mitigación y/o estrategias de reducción del riesgo. En el caso de comparaciones de pares o un solo lugar con múltiples desastres, las reconstrucciones longitudinales permiten un análisis de qué estrategias de mitigación funcionaron, cuáles podrían haber funcionado si se hubieran implementado, las lecciones aprendidas, y las lecciones no aprendidas (Burton, 2010, pp. 38-39; IRDR, 2011, p. 17).

Escenarios de desastres. Retrospectivamente, reconstruye y especifica las condiciones, causas y respuestas involucradas en eventos particularmente destructivos. Son "forénsicas" en el sentido que el proceso incluye un área más amplia de cobertura para tazar y asignar explicaciones causales de las pérdidas y las condiciones de intervención que incrementaron o redujeron las pérdidas. El escenario puede basarse en la ciencia, y ser seleccionado de la base de los peligros conocidos que representa una real e inevitable posibilidad para el área de estudio. Este tipo de trabajo podría contemplarse como "forénsico proyectivo o predictivo", ya que proyecta pérdidas y sus causas en el futuro en contraposición con el examen y explicación de las pérdidas reales en el pasado (Burton, 2010, pp. 39-40; IRDR, 2011, p. 17).

La investigación forénsica es una metodología que tiene fuertes puntos de contacto con la geología, en tanto y en cuanto implica la necesidad de realizar investigaciones retrospectivas para determinar las causas de un evento en particular y poder reconstruirlo. 


\begin{tabular}{|c|c|c|c|c|}
\hline $\begin{array}{l}\text { Línea teórico- } \\
\text { metodológica }\end{array}$ & Representantes & Concepción de riesgo & $\begin{array}{l}\text { Concepción de } \\
\text { vulnerabilidad }\end{array}$ & $\begin{array}{c}\text { Concepción del } \\
\text { desastre }\end{array}$ \\
\hline $\begin{array}{l}\text { FORIN - } \\
\text { Investigación } \\
\text { forénsica de } \\
\text { desastres } \\
(2010)\end{array}$ & $\begin{array}{l}\text { IRDR (Integrated } \\
\text { Research on } \\
\text { Disaster Risk) } \\
\text { Burton, Oliver- } \\
\text { Smith }\end{array}$ & $\begin{array}{l}\text { Interpretaciones de las causas y los } \\
\text { procesos subyacentes al riesgo de } \\
\text { desastre: } \\
\text { Análisis de causas críticas: causas } \\
\text { fundamentales de los eventos de } \\
\text { desastre. } \\
\text { Meta-análisis: críticas sistemáticas de } \\
\text { la literatura disponible usadas para } \\
\text { identificar y evaluar resultados a través } \\
\text { de diversos estudios. } \\
\text { Análisis longitudinal: comparaciones } \\
\text { de pares o un solo lugar con múltiples } \\
\text { desastres. des } \\
\text { Escenarios de desastres: } \\
\text { reconstruye y especifica las } \\
\text { condiciones, causas y respuestas } \\
\text { involucradas en eventos destructivos. }\end{array}$ & $\begin{array}{l}\text { Aparece como } \\
\text { transversal al análisis } \\
\text { de las causas de } \\
\text { desastres. } \\
\text { Explícitamente, } \\
\text { analizan } \\
\text { conjuntamente la } \\
\text { vulnerabilidad con la } \\
\text { exposición, } \\
\text { particularmente en el } \\
\text { análisis de las causas } \\
\text { críticas. }\end{array}$ & $\begin{array}{l}\text { Las consecuencias } \\
\text { de que los } \\
\text { "eventos de } \\
\text { desastre natural" } \\
\text { están ligados a } \\
\text { patrones } \\
\text { decisiones de } \\
\text { todos los días. }\end{array}$ \\
\hline
\end{tabular}

Cuadro N4. Síntesis del enfoque presentado por la metodología FORIN. Fuente: elaboración propia.

\subsection{Riesgo, vulnerabilidad y desastres en perspectiva teórica: una discusión abierta}

La caracterización de cada enfoque trae aparejada la posibilidad de subrayar aportes singulares y puntos de contacto entre ellos, los cuales sientan algunos cimientos sólidos en materia de estudios sobre vulnerabilidad y riesgo.

En primer lugar, sobresale un acuerdo generalizado respecto que los desastres no tienen un origen estrictamente natural sino que se trata de una construcción social, aunque los peligros naturales adquieren un rol relevante para el desarrollo de un desastre o una catástrofe.

Gradualmente, se ha visto que la vulnerabilidad adquirió un rol fundamental en el estudio de los desastres. Se puede advertir en los distintos enfoques que, en la construcción de la vulnerabilidad, adquiere relevancia una perspectiva dinámica, es decir de proceso, quedando implícita la dimensión histórica. Desde la metodología FORIN, Burton (2010) lo resume asegurando que las consecuencias de los eventos de un desastre natural están ligadas a patrones y decisiones de todos los días (p. 37).

En líneas generales, la complejidad que subyace al tratamiento de los desastres y de la vulnerabilidad en particular, es una circunstancia que se desprende de todos los enfoques: aspectos políticos, institucionales, demográficos, económicos, sociales, culturales, históricos, aparecen como denominadores comunes.

Como se mencionó con anterioridad, dentro de la Teoría Social del Riesgo, una dimensión constitutiva es la incertidumbre. Su relevancia, en cierta medida, es un punto de 
vista compartido por Blaikie et al. (1996) cuando reconocen que al analizar los vínculos entre causas de fondo, presiones dinámicas y condiciones inseguras, es bastante excepcional tener evidencia confiable, especialmente mayor respaldo en la cadena de explicaciones ( $p$. 35). La incertidumbre científica, es decir, las limitaciones en el conocimiento pueden afectar la capacidad de preparación ante una emergencia, al desconocer las posibles consecuencias de un fenómeno. En este sentido, por ejemplo, los estudios de base volcanológica emergen como indispensables para conocer la recurrencia y magnitud de las erupciones que han afectado una zona determinada en el pasado geológico reciente, cooperando en la determinación del grado de exposición a los eventos volcánicos.

En buena medida, la causa de la incertidumbre puede encontrarse en dos aspectos. Por un lado, el grado de interdisciplinariedad con el que se estudian los riesgos (y especialmente la vulnerabilidad) requiriéndose trabajos cada vez más multidisciplinarios. Profundizando la discusión, el tema de la multidisciplina resulta clave para formular y mitigar los problemas relativos a desastres en ámbitos urbanos, siendo imprescindible para lograr un manejo integrado de la relación naturaleza-sociedad la presencia del Estado (nivel político), del mundo del trabajo (nivel económico), la ciencia y la técnica (nivel científico-profesional) y las poblaciones afectadas (nivel social) (Herzer y Gurevich, 1996b, p. 81).

Por otro lado, la tendencia a nivel temático exhibe un predominio del estudio de las inundaciones, relegándose el análisis de otros riesgos $\mathrm{y}$, por ende, reduciéndose la posibilidad de progresar en otros campos temáticos, como por ejemplo, los riesgos volcánicos y tsunamigénicos en Argentina.

Blaikie et al. (1996) intentan superar la limitación a nivel de conocimiento científico cuando sostienen que aunque nuestros conocimientos de mecanismos causales físicos son incompletos, algunos registros largos (por ejemplo de huracanes, terremotos, avalanchas de nieve o sequías), nos permiten especificar la probabilidad estadística de muchas amenazas o peligros en tiempo y espacio aunque reconocen que esos conocimientos son de utilidad limitada para calcular el nivel real del riesgo (p. 27).

La exposición, que en la Teoría Social del Riesgo contempla los resultados concretos que surgirían si el potencial peligro se torna realidad (Natenzon, 1995, p. 7), tiene su correlato en la metodología FORIN, particularmente, en la construcción de escenarios predictivos. Población y bienes afectables resumen el conjunto de elementos potencialmente afectables frente a un desastre. Para Blaikie et al. (1996), la vulnerabilidad es una combinación de características de una persona o grupo, expresadas en relación con la exposición a la amenaza que se deriva de la condición social y económica del individuo o 
comunidad interesada (p. 66). La exposición, en este sentido, aparece asociada a la vulnerabilidad y no directamente a los efectos potenciales de un desastre.

Esta dimensión puede verse como uno de los componentes más geográficos en el estudio de los riesgos volcánicos ya que interrelaciona factores humanos y físicos expresados territorialmente. Las pérdidas asociadas a una erupción están directamente relacionadas con los espesores de ceniza acumulados. Una herramienta práctica para evaluar a priori impactos directos e indirectos asociados a una erupción reciente son los mapas de isopacas, que se consisten en líneas que unen puntos con igual espesor de tefra.

La exposición no sólo está dada por el conjunto de componentes socioeconómicos susceptibles de daño sino que la amenaza también requiere de una comprensión más acabada. De aquí la necesidad de realizar investigaciones retrospectivas para determinar el tiempo y el origen de estos eventos, haciendo evidente la conexión entre la aproximación forense a los estudios de riesgo y la tefrocronología. Esta disciplina se definió como un método de datación basado en la identificación, clasificación y datación de las capas de tefra (Thorarinsson, 1981, en Lowe y Hunt, 2001, p. 19). Esta técnica permite, entre otras cosas, estudiar el registro de episodios de caída de ceniza volcánica a partir de testigos sedimentarios lacustres. La determinación de la continuidad y rango de dispersión geográficos de estos niveles piroclásticos conjuntamente con una cuidadosa caracterización y datación permiten establecer un marco tefrocronológico para en un sitio determinado (Villarosa et al., 2002, p. 1). La depositación de los niveles piroclásticos es de carácter prácticamente instantáneo, por lo que en función de su espesor y extensión pueden convertirse en excelentes marcadores crono-estratigráficos regionales.

En este sentido, el estudio de la recurrencia de caída de cenizas apoyado en modelos cronológicos emerge como un aspecto clave para entender la exposición a la amenaza que representa el volcanismo explosivo en la región. El estudio de la vulnerabilidad en sí misma no alcanza para entender el riesgo en su conjunto, sino que se deben orientar los esfuerzos para comprender también los fenómenos naturales que exponen las condiciones de vulnerabilidad en situación de desastre. Como resultado de ello se esperaría una reducción de la incertidumbre científica, es decir, que en la medida que la peligrosidad sea conocida con más detalle, se pueden tener a disposición información de base científica que aporte conocimientos sólidos en materia de recurrencia de caída de ceniza.

Si bien todas las perspectivas analizadas son sumamente valiosas, se debe fomentar aún más el desarrollo y la discusión a nivel metodológico. Algunos trabajos en particular atienden esta falencia aunque se trata de estudios de casos, muchos de ellos aplicados al 
análisis de la vulnerabilidad social en contexto de inundaciones (Natenzon, 2003; Andrade et al., 2003; Natenzon y González, 2010). Además, desde el PIRNA se ha desarrollado un Índice de Vulnerabilidad Social (IVS) aplicado a la Argentina a nivel departamental (Natenzon y González, 2010, p. 205).

Sin embargo, la gran variedad de riesgos exige la necesidad de ampliar la temática e incorporar dentro del interés de las ciencias sociales, en especial la geografía, el estudio de otros riesgos no sólo a nivel teórico sino también metodológico, definiendo técnicas, instrumentos e indicadores adecuados para abordar cada riesgo de manera puntual, es decir, conocer tanto las características del peligro como así también la vulnerabilidad asociada al mismo. Trabajos como los realizados por Jenkins et al., 2014, Wilson et al., 2014 y Craig et al., 2016, tienen una orientación hacia la evaluación de los impactos de las cenizas volcánicas en las infraestructuras críticas tales como los sistemas de abastecimiento de agua potable, el servicio eléctrico y el transporte, entre otros. Actualmente, se están orientando los esfuerzos para abordar la vulnerabilidad y la peligrosidad frente a la caída de material piroclástico (Delménico et al., 2015, 2016 y 2018), aunque el camino que queda por recorrer en esa dirección es aún extenso.

A partir de este marco teórico referencial general, la tesis se ordena proponiendo un capítulo introductorio al problema de investigación (Capítulo II), con desarrollo de objetivos e hipótesis orientadoras del trabajo de investigación. Luego, en el Capítulo III, se realiza una caracterización del ambiente regional incluyendo aspectos históricos, demográficos y físicos (clima, relieve y vegetación).

Para facilitar el orden y la lectura del trabajo, las hipótesis planteadas se desarrollan individualmente en diferentes apartados, donde se imbrican aspectos conceptuales referidos a cada temática específica. En el Capítulo IV se trabaja la vulnerabilidad asociada a la caída de ceniza volcánica, tratando tanto aspectos físicos (la recurrencia de eventos) como sociales en la construcción de una metodología para evaluar la vulnerabilidad social. El Capítulo $\mathrm{V}$ trata exclusivamente la vulnerabilidad litoral de espacios costeros urbanizados del lago Nahuel Huapi, donde aspectos sociales y naturales convergen en una metodología para reconocer grados de vulnerabilidad frente a olas extraordinarias.

Por último, el Capítulo VI reúne las principales conclusiones a las que se arriba a partir del trabajo desarrollado a lo largo de varios años de trabajo que dan continuidad al trabajo que se viene desarrollando desde el Grupo de Estudios Ambientales desde hace ya más de una década. 


\section{La incertidumbre como supuesto básico subyacente}

La incertidumbre es un aspecto que subyace a las cuestiones de riesgo y de la cuales numerosos autores dan cuenta, entre los que se destacan Funtowicz, Ravetz y Wynne.

Para Funtowicz (1994), el riesgo no es solamente la posibilidad de que suceda algo, sino la posibilidad de que suceda algo a lo que se agrega cuál puede ser la magnitud de las consecuencias (p.19), perspectiva que se encuentra enmarcada en un cambio de paradigma en las ciencias hacia lo que denomina Ciencia Posnormal. La cosmovisión reduccionista analítica, que divide los sistemas en elementos cada vez más pequeños, es reemplazada por un enfoque sistémico, sintético y humanístico. Reconocer los sistemas naturales reales como complejos y dinámicos implica moverse hacia una ciencia cuya base es la impredictibilidad, el control incompleto y una pluralidad de perspectivas legítimas (Funtowicz y Ravetz, 1993). Una de las características significativas de la nueva ciencia paradigmática es que ya no puede permitir que sus explicaciones no se relacionen con el espacio, el tiempo y el proceso (Funtowicz y Ravetz, 1993, p. 3).

Por otra parte, Wynne (1992) reconoce diversos tipos de incertidumbre:

- $\quad$ se habla de riesgo cuando el comportamiento del sistema es básicamente bien conocido y las posibilidades de resultados diferentes pueden ser definidas y cuantificadas mediante un análisis estructurado de los mecanismos y probabilidades (Wynne, 1992, p. 114).

- $\quad$ cuando se conocen los parámetros importantes del sistema, pero no las distribuciones de probabilidad, podemos hablar en términos de incertidumbre (Wynne, 1992, p. 114).

- la ignorancia es endémica al conocimiento científico, que tiene que reducir el marco de lo conocido a lo que es susceptible a sus propios métodos y modelos parroquiales. Siempre que los hechos exponen la ignorancia que siempre subyace a los modelos científicos utilizados en las políticas públicas, la respuesta dominante es invariablemente centrarse en mejorar el modelo científico (Wynne, 1992, p. 114).

- $\quad$ La indeterminación existe en la pregunta abierta de si el conocimiento está adaptado a las realidades desajustadas de las situaciones de aplicación, o si esas situaciones (técnicas y sociales) se reconfiguran para "validar" el conocimiento (Wynne, 1992, p.115).

Wynne (1992) vería el riesgo, la incertidumbre, la ignorancia y la indeterminación como superpuestos uno al otro, expresándose en función de la escala de los compromisos sociales («decisiones en juego») que apuestan a que el conocimiento sea correcto (p. 116). La distinción entre incertidumbre e indeterminación es importante porque la primera consagra la noción de que el control inadecuado de los riesgos ambientales se debe sólo a un conocimiento científico inadecuado y la atención exclusiva se centra en intensificar ese conocimiento para hacerlo más preciso (Wynne, 1992, p.118). 


\subsection{Bibliografía del capítulo}

ANDRADE M. I; PLOT B.; INFESTA M. E.; SCARPATTI O. E.; PINTOS P.; PAPALARDO M. M.; VALLEJOS V. H.; MONTES M. del C.; GRATTI P.; LOSANO G.; CARUT C.; BENITEZ M.; DEL RÍO J. P. 2003. Problemática de inundaciones en el Gran La Plata: mapa de riesgo hídrico desde la teoría social del riego. En PINTO P. (Comp.). 2003. Pensar La Plata. Políticas públicas, Sociedad y Territorio en la década de los noventa. Ed. Al Margen; La Plata; Págs. 71-99.

ANDRADE M. I.; LUCIONI N. C.; IEZZI L. E. 2012. Factores de riesgo hídrico en el Gran La Plata, Argentina. En Actas de las IX JORNADAS NACIONALES DE GEOGRAFIA FISICA BAHIA BLANCA, 19 al 21 de abril de 2012. Págs. 14-24.

ANDRADE M. I. 2013. Ocurrencia de inundaciones en el Gran La Plata Abril de 2013". IV Congreso Nacional de Geografía de Universidades Públicas y XI Jornadas Cuyanas de Geografía. Facultad de Filosofía y Letras de la Universidad Nacional de Cuyo. Mendoza. 23 al 26 de octubre 2013

ARIZTEGUI D.; ANSELMETTI F. S.; GILLI A.; WALDMANN N. 2008. "Late Pleistocene environmental changes in Patagonia and Tierra del Fuego - A limnogeological approach". En: J. Rabassa (Ed.), The Late Cenozoic of Patagonia and Tierra del Fuego. Developments in Quaternary Sciences Series 11, Págs. 241-253. ISSN 1571-0866. Elsevier Science.

ARIZTEGUI D.; BÖSCH P.; DAVAUD E. 2007. "Dominant ENSO frequencies during the Little Ice Age (LIA) in Northern Patagonia. The laminated record of proglacial Lago Frías (Argentina)". Quaternary International 161, Págs. 46-55.

BARRENECHEA J.; GENTILE E.; GONZÁLEZ S.; NATENZON C. 2000. Una propuesta metodológica para el estudio de la vulnerabilidad social en el marco de la Teoría Social del Riesgo. IV Jornadas de Sociología. Facultad de Ciencias Sociales. UBA. Buenos Aires, 6 al 9 de Noviembre de 2000, 13 Págs.

BECK U. 2007. Vivir en la sociedad del riesgo mundial. Serie: Dinámicas interculturales. Documentos CIDOB, $\mathrm{N}^{\circ}$ 8, Barcelona, Julio de 2007, 57 Págs. En: http://www.cidob.org/es/publicaciones/documentos/dinamicas_interculturales/vivir_en_la_soci edad_del_riesgo_mundial_living_in_the_world_risk_society. Consultada el 1 de Diciembre de 2013.

BEIGT D.; VILLAROSA G.; GÓMEZ E. A. 2012 (a) "Deslizamientos subacuáticos en sistemas deltaicos del lago Nahuel Huapi: resultados preliminares de una evaluación de peligrosidad para la localidad de Villa La Angostura (Neuquén)". 2das Jornadas Nacionales de Investigación y Docencia en Geografía Argentina (2da. JONIDGA) y 8vas. Jornadas de Investigación y Extensión del Centro de Investigaciones Geográficas (8 JIECIG). ISBN 978 950658309 5. Tandil, 14-16 Noviembre 2012. 7 Págs.

BEIGT D.; VILLAROSA G.; OUTES V.; DZENDOLETAS M. A.; GÓMEZ E. A. 2012. (b). "El lago Nahuel Huapi: un registro de erupciones, deslizamientos y tsunamis". Ciencia Hoy. Volumen 22, número 130, diciembre 2012 - enero 2013. Págs. 50 - 56

BEIGT D.; VILLAROSA G.; GÓMEZ E. A. 2010. "Mass-wasting events and related morphology along a coastal portion of Nahuel Huapi lake bed (Patagonia)". $18^{\circ}$ Congreso Sedimentológico Internacional. Mendoza, 26 Septiembre - 1 Octubre 2010. Pág. 166.

BEIGT D.; VILLAROSA G.; GOMEZ E. A. 2014. Análisis de deslizamientos subacuáticos en deltas lacustres (lago Nahuel Huapi, Argentina) a partir de batimetrías de alta resolución. Cuadernos de Investigación Geográfica. Núm. 40 (1). Págs. 247-259. 
BEIGT D.; VILLAROSA G.; OUTES V.; DZENDOLETAS M.A.; GÓMEZ E. A. 2013. "Tsunamis en el lago Nahuel Huapi: historias de deslizamientos y erupciones". Desde La Patagonia Difundiendo Saberes. Vol. 10, Págs. 10-15

BEIGT D.; VILLAROSA G.; GÓMEZ E. A. 2013. "Procesos de remoción en masa subacuáticos en deltas del lago Nahuel Huapi (Argentina): hacia una evaluación de peligrosidad para las localidades de Bariloche y Dina Huapi”. Cuadernos de Investigación Geográfica, Univ. de La Rioja, España.

BLAIKIE P.; CANNON T.; DAVID I.; WISNER B. 1996. Vulnerabilidad. El entorno social, económico y político de los desastres. En: http://www.desenredando.org, La Red, Julio de 1996, 290 Págs.

BURTON I. 2010. Forensic disaster Investigations in Deph. A New Case Study Model. En: www.environmentmagazine.org. Volumen 52. Number 5. Sept./Oct. 2010, 6 Págs.

CAPUTO M. G.; HARDOY J. E.; HERZER H. M. 1985. La inundación en el Gran Resistencia (Provincia del Chaco, Argentina) 1982-1983. Desastres Naturales y Sociedad en América Latina, Vol. 4, Grupo Editor Latinoamericano, Buenos Aires, Págs. 129-156.

CARDONA O. D. 1993. Evaluación de la amenaza, la vulnerabilidad y el riesgo. "Elementos para el Ordenamiento y la Planeación del Desarrollo". En MASKREY A. (Comp.). 1993. Los desastres no son naturales. La Red. En: http://www.desenredando.org, Págs. 45-65.

CASALBORE D.; ROMAGNOLI C.; BOSMAN A.; CHIOCCI F. L 2011. "Potential tsunamigenic landslides at Stromboli Volcano (Italy): Insight from marine DEM analysis". Geomorphology, № 126; Págs. 42-50.

CEMBRANO J.; HERVÉ F.; LAVENU A. 1996. "The Liquiñe-Ofqui fault zone: a long-lived intra-arc fault system in southern Chile". Tectonophysics, Vol. 259, Págs. 55-66.

CEMBRANO J.; SCHERMER E.; LAVENU A.; SANHUEZA A. 2000. "Contrasting nature of deformation along an intra-arc shear zone, the Liquiñe-Ofqui fault zone, southern Chilean Andes". Tectonophysics, Vol. 319, Págs. 129-149.

CHAPRON E.; ARIZTEGUI D.; MULSOW S.; VILLAROSA G.; PINO M.; OUTES V.; JUVIGNIE E.; CRIVELLI E. 2006. "Impact of the 1960 major subduction earthquake in Northern Patagonia (Chile, Argentina)". Quaternary International 158, Págs. 58-71.

CHIOZZA E. M. y CARBALLO C. T. 2006. Introducción a la geografía. Universidad Nacional de Quilmes; Bernal; 160 Págs.

CÓRDOBA G.; VILLAROSA G.; BEIGT D.; VIRAMONTE J. G.; SALMUNI G.; SHERIDAN M.; PITMAN B. 2011. Modelado de lahares secundarios en Villa La Angostura a partir de los depósitos generados por la erupción del Cordón Caulle "Wé Pillan". Informe Preliminar. Inédito. 17 Págs.

CÓRDOBA G.; VILLAROSA G.; SHERIDAN, M.; VIRAMONTE J. G.; BEIGT D.; SALMUNI G. 2015. Secondary lahar hazard assessment for Villa La Angostura, Argentina, using TwoPhase-Titan modelling code during 2011 Cordón Caulle eruption. Natural Hazards and Earth System Sciences Discussions, 15, p. 757-766

DELMÉNICO A.; VILLAROSA G.; BEIGT D.; OUTES V. 2015. Pensando el volcanismo en términos de Vulnerabilidad: la construcción de escenarios como herramienta de gestión de riesgos frente a la caída de ceniza volcánica en Bariloche y Dina Huapi (Patagonia, Argentina). En actas del Seminario Internacional "Ciencias sociales y riesgo de desastres en América Latina: un encuentro inconcluso". Buenos Aires, 15-17 de Septiembre de 2015. 
Disponible en www.pirna.com.ar/files/pirna/SICSYRD_PON_DELMENICO_Agustin.pdf. Consultada el 1 de Febrero 2017.

DELMÉNICO A.; VILLAROSA G.; BEIGT D.; OUTES V. ANDRADE M. I.; MANZONI C. 2018. Los indicadores censales como herramienta para evaluar la vulnerabilidad social frente a la caída de ceniza volcánica. El caso de Villa La Angostura (Argentina) durante la erupción del Cordón Caulle 2011. Revista Universitaria de Geografía. En prensa.

DELMÉNICO A.; VILLAROSA G.; BEIGT D.; OUTES V.; ANDRADE M. I.; MANZONI C. 2016. Census indicators as a tool to assess social vulnerability to ashfall events in Argentina: the case of Villa La Angostura during 2011 Cordón Caulle eruption. En Actas del Congreso "Cities on volcanoes 9". Puerto Varas, Chile, 20-25 de Noviembre de 2016.

EIRD/ONU. 2004. Vivir con el Riesgo. Informe mundial sobre iniciativas para la reducción de desastres. ONU. Ginebra. En: http://www.eird.org/vivir-con-el-riesgo/index2.htm. Consultada el 1 de Marzo de 2014; 624 Págs.

FANETTI D.; ASELMETTI F.S.; CHAPRON E.; STURM M.; VEZZOLI L. 2008. "Megaturbidite deposits in the Holocene basin fill of Lake Como (Southern Alps, Italy)". Palaeogeography, Palaeoclimatology, Palaeoecology 259, Págs. 323-340.

FERNANDEZ M. A. y RODRIGUEZ L. 1996. “¿Cuál es el problema? Introducción a la temática”. En FERNANDEZ M. A (Comp.). 1996. Ciudades en riesgo. Degradación Ambiental, Riesgos Urbanos y Desastres. Red de Estudios Sociales en Prevención de Desastres en América Latina. La Red-USAID, Págs. 7-11.

FILGUEIRA C. y PERI A. 2004. América Latina: los rostros de la pobreza y sus causas determinantes. Santiago de Chile. CELADE/CEPAL. Serie Población y Desarrollo. $\mathrm{N}^{\circ} 54$. En: http://www.eclac.org/publicaciones/xml/2/15062/lcl2149-serie54.pdf, 65 Págs.

FUNTOWICZ S. y RAVETZ J. 1993. "Riesgo global, incertidumbre e ignorancia". En Epistemología política. Ciencia con la gente. Buenos Aires, CEAL, 17 Págs.

GARCÍA ACOSTA V. 2005. "El riesgo como construcción social y la construcción social de riesgos". Desacatos, Septiembre-Diciembre, número 019. Centro de Investigaciones y Estudios Superiores en Antropología Social. Distrito Federal, México. Págs. 11-24.

GELLERT-DE PINTO G. I. 2012. El cambio de paradigma: de la atención de desastres a la gestión del riesgo. Boletín Científico Sapiens Research, 2 (1), Págs. 13-17.

GIDDENS A. 1993. Consecuencias de la Modernidad. Madrid, Alianza Editorial, Sec. I, Págs. 15-59.

GIRARDCLOS S.; SCHMIDT O.T.; STURM M.; ARIZTEGUI D.; PUGIN A.; ANSELMETTI F.S. 2007. "The 1996 AD delta collapse and large turbidite in Lake Brienz". Marine Geology 241, Págs. 137-154.

GONZALEZ S. 2001. Gestión del riesgo por inundaciones en la ciudad de Buenos Aires. Situación actual y alternativa. Realidad Económica, N¹77, Págs. 1-14.

HABERZETTL T.; KÜCK B.; WULF S.; ANSELMETTI F. S.; ARIZTEGUI D.; CORBELLA H.; FEY M.; JANSSEN S.; LÜCKE A.; MAYR C.; OHLENDORF C.; SCHÄBITZ F.; SCHLESER G. H.; WILLE M. y ZOLITSCHKA B. 2008. "Hydrological variability and explosive volcanic activity in southeastern Patagonia during Oxygen Isotope Stage 3 and the Holocene inferred from lake sediments of Laguna Potrok Aike, Argentina". Palaeogeography, Palaeoclimatology, Palaeoecology 259: (2-3): 213229. 
HERZER H. y GUREVICH R. 1996(a). Construyendo el riesgo ambiental en la ciudad. Desastres y sociedad, № 7, Año 4. La red. Julio/Diciembre 1996, Págs. 9-17.

HERZER, H. y GUREVICH, R. 1996(b). Degradación y desastres: parecidos y diferentes: tres casos para pensar y algunas dudas para plantear. En FERNANDEZ M. A. (Comp.). 1996. Ciudades en riesgo. Degradación Ambiental, Riesgos Urbanos y Desastres. La Red, Lima, Págs. 75-91.

IRDR (Integrated Research on Disaster Risk). 2011. Forensic Investigations of Disasters: The FORIN Project (IRDR FORIN Publication No. 1). Beijing: Integrated Research on Disaster Risk; 32 Págs.

JENKINS S.F.; WILSON T.M.; MAGILL C.R.; MILLER V.; STEWART C. 2014. Volcanic ash fall hazard and risk. Technical background paper for the UN-ISDR Global Assessment Report on Disaster Risk Redution 2015. Global Volcano Model and IAVCEI. En: www.preventionweb.net/english/hyogo/gar; 39 Págs.

KITZBERGER T.; VEBLEN T.T.; VILLALBA R. 1995. Tectonic influences on tree-ring and stand response in northern Patagonia (Argentina). Canadian Journal of Forest Research 25: 1684-1696.

LARA L.; LAVENU A.; CEMBRANO J.; RODRÍGUEZ C. 2006. "Structural controls of volcanism in transversal chains: Caulle-Puyehue area $\left(40.5^{\circ} \mathrm{S}\right)$, Southern Andes Resheared faults and neotectonics in the Cordón". Journal of Volcanology and Geothermal Research, 158, Págs. 70-86.

LASTRAS G.; AMBLAS D.; CALAFAT A. M.; CANALS M.; FRIGOLA J.; HERMANNS R. L.; LAFUERZA S.; LONGVA O.; MICALLEF A.; SEPÚLVEDA S. A.; VARGAS G.; DE BATIST M.; VAN DAELE M.; AZPIROZ M.; BASCUÑÁN I.; DUHART P.; IGLESIAS O.; KEMPF P.; RAYO X. 2013. Landslides Cause Tsunami Waves: Insights From Aysén Fjord, Chile, Eos Trans. AGU, 94 (34), Pág. 297.

LAVELL A. 1993. "Ciencias Sociales y desastres naturales en América Latina: un encuentro inconcluso". En MASKREY A. (Comp.). 1993. Los desastres no son naturales. La Red. En: http://www.desenredando.org, Págs. 111-127.

LAVELL A. 1996. Degradación ambiental, riesgo y desastre urbano. Problemas y conceptos: hacia la definición de una agenda de investigación. En FERNANDEZ M. A (Comp.). 1996. Ciudades en riesgo. Degradación Ambiental, Riesgos Urbanos y Desastres. La Red, Lima, Págs. 12-42.

LAVELL A. 2009. Reducción del Riesgo de Desastres en el Ámbito Local: Lecciones desde la Subregión Andina. Serie: Experiencias significativas de desarrollo local frente a los riesgos de desastres. Primera Edición. Comunidad Andina. Lima, Perú, 85 Págs.

LLAMBÍAS E. J. 2009. Volcanes: nacimiento, estructura, dinámica. Ed. Vazquez Mazzini. Buenos Aires.

LOWE D. J. y HUNT J. B. 2001. A summary of terminology used in tephra-related studies. En: JUVIGNE, E.T.; RAYNAL, J-P. (Eds), 'Tephras: Chronology, Archaeology", CDERAD éditeur, Gaudet. Les Dossiers de l'Archeo-Logis 1. Págs.17-22

LLAMBÍAS E. J. 2009. Volcanes: nacimiento, estructura, dinámica. 1. Ed. Vazquez Mazzini. Buenos Aires, 144 Págs.

LONGHI F. 2007. Mortalidad infantil y perfil epidemiológico en los "núcleos duros" de pobreza del Norte Grande Argentino (1992-2005). IX Jornadas Argentinas de Estudios de 
Población. Asociación de Estudios de Población de la Argentina, Huerta Grande, Córdoba; 26 Págs.

MANZONI C.; DELMÉNICO A.; BEIGT D.; VILLAROSA G. 2013. Análisis preliminar de susceptibilidad frente a tsunamis lacustres en costas urbanizadas del lago Nahuel Huapi (Río Negro) en base a la interpretación de imágenes satelitales y fotos aéreas. En Libro de Resúmenes y Trabajos Completos $1^{\circ}$ Congreso Internacional sobre Riesgos de Desastres y Desarrollo Territorial Sostenible / Niz, Ortiz, Ramos y Carrizo (Eds.)-1a ed. Catamarca: Editorial Científica Universitaria de la Universidad Nacional de Catamarca. Año 2013. Págs. 428-429.

MASKREY A. (Comp.). 1993. Los desastres no son naturales. En: http://www.desenredando.org. La Red, 140 Págs.

MOERNAUT J.; VAN DAELE M.; HEIRMAN K.; FONTIJN K.; STRASSER M.; PINO M.; R. URRUTIA; DE BATIST M. 2014. Lacustrine turbidites as a tool for quantitative earthquake reconstruction: New evidence for a variable rupture mode in south central Chile, Journal of Geophysical Research-Solid Earth, 119, 1607-1633, doi:10.1002/2013JB010738.

MONECKE K.; ANSELMETTI F.S.; BECKER A.; STURM M.; GIARDINI D. 2004. "The record of historic earthquakes in lake sediments of Central Switzerland". Tectonophysics 394, Págs. 21-40.

NATENZON C. E. 1995. Catástrofes naturales, riesgo e incertidumbre. Serie de Documentos e Informes de Investigación, №197; FLACSO; 19 Págs.

NATENZON C. E. 2003. Inundaciones catastróficas, vulnerabilidad social y adaptaciones en un caso argentino actual. Cambio climático, elevación del nivel medio del mar y sus implicancias. En: Climate Change Impacts and Integrated Assessment EMF (Energy Modeling Forum) Workshop IX. Stanford University. Snowmass, Colorado. July 28 - August 7; 16 Págs.

NATENZON C. E. 2005. "Social Vulnerability, Disasters and Climate Change in Latin America. Thematic, Theoretical and Methodological Approaches" / "Vulnerabilidad social, catástrofes y cambio climático. Comentarios temáticos, teóricos y metodológicos para América Latina". En: II Regional Conference on Global Change: South America. Universidad de San Pablo, 7-10 de Noviembre, 15 Págs.

NATENZON C. E. y GONZALEZ S. G. 2010. "Riesgo Vulnerabilidad social y construcción e indicadores. Aplicaciones para Argentina". En: Argentina e Brasil. Posibilidades e obstáculos no proceso de integração territorial. Universidade de São Paulo/ Universidad de Buenos Aires. São Paulo, Humanitas; Págs. 195-217.

NATENZON C. E. y RÍOS D. (Eds.). 2016. Riesgos, catástrofes y vulnerabilidades. Aportes desde la Geografía y otras Ciencias Sociales para casos argentinos. Imago Mundi. Buenos Aires. 228 Págs.

OUTES V. y VILLAROSA G. 2007. "Estudio ambiental Centro Cultural y de Eventos San Carlos de Bariloche. Aspectos geoambientales”. Inédito. 30 Págs.

OUTES V.; VILLAROSA G.; DELMÉNICO A.; GÓMEZ LISSARRAGUE M.; BEIGT D.; MANZONI, C. y ARRETCHE M. 2015. La erupción del Cordón Caulle 2011 en Villa La Angostura: una experiencia de cooperación entre los sistemas científico y de protección civil. En VIAND J. y BRIONES F. (Comps.). 2015. Riesgos al sur. Diversidad de riesgos de desastres en Argentina. Imago Mundi/La Red. Págs. 229-256. 
PERANOVICH A.; ANDRADA M.; BERTONE C. 2008. Mortalidad infantil, causas y determinantes. Una perspectiva comparada entre la ciudad de Córdoba (Argentina) y Campiñas (Brasil), para el período 2000-2005. Trabajo presentado en el III Congreso de la Asociación Latinoamericana de Población, ALAP. Córdoba, Argentina, del 24 al 26 de Septiembre de 2008; 16 Págs.

PEREYRA F. X. 2007. "Geomorfología urbana de San Carlos de Bariloche y su influencia en los peligros naturales, Rio Negro". Revista de la Asociación Geológica Argentina 62 (2), Págs. 309- 320.

PUYOL R.; ESTÉBANEZ, J.; MENDEZ, R. 1992. Geografía Humana. Segunda edición. Ed. Cátedra. Madrid, 728 Págs.

REALE A. y HANDMER J. 2011. Land tenure, disasters and vulnerability. Disasters. Overseas Development Institute. 35 (1), Págs. 160-182.

ROMERO G. y MASKREY A. 1993. "Cómo entender los desastres naturales". En MASKREY A. (Comp.). 1993. Los desastres no son naturales. La Red. En: http://www.desenredando.org, Págs. 6-10.

SCHNELLMANN M.; ANSELMETTI F.S.; GIARDINI D.; MCKENZIE J.A.; WARD S.N. 2002. "Prehistoric earthquake history revealed by lacustrine slump deposits". Geology 30: 11311134.

SCHNELLMANN M.; ANSELMETTI F.S.; MCKENZIE J.A.; GIARDINI D. 2006. "15,000 yr of massmovement history in Lake Lucerne: implications for seismic and tsunami hazards". Eclogae Geol. Helv. 99. doi:10.1007/s00015-006-1196-7.

SEGEMAR. 2005. Estudio geocientífico aplicado al ordenamiento territorial. San Carlos de Bariloche. Provincia de Río Negro. República Argentina. SEGEMAR-BGR. Anales No 42. Buenos Aires, 181 Págs.

STERN C. 2004. "Active Andean volcanism: its geologic and tectonic setting. Revista Geológica de Chile, 31(2), Págs. 161-206.

STEWART C.; CRONIN S.; WILSON T.; BICKERTON H.; VILLAROSA G.; OUTES V.; BAXTER P. 2012. Volcanic ashfall, drinking water and public health - recent experiences from the 2011 Puyehue-Cordón Caulle and 2012 Tongariro eruptions. En Cities on Volcanoes, Colima, 19-23 de Noviembre de 2012, 1 Pág.

STRASSER M.; STEGMANN S; BUSSMANN F.; ANSELMETTI F. S.; RICK B.; KOPF A. 2007. Quantifying subaqueous slope stability during seismic shaking: Lake Lucerne as model for ocean margins. Marine Geology 240, Pág. 77-97.

TILLING R. I. 2005. Volcano hazards. En MARTí J. y ERNST G. G. J. (Eds.) 2005. Volcanoes and environment. Cambridge University Press. Edimburgo, Reino Unido. Págs. 55-89.

UNESCO. 2008. "Preparación para casos de tsunami. Guía informativa para los planificadores especializados en medidas de contingencia ante catástrofes". Comisión Oceanográfica Intergubernamental de la UNESCO. Manual y Guías N49, 27 Págs.

VAN DAELE M.; MOERNAUT J.; DOOM L.; BOES E.; FONTIJN K.; HEIRMAN K.; BRÜMMER R. 2015. A comparison of the sedimentary records of the 1960 and 2010 great Chilean earthquakes in 17 lakes: Implications for quantitative lacustrine palaeoseismology. Sedimentology, 62(5), 1466-1496. 
VILLALÓN SEMANAT M. 2003. "Guía para la elaboración de inventarios de elementos en riesgo en áreas vulnerables a inundaciones y sismos en Costa Rica". IFA Report. International Institute for Geo-Information Science and Earth Observation (ITC), The Netherlands. 39 Págs.

VILLAROSA G.; OUTES V.; GOMEZ E. A.; CHAPRON E.; ARIZTEGUI D. 2009. Origen del tsunami de mayo de 1960 en el Lago Nahuel Huapi, Patagonia: aplicación de técnicas batimétricas y sísmicas de alta resolución. Rev. Asoc. Geol. Argent. [online]., vol.65, N.3. Págs. 593-597.

VILLAROSA G. y OUTES V. 2013. Distribución, características de la ceniza volcánica caída en la región e impactos en la comunidad. En Convenio de Asistencia Técnica, Centro Regional Universitario Bariloche (Universidad Nacional del Comahue)-Legislatura de Neuquén: Efectos de la caída de cenizas del CPCC sobre la región del lago Nahuel Huapi. Informe Final, Diciembre de 2013, Págs. 12-59.

VILLAROSA G.; V. OUTES; E. CRIVELLI. 2006. Los niveles piroclásticos de la laguna EI Trébol: Registro clave para el desarrollo de una tefrocronología postglacial en el área de Nahuel Huapi, Patagonia. IV Congreso Latinoamericano de Sedimentología y XI Reunión Argentina de Sedimentología, San Carlos de Bariloche. Actas, Pág. 238.

VILLAROSA G.; OUTES V.; GÓMEZ E. 2012 (a). La erupción del CC del 4 de junio de 2011: Mapa de distribución, características de la ceniza volcánica caída en la región e impactos en la comunidad. Convenio CRUB, UNCOMA-Legislatura de Neuquén. Mayo de 2012, Págs. 12-59.

VILLAROSA G.; OUTES V.; GÓMEZ E. A., CHAPRON E.; ARIZTEGUI D. 2009. "Origen del tsunami de mayo de 1960 en el lago Nahuel Huapi, Patagonia: aplicación de técnicas batimétricas y sísmicas de alta resolución". Revista de la Asociación Geológica Argentina 65 (3), Págs. 593-597.

VILLAROSA G.; OUTES V.; GÓMEZ E.; CHAPRON E. 2007. "Estudio sobre el origen del tsunami de Nahuel Huapi de 1960 mediantes técnicas sísmicas y batimétricas de alta resolución. Evaluación de peligrosidad". Bariloche. Inédito.

VILLAROSA G.; SCHNEIDER M.; OUTES V.; LÓPEZ E.; DZENDOLETAS M. A.; BEIGT D.; VILLAROSA F.; GALOSI C.; RUIZ M. 2012 (b). Estudio de Peligrosidad de avalanchas en el Parque Nahuel Huapi vinculados a la erupción del Cordón Caulle (CC). Informe Inédito. Convenio de Asistencia Técnica INIBIOMA (CONICET-Universidad Nacional del Comahue)Administración de Parques Nacionales, Diciembre 2012, 81 págs.

WILCHES-CHAUX G. 1993. La vulnerabilidad global. En MASKREY A. (Comp.). 1993. Los desastres no son naturales. La Red. En: http://www.desenredando.org, Págs. 11-44.

WILSON G.; WILSON T. M.; DELIGNE N. I.; COLE J. W. 2014. Volcanic hazard impacts to critical infrastructure: A review. Journal of Volcanology and Geothermal Research 286; Págs. 148-182.

WILSON T.; STEWART C.; BICKERTON H; BAXTER P.; OUTES V.; VILLAROSA G. y ROVERE E. 2013. Impactos en la salud y el medioambiente producidos por la erupción del Complejo Volcánico Puyehue-Cordón Caulle del 4 de Junio de 2011: Informe de un equipo de investigación multidisciplinario. GNS Science Report 2012/20, enero de 2013. 88 Págs.

WYNNE B. 1992. Uncertainty and environmental learning. Reconceiving science and policy in the preventive paradigm. Global environmental change, 2 (2). Págs. 111-127. 


\section{Otras fuentes}

"Precaución por alerta meteorológico". Diario Río Negro, edición digital, 10 de Febrero de 2013. http://www.rionegro.com.ar/diario/precaucion-por-alerta-meteorologico-1067896-9574nota.aspx. Consultada el 1 de Junio de 2013.

"Una avalancha de cenizas volcánicas cortó el paso a Chile en Neuquén”. Sábado, 11 de junio de 2011. Diario Los Andes, edición digital. http://www.losandes.com.ar/notas/2011/6/11/avalancha-cenizas-volcanicas-corto-paso-chileneuquen-573950.asp. Consultada el 1 de Junio de 2013.

Mapa: www.fotosimagenes.org. Consultada el 8 de Junio de 2013.

"Conformaron Comisión de Emergencia por temporal". ANB (Agencia de Noticias Bariloche). 9 de marzo de 2012. http://www.anbariloche.com.ar/noticias/2012/03/09/26871-. Consultada el 19 de Diciembre de 2017.

Real Academia Española. http://www.rae.es/. Consultada el 31 de mayo de 2017. 


\section{CAPÍTULO II}

\section{FORMULACIÓN DEL PROBLEMA DE INVESTIGACIÓN}

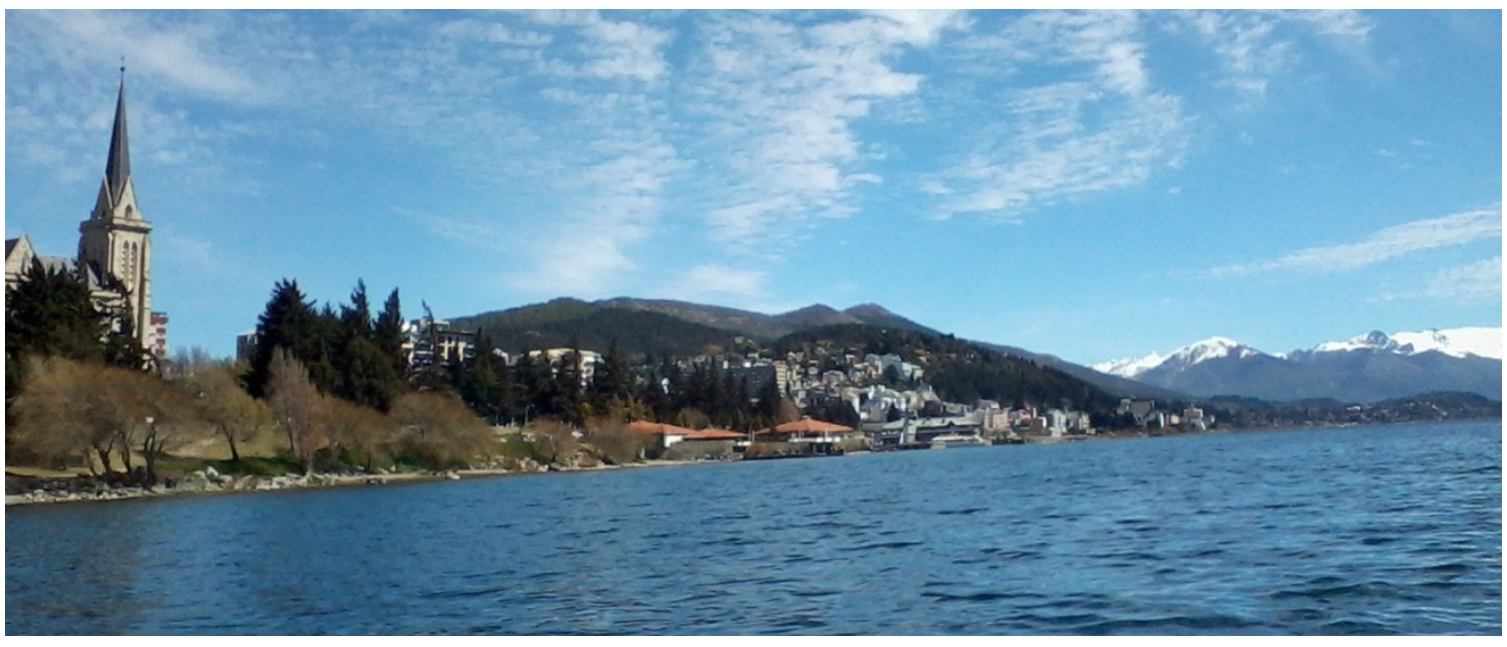

Vista parcial de la ciudad de San Carlos de Bariloche. 14 de octubre de 2014. Foto del autor. 


\subsection{Formulación del problema}

El rápido crecimiento que vienen registrando desde hace unas décadas los espacios urbanos localizados en torno a las costas del lago Nahuel Huapi, San Carlos de Bariloche, Dina Huapi y Villa La Angostura (Figura $\mathrm{N}^{\circ} 1$ ), sumado a los recientes eventos de caída de cenizas, muestran la importancia actual de estudiar la vulnerabilidad que presentan estas localidades frente a tsunamis lacustres y caída de material piroclástico.

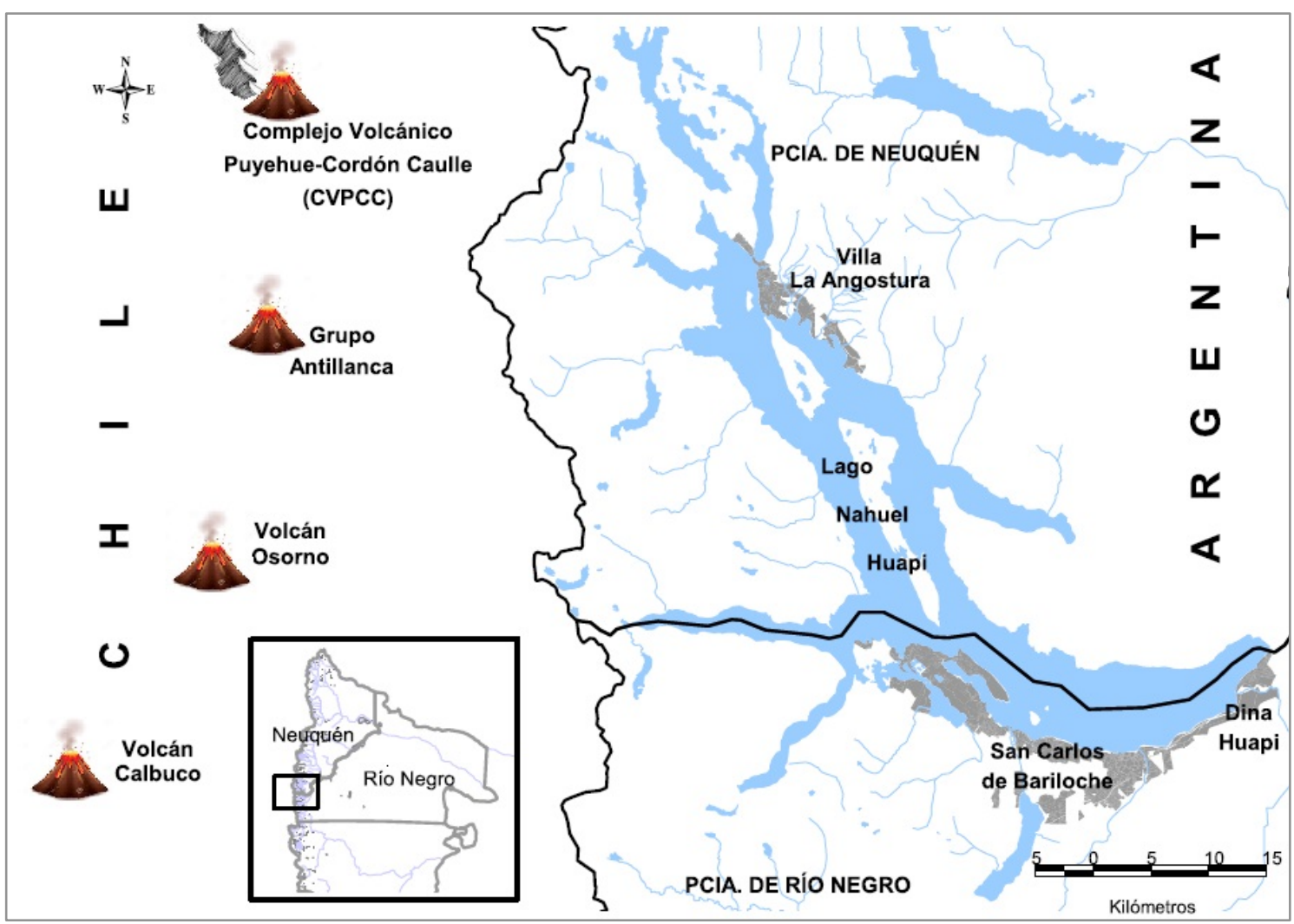

Figura $N^{\circ}$ 1. La Región del Nahuel Huapi. Si bien la mayoría de los volcanes activos se localizan en territorio chileno, los vientos dominantes del Oeste son los responsables de transportar gran parte del material piroclástico al territorio argentino. La imagen evidencia la exposición de las localidades costeras del lago Nahuel Huapi a la caída de ceniza volcánica por su cercanía a los sistemas volcánicos. Asimismo, en la medida en que la expansión urbana se extendió sobre las márgenes del lago Nahuel Huapi ocupando espacios naturalmente susceptibles como los deltas, evidencia una marcada exposición de las localidades a los tsunamis lacustres.

Norpatagonia andina se encuentra bajo la influencia de las erupciones explosivas de los volcanes cordilleranos de la Zona Volcánica Sur (ZVS). Este volcanismo es el producto de la subducción de la placa de Nazca por debajo de la placa Sudamericana que origina un arco volcánico que se extiende entre las latitudes 33 y $46^{\circ} \mathrm{S}$, siguiendo el sistema de LiquiñeOfqui en territorio chileno (Cembrano et al., 1996 y 2000). La ZVS incluye al menos 60 volcanes activos o potencialmente activos con actividad histórica en Chile y Argentina, así 
como tres sistemas de calderas gigantes y numerosos centros eruptivos menores (Stern, 2004). Debido a ello, la Patagonia Norte está expuesta a recurrentes caídas de cenizas volcánicas generadas en las erupciones explosivas de los volcanes andinos y transportadas por los vientos dominantes del oeste. Se ha sugerido además que los niveles de tefra ubicados a distintas profundidades en el lecho del lago Nahuel Huapi (Chapron et al., 2006, p. 63) pueden constituir potenciales planos de deslizamiento de los sedimentos suprayacentes (Beigt et al., 2016).

El sistema de subducción es responsable además de una marcada sismicidad, definiendo una peligrosidad sísmica moderada (INPRES, 1991) para la región norpatagónica andina y periandina, donde se encuentran situados los grandes lagos glaciarios de la región (Nahuel Huapi, Traful, Lacar, Aluminé, Huechulafquen, entre otros). A esta sismicidad se han asociado fenómenos de remoción en masa subaéreos y subacuáticos registrados en la región (Lara et al., 2004a; Kitzberger et al., 1995; Chapron et al., 2006, Villarosa et al., 2009, Lastras et al., 2013).

Los deslizamientos subaéreos o subacuáticos que afectan la topografía de las cubetas lacustres de la región introducen y/o movilizan grandes volúmenes de sedimentos en los lechos lacustres, pudiendo generar olas extraordinarias en la superficie de estos cuerpos de agua, como ocurrió con el tsunami de 1960 en el lago Nahuel Huapi, inducido por un gran deslizamiento subacuático en el área de Puerto San Carlos (Villarosa et al., 2009).

\subsection{OBJETIVOS}

\section{Objetivo general}

El objetivo de la presente investigación consiste en establecer bases metodológicas para la identificación y análisis de la peligrosidad y la vulnerabilidad de las áreas urbanizadas en grandes lagos de Patagonia Norte ante erupciones volcánicas y olas extraordinarias (olas tipo tsunami), basado en el análisis de indicadores referidos a los factores naturales desencadenantes y precondicionantes de estos fenómenos, e indicadores relacionados con la vulnerabilidad de las localidades costeras.

\section{Objetivos específicos}

1. Estudiar la frecuencia, peligrosidad e impactos de eventos eruptivos registrados.

2. Analizar los fenómenos de remoción en masa subacuáticos en lago Nahuel Huapi a partir de registros sedimentarios lacustres y datos históricos. 
3. Identificar sectores deslizados y potencialmente inestables del lecho lacustre, susceptibles de remoción en masa, en ambientes costeros.

4. Reconocer, de manera preliminar, los sectores costeros del lago Nahuel Huapi más susceptibles frente a posibles olas extraordinarias y por otra parte, identificar los sectores urbanos susceptibles de ser afectados por posibles caídas de cenizas volcánicas.

5. Identificar los principales factores y determinar el grado de vulnerabilidad de las poblaciones analizadas frente a caídas de cenizas volcánicas y tsunamis lacustres.

\subsection{HIPÓTESIS}

La vulnerabilidad y la peligrosidad en torno a las localidades norpatagónicas expuestas a procesos volcánicos y fenómenos tsunamigénicos es el resultado de la conjugación de factores naturales desencadenantes, factores propiciantes de tipo natural y factores propiciantes de orden antrópico. Para abordar el estudio de cada una de estas amenazas en las localidades costeras del lago Nahuel Huapi de manera independiente, se han delineado dos hipótesis específicas que se desarrollan a continuación.

\subsubsection{Hipótesis específica relacionada a eventos volcánicos}

Las erupciones volcánicas explosivas de la Zona Volcánica Sur crean una condición específica de peligrosidad natural en las localidades de la región del lago Nahuel Huapi Bariloche, Dina Huapi, Villa La Angostura- frente a la caída de cenizas. La vulnerabilidad social ligada a este peligro natural se halla fuertemente vinculada a diversos factores socioeconómicos presentes en las comunidades costeras.

Los indicadores referidos a peligrosidad frente a la caída de ceniza volcánica son los siguientes:

- Sistemas volcánicos activos, cuyas erupciones pueden afectar potencialmente el área de estudio.

- Índice de explosividad de erupciones conocidas.

- Registros de caídas de cenizas asociadas a eventos volcánicos (número de eventos, espesores) como indicadores de magnitud y recurrencia.

Los indicadores identificados en torno a la vulnerabilidad son:

- Consecuencias económicas de la caída de cenizas: pérdidas estimadas, actividades afectadas, etc. 
- Consecuencias de la caída de cenizas: impacto en la red de agua potable, los sistemas pluviales y la red cloacal. Cambios implementados a partir de la experiencia de 2011.

- Indicadores censales en las tres localidades de estudio (NBI, desocupación, analfabetismo, jefe de hogar femenino, material de la cubierta exterior del techo, entre otros).

- Preparación ante la emergencia a través de programas de actuación locales.

\subsubsection{Hipótesis específica relacionada a fenómenos tsunamigénicos lacustres}

Los deslizamientos subacuáticos que se desarrollan en el lecho del lago Nahuel Huapi, debido a su potencial capacidad para generar tsunamis lacustres, crean una condición de peligrosidad natural en las áreas costeras de las localidades de Bariloche, Dina Huapi, Villa La Angostura, donde diversos factores socioeconómicos se combinan para definir grados de vulnerabilidad social frente a esta problemática.

Los indicadores de peligrosidad en torno a las costas urbanizadas del lago Nahuel Huapi se detallan a continuación:

- Factores naturales desencadenantes de tsunamis:

- $\quad$ Eventos sísmicos conocidos (cantidad e intensidad). Mapa de zonificación sísmica.

- Deslizamientos subacuáticos (sectores deslizados del sustrato lacustre).

- Tsunamis conocidos (alcance, zonas afectadas, recurrencia), especialmente el acontecido en el lago Nahuel Huapi en 1960.

Factores propiciantes de deslizamientos subacuáticos de orden natural:

- Características morfológicas del sustrato lacustre (pendientes).

- Características sedimentológicas y estructura sedimentaria de los depósitos del fondo lacustre.

- Características geológicas del área.

- Sectores no deslizados del sustrato lacustre.

Entre los indicadores de susceptibilidad y vulnerabilidad frente a una ola de tsunami en las costas urbanizadas del lago Nahuel Huapi se cuentan:

- Tipos de costas. 
- Variaciones del nivel del lago.

- Vegetación costera (tipo, grado de alteración).

- Posibles actividades antrópicas desestabilizadoras en las costas.

- Distribución espacial de las infraestructuras costeras y de comunicaciones (puertos, muelles, carreteras, etc.).

- Localización y densidad de las poblaciones.

- Normativa referida a ocupación de espacios litorales.

- Existencia o no de estrategias de gestión y protocolos de emergencia.

- Cercanía a sectores inestables en el lecho lacustre, propensos a ser movilizados.

\subsection{Fuentes de información}

La línea de investigación seguida es la hipotética-deductiva llevada adelante a través de un estudio de caso. Partiendo de los supuestos iniciales anteriormente mencionados, se abordará la problemática descripta con la finalidad de alcanzar cimientos sólidos que permitan la definición de bases metodológicas para el análisis de la peligrosidad y la vulnerabilidad ante tsunamis lacustres y erupciones volcánicas. La solidez de este punto de partida dará en buena medida la replicabilidad de las líneas metodológicas resultantes en otros ámbitos urbanos litorales de las márgenes de los lagos andinos de la región patagónica norte.

Metodológicamente, se prevé la utilización de diversas fuentes de información, las cuales se detallan a continuación:

- Fuentes primarias de información:

- Observaciones de campo.

Se realizaron trabajos de campo para relevar las costas urbanizadas del lago Nahuel Huapi durante los períodos estivales de 2015 y 2016 (sumados a relevamientos previos en 2012 y 2013).

- Batimetrías de los sectores costeros del lecho (0-100m de profundidad).

Se realizaron batimetrías en el lago Nahuel Huapi en diferentes oportunidades, destacándose las realizadas a comienzos de 2014 en las costas urbanizadas de Bariloche y Dina Huapi y en el Brazo Rincón. Se contó como insumo para este trabajo con un mapa de abundancia de deslizamientos subacuáticos en los sectores costeros de la cuenca distal del 
lago Nahuel Huapi (extraído de Beigt et al., 2014), realizado a partir de batimetrías efectuadas en el año 2010.

- Trabajos de campo para obtener testigos con la finalidad de conocer la recurrencia de fenómenos volcánicos y de eventos de remoción en masa.

A fines de 2013 se extrajo un testigo sedimentario en la Laguna El Trébol, a partir del cual confeccionó el modelo cronológico presentado en esta tesis, a comienzos de 2017 se extrajo un testigo sedimentario del Brazo Rincón para abordar la recurrencia de eventos turbidíticos en el sector distal del delta conformado por los arroyos Pireco y Totoral.

- Entrevistas semiestructuradas a informantes calificados.

Se realizaron diferentes entrevistas a informantes calificados tanto en San Carlos de Bariloche como en Villa La Angostura. Al no tratarse de la ciudad cabecera del Departamento Pilcaniyeu y al sumarse la cercanía con san Carlos de Bariloche, la localidad de Dina Huapi tiene muchas aristas en común con esta ciudad. Asimismo, en asuntos puntuales, sobre todo relativos la legislación sobre edificaciones, se efectuaron las averiguaciones pertinentes.

Se entrevistaron a personas que estuvieron a cargo del trabajo técnico, tanto en materia de protección civil como en el suministro de agua potable durante la emergencia volcánica de 2011 tanto en Bariloche como en Villa La Angostura (diciembre 2013, diciembre 2014, febrero 2015, septiembre 2016. Febrero-Marzo 2018). También se recurrió a la información aportada por operadores turísticos y de organismos encargados del servicio de tratamiento de efluentes cloacales y la limpieza de desagües pluviales en San Carlos de Bariloche durante dicha emergencia.

Para relevar los acontecimientos de 1960 (sismo y tsunami), se entrevistaron a 5 personas que habitaban en Bariloche desde ese entonces, quienes contaron sus experiencias y la de allegados.

- Fuentes secundarias de información:

- Lectura de bibliografía nacional e internacional tanto en lo referente a peligrosidad y vulnerabilidad como a los aspectos físicos de la problemática.

- Datos estadísticos provenientes de organismos municipales, provinciales y nacionales de Argentina (INDEC, Direcciones provinciales de estadística). 
- Información proveniente de organismos no gubernamentales.

- Diarios, revistas y periódicos locales, provinciales y nacionales.

- Fotos aéreas, hojas geológicas, cartas topográficas e imágenes satelitales del área de estudio

- Cartografía histórica.

- Legislación municipal, provincial y nacional.

- Técnicas de análisis de la información

- $\quad$ Técnicas informáticas, visuales y gráficas de tratamiento de la información (tablas, gráficos, cuadros, etc.).

- Estadística descriptiva para datos procedentes de fuentes primarias y secundarias.

- Análisis batimétrico (Software GS+, Instituto Argentino de Oceanografía, IADO).

- $\quad$ Sistemas de información geográfica (Softwares libres gvSIG versiones 1.11 y 1.12 y QGIS Versión 1.18.9 Las Palmas).

- $\quad$ Análisis cartográfico, de fotos aéreas y de imágenes satelitales a través de teledetección (Google Earth y fotos aéreas de 1940 e INTA 1967, Servicio Hidrológico Naval 1970).

Con base en estas fuentes, y dadas las diferencias en la naturaleza de la vulnerabilidad frente a procesos tsunamigénicos lacustres y caída de ceniza volcánica, se trabajaron diferentes metodologías, aunque las mismas presentan algunos puntos de contacto entre ellas.

\subsection{Limitaciones en el proceso de investigación}

La disponibilidad de información estadística ha sido una dificultad recurrente en el proceso de investigación. Asimismo, la información referente a contextos de crisis (emergencias volcánicas) ha sido muy difícil de recuperar dado que no se cuenta con los registros acabados de esos momentos. Aún no se cuenta con registros sistematizados en el tiempo que permitan un análisis de la situación socioeconómica de las localidades de la región para realizar estudios retrospectivos en esta materia.

Una de las cuestiones planteadas inicialmente en la hipótesis específica referida a caída de ceniza volcánica, sugería la posibilidad de trabajar la percepción de la amenaza que otorgaba un contexto a la vulnerabilidad social. A medida que fue avanzando la 
investigación, esta posibilidad se fue diluyendo, entre otros motivos, por la complejidad de su abordaje dado que, para ello, debería contemplarse tanto la percepción previa a la caída de ceniza producto de la erupción del Cordón Caulle en 2011 como así también con posterioridad a la misma, estando dicha percepción mediada por este evento así como también por la erupción del volcán Calbuco iniciada en abril de 2015. Por este motivo, resulta dificultoso obtener información fehaciente acerca de la percepción que poseían tanto los funcionarios como la comunidad en general sobre el riesgo volcánico con anterioridad a estos eventos. El relevamiento de los impactos de la erupción del volcán Calbuco en 2015 en las localidades más afectadas que fueron San Martín de los Andes, Junín de los Andes y Villa La Angostura, presentaba dificultades para identificar los aprendizajes obtenidos de la erupción del Cordón Caulle, dado que mucha de la información que se brindaba se centraba en la erupción de 2011 por considerarla más significativa.

En lo que refiere a la hipótesis específica sobre eventos tsunamigénicos, la extensión y profundidad del lago Nahuel Huapi, sumado a las características del sustrato lacustre, sobre todo en ambientes deltaicos, dificultaron la labor de extracción de testigos sedimentarios, situación que condujo a una demora en el tratamiento de los eventos turbidíticos.

La lejanía en el tiempo a los eventos de 1960 (sismo y posterior tsunami), condujo a la posibilidad de encontrar escasos pero muy valiosos testimonios de habitantes de ese entonces, así como rescatar las experiencias de sus familiares y allegados. Los entrevistados manifestaron que personas que estaban con ellos en ese momento, o podrían aportar su experiencia, ya han fallecido o no se encuentran viviendo en la región. Lo interesante es que en varios aspectos los entrevistados coincidieron, por ejemplo, qué hacían ese día, cómo estaba el tiempo. Pese a que parecieran pocos casos, en algunos aspectos se notó cierto efecto saturación, es decir, repeticiones de algunas informaciones que darían credibilidad a los testimonios y que se desarrollará con detalle en el Capítulo 5. 


\subsection{Bibliografía del capítulo}

BEIGT D.; VILLAROSA G.; GOMEZ E. A. 2014. Análisis de deslizamientos subacuáticos en deltas lacustres (lago Nahuel Huapi, Argentina) a partir de batimetrías de alta resolución. Cuadernos de Investigación Geográfica. Núm. 40 (1). Págs. 247-259.

CEMBRANO J.; HERVÉ F.; LAVENU A. 1996. "The Liquiñe-Ofqui fault zone: a long-lived intra-arc fault system in southern Chile". Tectonophysics, Vol. 259, Págs. 55-66.

CEMBRANO J.; SCHERMER E.; LAVENU A.; SANHUEZA A. 2000. "Contrasting nature of deformation along an intra-arc shear zone, the Liquiñe-Ofqui fault zone, southern Chilean Andes". Tectonophysics, Vol. 319, Págs. 129-149.

CHAPRON E.; ARIZTEGUI D.; MULSOW S.; VILLAROSA G.; PINO M.; OUTES V.; JUVIGNIE E.; CRIVELLI E. 2006. "Impact of the 1960 major subduction earthquake in Northern Patagonia (Chile, Argentina)". Quaternary International 158, Págs. 58-71.

KITZBERGER T.; VEBLEN T.T.; VILLALBA R. 1995. Tectonic influences on tree-ring and stand response in northern Patagonia (Argentina). Canadian Journal of Forest Research 25: 1684-1696.

LARA L.; LAVENU A.; CEMBRANO J.; RODRÍGUEZ C. 2006. "Structural controls of volcanism in transversal chains: Resheared faults and neotectonics in the Cordón CaullePuyehue area $\left(40.5^{\circ} \mathrm{S}\right)$, Southern Andes". Journal of Volcanology and Geothermal Research, 158, Págs. 70-86.

LASTRAS G.; AMBLAS D.; CALAFAT A. M.; CANALS M.; FRIGOLA J.; HERMANNS R. L.; LAFUERZA S.; LONGVA O.; MICALLEF A.; SEPÚLVEDA S. A.; VARGAS G.; DE BATIST M.; VAN DAELE M.; AZPIROZ M.; BASCUÑÁN I.; DUHART P.; IGLESIAS O.; KEMPF P.; RAYO X. 2013. Landslides Cause Tsunami Waves: Insights From Aysén Fjord, Chile, Eos Trans. AGU, 94 (34), Pág. 297.

VILLAROSA G.; OUTES V.; GÓMEZ E. A., CHAPRON E.; ARIZTEGUI D. 2009. "Origen del tsunami de mayo de 1960 en el lago Nahuel Huapi, Patagonia: aplicación de técnicas batimétricas y sísmicas de alta resolución". Revista de la Asociación Geológica Argentina 65 (3), Págs. 593-597. 


\section{CAPÍTULO III}

\section{LA REGIÓN DEL NAHUEL HUAPI}

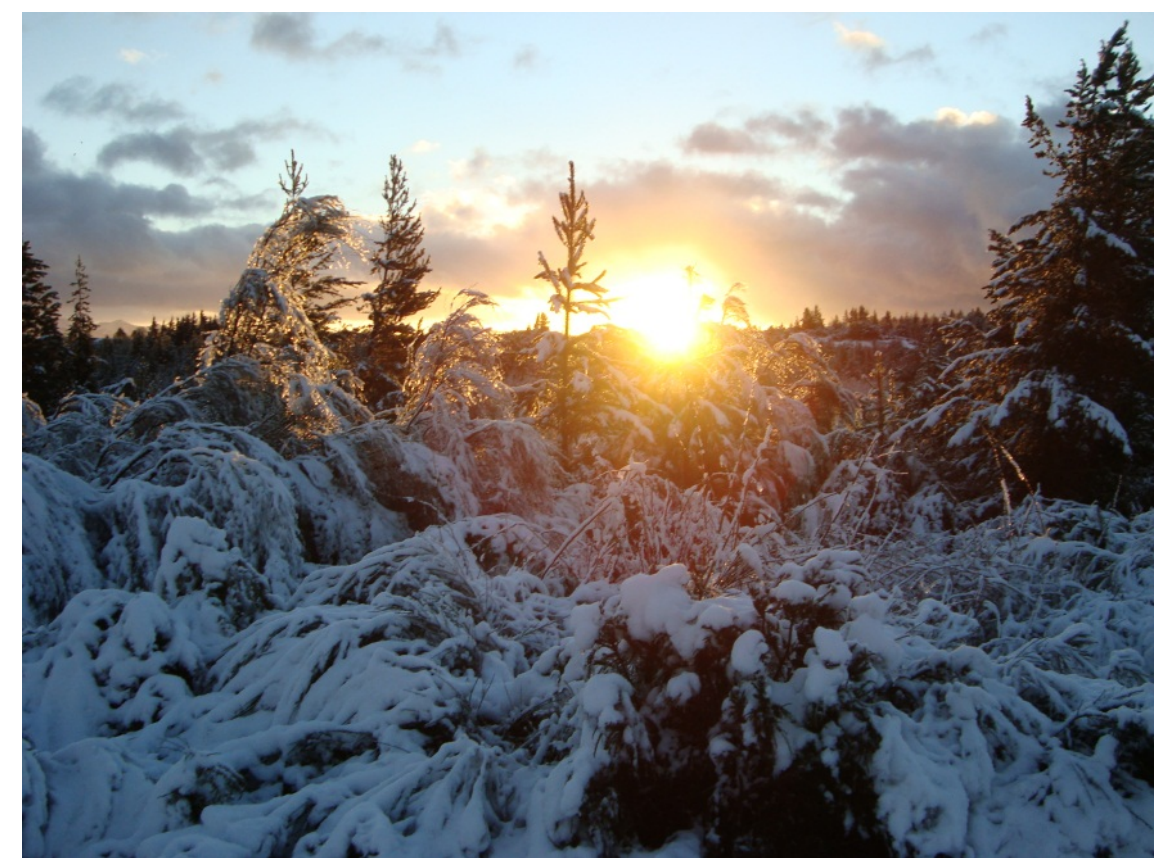

Amanecer nevado en el acceso al Centro de Salmonicultura Bariloche de la Universidad Nacional del Comahue.18 de junio de 2013. Foto del autor. 


\subsection{Historia de la región del Nahuel Huapi}

La historia local tiene un componente de carácter regional ligado, en un principio, a la presencia de exploradores y, posteriormente, a la conquista de la Patagonia por parte del Estado argentino. Los acontecimientos históricos se expresan más marcadamente en la ciudad de San Carlos de Bariloche, la más relevante de la región del Nahuel Huapi.

Los indígenas (unos cazadores y otros agricultores), antes de la llegada de los españoles, devienen en una comunidad de pastores y finalmente ganaderos y comerciantes organizando su vida económica en función de la sociedad hispano-agrícola de Chile, consumidora de sus productos (Méndez e Iwanow, 2001, p. 134).

Luego de concluida la conquista militar y retiradas las tropas nacionales del lago,

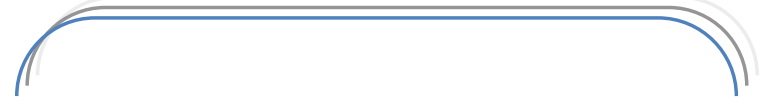

El descubrimiento del lago

En los primeros inicios de la historia local, tendrán importancia los exploradores. Se tiene certeza que llegó al Nahuel Huapi y le corresponde el mérito del descubrimiento del lago al capitán Juan Fernández en el año 1620, descubrimiento durante muchos años atribuido erróneamente al capitán Diego Flórez de León (Biedma, 1997, p. 13; Laria, 1970, p. 90).

\section{.}

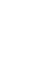

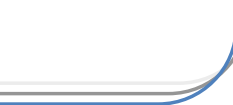

del este, menos fuerte que la anterior la constituyeron argentinos, suizos, alemanes, españoles, franceses, italianos y anglosajones y se dirigió a los pueblos y estancias (Biedma, 1997, p. 156).

Los inmigrantes daneses, menos numerosos, tendrán una ubicación preferencial en la costa sudeste del lago, donde actualmente se encuentra Dina Huapi. El nombre de la localidad proviene de "dina" por Dinamarca y del mapuche "huapi" que significa isla, por su ubicación entre los ríos Ñirihuau, Limay y el Lago Nahuel Huapi. Por ello, "Isla Danesa”, se refiere a los primeros habitantes de la zona, que son de ese origen (CFI, versión web).

Biedma (1997), sostiene que desde comienzos de la colonización se insinúan y luego se afianzan tres políticas de poblamiento: la primera encara el desarrollo como zona de explotación agrícola, ganadera e industrial, la segunda como reserva natural y la tercera como centro de atracción turística (p. 156). 


\section{El desarrollo agrario en la región}

La primera casa comercial fue instalada por Carlos Wiederhold, comerciante de origen germano: primero se llamó "La Alemana" y luego "San Carlos". Obligado punto de reunión de los pobladores, va a dar origen al nombre de la ciudad a la que para diferenciar de otros San Carlos, en el correo le agregaban de Bariloche, palabra deformada que hace alusión a los indígenas vuriloches o furilofches que habitaban la zona (Méndez e Iwanow, 2001, p. 135).

En 1902 el Gobierno Nacional, a través de un decreto presidencial, fundó la Colonia Agrícola Nahuel Huapi dándole así entidad jurídica a un conjunto poblacional que venía nucleándose alrededor del lago y se dispuso reservar ciertas fracciones para la fundación de

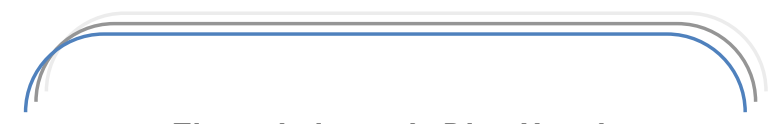

El surgimiento de Dina Huapi

En el Art. $2^{\circ}$ de la Carta Orgánica

Municipal del Pueblo de Dina Huapi se declara que por ley 2353 del 29 de diciembre de 1989, sancionada por la legislatura de la Provincia de Río Negro, se acepta como fecha oficial de creación institucional del pueblo de Dina Huapi, el día 25 de noviembre de 1986, mediante resolución dictada por la Comisión de Fomento (Carta Orgánica Municipal del Pueblo de Dina Huapi, versión web).

El Decreto provincial $N^{\circ}$ 605/08 convocó a un plebiscito para definir la municipalización de la localidad. Ante el resultado positivo de esta convocatoria, se inicia en el año 2009 el proceso de municipalización de Dina Huapi.

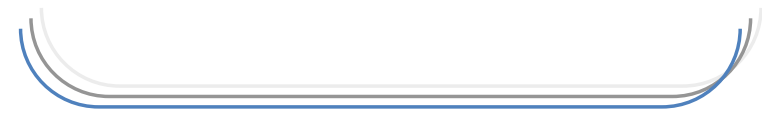
pueblos (de 400 hectáreas cada una) entre ellos Villa La Angostura, Bariloche y Brazo Rincón (Méndez, 2010, p. 112).

Gradualmente, se fue configurando un espacio con un perfil productivo primario orientado a la explotación agropecuaria y su vínculo comercial con Chile. Por este motivo, hacia fines del siglo XIX el actor social más relevante es el pequeño productor ganadero que practicaba agricultura de autoconsumo y se asentó próximo a los cursos de agua (Méndez e Iwanow, 2001, p. 136).

La agricultura y la ganadería encuentran otro complemento en la actividad forestal, que aprovechaba las riquezas del bosque circundante. Este mercado tenía como principales demandantes al Regimiento Militar, algunas pocas grandes estancias y comercios, luego a las pequeñas y medianas producciones rurales (granjeras y ganaderas) y asalariados en general (Rey, 2005, p. 37), existían aserraderos en la Isla Victoria, Península Huemul y Correntoso, este último en 
cercanías de donde actualmente se emplaza la localidad de Villa La Angostura, siendo su propietario Primo Capraro, quién además era un reconocido ganadero de la zona.

La Instalación de la aduana en 1920 fue clave en el cambio de función de Bariloche que vio limitada su capacidad de intercambio comercial tan intenso hasta entonces (Matossian, 2012, p. 74).

\section{El desarrollo a partir del parque nacional}

Esta etapa comienza en 1904 con la donación del Perito Moreno y se continúa con los decretos de 1907 y 1922 que crean el Parque Nacional del Sur (Biedma, 1997, p. 156). La donación consistió en tres leguas cuadradas -7.500 hectáreas- ubicadas en cercanías de Laguna Frías y Puerto Blest, en la zona fronteriza con Chile.

El 8 de abril de 1922 se creó el Parque Nacional del Sur con una superficie total de 785.000 hectáreas, siendo su primer intendente el ingeniero Emilio Frey (Administración de Parques Nacionales, versión web).

En 1934 se aprueba la ley 12.103 se crearon la Administración General de Parques Nacionales y Turismo -nombre que más adelante (1958) cambiaría a Dirección de Parques Nacionales- y los Parques Nacionales Iguazú y Nahuel Huapi, este último sobre la base del Parque Nacional del Sur (Administración de Parques Nacionales, versión web).

En 1971 se crearon los Parques Nacionales Los Arrayanes y Lago Puelo. El primero cumple con la curiosa circunstancia de constituir un Parque dentro de otro, ya que su superficie se halla íntegramente comprendida dentro del Parque Nacional Nahuel Huapi (Administración de Parques Nacionales, versión web). Este parque conserva un bosque único de arrayanes y su administración se encuentra en la localidad de Villa La Angostura, constituyendo uno de sus principales atractivos turísticos con acceso a través de excursiones lacustres y senderos habilitados para peatones y ciclistas.

\section{El desarrollo de la región como destino turístico}

Uno de los primeros visitantes de Buenos Aires en calidad de turista fue Aarón Anchorena, quién arribó a Bariloche en 1902 (Bandieri, 2005, p. 313), pero la distancia a las principales ciudades, especialmente a Buenos Aires, determinará la importancia de las comunicaciones para la región del Nahuel Huapi, llegando en 1913 a San Carlos de Bariloche el primer camino para autos.

La década de 1930 traerá novedades que cooperan para otorgarle a Bariloche un perfil turístico, situación que se acentúa en la década siguiente. En 1921 el Ferrocarril del Sud 
llega hasta Carmen de Patagones, Ferrocarriles del Estado continuaba desde Viedma llegando en 1930 a Pilcaniyeu, a sólo 50 kilómetros de San Carlos de Bariloche (Vallmitjana, 1993, p. 22). Será finalmente en diciembre de 1934 el año en que el ferrocarril llega a San Carlos de Bariloche.

Con el impulso de esta época se concretaron numerosas obras urbanísticas alentando el desarrollo del lugar: la ruta costanera, el Centro Cívico, Intendencia del Parque Nacional Nahuel Huapi y el Hotel LLao Llao (Matossian, 2012, p. 79).

La relevancia local que adquirió la

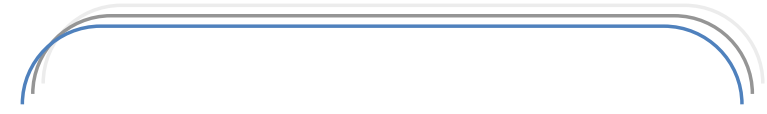

El nacimiento de Villa La Angostura En 1902, cuando se creó la Colonia Nahuel Huapi se reservaron 400 hectáreas para la creación de pueblos de El Rincón y en La Angostura (Lolich, 1992, p. 157)

El 15 de mayo de 1932, en presencia de un numeroso grupo de vecinos, se realizó un sencillo acto que inauguraba el edificio de la oficina radiotelegráfica "Correntoso". Este acto es considerado al acto fundacional de la localidad; sin embargo, el nombre Villa la Angostura fue impuesto por Exequiel Bustillo recién cuatro años después (de Mendieta, versión web).

La provincialización del Territorio Nacional del Neuquén en 1955 conduce a la definición las unidades administrativas, declarándose a Villa La Angostura ciudad cabecera del Departamento Los Lagos.

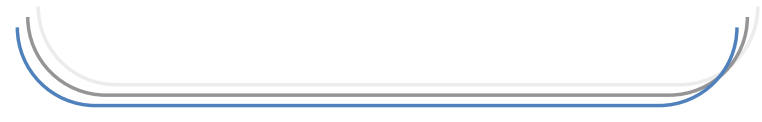
figura de Otto Meiling se debe al impulso que otorgó al andinismo, actualmente una de las actividades más difundidas. Esto estará apoyado por la fundación, en 1931, del Club Andino Bariloche (CAB).

Por otra parte, el esquí turístico y comercial tiene su inicio en el cerro Otto, cuando en 1934 Otto Meiling funda la Escuela de Esquí Tronador (Vallmitjana, 1993, p. 33). Otro hito de este deporte fue, desde 1940, el centro de esquí del Cerro Catedral (Rey, 2005, p. 51). Posteriormente, en la década de 1970, Cerro Bayo -un pequeño centro invernal ubicado a 9 kilómetros de Villa La Angostura-se abre a los deportes invernales.

Un gran cambio en las comunicaciones se va a dar con la difusión del transporte aéreo, y será en 1940 cuando se inicie el servicio aéreo

de pasajeros desde Buenos Aires a San Carlos de Bariloche.

Otro temprano incentivo turístico fue el de la pesca de salmónidos sobre la base de la piscifactoría que, desde 1904, comenzó su actividad con la siembra de alevinos (Rey, 2005, p. 51). 
En la segunda mitad de la década de 1940, Napoleón Irusta introduce la modalidad de turismo social; en paralelo, el Automóvil Club también atendía algo de turismo y funcionaban desde unos años antes sus estaciones de servicio de San Carlos de Bariloche, Confluencia Traful y Villa La Angostura, proporcionando hospedaje en cantidad muy limitada (Vallmitjana, 1993, p. 45-46). Los sectores altos buscaron otros sitios más exclusivos y nuevamente cambió el perfil del turismo en Bariloche, que con los años fue orientándose al sector estudiantil y a la tercera edad; y en la actualidad, con una relación cambiaria distinta, el turismo extranjero mayoritariamente brasileño y chileno, vuelve a reflotar el consumo (Bandieri, 2005, p. 316).

\section{El Polo Científico-Tecnológico}

A partir de la creación de la Comisión Nacional de Energía Atómica (CNEA) en la década de 1950, fue necesaria la formación de profesionales especializados en el área nuclear, por lo que en 1955 comienza a funcionar el Instituto de Física Bariloche (posteriormente Instituto Balseiro). Simultáneamente, se crea el Centro Atómico Bariloche (CAB) en terrenos que cede el Ejército y en 1963 se crea la Fundación Bariloche para promover la enseñanza e investigación científica en todas las ramas (Méndez e Iwanow, 2001, p. 194-195).

En la década de 1970 surge Investigaciones Aplicadas Sociedad del Estado (INVAP), empresa de alta tecnología en materia nuclear y aeroespacial, que cuenta con una planta de enriquecimiento de Uranio en la zona de Pilcaniyeu, construye reactores nucleares, participa en satélites para la NASA y la construcción de satélites nacionales.

A la creación del Instituto Balseiro, el Centro Atómico Bariloche (CAB), la Fundación Bariloche y el INVAP, se suma la creación del Centro Regional Universitario Bariloche (CRUB) de la Universidad Nacional del Comahue y la estación experimental agropecuaria (EEA) del Instituto Nacional de Tecnología Agropecuaria (INTA). Desde principios de este siglo, se radica en Bariloche la sede andina de la Universidad de Río Negro (creada por la Ley 26.330, promulgada el 19 de diciembre de 2007).

De los años noventa a la actualidad

La década de los noventa traerán novedades en materia política: convertibilidad de la moneda, reducción de la participación del Estado (entre las que se cuentan las privatizaciones) y liberalización económica. 
Con la reforma del Estado, comienzan los recortes de presupuesto y los organismos que dependen del gobierno ven reducidos sus aportes y cierran o reducen su funcionamiento al mínimo. El Polo Científico y Tecnológico, como otros proyectos se desvanece, quedando en funcionamiento apenas algunas de esas instituciones o empresas y, a la vez que el turismo no crece en proporción a la población, las fuentes de trabajo van desapareciendo y para amplios sectores de la población- la situación económica empeora notablemente (Méndez e Iwanow, 2001, p. 197).

La ciudad continúo aumentando su población y la presión demográfica se tradujo en una gran extensión geográfica. Siguiendo a Guevara y Núñez (2014) se puede observar que la ciudad continuó extendiéndose y completándose hacia el sur y este en los últimos años con un alto grado de informalidad a la vez que emergieron nuevas tipologías habitacionales como las urbanizaciones cerradas, donde se localizaron sectores de ingresos medios-altos, introduciendo heterogeneidad en la trama urbana (p. 156). Estas urbanizaciones cerradas tienden a ocupar los espacios intersticiales entre San Carlos de Bariloche y Dina Huapi, configurando, de este modo, un continuo urbano recostado en la margen austral del lago Nahuel Huapi.

\subsection{Aspectos físicos del territorio}

La cordillera patagónica tiene como característica principal una menor altura media que el resto de los Andes, valles transversales, gran cantidad de crestas aserradas, puntiagudas, circas, artesas, lagos y morenas (Pica, 2005, p. 10).

La geomorfología está dominada por formas glaciarias. Los depósitos de till glaciario se encuentran bien desarrollados en tres áreas: la costa del lago Nahuel Huapi, el Lago Moreno y el sector norte del lago Gutiérrez (Pereyra et al., 2005, p. 21). Las condiciones montañosas en general predisponen a la zona a diferentes procesos de remoción en masa. Las fluctuaciones climáticas postglaciales y la propia naturaleza de las geoformas glaciarias preexistentes han determinado la continuidad en el tiempo del equilibrio inestable (Pereyra, 2007, p. 314).

Los depósitos fluviales también son importantes en la región. El material fluvial está distribuido en las terrazas, llanuras aluviales y conos de los arroyos Ñireco, del Medio y su unión con el arroyo Ñirihuau, habiendo un menor desarrollo en los arroyos Gutiérrez, Goye y Cascada de la Virgen (Pereyra et al., 2005, p. 22).

Los depósitos piroclásticos son muy abundantes en la región y constituyen el material parental principal de los andisoles, que son los suelos más frecuentes de la zona, la cual 
está expuesta a recurrentes caídas de ceniza volcánica, formada por materiales expulsados a la atmósfera por las erupciones explosivas de volcanes andinos ubicados en su mayoría en territorio de Chile. Los vientos dominantes del oeste transportan esas cenizas hacia territorio argentino, donde se produce normalmente la depositación "instantánea" del material eruptivo (Villarosa et al., 2006, p. 46; Beigt et al., 2012, p. 52).

El clima se halla dentro de los templados a templados fríos níveos. Las precipitaciones decrecen rápidamente hacia el este -desde unos 2000 milímetros anuales en la cordillera a 200 milímetros anuales en la inmediata precordillera-, en tanto que las precipitaciones invernales (Cuadro $\mathrm{N}^{\circ} 1$ ), de mayo a agosto, producidas en forma de nevadas se acumulan en las cumbres y altos valles formando las reservas hídricas de las cuencas (Pica, 2005, p. 10-11).

\begin{tabular}{|c|c|c|c|c|c|c|}
\hline Mes & $\begin{array}{l}\text { Precipitación } \\
\text { media mensual } \\
\text { (en } \mathrm{mm} \text { ) }\end{array}$ & $\begin{array}{c}\text { Temperatura } \\
\text { mínima } \\
\text { media }\left(e^{\circ} \mathrm{C}\right)\end{array}$ & $\begin{array}{c}\text { Temperatura } \\
\text { media (en } \\
{ }^{\circ} \mathrm{C} \text { ) }\end{array}$ & $\begin{array}{c}\text { Temperatura } \\
\text { máxima media } \\
\left(e n^{\circ} \mathrm{C}\right)\end{array}$ & $\begin{array}{l}\text { Viento } \\
\text { medio } \\
(\mathrm{km} / \mathrm{h})\end{array}$ & $\begin{array}{l}\text { Humedad } \\
\text { relativa }\end{array}$ \\
\hline Enero & 22,2 & 6.4 & 14.3 & 21.5 & 29 & 60 \\
\hline Febrero & 21,7 & 5.7 & 14 & 21.8 & 25 & 62 \\
\hline Marzo & 29,2 & 4 & 11.3 & 19 & 22 & 67 \\
\hline Abril & 53,5 & 1.8 & 7.7 & 14.6 & 21 & 74 \\
\hline Mayo & 134 & 0.6 & 5 & 10.1 & 21 & 81 \\
\hline Junio & 140,7 & -1 & 2.6 & 6.7 & 20 & 84 \\
\hline Julio & 128,7 & -1.4 & 2.1 & 6.4 & 20 & 84 \\
\hline Agosto & 115,6 & -0.9 & 3 & 7.9 & 23 & 81 \\
\hline Septiembre & 57,8 & -0.5 & 4.7 & 10.7 & 23 & 75 \\
\hline Octubre & 38,8 & 1.1 & 7.5 & 14 & 25 & 68 \\
\hline Noviembre & 24,8 & 3.5 & 10.6 & 17.3 & 29 & 63 \\
\hline Diciembre & 32 & 5.4 & 12.9 & 19.7 & 29 & 61 \\
\hline
\end{tabular}

Cuadro N¹: Datos correspondientes a la estación meteorológica del Aeropuerto de San Carlos de Bariloche. Período 1981-1990. Fuente: Servicio Meteorológico Nacional (SMN), disponible el 17 de marzo de 2017 en http://www.smn.gov.ar/serviciosclimaticos/index.php?mod=elclima\&id=7\&provincia=R\%EDo\%20Negro\&ciudad=B ariloche. Consultada 17 de marzo de 2017.

Las elevadas precipitaciones, especialmente en cordillera, dan lugar a la formación de un bosque mixto compuesto por especies como ciprés (austrocedrus chilensis), alerce (fitzroya cupressoides), arrayán (luma apiculata), maitén (maytenus boaria). La especies más características del bosque andino corresponden al género nothofagus como lenga (nothofagus pumilio), ñire (nothofagus antarctica), coihue (nothofagus dombeyi) y roble pellín 
(nothofagus obliqua). Varias especies componen el sotobosque, entre las que sobresale la caña colihue (chusqueda culeou).

\subsection{Principales actividades económicas}

El desarrollo histórico de la región gradualmente colocó al turismo como una de las principales actividades económicas, especialmente en San Carlos de Bariloche. Si bien son escasos los datos estadísticos referidos a la estructura según los sectores de la economía ${ }^{4}$, un estudio realizado por la Universidad Fasta en 2006 señala que el Producto Bruto Interno (PBI) de esta localidad en 2005 fue de 2.340.531.600 pesos y dentro de ese total el turismo y sus actividades vinculadas representaron el 42,46\% (diario Río Negro, edición digital, 6 de diciembre de 2006).

El segundo rubro de mayor peso en la economía local es el complejo de ciencia y técnica, que representa un $11,88 \%$ del PBI, aunque el $61,2 \%$ de ese volumen es absorbido por una sola empresa: INVAP SE. Por debajo aparece el comercio mayorista y minorista, con el 10,91\%; seguido por la actividad inmobiliaria, con 6,5\%; la administración pública (5,01\%); construcción $(4,52 \%)$ y transporte y comunicaciones con el 2,11\% (diario Río Negro, edición digital, 6 de diciembre de 2006).

La fuerte dependencia de un sector económico caracterizado por la sensibilidad a eventos disruptivos de distinta naturaleza, como las erupciones volcánicas y caídas de ceniza asociadas, constituye el origen de una vulnerabilidad económica determinada especialmente por la alta sensibilidad del sector transporte a la presencia de material piroclástico, potenciada por una menor elección del destino frente a la presencia de cenizas. Los impactos a la actividad turística generados por la caída de ceniza volcánica en el año 2011 se abordan en profundidad en el Capítulo IV.

\subsection{La población en la región según los censos: crecimiento acelerado y urbanización}

Los censos nacionales de población constituyen la fuente más fiable para delinear la evolución de la población en la región del Nahuel Huapi. En este apartado se analizan, por un lado, la población de los departamentos que comprenden al área y, por otro, la población urbana de las localidades costeras del lago Nahuel Huapi.

\footnotetext{
${ }^{4}$ No se realizan mediciones regulares del Producto Bruto Geográfico (PBG), de dónde se podrían obtener los datos del producto bruto por rama de actividad y su evolución a lo largo del tiempo, determinando el impacto económico, por ejemplo, de la erupción del Cordón Caulle iniciada en 2011.
} 
El número de habitantes de un área determina la importancia que tendrá un fenómeno adverso en términos de personas potencialmente afectadas. Desde la Teoría Social del Riesgo, le confieren a la población un lugar relevante dentro de la exposición (Natenzon, 1995; Barrenechea et al., 2010), dimensión que se cuantifica como población involucrada y/o como valor de los bienes expuestos (Natenzon, 1995, p. 7).

En el Modelo de Presión y Liberación de los Desastres, la urbanización y el crecimiento rápido de la población ocupan un lugar significativo dentro de las presiones dinámicas (Blaikie et al., 1996) dado que el crecimiento de la población es una presión global significativa que contribuye al aumento de la vulnerabilidad (Blaikie et al., 1996, p. 39).

\subsubsection{La población de los departamentos de la región del Nahuel Huapi}

El lago Nahuel Huapi ocupa diferentes porciones de los departamentos de Bariloche y Pilcaniyeu (Río Negro) y Los Lagos (Neuquén) que tienen entre sus ciudades cabeceras a San Carlos de Bariloche, Pilcaniyeu y Villa La Angostura, respectivamente.

Si se observan los datos a nivel departamental (Cuadro $N^{\circ} 2$ ) en el período 1895-2010 se destaca un cambio de composición, pasando de ser marcadamente rural a ser eminentemente urbana. El crecimiento más acelerado lo registró el departamento Bariloche impulsado por el crecimiento urbano, particularmente de la ciudad de San Carlos de Bariloche y, en menor magnitud, El Bolsón.

\begin{tabular}{|c|c|c|c|c|c|c|c|c|c|c|}
\hline \multicolumn{2}{|c|}{ Departamento } & 1895 & 1914 & 1947 & 1960 & 1970 & 1980 & 1991 & 2001 & 2010 \\
\hline \multirow{3}{*}{ Bariloche (a) } & Urbana & IIIIIIII & 1.796 & 6.562 & 18.602 & 29.477 & 53.990 & $\begin{array}{l}87.587 \\
\text { (d) }\end{array}$ & 102.652 & 126.366 \\
\hline & Rural & 196 & 5.113 & 7.448 & 5.179 & 5.321 & 6.344 & 7.053 & 7.174 & 7.134 \\
\hline & Total & 196 & 6.909 & 14.010 & 23.781 & 34.798 & 60.334 & 94.640 & 109.826 & 133.500 \\
\hline \multirow{3}{*}{ Pilcaniyeu (b) } & Urbana & IIIIIIII & IIIIIIII & IIIIIIII & IIIIIIII & IIIIIIII & IIIIIIII & IIIIIIII & 2.043 & 3.469 \\
\hline & Rural & IIIIIIII & IIIIIIII & 4.915 & 4.964 & 3.788 & 4.486 & 4.963 & 4.071 & 3.959 \\
\hline & Total & IIIIIIII & IIIIIIII & 4.915 & 4.964 & 3.788 & 4.486 & 4.963 & 6.114 & 7.428 \\
\hline \multirow{3}{*}{ Los Lagos (c) } & Urbana & IIIIIIII & 955 & IIIIIIII & IIIIIIII & IIIIIIII & IIIIIIII & 3.056 & 7.325 & 11.063 \\
\hline & Rural & IIIIIIII & 2.299 & 2.082 & 1.958 & 2.135 & 2.566 & 1.125 & 1.329 & 935 \\
\hline & Total & IIIIIIII & 3.254 & 2.082 & 1.958 & 2.135 & 2.566 & 4.181 & 8.654 & 11.998 \\
\hline
\end{tabular}

Cuadro $\mathrm{N}^{\circ} 2$ : Evolución de la población según departamentos.

(a) Departamento Bariloche: se crea en 1885. Sus nombres anteriores fueron departamento VII y Nahuel Huapí. Límites fijados en 1915.

(b) Departamento Pilcaniyeu: se crea en 1915 con superficie del departamento VII.

(c) Departamento Los Lagos: sus nombres anteriores fueron departamento IV y Los Lagos.

Límites fijados en 1915.

(d) Estimado por la sumatoria de las localidades de San Carlos de Bariloche y El Bolsón.

Fuente: elaboración propia sobre la base de datos de los Censos Nacionales de Población. Instituto Nacional de 
Estadísticas y Censos (INDEC).

\subsubsection{La población de las localidades costeras del lago Nahuel Huapi}

Las localidades costeras del lago Nahuel Huapi son San Carlos de Bariloche (Departamento Bariloche), Dina Huapi (Departamento Pilcaniyeu) y Villa La Angostura (Departamento Los Lagos). Si se observa la evolución de las localidades según los censos de población (Cuadro $\mathrm{N}^{\circ} 3$ ) se aprecia el fuerte crecimiento demográfico, especialmente de San Carlos de Bariloche, como se mencionara anteriormente. En los últimos años crecieron fuertemente Villa La Angostura y Dina Huapi, esta última asociada a la expansión de San Carlos de Bariloche.

La estrecha distancia de 20 kilómetros entre San Carlos de Bariloche y Dina Huapi y el crecimiento permanente de ambas localidades han generado un continuo urbano de más de 50 kilómetros de extensión sobre la margen austral del lago Nahuel Huapi el cual se podría definir como aglomerado Bariloche-Dina Huapi ${ }^{5}$. La presencia de múltiples unidades administrativas puede implicar dificultades en la gestión urbana en general y en materia de gestión de riesgos en particular.

\begin{tabular}{|c|c|c|c|c|c|c|c|}
\hline LOCALIDAD & $\mathbf{1 9 4 7}$ & $\mathbf{1 9 6 0}$ & $\mathbf{1 9 7 0}$ & $\mathbf{1 9 8 0}$ & $\mathbf{1 9 9 1}$ & $\mathbf{2 0 0 1}$ & $\mathbf{2 0 1 0}$ \\
\hline San Carlos de Bariloche (a) & 6.562 & $17.894(1)$ & 26.799 & 48.980 & $79.498(2)$ & $95.860(3)$ & 112.887 \\
\hline Dina Huapi (b) & $I / I I I I I /$ & $/ I I I I I I /$ & $I / I I I I I /$ & $(4)$ & 849 & 2.243 & $3.730(5)$ \\
\hline Villa La Angostura (c) & IIIIIIIII & 804 & 550 & 1.533 & 3.056 & 7.325 & 11.063 \\
\hline $\begin{array}{c}\text { Población urbana total } \\
\text { Región Nahuel Huapi }\end{array}$ & $\mathbf{6 . 5 6 2}$ & $\mathbf{1 8 . 6 9 8}$ & $\mathbf{2 7 . 3 4 9}$ & $\mathbf{5 0 . 5 1 3}$ & $\mathbf{8 3 . 4 0 3}$ & $\mathbf{1 0 5 . 4 2 8}$ & $\mathbf{1 2 7 . 6 8 0}$ \\
\hline
\end{tabular}

Cuadro №3: Evolución de la población según localidades.

(a) La localidad fue fundada el 3 de mayo de 1902

(b) La localidad fue fundada el 25 de noviembre de 1986

(c) La localidad fue fundada el 15 de mayo de 1932

(1) Incluye Villa Llao Llao, Playa Bonita y San Pedro.

(2) Incluye Villa Llao Llao, Villa Los Coihues, Villa Campanario y Barrio El Pilar. Villa Campanario a su vez incluye Selva Negra, Villa Antumalal y Villa Don Bosco.

(3) Incluye Villa Llao Llao, Villa Los Coihues, Villa Campanario y Barrio El Pilar. Villa Campanario a su vez incluye Selva Negra, Villa Antumalal y Villa Don Bosco.

(4) El dato del censo de 1980 no es comparable por incluir población rural dispersa

(5) 261 habitantes son considerados pobladores rurales aunque el censo los asigna a la localidad de Dina Huapi. Fuente: elaboración propia sobre la base de datos de los Censos Nacionales de Población. Instituto Nacional de Estadísticas y Censos (INDEC).

En la región del Nahuel Huapi, la localización de la población recostada principalmente sobre la margen austral del lago Nahuel Huapi (Figura $\mathrm{N}^{\circ} 1$ ) en torno a la ciudad de San Carlos de Bariloche, caracteriza la distribución de la población urbana del área.

\footnotetext{
${ }^{5}$ Si la localidad compuesta tiene más de 100.000 habitantes se la denomina aglomerado (INDEC, 1999, p. 2).
} 


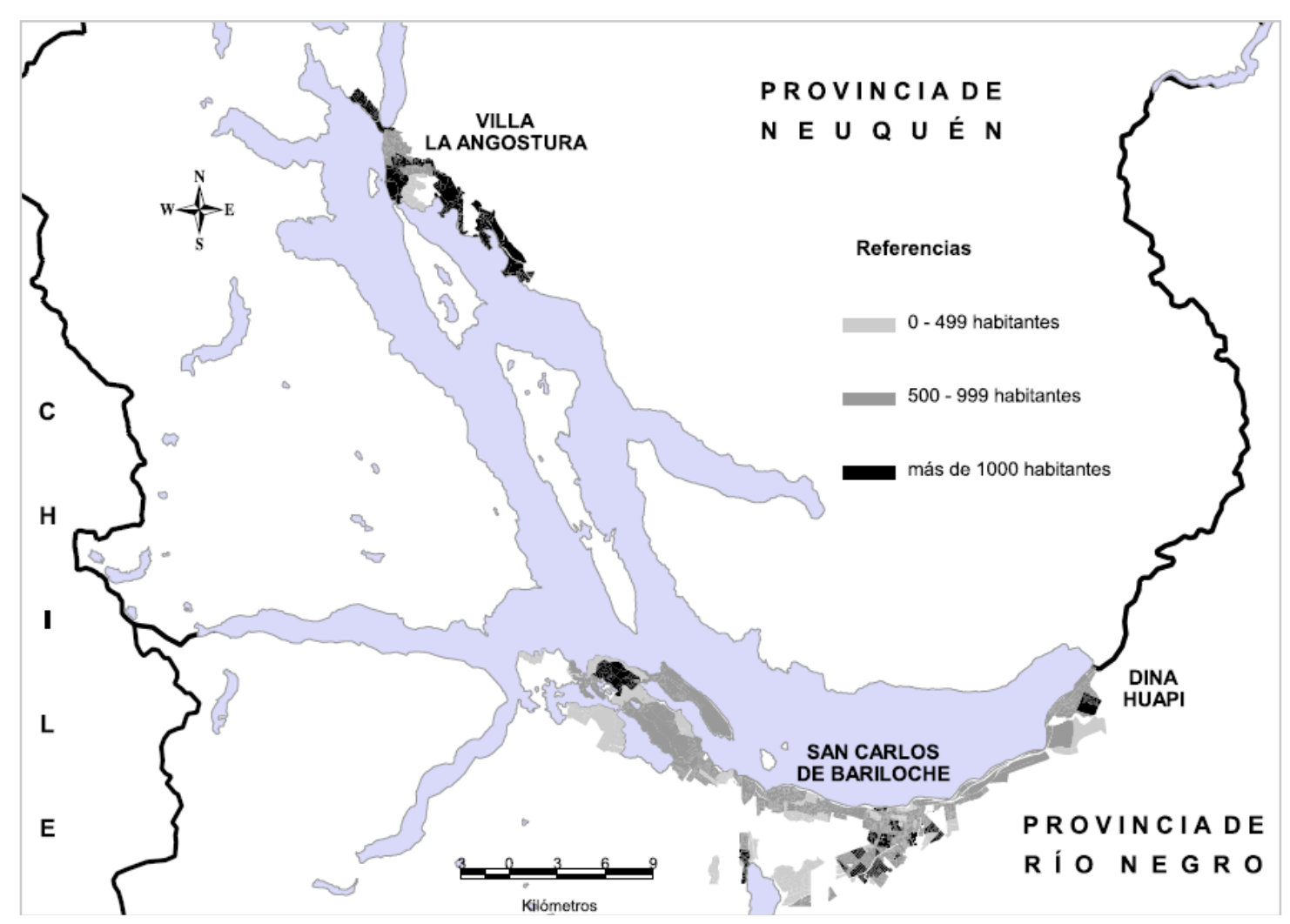

Figura $\mathrm{N}^{\circ}$ 1. Población de las localidades del Nahuel Huapi según radios censales. 2010. Fuente: elaboración propia en base a datos del INDEC. Censo Nacional de Población, Hogares y Viviendas 2010, procesado con Redatam $+S P$.

Según la Figura $\mathrm{N}^{\circ} 1$, algunos radios censales de Villa La Angostura y el Sur del área urbana de San Carlos de Bariloche exhiben una población superior a los mil habitantes. Valores intermedios se localizan en la margen austral del lago Nahuel Huapi, siendo poco frecuentes los radios censales con población menor a 499 habitantes. Estos últimos corresponden a áreas en expansión y densificación (por ejemplo, el sector occidental del área urbana de San Carlos de Bariloche).

Con casi 130.000 habitantes hacia el año 2010, la región del Nahuel Huapi es el área más poblada del sector cordillerano patagónico donde sólo la ciudad de San Carlos de Bariloche representa el 88,4\% del total de población urbana. Asimismo, la baja participación de la población rural a nivel departamental indica que los riesgos en la zona es una problemática predominantemente urbana.

\subsubsection{Los aspectos demográficos y su vinculación con el riesgo}

El análisis demográfico de las localidades costeras del lago Nahuel Huapi se orienta a identificar a la población expuesta a caída de ceniza volcánica y tsunamis lacustres. Como se mencionó en el Capítulo I, la exposición involucra, entre otros aspectos, la cantidad de 
personas potencialmente afectables frente a un evento peligroso Además, la percepción del riesgo y la ponderación que se hace del mismo puede variar, entre otros aspectos, por la experiencia acumulada según se trate de comunidades que históricamente han convivido con el peligro o bien que tienen un alto porcentaje de inmigrantes que deben reconstruir su sentido de pertenencia al lugar incorporando el riesgo en su imaginario (Barrenechea et al., 2000, p. 10).

\subsubsection{Departamentos Bariloche y Pilcaniyeu (Provincia de Río Negro)}

El departamento Bariloche se ubica en el sector cordillerano de la provincia de Río Negro y posee numerosas localidades, siendo las más importantes San Carlos de Bariloche y El Bolsón. Por su parte, el departamento Pilcaniyeu se encuentra en la meseta patagónica, su población es muy reducida y las localidades más importantes son Dina Huapi, Comallo y Pilcaniyeu. Ambos departamentos registraron un incremento de población superior al $20 \%$ en el período intercensal 2001-2010 (Cuadro N4).

\begin{tabular}{|c|c|c|c|c|}
\hline Departamento & $\begin{array}{c}\text { Población } \\
\text { en } 2010\end{array}$ & $\begin{array}{c}\text { Variación } \\
2001-2010 \text { (en \%) }\end{array}$ & Localidad & $\begin{array}{l}\text { Población } \\
\text { (2010) }\end{array}$ \\
\hline \multirow{2}{*}{ Bariloche } & \multirow{2}{*}{$\begin{array}{l}133.500 \\
\text { Hab. }\end{array}$} & \multirow{2}{*}{$+21,6$} & San Carlos de Bariloche & 112.887 Hab. \\
\hline & & & El Bolsón & 19.009 Hab. \\
\hline \multirow{3}{*}{ Pilcaniyeu } & \multirow{3}{*}{ 7.428 Hab. } & \multirow{3}{*}{$+21,5$} & Dina Huapi & $3.730 \mathrm{Hab}$. \\
\hline & & & Comallo & $1.497 \mathrm{Hab}$. \\
\hline & & & Pilcaniyeu & $757 \mathrm{Hab}$. \\
\hline
\end{tabular}

Cuadro N4: Población por departamento y localidad. 2010. Fuente: elaboración propia sobre la base de datos del Censo Nacional de Población, Hogares y Viviendas 2010. INDEC.

Dados los valores poblacionales para San Carlos de Bariloche y El Bolsón, se desprende que la caída de ceniza volcánica es un problema eminentemente urbano ya que entre ambas localidades representan casi el 99\% de la población departamental de Bariloche (siendo más reducido en el caso del Departamento Pilcaniyeu).

Por otra parte, es importante considerar a las migraciones como un aspecto inherente al estudio de la vulnerabilidad en el contexto de la estructura demográfica (Figura №2). 


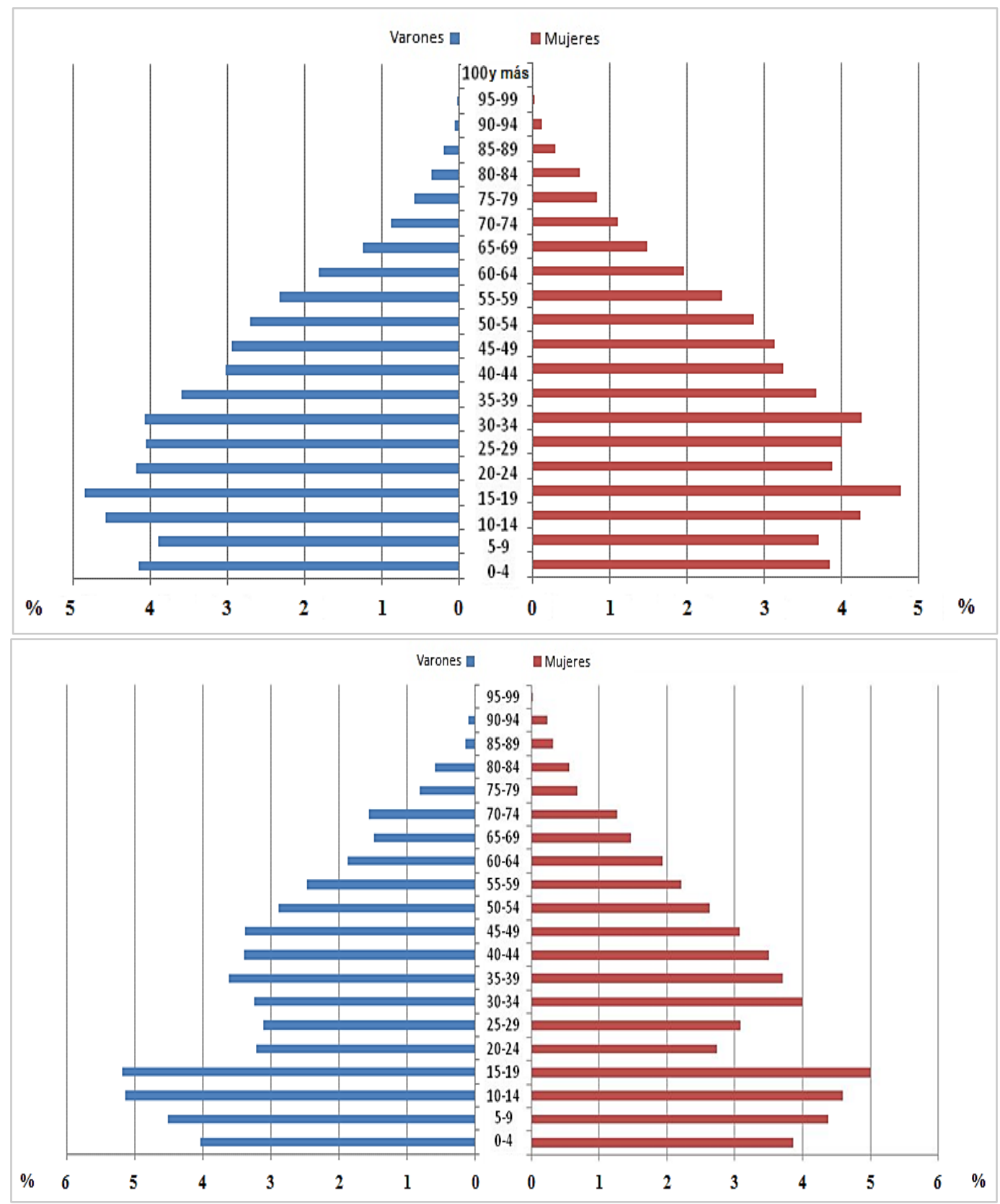

Figura $\mathrm{N}^{\circ} 2$. Estructuras de la población por edad y sexo. Departamentos Bariloche (arriba) y Pilcaniyeu (abajo). 2010. Fuente: elaboración propia sobre la base de datos del Censo Nacional de Población, Hogares y Viviendas 2010. INDEC.

La estructura de la población, es decir su composición por edad y sexo, revela un importante componente migratorio en las poblaciones de Bariloche y Pilcaniyeu, especialmente en edades jóvenes (10-20 años) y adultas (25-35 años). El aspecto más significativo se observa en la población de Pilcaniyeu, en la que la población de entre 20 y 30 años se ve fuertemente reducida, particularmente la femenina. 


\subsubsection{Departamento Los Lagos (Provincia de Neuquén)}

El Departamento Los Lagos se ubica en el extremo sur de la provincia de Neuquén y su ciudad cabecera es Villa La Angostura; también se encuentran pequeñas localidades y parajes como Villa Traful, Confluencia y Cuyín Manzano, entre otras.

La población departamental creció vertiginosamente duplicando su población en el período 1991-2001, pasando de 4.181 a 8.654 habitantes, respectivamente. La población de 5 años o más de edad que en 1996 vivía en otra localidad argentina y en 2001 residía en Villa La Angostura alcanzó las 2.547 personas, es decir, el 32.5\% de la población. En otros términos, el fuerte crecimiento demográfico se debe en gran medida al aporte inmigratorio, fundamentalmente de origen nacional ${ }^{6}$.

Sin embargo, y de acuerdo con la información aportada por el Censo 2010, sobresale que la población que vive en el Departamento Los Lagos sigue siendo escasa, alcanzando los 11.998 habitantes. Si se analiza su estructura (Figura $\mathrm{N}^{\circ} 3$ ), se observa un leve predominio de los hombres por sobre las mujeres.

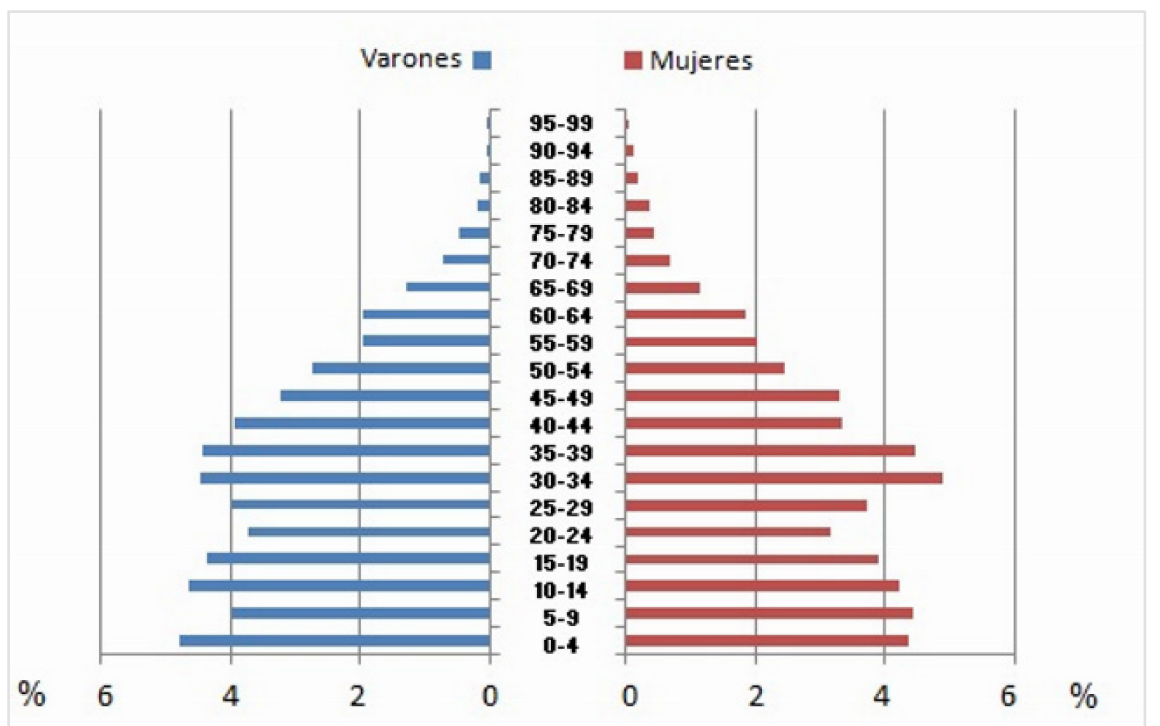

Figura $\mathrm{N}^{\circ} 3$. Estructura de la población por edad y sexo. Departamento Los Lagos. 2010. Fuente: elaboración propia sobre la base de datos del Censo Nacional de Población, Hogares y Viviendas 2010 (INDEC), suministrados por la Dirección Provincial de Estadística y Censos de la Provincia del Neuquén.

De esta estructura, sobresale nuevamente el componente inmigratorio de esta población, especialmente en edades adultas (25 a 39 años). Por último, la localidad de Villa La Angostura contaba en 2010 con una población que alcanzaba los 11.063 habitantes, lo

${ }^{6}$ La población extranjera alcanzaba 1.205 habitantes del total. 
que representa el $92.2 \%$ de la población del departamento Los Lagos, encontrándose en estos valores un indicador de la importancia de analizar la vulnerabilidad urbana de esta localidad frente a la caída de ceniza volcánica y los procesos tsunamigénicos.

\subsection{Reflexiones finales}

Los espacios geográficos se van configurando, resignificando y redefiniendo a través del tiempo. La región del Nahuel Huapi atravesó una serie de cambios que le otorgan una identidad particular. De la producción ganadera y maderera a la actividad turística, las implicancias de la redefinición económica del espacio fueron especialmente significativas desde la óptica de los riesgos. Los impactos económicos de la caída de ceniza de 2011 se desarrollan con profundidad en el siguiente capítulo.

El turismo depende básicamente de personas que arriban a la región para consumir sus productos y servicios, con una clara sensibilidad frente a procesos naturales disruptivos característicos de la zona:

- grandes nevadas, asociadas a un conjunto de condiciones climáticas particulares donde son frecuentes las precipitaciones níveas durante el período invernal,

- Las caídas piroclásticas, producto de erupciones explosivas de volcanes activos de la región, transportadas hacia la zona de estudio a través de los westerlies,

- procesos de remoción en masa subaéreos, producto de un relieve montañoso y estación húmeda concentrada en un período del año, potenciados por las modificaciones antrópicas realizadas en el ambiente y,

- procesos de remoción en masa subacuáticos en grandes lagos proglaciares.

Todos estos peligros representan una problemática para la región, debido a las interrupciones en las comunicaciones aéreas, terrestres y lacustres, que dificultan su acceso no sólo cuando se hacen presentes, sino también cuando se prolongan en el tiempo, como sucedió con la erupción del Cordón Caulle iniciada en 2011 y se prolongó hasta bien entrado el año 2012. Adicionalmente, la removilización eólica continuó en los meses subsiguientes, haciéndose muy notoria en los períodos estivales, durante las estaciones secas.

Frente a este panorama y la gran importancia que tiene la actividad turística en la región, se evidencia una gran sensibilidad en general y particularmente frente a las caídas de cenizas, notándose en la reducción significativa en la cantidad de turistas, como se verá en el siguiente capítulo.

Otra arista la aporta el crecimiento poblacional vertiginoso de finales de siglo $X X$ y comienzos del XXI por aporte migratorio. Esto presenta no sólo un aspecto cuantitativo, es 
decir, un incremento de la población expuesta a los peligros naturales sino también cualitativo, ya que comúnmente se trata de inmigrantes que desconocen los riesgos a los que la región se encuentra expuesta y una prueba de ello fue la sorpresa que causó la erupción del Cordón Caulle en 2011, aspecto en el que se ahonda en el Capítulo V. 


\subsection{Bibliografía del capítulo}

BANDIERI S. 2005. Historia de la Patagonia. Sudamericana. Buenos Aires. 448 págs.

BARRENECHEA J.; GENTILE E.; GONZÁLEZ S.; NATENZON C. 2000. Una propuesta metodológica para el estudio de la vulnerabilidad social en el marco de la Teoría Social del Riesgo. IV Jornadas de Sociología. Facultad de Ciencias Sociales. UBA. Buenos Aires, 6 al 9 de noviembre de 2000, p. 1-13.

BEIGT D.; VILLAROSA G.; OUTES V.; DZENDOLETAS M. A.; GÓMEZ E. A. 2012. El lago Nahuel Huapi: un registro de erupciones, deslizamientos y tsunamis. Ciencia Hoy, Vol. 22 núm. 130; diciembre 2012 - enero 2013. Págs. 50-56.

BIEDMA J. M. 1997. Crónica histórica del lago Nahuel Huapi. Tercera edición. Ediciones Caleuche. Bariloche. 231 Págs.

BLAIKIE P.; CANNON T.; DAVID I.; WISNER B. 1996. Vulnerabilidad. El entorno social, económico y político de los desastres. En http://www.desenredando.org, La Red, julio de 1996, p. 1-290.

GUEVARA T. y NÚÑEZ P. 2014. LA CIUDAD EN DISPUTA. DESARROLLO URBANO Y DESARROLLO ECONÓMICO EN SAN CARLOS DE BARILOCHE. Diálogo Andino núm. 45, dic. 2014, Arica. Págs. 153-167.

INDEC. 1999. Municipium. Publicación del Programa de Información Estadística y Apoyo a los Municipios-PRINEM; $\mathrm{N}^{\circ}$ 3; julio de 1999; p. 1-9. Disponible en http://www.indec.gov.ar/nuevaweb/cuadros/18/municipium03.pdf. Consultada el 9 de enero de 2015.

LARIA S. C. 1970. Introducción histórica al estudio de la geografía de la Región del Nahuel Huapi. En Estudio de la Región del Nahuel Huapi. Anales de Sociedad Argentina de Estudios Geográficos. Coni. Buenos Aires. Págs. 89-231.

LOLICH L. 1992. Tipos de asentamientos rurales y semirrurales en la Zona Nahuel Huapi. Inédito. 226 Págs.

MATOSSIAN B. 2012. Modelos de desarrollo, poblamiento y frontera. El caso del Parque Nacional Nahuel Huapi. Estudios Sociales Contemporáneos N5/6. Págs. 67-84.

MÉNDEZ L. 2010. Estado, frontera y turismo: historia de San Carlos de Bariloche. Prometeo. Buenos Aires. 300 págs.

MÉNDEZ L. e IWANOW W. 2001. Bariloche: las caras del pasado. Editorial Manuscritos. Neuquén. 223 Págs.

NATENZON C. E. 1995. Catástrofes naturales, riesgo e incertidumbre. Serie de Documentos e Informes de Investigación, N 197; FLACSO; Págs. 1-19.

PEREYRA F. X. 2007. Geomorfología urbana de San Carlos de Bariloche y su influencia en los peligros naturales, Rio Negro. Revista de la Asociación Geológica Argentina Vól. 62, N². Págs. 309- 320.

PEREYRA F.; ALBERTONI J.; BRÉARD C.; CAVALIARO S.; COCCIA M.; DUCÓS E.; DZENDOLETAS M.; FOOKES S.; GETINO E.; HELMS F.; KRUCK W.; LÓPEZ R.; MUZIO C.; ROVERANO D.; TOBIO M.; TOLOCZYKI M.; WILSON C. 2005. Estudio geocientífico aplicado al ordenamiento territorial. San Carlos de Bariloche. Anales 42, SEGEMAR. Buenos Aires. 181 Págs. 
PICA E. M. 2005. Geografía de la Región Andina Rionegrina. En REY H. D. Comp. 2005. La codillera rionegrina. Economía, Estado y Sociedad en la primera mitad del siglo XX. Editorial 2010 Bicentenario. Viedma. Págs. 9-13.

VALLMITJANA R. 1993. 90 años de turismo de Bariloche. Edición Bodas de Oro. Asociación Hotelera Gastronómica Bariloche. Impresión Feher offset. Bariloche. 68 Págs.

VILLAROSA G.; OUTES V.; HAJDUK A.; CRIVELLI MONTERO E.; SELLES D; FERNANDEZ M; CRIVELLI E. 2006. Explosive volcanism during the Holocene in the Upper Limay River Basin: The effects of ashfalls on human societies, Northern Patagonia, Argentina. Quaternary International 158. Págs. 44-57.

\section{Otras fuentes}

Segundo Censo de la República Argentina. 1898. Tomo II. Población. Taller topográfico de la Penitenciaría Nacional. Buenos Aires.

Tercer Censo Nacional. 1916. Tomo II. Población. Talleres Gráficos de L- J- Rosso y Cía. Buenos Aires.

IV Censo General de la Nación, 1947. 1951. Resultados Generales del censo de población. Publicación de la Dirección de Servicios Técnicos del Estado. Dirección General del Servicio Estadístico Nacional. Buenos Aires.

IV Censo General de la Nación, 1947. 1951. Comparación de los resultados del censo de población. Publicación de la Dirección de Servicios Técnicos del Estado. Dirección General del Servicio Estadístico Nacional. Buenos Aires.

Censo Nacional de Población 1960. Tomo I. Total del país. Dirección Nacional de Estadísticas y Censos.

Censo Nacional de Población 1960. Tomo IX. Zona patagónica. Dirección Nacional de Estadísticas y Censos.

Censo Nacional de Población, Familias y Viviendas-1970. INDEC.

Censo Población 1970. Localidades menores de 1000 habitantes. INDEC.

Censo Nacional de Población, Familias y Viviendas-1970. 1974. Resultados obtenidos por muestra. Río Negro. INDEC.

Censo Nacional de Población, Familias y Viviendas-1970. 1973. Localidades con 1000 y más habitantes. Todo el país. INDEC. Buenos Aires.

Censo Nacional de Población y Vivienda 1980. Serie D. población. Total del País, por Provincia, Departamento y Localidad. República Argentina.

Censo Nacional de Población y Vivienda 1980. Localidades de más de 2000 habitantes ordenadas por magnitud. Publicaciones especiales. INDEC.

Censo Nacional de Población y Vivienda 1980. Localidades de 1000 a 2000 habitantes ordenadas por magnitud. Publicaciones especiales. INDEC.

Censo Nacional de Población y Vivienda 1991. Por localidad. Serie G N¹. INDEC. Buenos Aires.

Censo Nacional de Población y Vivienda 1991. 1992. Río Negro. Serie B N¹6. INDEC. Buenos Aires. 
Censo Nacional de Población y vivienda 1991. 1992. Neuquén. Serie B N¹5. INDEC. Buenos Aires.

Censo Nacional de Población, Hogares y Viviendas 2001. INDEC. http://www.indec.gov.ar/micro_sitios/webcenso/ Consultada el 10 de enero de 2015.

Censo Nacional de Población, Hogares y Viviendas 2010. INDEC. http://www.censo2010.indec.gov.ar/ Consultada el 10 de enero de 2015.

Consejo Federal de Inversiones (CFI). http://localidades.cfi.org.ar/R\%C3\%ADo-Negro/DinaHuapi/Bienvenidos/20159/32708. Consultada el 27 de julio de 2015.

Administración de Parques Nacionales (APN). http://www.parquesnacionales.gob.ar/institucional/historia-institucional/. Consultada el 4 de Agosto de 2015.

de Mendieta, Yayo. Aquel 15 de mayo de 1932. La Angostura digital. http://www.laangosturadigital.com.ar/v3.1/home/interna.php?id_not=46578\&ori=web. Consultada el 4 de Agosto de 2015.

Carta Orgánica Municipal del Pueblo de Dina Huapi. Versión web en: http://www.eldinahuapense.com/wp-content/uploads/CARTA-ORG..DH_.htm. Consultada el 4 de Agosto de 2015.

Universidad Nacional de Río Negro. http://www.unrn.edu.ar/sitio/index.php/informacioninstitucional. Consultada el 4 de Agosto de 2015.

Legislatura del Pueblo de la Provincia de Río Negro. http://www.legisrn.gov.ar. Consultada el 4 de Agosto de 2015.

Servicio Meteorológico Nacional (SMN). www.smn.gob.ar. Consultada 17 de marzo de 2017.

Diario Río Negro (edición digital). "El turismo representa el 42\% del PBI de Bariloche". 6 de diciembre de 2006.2 Disponible en: http://www1.rionegro.com.ar/diario/2006/12/06/200612e06f01.php. Consultada el 29 de septiembre de 2015. 


\section{CAPÍTULO IV}

\section{VULNERABILIDAD FRENTE A LA CAÍDA DE CENIZA VOLCÁNICA}

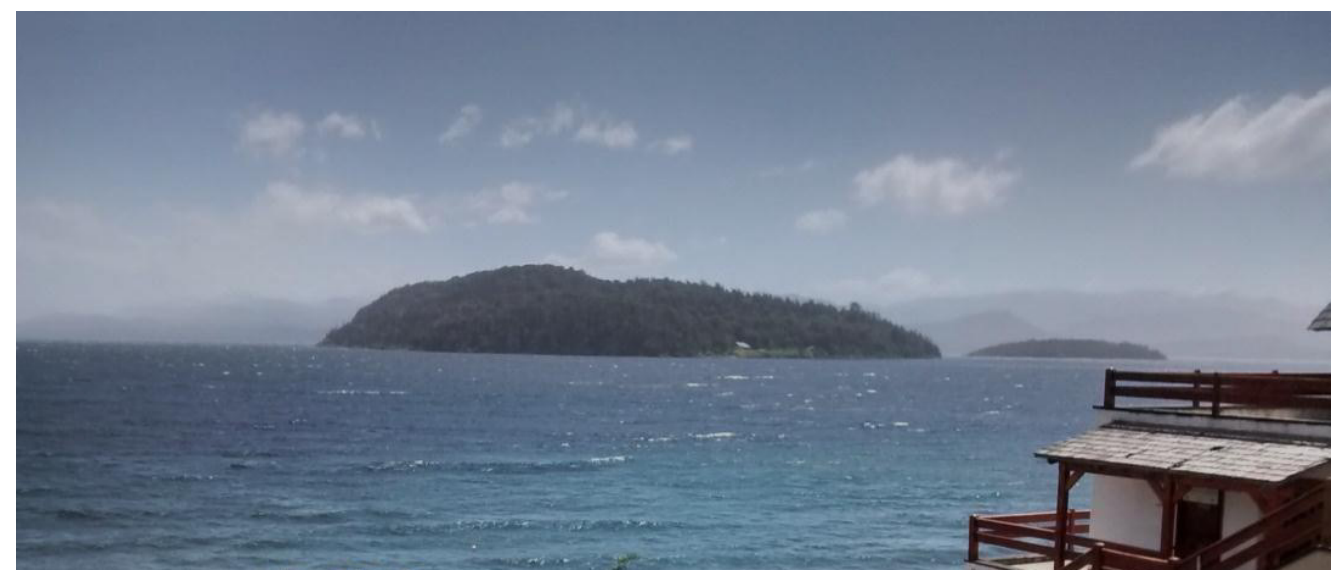

Vista del lago Nahuel Huapi desde Playa Bonita, Visibilidad reducida por removilización eólica de ceniza volcánica. San Carlos de Bariloche, 4 de diciembre de 2016. Foto del autor. 


\subsection{Recurrencia y desarrollo de cronologías de eventos volcánicos}

La reconstrucción, datación y ordenación temporal de los episodios de caída de ceniza conlleva la dificultad de encontrar registros superficiales preservados que presenten escasas alteraciones y es por ello que los registros lacustres, por su alto potencial de preservación, baja o nula removilización y adecuada resolución estratigráfica y temporal, aparecen como los más apropiados para analizar. Si bien no están exentos de problemas, los cuerpos de agua pequeños y relativamente someros en ambientes cordilleranos patagónicos son muy valiosos para realizar dataciones radiocarbónicas por el alto contenido de materia orgánica datable, baja contaminación por carbonatos y escasa removilización por

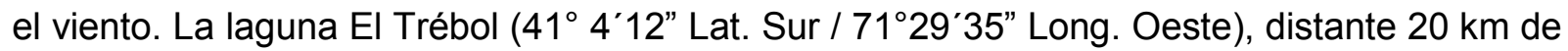
la ciudad de San Carlos de Bariloche, es un ejemplo de este tipo de cuerpos de agua y es por esta razón que se obtuvo un testigo sedimentario (Figura $\mathrm{N}^{\circ} 1$ ) para estudiar la recurrencia de eventos de caídas piroclásticas en el área (Figura №3).

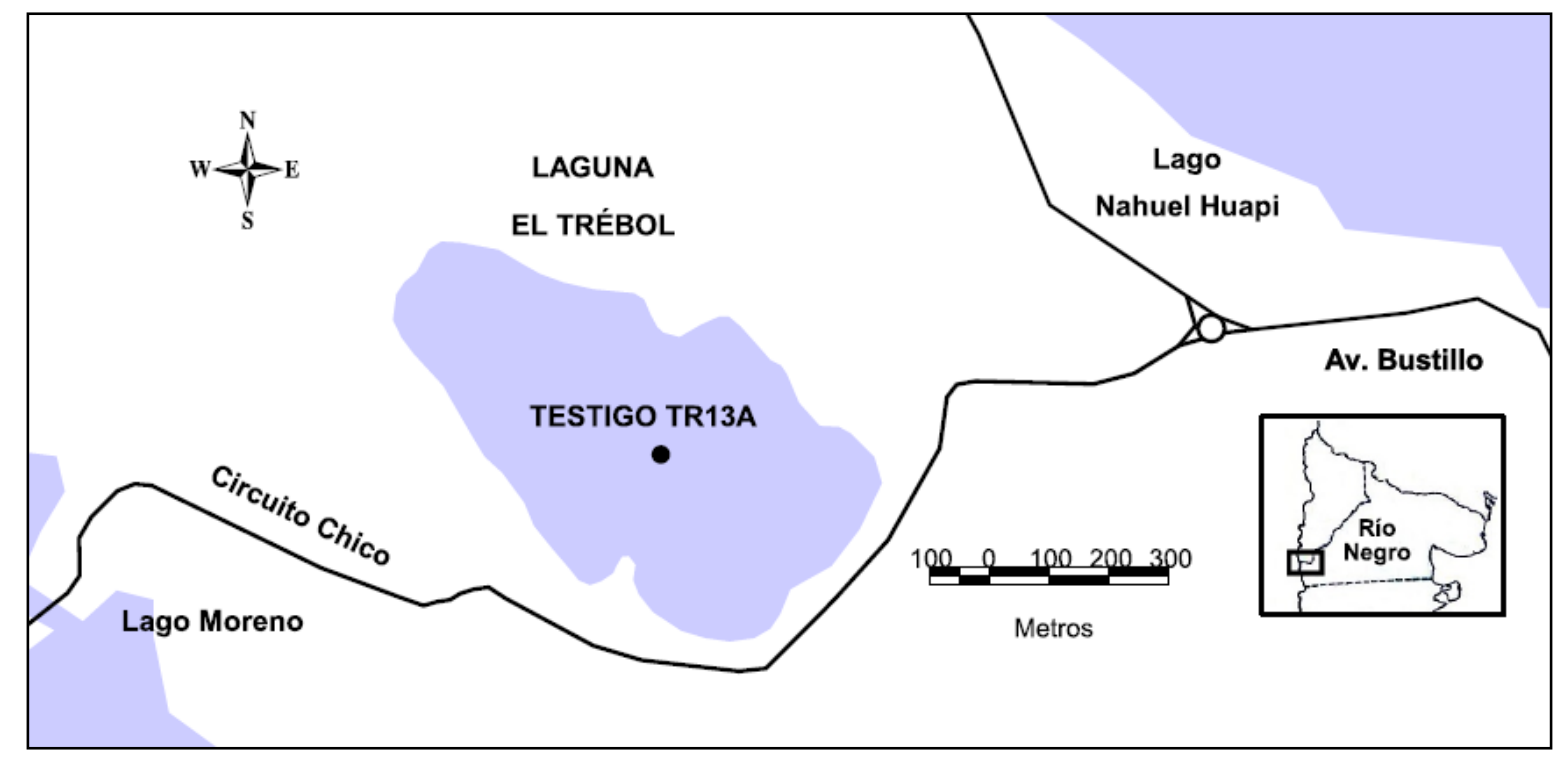

Figura N¹. Ubicación de la laguna El Trébol, donde se obtuvieron los testigos TR13A y TR13B.

El procedimiento de extracción consistió la utilización de un muestreador de gravedad, a percusión, marca Uwitec, operado desde un bote anclado. El trabajo de campo se desarrolló en el mes de Diciembre del año 2013, donde se obtuvieron los testigos TR13A y TR13B. El primero de ellos, con una longitud original de $107 \mathrm{~cm}$, se tomó de referencia para este estudio. El segundo, de $68 \mathrm{~cm}$ de longitud, se utilizó como soporte y control del trabajo realizado en laboratorio. 
En primer lugar, se procedió a sacar placas radiográficas al testigo sedimentario (Figura $\mathrm{N}^{\circ} 2$ ) con el objeto de identificar cambios en la densidad del sedimento. Esta técnica permite reconocer con nitidez los niveles de alta concentración mineral, incluyendo a las tefras, que por su alta reflectividad a los RX se observan con tonalidades claras (grises claros).

Una vez extruido el testigo en laboratorio, se procedió a cortarlo longitudinalmente para su descripción. Se describieron las características macroscópicas donde sobresalen cambios de coloración del sedimento y del tamaño de partículas a la vez que se identificaron las tefras a distintas profundidades del testigo.

\section{Descripción del Testigo TR13A y TR13B}

Como se mencionó anteriormente, el Testigo TR13A fue extraído de la Laguna El Trébol a una profundidad de 10 metros, con una longitud total de $107 \mathrm{~cm}$ pero, producto de la compactación derivada del proceso de extrusión, la misma se redujo a $98 \mathrm{~cm}$. En términos generales, se aprecia que el sedimento está compuesto por Gyttja, término de origen sueco utilizado para definir e identificar sedimentos oscuros producto de la descomposición parcial de la materia orgánica con granulometría fina (limo-arcilloso) y de consistencia similar al gel. La Gyttja presenta tonalidades oscuras que se ubican en torno a los colores Dark Yellowish Brown y Dusky Yellowish Brown (Rock-Color Chart, The Geological Society of America, 1991).

El sedimento se encuentra laminado entre los 98 y $21,5 \mathrm{~cm}$, con láminas de distinto espesor (pocos milímetros a unos centímetros, Cuadro $\mathrm{N}^{\circ} 1$ ), que se tornan más difusas entre los 63 y $21,5 \mathrm{~cm}$ de profundidad.

\begin{tabular}{|c|c|}
\hline Profundidad & Descripción sección \\
\hline $98-94$ & Lámina castaña oscura \\
\hline $94-89$ & Lámina castaña clara \\
\hline $89-87$ & Lámina castaña oscura \\
\hline $87-85$ & Lámina castaña clara \\
\hline $85-84,5$ & Lámina castaña oscura \\
\hline $84,5-84$ & Lámina castaña clara \\
\hline $84-82$ & Lámina castaña oscura \\
\hline $82-79$ & Lámina castaña clara \\
\hline $79-78,5$ & Tefra oscura, delgada, tamaño fino \\
\hline $78,5-76$ & Lámina castaña clara \\
\hline $76-75,5$ & Lámina castaña oscura \\
\hline $75,5-74$ & Lámina castaña clara \\
\hline $74-73,5$ & Lámina castaña oscura \\
\hline $73,5-71,5$ & Lámina castaña clara \\
\hline
\end{tabular}




\begin{tabular}{|c|c|}
\hline $71,5-71$ & Lámina castaña oscura \\
\hline $71-70$ & Lámina castaña clara \\
\hline $70-67$ & Lámina castaña oscura, con presencia de material limo-arcilloso \\
\hline $67-65,5$ & Tefra tamaño arena media, oscura, con fragmentos claros. \\
\hline $65,5-63,5$ & Lámina castaña oscura \\
\hline $63,5-60$ & Lámina castaña clara \\
\hline $60-57,5$ & Lámina castaña oscura \\
\hline $57,5-56,5$ & Lámina castaña clara \\
\hline $56,5-53$ & Lámina castaña oscura \\
\hline $53-48,5$ & Lámina castaña clara \\
\hline $48,5-47$ & Lámina castaña oscura \\
\hline $47-46$ & Tefra oscura, con fragmentos claros, tamaño arena con presencia de lapilli claros. \\
\hline $46-44$ & Tefra clara, fina. \\
\hline $44-33$ & Lámina gradada, que va desde el castaño oscuro entre 44 y 38 cm, hacia un \\
castaño más claro hasta los 33 cm.
\end{tabular}

Cuadro N¹. Descripción Testigo TR13A Y TR13B. Aunque con sutiles cambios en la coloración, la laminación se encuentra presente en el $80 \%$ del testigo, indicando variaciones en la materia orgánica. Fuente: elaboración propia con colaboración de la Lic. Manzoni.

Estás láminas presentan entre sí leves cambios de coloración que las permiten diferenciar, colores que oscilan entre las tonalidades antes mencionadas. Entre los 98 y 67 cm de profundidad, la laminación presenta una leve inclinación (probablemente por deformación ocurrida durante la extrusión), la cual se desaparece hacia el tramo superior del mismo. Por último, se pueden distinguir 5 tefras a simple vista y hasta 8 al tacto (Figura $\mathrm{N}^{\circ} 2$ ). 

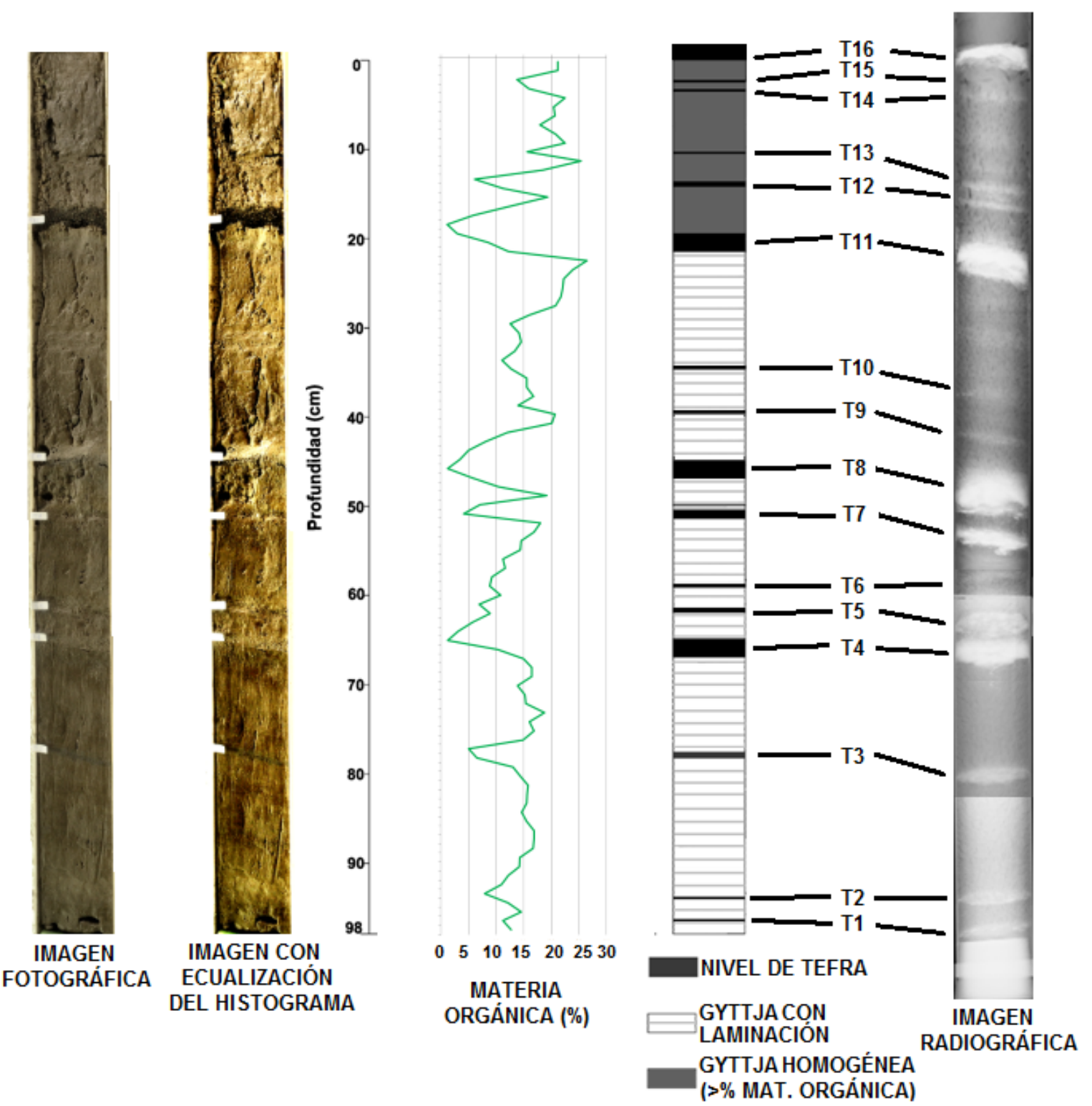

Figura $\mathrm{N}^{\circ} 2$. Testigo Laguna El Trébol. Niveles de Tefra macroscópicos y cambios de coloración y presencia de laminaciones en el sedimento compuesto fundamentalmente por Gyttja. La materia orgánica muestra valores sensiblemente más bajos en presencia de un nivel de tefra, dado el carácter instantáneo de su depositación. Fuente: elaboración propia con la colaboración de la Lic. Carolina Manzoni, a partir del trabajo de laboratorio, observaciones en lupa y placas radiográficas con colaboración de la Lic. Outes y Lic. Manzoni y la Dra. Serra. Fotos del autor.

Las tefras halladas en el registro sedimentario de la laguna El Trébol (Cuadro $\mathrm{N}^{\circ} 2$ ) presentan diferentes espesores, los cuales varían de unos milímetros a unos pocos centímetros. 


\begin{tabular}{|c|c|c|}
\hline Nombre Tefra & $\begin{array}{c}\text { Prof. Testigo Muestreo } \\
(\mathbf{c m})\end{array}$ & $\begin{array}{c}\text { Espesor Tefra } \\
(\mathbf{m m})\end{array}$ \\
\hline T16 & $0-3$ & 30 \\
\hline $\mathrm{T} 15$ & $2-3^{* *}$ & 1 \\
\hline $\mathrm{T} 14$ & $3-4^{* *}$ & 1 \\
\hline $\mathrm{T} 13$ & $10-11$ & 1 \\
\hline $\mathrm{T} 12$ & $13-15$ & 2 \\
\hline $\mathrm{T} 11$ & $18-21,5$ & 20 \\
\hline $\mathrm{T} 10$ & $34-34,5$ & 4 \\
\hline $\mathrm{T} 9$ & $39-40$ & 2 \\
\hline $\mathrm{T} 8$ & $43-49$ & 20 \\
\hline $\mathrm{T} 7$ & $50-52$ & 10 \\
\hline T6 & $58,5-60$ & 4 \\
\hline T5 & $61-62,5$ & 5 \\
\hline T4 & $63,5-66$ & 20 \\
\hline T3 & $77-79$ & 6 \\
\hline T2 & $93-95$ & 1 \\
\hline T1 & $96-97$ & 1 \\
\hline
\end{tabular}

Cuadro N²: Espesor y profundidad de los niveles de tefra en el testigo de Laguna El Trébol. Fuente: elaboración propia sobre la base de muestreo de campo, análisis de laboratorio e instrumental óptico, con colaboración de la Lic. Outes y Lic. Manzoni y la Dra. Serra.

*visible en el Testigo TR13-B, de $68 \mathrm{~cm}$ de longitud, menor que el testigo TR13-A pero que conserva mejor la tefra de la erupción del Cordón Caulle de 2011.

${ }^{* *}$ el material piroclástico se encuentra disperso en los intervalos señalados (no definen niveles discretos).

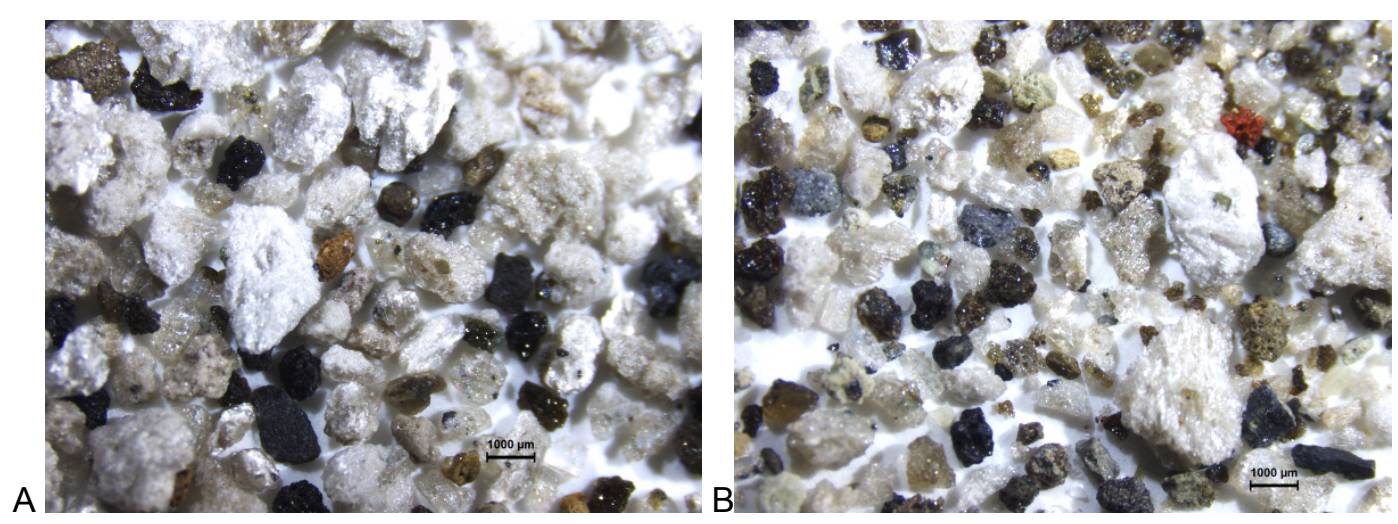



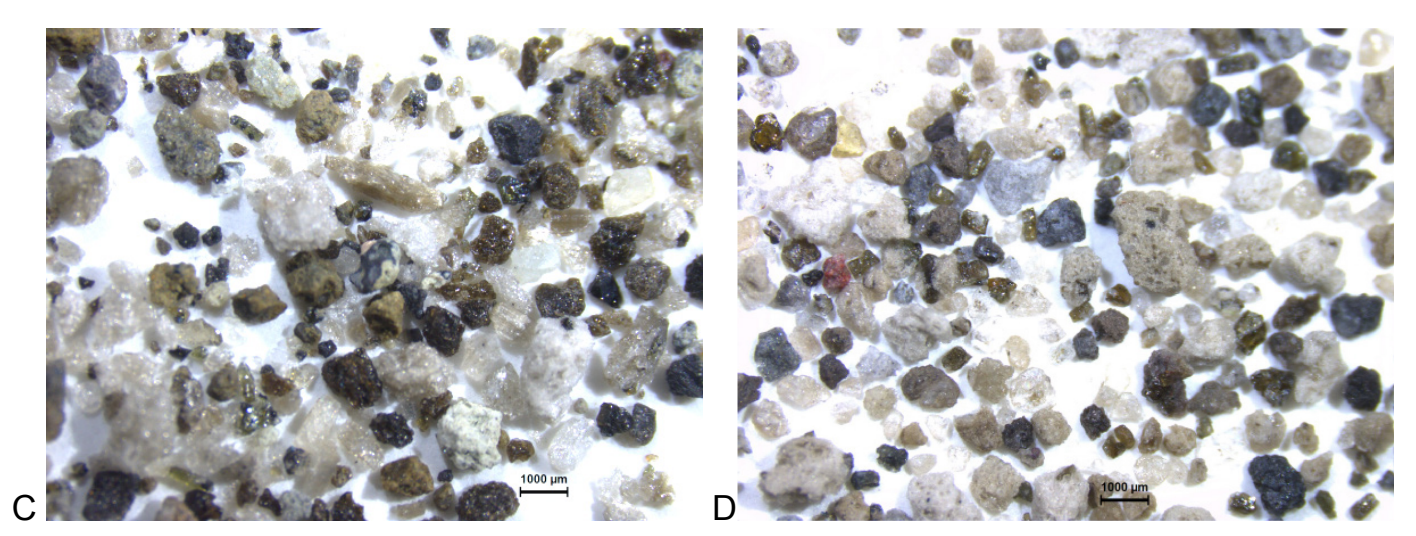

Figura $\mathrm{N}^{\circ} 3$. Muestra de ceniza de la Tefra T16 en lupa binocular. La secuencia de imágenes muestra la ceniza correspondiente a la erupción del Cordón Caulle de 2011 (imagen A). Los vidrios claros y traslúcidos predominan dentro del conjunto de piroclastos. Los fragmentos oscuros pertenecen a minerales magnéticos y vidrios con tonalidades grises a verdosas. La caracterización de esta ceniza permitió asociarla con otras tefras, pudiéndose atribuir a este volcán el origen de las tefras T15 (erupción de 1960, imagen B), T14 (erupción de 1921-1922, imagen C) y la Tefra T4, fechada por el modelo en 633 AD (imagen D).

En términos generales, es significativo destacar que, en el período considerado (Holoceno Tardío), la mayor amenaza volcánica para la región del Nahuel Huapi está representada por el Cordón Caulle, lo que queda de manifiesto tanto por el número de erupciones recientes como también por las evidencias en el registro sedimentario, observándose numerosas tefras de coloración clara, con fragmentos pumíceos que predominan en el testigo, similar a la correspondiente a la erupción del Cordón Caulle de 2011.

\subsubsection{Cronología de eventos: Modelos bayesianos con OxCal}

El estudio de la recurrencia eruptiva en la región del Nahuel Huapi a partir de registros sedimentarios lacustres obtenidos en la Laguna El Trébol requiere de la elaboración de un modelo cronológico que incorpore numerosas variables, además de las dataciones absolutas de episodios de caída de ceniza, sobre todo para los niveles del registro correspondiente a períodos sin registros históricos. Para ello se recurrió a la aplicación del análisis bayesiano a través del software OxCal (Oxford Radiocarbon Accelerator Unit) versión 4.3.

Estos modelos parten de una base de información cronológica. Las edades disponibles para este testigo son las siguientes:

- una de ellas es la Tefra TT1-6 de edad 977 +/- 92, según modelado Bayesiano, (Villarosa, 2008),

- otra obtenida por datación AMS (espectrometría de masas con aceleradores, laboratorio BETA ANALYTIC INC.), para una muestra de sedimento obtenida a una profundidad de 21-21,5 cm del testigo y, 
- la Tefra T16 presente en el techo del testigo, correspondiente a la erupción del Cordón Caulle iniciada en 2011.

El análisis bayesiano propuesto en OxCal agrega criterios geológicos al mero procesado matemático de funciones de edades versus profundidad. Este análisis es una herramienta acreditada para la combinación de información estratigráfica y sedimentológica con fechas absolutas que mejoran la precisión y la exactitud de las cronologías arqueológicas y paleoambientales (Lee et al., 2013, p. 742). Los modelos bayesianos tienen aplicación en el campo de la probabilidad, dado que tienen en común la asignación de la probabilidad como medida de credibilidad de una hipótesis, a la vez que permite la introducción de factores condicionantes especialmente estratigráficos (variaciones en las tasas de sedimentación, interrupciones, relaciones cronológicas). Bronk Ramsey (2008) reconoce dos aspectos esenciales al momento de recurrir a los modelos bayesianos. Por un lado, lo que sabemos acerca de cualquier sistema antes de empezar un conjunto de mediciones. Por otro, la probabilidad que describe la información que obtenemos de un conjunto de mediciones en sí. El teorema de Bayes nos dice cómo combinar estos tipos de información (Bronk Ramsey, 2008, p. 43).

\subsubsection{Cronología de eventos}

El modelo presentado en este apartado es de profundidad-edad calendario (deposicion model), donde se representan en distinto color cada sección del modelo separado por límites impuestos (boundaries). Las edades calibradas están contenidas en dos áreas: la más amplia y de color suave representa la distribución de probabilidad de 95,4\% y el área interna más oscura la distribución del 68,2\%.

Los tres boundaries en que se apoya el modelo están constituidos por el límite inferior del testigo obtenido (bottom), el superior (top) y un límite hallado durante el trabajo de laboratorio que se apoya en el cambio de coloración del sedimento (véase descripción del testigo, donde se muestra cambio de tonalidades en el sedimento en torno a los $21,5 \mathrm{~cm}$ de profundidad de la muestra) que, a su vez, coincide con un cambio en la tasa de sedimentación, como se verá más adelante.

Las edades radiocarbónicas ${ }^{7}$, junto con las edades de tefras conocidas previamente (Figura $\mathrm{N}^{\circ} 4$ ) aparecen a la izquierda del gráfico a la profundidad correspondiente y las tefras

\footnotetext{
${ }^{7}$ Se utilizó la función $R \_$Date para la muestra de materia orgánica datada por el laboratorio Beta y la función $R \_$Simulate para la edad modelada para la Tefra TT1-6 (en Villarosa, 2008), correlacionada con la Tefra 8 del testigo de laguna El Trébol.
} 
están incluidas como eventos para ser estimada su edad (función Date) ya que para confeccionar el modelo cronológico se deben descontar las tefras a la profundidad del testigo por tratarse de eventos instantáneos de depositación que alteran la tasa normal de sedimentación de la cuenca. Las áreas más claras corresponden a la distribución de edades calibradas y las más oscuras a la distribución de probabilidad dentro del modelo.

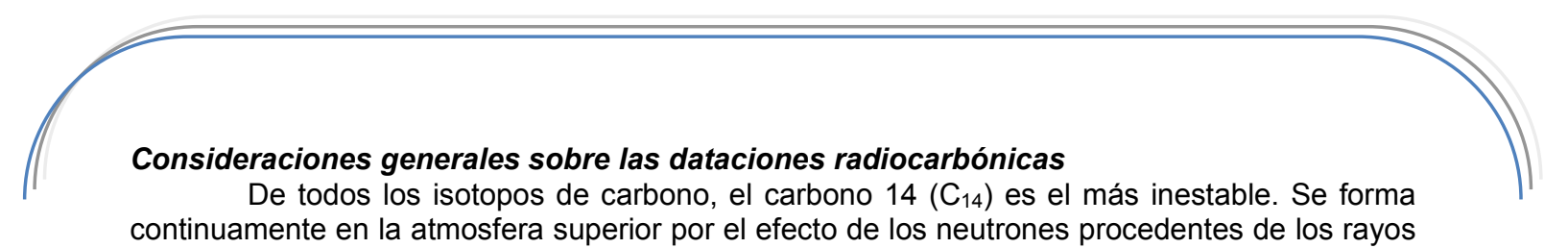
cósmicos sobre los átomos de nitrógeno $14\left(\mathrm{~N}_{14}\right)$, oxidándose para formar dióxido de carbono $\left(\mathrm{CO}_{2}\right)$ y entrar de este modo en el ciclo del carbono.

Durante toda su vida, los seres vivos asimilan $\mathrm{C}_{14}$ a partir del $\mathrm{CO}_{2}$ pero cuando mueren, dejan de intercambiar carbono y su contenido de $\mathrm{C}_{14}$ comienza a disminuir a una tasa relativamente constante, la cual está determinada por la Ley del Decaimiento Radiactivo (deviene en isótopos estables $\mathrm{C}_{13}$ y $\mathrm{C}_{12}$ ).

Los problemas más frecuentes son el efecto reservorio, percolación de ácidos húmicos en secuencias edáficas, retrabajo de orgánicos datables en la secuencia, incorporación de carbonatos y, en ambientes volcánicos activos, el envejecimiento de las edades producida por la emanación de $\mathrm{CO}_{2}$ (Villarosa, 2008, p. 54).

Las edades procedentes de dataciones radiocarbónicas sólo pueden ser utilizadas si se calibran considerando la variación del contenido de $\mathrm{CO}_{2}$ atmosférico a lo largo del tiempo, para lo cual se pueden utilizar diferentes programas. El utilizado en este apartado es el OxCal 4.2. y, para comprender esto de una manera más acabada, la imagen siguiente (Figura $\mathrm{N}^{\circ} 1$ ) muestra la distribución de la probabilidad de edades para la edad una edad convencional de $\mathrm{C}_{14}$ :

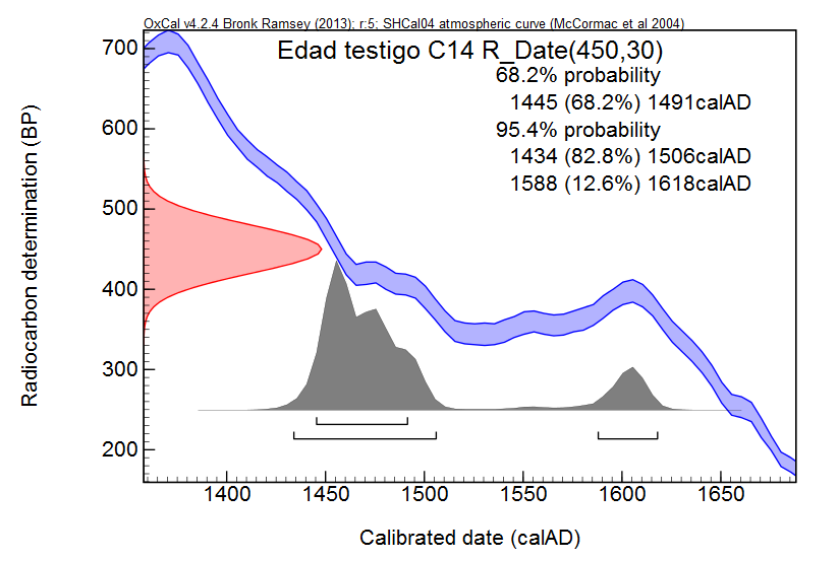

Figura. En el eje de las ordenadas se sitúa la distribución gaussiana de la fecha $\mathrm{C}_{14}$ convencional (en rosa), centrada en los 450 y el $68,2 \%$ de su área (un sigma) se sitúa en $450 \pm$ 30. La curva de calibración ShCal04 (en celeste) tiene una forma irregular debido a la variación desigual del contenido en $\mathrm{C}_{14}$ a lo largo del tiempo. La edad calibrada también presenta una distribución irregular, resultante de proyectar la probabilidad de cada punto de la edad convencional sobre la curva de calibración. Debido a la presencia de "dientes de sierra" (wiggles) en la curva de calibración, a un punto de la distribución de edad convencional puede corresponderle más de un punto de la distribución de la edad calibrada y puede también que no exista edad real posible dentro del rango de edad convencional. Tras la calibración, la fecha real se encuentra, con un $95,4 \%$ de probabilidad (dos sigmas), en el intervalo 1434-1618 calAD anno domini, del calendario gregoriano (Rubinos Perez, 2009, p. 334). 


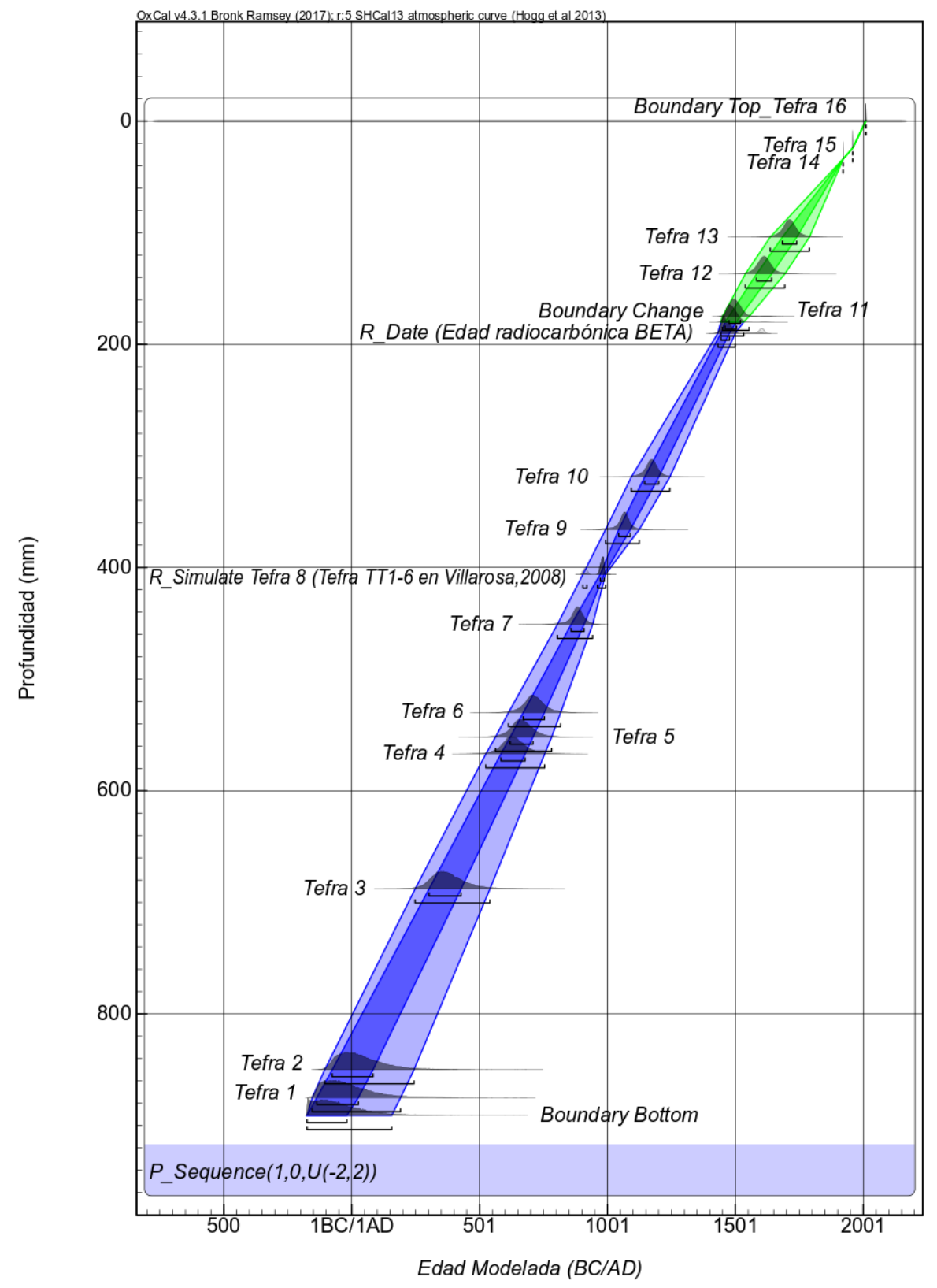

Figura N4. Modelo cronológico para la Región del Nahuel Huapi. Los registros sedimentarios de la laguna El Trébol permitieron elaborar un modelo cronológico para analizar la secuencia y recurrencia de eventos volcánicos a través de un modelo de edad-profundidad. Fuente: elaboración propia sobre la base de testigo sedimentario, dataciones radiocarbónicas, edad modelada (Villarosa, 2008) y software OxCal versión 4.3. 


\begin{tabular}{|c|c|c|c|c|c|c|c|c|c|c|c|c|c|c|c|c|c|c|c|c|}
\hline \multirow{3}{*}{$\begin{array}{l}\text { Name } \\
\text { Show all } \\
\text { Show structure } \\
2011\end{array}$} & \multicolumn{8}{|c|}{$=\equiv$} & \multicolumn{7}{|c|}{ Modelled (BC/AD) } & \multicolumn{3}{|c|}{$\begin{array}{l}\text { Indices } \\
A_{\text {model }}=113.8 \\
A_{\text {overall }}=113.8\end{array}$} & \multirow{3}{*}{$\begin{array}{l}\text { Select } \\
\begin{array}{l}\text { All } \\
\text { Visible } \\
\square 23\end{array}\end{array}$} & \multirow{3}{*}{$\begin{array}{l}\begin{array}{l}\text { Page } \\
\text { break }\end{array} \\
\square\end{array}$} \\
\hline & \multicolumn{3}{|c|}{ from to } & \multirow[t]{2}{*}{$\%$} & \multicolumn{2}{|c|}{ from to } & \multirow[t]{2}{*}{$\%$} & \multirow[t]{2}{*}{ m } & \multirow[t]{2}{*}{ from } & \multirow[t]{2}{*}{ to } & \multirow[t]{2}{*}{$\%$} & \multirow[t]{2}{*}{ from } & \multirow[t]{2}{*}{ to } & \multirow[t]{2}{*}{$\%$} & \multirow[t]{2}{*}{ m } & \multirow{2}{*}{\multicolumn{2}{|c|}{$A_{\text {comb }} A$}} & LPC & & \\
\hline & 非 & & & & & & & & & & & & & & & & & & & \\
\hline A Boundary Top_TR13A-T16 & 汪2 & 2010 & 2011 & 68.2 & 2010 & 2011 & 95.42 & 2011 & 2009 & 2011 & 68.2 & 2009 & 2011 & 95.4 & 2010 & & 100 & 100 & $\nabla 22$ & $\square$ \\
\hline TR13A-T15 & 非 & & & & & & & & 1959 & 1960 & 68.2 & 21959 & 1960 & 95.4 & 1960 & & & 100 & $\nabla 21$ & $\square$ \\
\hline TR13A-T14 & 非 & & & & & & & & 1921 & 1922 & 68.2 & 21921 & 1922 & 95.4 & 1922 & & & 100 & $\nabla 20$ & $\square$ \\
\hline TR13A-T13 & 拝 & & & & & & & & 1684 & 1741 & 68.2 & 21637 & 1790 & 95.4 & 1712 & & & 99.2 & $\nabla 19$ & $\square$ \\
\hline TR13A-T12 & 玗 & & & & & & & & 1584 & 1642 & 68.2 & 21540 & 1694 & 95.4 & 1614 & & & 99.6 & $\nabla 18$ & 回 \\
\hline TR13A-T11 & 䏠 & & & & & & & & 1475 & 1520 & 68.2 & 21450 & 1555 & 95.4 & 1499 & & & 99.2 & $\nabla 17$ & $\square$ \\
\hline Boundary Change & 非 & & & & & & & & 1460 & 1505 & 68.2 & 21444 & 1533 & 95.4 & 1484 & & & 99.3 & $\nabla 16$ & $\square$ \\
\hline R_Date BETA & 暳 & 1445 & 1491 & 68.2 & 1434 & 1618 & 95.4 & 1471 & 1444 & 1477 & 68.2 & 21432 & 1501 & 95.4 & 1462 & & 112.7 & 99.5 & $\nabla 15$ & $\square$ \\
\hline TR13A-T10 & 非 & & & & & & & & 1146 & 1201 & 68.2 & 21094 & 1244 & 95.4 & 1173 & & & 99.5 & $\nabla 14$ & 回 \\
\hline TR13A-T9 & 晅 & & & & & & & & 1045 & 1090 & 68.2 & 993 & 1125 & 95.4 & 1067 & & & 99.7 & $\nabla 13$ & $\square$ \\
\hline R_Simulate TR13A-T8_TT1-6 & S拝 & 907 & 990 & 68.2 & 900 & 994 & 95.4 & 977 & 973 & 988 & 68.2 & 905 & 993 & $95.4 \mathrm{~S}$ & 979 & & 114.9 & 99.8 & $\nabla 12$ & $\square$ \\
\hline TR13A-T7 & 玗 & & & & & & & & 859 & 909 & 68.2 & 805 & 943 & 95.4 & 883 & & & 99.5 & $\nabla 11$ & $\square$ \\
\hline TR13A-T6 & 玗 & & & & & & & & 671 & 754 & 68.2 & 614 & 818 & 95.4 & 712 & & & 98.7 & $\nabla 10$ & $\square$ \\
\hline TR13A-T5 & 拝 & & & & & & & & 620 & 709 & 68.2 & 563 & 782 & 95.4 & 665 & & & 98.6 & $\nabla 9$ & $\square$ \\
\hline TR13A-T4 & 琴 & & & & & & & & 584 & 679 & 68.2 & 525 & 755 & 95.4 & 633 & & & 98 & $\nabla 8$ & 回 \\
\hline TR13A-T3 & 王 & & & & & & & & 303 & 428 & 68.2 & 249 & 541 & 95.4 & 372 & & & 97.2 & $\nabla 7$ & $\square$ \\
\hline TR13A-T2 & 非 & & & & & & & & -77 & 84 & 68.2 & -106 & 244 & 95.4 & 21 & & & 95.3 & $\nabla 6$ & 回 \\
\hline TR13A-T1 & 拝 & & & & & & & & -137 & 27 & 68.2 & -155 & 192 & 95.4 . & -35 & & & 96.7 & $\nabla 5$ & $\square$ \\
\hline Boundary Bottom & 非 & & & & & & & & -175 & -20 & 68.2 & -175 & 157 & 95.4 . & -70 & & & 97 & $\nabla 4$ & $\square$ \\
\hline$\Delta P_{-}$Sequence $(1,0, U(-2,2))$ & 无 & -2 & 2 & 68.2 & -2 & 2 & 95.4 & $1.96891 \mathrm{e}-15$ & -0.665121 & 0.214879 & 68.2 & -1.22512 & 0.450879 & 95.4 & -0.285121 & & 100 & 96.9 & $\nabla 3$ & $\square$ \\
\hline Curve ShCal13 & 主 & & & & & & & & & & & & & & & & & & $\nabla 2$ & $\square$ \\
\hline
\end{tabular}

Figura $N^{\circ} 5$. Detalle del modelo cronológico para el registro sedimentario de laguna El Trébol. La secuencia sedimentaria de $101 \mathrm{~cm}$ se obtiene del complementar $98 \mathrm{~cm}$ de longitud del testigo TR13A y $3 \mathrm{~cm}$ de la tefra de 2011, sólo presente en el testigo TR13B. Dado que para elaborar los modelos cronológicos las tefras se descuentan, la longitud final obtenida es de $89,1 \mathrm{~cm}$. Esta sección cubre una edad estimada de casi 2200 años, permitiendo estudiar con detalle el registro eruptivo del Holoceno tardío en la región del Nahuel Huapi. Fuente: elaboración propia sobre la base de testigo sedimentario, dataciones radiocarbónicas, edad modelada (Villarosa, 2008) y software OxCal versión 4.3.

Si bien diversas erupciones conocidas han afectado la región del Nahuel Huapi, por ejemplo algunas procedentes del volcán Calbuco como las de 1961 y 2015, muchas de ellas no han dejado registro macroscópico en la secuencia sedimentaria. Por este motivo, la recurrencia estimada es válida para erupciones significativas, observables como niveles discretos de tefra en el registro sedimentario lacustre. Estas erupciones quedan preservadas como niveles con alta concentración de cenizas dispersas en los sedimentos lacustres, conocidos como microtefras o criptotefras, que a veces pueden ser percibidos en las imágenes radiográficas.

A partir del modelo (Figura $\mathrm{N}^{\circ} 5$ ) se pueden reconocer tres períodos con tasas de sedimentación diferentes (Cuadro $\mathrm{N}^{\circ} 3$ ), que posiblemente reflejen cambios climáticos e hidrológicos que afectaron a la cuenca hidrográfica de la laguna y, por ende, a la productividad de la laguna y de los bosques circundantes y estabilidad de sus suelos (Serra et al., 2016). 


\begin{tabular}{|c|c|c|c|c|c|c|}
\hline $\begin{array}{l}\text { EDAD } \\
\text { INICIAL } \\
\text { (BC/AD) }\end{array}$ & $\begin{array}{l}\text { EDAD } \\
\text { FINAL } \\
\text { (BC/AD) }\end{array}$ & DIFERENCIA & $\begin{array}{l}\text { PROFUNDIDAD } \\
\text { FINAL } \\
\text { (en } \mathrm{mm} \text { ) }\end{array}$ & $\begin{array}{l}\text { PROFUNDIDAD } \\
\text { INICIAL } \\
\text { (en mm) }\end{array}$ & $\begin{array}{l}\text { DIFERENCIA } \\
\text { (en mm) }\end{array}$ & $\begin{array}{c}\text { TASA DE SEDIMENTACIÓN } \\
\text { (DIFERENCIA PROFUNDIDAD / } \\
\text { DIFERENCIA EDAD - en mm/año) }\end{array}$ \\
\hline 1484 & 2011 & 527 & 0 & 180 & 180 & 0,34 \\
\hline 979 & 1484 & 505 & 180 & 400 & 220 & 0,44 \\
\hline-70 & 979 & 1049 & 400 & 891 & 610 & 0,52 \\
\hline \multicolumn{3}{|c|}{ Total años $=2081$} & \multicolumn{3}{|c|}{ Total profundidad $=891 \mathrm{~mm}$} & Promedio $=0,43$ \\
\hline
\end{tabular}

Cuadro $\mathrm{N}^{\circ} 3$. Tasas de sedimentación calculadas a partir de la mediana de las edades asignadas por el modelo. Fuente: elaboración propia a partir del modelo cronológico.

a- Entre los 891 y $400 \mathrm{~mm}$ de profundidad, se observa una tasa de sedimentación del orden de los 0,52 mm por año.

b- $\quad$ Entre los 400 y $180 \mathrm{~mm}$, la tasa de sedimentación decae a 0,44 mm por año.

c- $\quad$ Entre los $180 \mathrm{~cm}$ y el top $(0 \mathrm{~mm})$, la tasa desciende aún más alcanzando los

\section{$0,34 \mathrm{~mm}$ por año.}

El modelo presentado se realizó a partir del reconocimiento en laboratorio de un total de 16 niveles de tefras en los últimos 2206 años. Ocho niveles son macroscópicos (reconocibles a simple vista y al tacto) y otros ocho no se observan macroscópicamente, sino que son identificables con placas radiográficas, observaciones con lupa binocular y procedimiento de determinación de materia orgánica ${ }^{8}$.

Si bien pueden obtenerse diversos indicadores volcanológicos (Cruz Reyna, 1996; Polanco y Clavero, 2003) a continuación se ofrece la tasa de recurrencia de caída de ceniza volcánica en la región del Nahuel Huapi:

\section{Recurrencia $=\mathrm{N}^{\circ}$ de erupciones $/$ intervalo total de tiempo}

A partir de los 16 niveles de tefra reconocidos en el testigo sedimentario de una edad aproximada de 2200 años, se obtiene como resultado una erupción significativa cada 137 años. Si bien este valor implica una frecuencia relativamente baja, se deben tener en cuenta una serie aspectos:

\footnotetext{
${ }^{8}$ El método al que se recurrió para determinar contenido de materia orgánica, comúnmente utilizado en sedimentos lacustres, se conoce con el acrónimo de LOI (Loss On Ignition, en inglés / Pérdidas por calcinación, en español) (procedimientos de laboratorio basado en los trabajos de Bengtsson y Enell, 1986 y Heiri et al., 2001). En primer lugar se determina el contenido de humedad de una muestra de $1 \mathrm{~cm}^{3}$ de sedimento al someterla a elevadas temperaturas (de $105^{\circ} \mathrm{C}$ en estufa eléctrica, por un período de $24 \mathrm{hs}$ ). Luego se retira de la estufa y se estima el peso seco. Posteriormente, se somete la muestra a una temperatura de $550^{\circ} \mathrm{C}$ por un lapso de 2 horas en una mufla. A partir de las diferencias de peso entre las muestras secas y las calcinadas se realizan cálculos para determinar la cantidad de materia orgánica, la cual es muy escasa en los niveles de tefra dado que los depósitos piroclásticos se depositan de manera instantánea.
} 
- No todas las erupciones conforman un depósito identificable en el registro sedimentario (esto es válido para cuando la pluma toma una dirección diferente).

- Muchas veces la ceniza volcánica puede mezclarse con el sedimento: el sedimento más superficial no se encuentra compactado, por lo que una ceniza puede depositarse ingresando en el mismo.

- Al menos 5 erupciones que han afectado la zona se sucedieron en el último siglo: Cordón Caulle en 1921-22, 1960 y 2011 y Calbuco en 1961 y 2015, señalando una alta exposición reciente a las caídas de ceniza.

\section{Los principales volcanes activos de la zona}

Los volcanes activos más relevantes se encuentran en territorio chileno. Algunos de ellos, los más significativos por el número e importancia de las erupciones recientes, se describen en este apartado. El índice de explosividad volcánica (VEI, por sus siglas en inglés) indica la magnitud de la erupción.

Complejo Volcánico Puyehue-Cordón Caulle (CVPCC): se ubica al sudeste del lago Ranco Chile. Es una extensa cadena volcánica basáltica-riolítica que se extiende en dirección NO-SE, de origen Pleistoceno tardío al Holoceno. Las erupciones recientes más importantes son las de 1921-22 (VEI 3), 1960 (VEI 3) y 2011 (VEI 5).

Calbuco. Es uno de los volcanes más activos de los Andes del Sur de Chile, junto con su vecino, Osorno. Ubicado al sudeste del lago Llanquihue, en Chile, es un volcán andesítico de origen Pleistoceno tardíoHoloceno. En su historia eruptiva reciente se destacan las erupciones de 1961 (VEI 3) y 2015 (VEI 4).

Osorno. Localizado entre los lagos Llanquihue y de Todos los Santos, Chile, fue construido sobre un estratovolcán erosionado de aproximadamente 250 mil años, de composición predominantemente basáltico a basáltico-andesítico. La última erupción registrada fue en 1869 (VEI 2).

Fuente: Global Volcanism Program, 2013. Volcanoes of the World, v. 4.6.6. Venzke, E (ed.). Smithsonian Institution. Downloaded 16 Mar 2018. https://dx.doi.org/10.5479/si.GVP.VOTW4-2013.

\subsection{Erupciones recientes en Norpatagonia Andina: la experiencia del Cordón Caulle en} 2011

La erupción del Cordón Caulle iniciada el 4 de junio de 2011 trajo significativas consecuencias a localidades costeras del lago Nahuel Huapi como San Carlos de Bariloche, Dina Huapi y, sobre todo, Villa La Angostura. La magnitud de dicha erupción (Figura $\mathrm{N}^{\circ} 6$ ) fue tal que la superficie afectada por 10 centímetros o más de tefra alcanzó los $1450 \mathrm{Km}^{2}$, mientras que $170 \mathrm{Km}^{2}$ fueron cubiertos por 30 o más centímetros (Villarosa y Outes, 2013, pp. 21-22). 


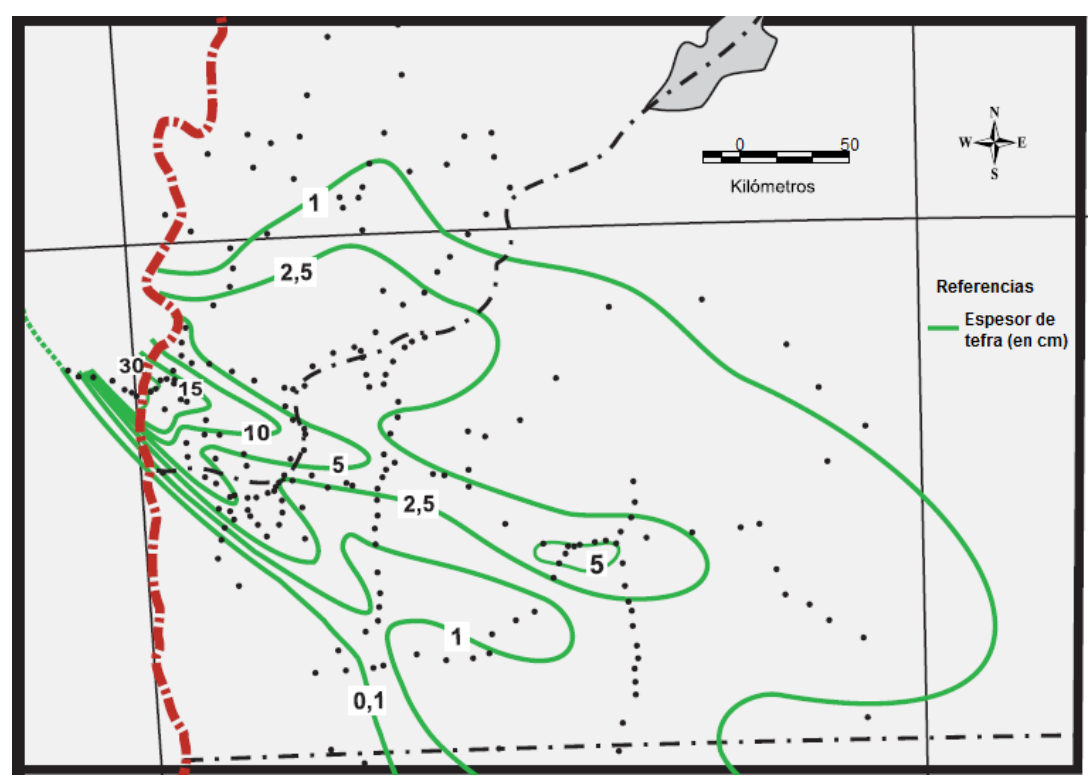

Figura N6: Mapa isopáquico. Erupción Cordón Caulle 2011. La mayor parte de la depositación de material piroclástico se produjo durante las primeras semanas luego de iniciada la erupción, sin embargo, la removilización del material depositado continuó en los meses subsiguientes. Fuente: modificado de Alloway et al., 2015 , p. 3.

En toda el área impactada, la erupción del Cordón Caulle acarreó diversos problemas a la población asociados a la ceniza suspendida en el aire y en el agua, además de inconvenientes a las actividades ganaderas, al abastecimiento de servicios básicos, al tratamiento de aguas residuales/domiciliarias, al transporte y las comunicaciones (Wilson et al., 2013, pp. 53-65); muchos de los cuales se registraron también en localidades extraandinas (Villarosa y Outes, 2013, p. 19).

Durante la emergencia volcánica generada por la erupción del Cordón Caulle, se implementaron diferentes medidas tanto en Villa La Angostura como en San Carlos de Bariloche y Dina Huapi. En las distintas tareas llevadas a cabo, trabajaron diversos organismos municipales, grupos comunitarios, Protección Civil, Ejército Argentino, Bomberos Voluntarios, Parques Nacionales y Prefectura Naval Argentina.

Dado que los niveles depósitos de ceniza volcánica fueron significativamente más elevados en Villa La Angostura, las medidas allí adoptadas fueron más complejas. Outes et. al. (2015) describen las medidas tomadas con inmediatez a la erupción del Cordón Caulle en esa localidad neuquina, entre las que se cuenta:

- la conformación de un Comando de Operaciones en Emergencias (COE). Hacia fines del mes de Junio de 2011, desde la intendencia se decretó la creación de un Comité de Asistencia Técnico-Científica a los fines de asistir al COE y, desde un primer momento, la 
Oficina Regional Patagónica de la Dirección Nacional de Protección Civil se asesoró para la conformación de dicho COE.

- se buscó garantizar la transitabilidad en los barrios más afectados para que pudiera circular el personal abocado al mantenimiento del sistema eléctrico y asistencia a los pobladores.

- garantizar el suministro de energía eléctrica, dado que el sistema es muy vulnerable a los efectos de la ceniza, la cual tiene una gran capacidad conductora de la electricidad. Por ello, se debió reemplazar las piezas del sistema de distribución y transmisión eléctricas.

- dar apoyo a las familias afectadas en la reparación y apuntalamiento de techos de viviendas precarias.

- el Grupo de Búsqueda y Rescate en Zonas Agrestes (BRZA) apoyó las áreas de limpieza de techos, distribución de agua, control de nivel de los cauces, relevamientos de las familias y viviendas en zonas inundables y con posibilidad de ser afectadas por lahares secundarios.

- se priorizó asegurar el abastecimiento de agua potable de calidad, para lo cual se analizaron muestras de agua del lago Nahuel Huapi y de arroyos próximos la ciudad para verificar la posible presencia de contaminantes inorgánicos aportados por la ceniza (Wilson et al., 2013, p. 55). A su vez, la capacidad de la ceniza de anular el efecto del cloro en el agua, llevó a elevar sustancialmente la clorinación de la misma para el suministro de agua de red.

- fuentes consultadas a la Subsecretaría de Desarrollo Social de Villa La Angostura sostuvieron que durante la emergencia se distribuyeron módulos alimentarios de la siguiente manera:

- Junio: 1450 módulos alimentarios.

- Julio: 800 módulos alimentarios, ya ordenada la entrega en forma quincenal.

- Agosto: 690 módulos alimentarios.

- Septiembre: Se regulariza la entrega de módulos alimentarios una vez por mes y se entregan 700 .

- En Octubre, Noviembre y Diciembre, se entregan mensualmente los módulos alimentarios a razón de 700 módulos por mes.

Las medidas adoptadas con posterioridad a la emergencia, según manifestaron diversas fuentes municipales como la Dirección de Bromatología, Dirección de Agua y la Secretaría de Servicios públicos) apuntaron a reducir la vulnerabilidad del sistema de 
provisión de agua y la protección de las captaciones. En tal sentido, se instalaron filtros de agua, se reemplazaron algunas bombas (en los barrios Las Bandurrias, Puerto Manzano, Calfuco) y determinadas captaciones localizadas en arroyos cercanos a la ciudad fueron excluidas del sistema de abastecimiento, como fueron los casos del arroyo Las Piedritas y el río Bonito, que beneficiaron al servicio de agua de red pública en toda la localidad, pero cuyos beneficios se visualizaron muy fuertemente en los barrios del sudeste como Puerto Manzano y Calfuco.

Asimismo, se implementó un sistema de alerta ante el desborde de arroyos dado que, muchos de ellos, continuaron con una importante carga sedimentaria aún después de varios meses de finalizada la erupción. Si bien estas medidas se orientan a una reducción de la vulnerabilidad, el proceso es muy complejo y las experiencias transitadas cooperan para enfrentar de una mejor manera un nuevo evento eruptivo, siendo fundamental en este esquema la continua preparación de la población y las autoridades, incluyendo al riesgo volcánico como parte de la realidad de Villa La Angostura.

En el caso de San Carlos de Bariloche y Dina Huapi, gran parte de los inconvenientes se produjeron en el sistema de abastecimiento de agua potable. Es por ello que durante la emergencia volcánica se conformó una mesa de trabajo donde se evaluaron las medidas a seguir. El manejo del servicio de agua potable consistió en disminuir el caudal del agua extraída para reducir el ingreso de cenizas al sistema. Además, se hizo decantar el material ingresado y se monitorearon los niveles de turbidez. Por otra parte, se realizaron análisis químicos en tres puntos del lago Nahuel Huapi, principal fuente de captación: frente a la localidad de Dina Huapi, frente a la ciudad de San Carlos de Bariloche y en el Brazo Campanario.

A mayor turbidez, el cloro es menos efectivo y es por esta razón que se aumentó la clorinación del agua. La medida adoptada condujo a elevar los niveles de cloro de 0.2 ppm a 0.5 ppm medidos en el extremo de la red. Además, la abrasión producida por las cenizas en las bombas trajo problemas al abastecimiento en algunos barrios como Nahuel Malal, Casa de Piedra y Melipal, entre otros. El problema se solucionó con un mantenimiento anticipado del sistema de extracción, pero la abrasión redujo la vida útil de la maquinaria de 10 a 6 años aproximadamente.

En el caso particular de la toma de agua de Las Vertientes, procedente de manantiales, el agua se capta a través de canales presentando una alta susceptibilidad ambiental por elevada exposición a la caída de ceniza volcánica. Por este motivo, la emergencia de 2011 requirió un mantenimiento constante de los canales. La situación de esta fuente es más 
delicada aún al presentar una fuerte erosión y, la ausencia de cobertura vegetal, conduce a una colmatación de los canales con las lluvias.

En San Carlos de Bariloche, se conformó la Junta Municipal de Defensa Civil convocada por el intendente para las 17 horas del día 4 de Junio. Desde allí, se acordaron diversas medidas desde diferentes organismos públicos. Desde ese día y por espacio de un año, se declara la emergencia económica y social de la ciudad de San Carlos de Bariloche (Ordenanza N²188-CM-11).

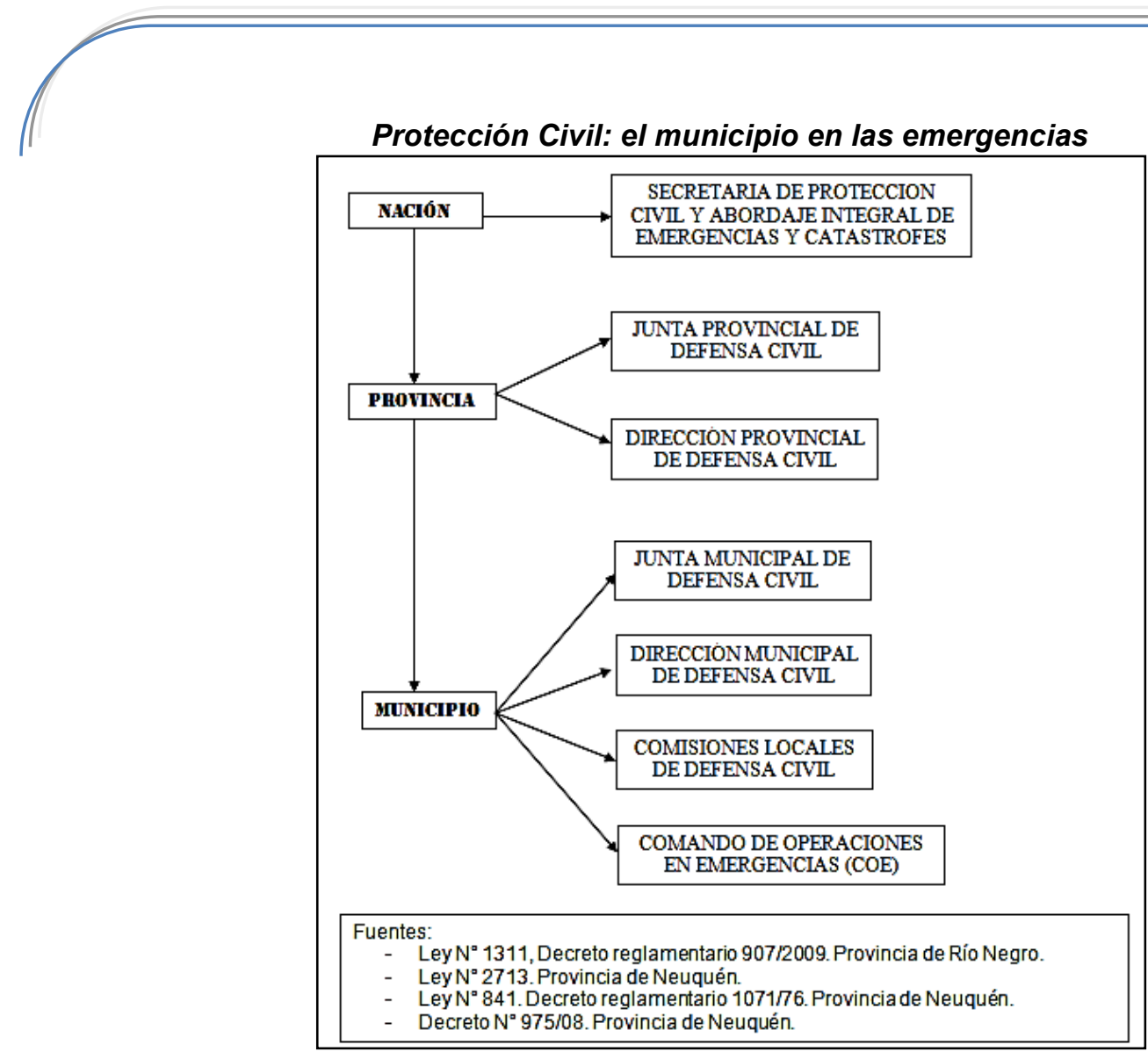

Si bien la estructura que ordena la Defensa Civil en Argentina es compleja, este cuadro sintetiza las relaciones entre niveles administrativos. El más interesante a los fines de esta propuesta es el nivel municipal, donde adquieren relevancia las Juntas Municipales de Defensa Civil y la conformación de los Comandos de Operaciones en Emergencia (COE) para la atención de las emergencias. Fuente: elaboración propia.

Puntualmente, desde el área Protección $\mathrm{Civil}^{9}$ se llevaron a cabo diferentes tareas que consistieron en:

\footnotetext{
${ }^{9}$ Entrevista a informante calificado, responsable técnico del área de Protección Civil de Bariloche en momento de la emergencia volcánica de la erupción del Cordón Caulle en 2011.
} 
- Establecer una comunicación permanente con la población a través de la televisión y radios que tenían guardia permanente las 24 horas.

- distribuir agua sobre los sectores que tenían mayor problema, en un trabajo conjunto con el Ejército, que trajo su planta potabilizadora.

- repartir barbijos: llegaron a Bariloche unos 150 mil barbijos y todos fueron repartidos a la población.

- Asesorar en tareas de limpieza, que estuvo a cargo de la municipalidad, la cual cubrió los costos de dichas tareas, a la que se sumaron fondos de créditos obtenidos, sobre todo de la CAF (Corporación Andina de Fomento).

- Asistencia en la limpieza y apuntalamiento de techos. Junto con Bomberos se hizo limpieza de techos de los edificios públicos y escuelas. Con respecto a la disposición final de la ceniza, en un principio hubo una pequeña descoordinación y se empezó a arrojar la ceniza a las playas, sobre todo en aquellas que no eran de acceso público y dados los perjuicios que eso podía acarrear, se empezó a depositar en la cantera municipal (en la cantera que se utiliza para disponer los residuos forestales) y también se hizo bastante acopio en la zona del barrio Ñireco porque no había más lugar, ya que la cantera colapsó. Allí la municipalidad cuenta con un depósito muy grande, donde se apiló la ceniza y, desde Defensa Civil, se solicitó que se cubra con tierra para evitar su removilización.

- Asistir a comunidades satélites de San Carlos de Bariloche, con Gendarmería y el Ejército. En las comunidades de la Línea Sur (principalmente Pilcaniyeu y Jacobacci), la asistencia consistió sobre todo en la entrega de fardos para alimentar el ganado y reparto de ropa para la población.

- Trabajar en conjunto con otros organismos públicos en materia de:

- Agua potable: el Departamento Provincial de Aguas (DPA) enviaba a Protección Civil casi a diario los informes de calidad de agua donde mostraba como estaba cada una de las bocas.

- Salud: el entonces director del Hospital siguió el procedimiento de la Organización Panamericana de la Salud. Entre otras medidas, se externaron pacientes, es decir, los que no merecían permanecer en el Hospital fueron derivados a sus hogares y se paró el quirófano (hubo problema con el techo del Hospital, por acumulación de ceniza y por el estado del techo). Las atenciones en la guardia no se incrementaron significativamente, sino que se manejaron niveles de consulta normales (sólo emergieron algunos problemas menores como irritación ocular y dificultades respiratorias). 
Por su parte, la red cloacal, sólo presente en San Carlos de Bariloche, registró algunas dificultades para operar durante la caída de cenizas de 2011. La Cooperativa de Electricidad Bariloche (CEB), a cargo del servicio de tratamiento de efluentes cloacales posee una planta de fango biológico activado de aireación extendida tipo carrusel (conocida también como de tipo flujo en pistón), donde todo el proceso se realiza a cielo abierto (Figura $\mathrm{N}^{\circ} 7$ ). Actualmente hay unas 27.000 viviendas ${ }^{10}$ conectadas al sistema que generan unos 250 litros/habitante al día, que es el cálculo que se estima que se procesan, lo que representa entre 5 y 6 mil kg al día de DBO (demanda biológica de oxígeno).

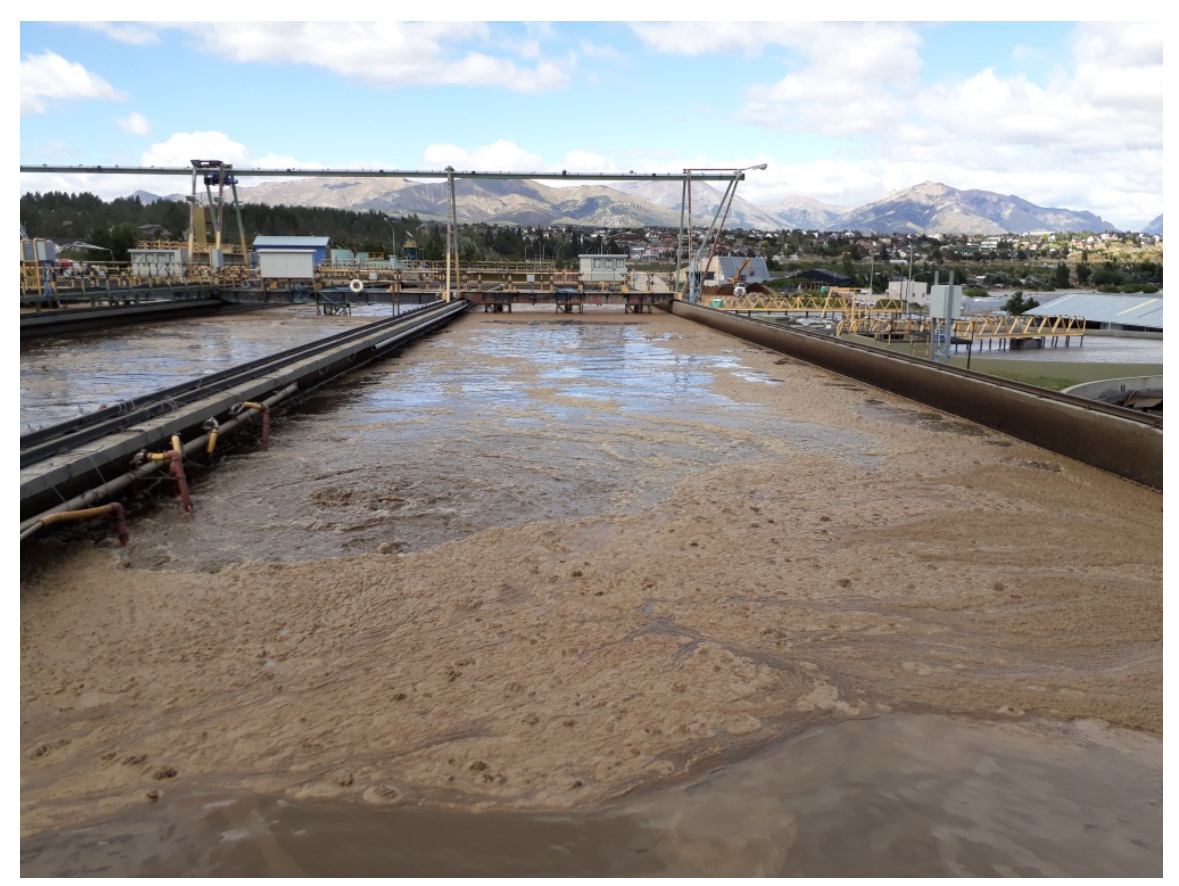

Figura $\mathrm{N}^{\circ} 7$. Vista del reactor de la planta de tratamiento de efluentes cloacales de San Carlos de Bariloche. Actualmente se encuentra en ampliación a través de la construcción del segundo módulo. A excepción del sector de procesamiento de barros, el resto de la planta opera a cielo abierto, infraestructura ampliamente expuesta a la caída de material piroclástico. Fuente: foto del autor (8 de febrero de 2018).

La ceniza volcánica producto de la erupción del Cordón Caulle iniciada el 4 de Junio de 2011 no afectó de manera significativa el funcionamiento ni se registraron variaciones en el tratamiento biológico. Un Informe interno señalaba que hasta el 23 de Junio no había efectos en la planta y el día 29 de junio se hacen nuevos controles por la Universidad Nacional del Comahue (UNCo Bariloche) que no mostraron alteraciones en los resultados.

${ }^{10}$ Este dato representa cerca de un $90 \%$ del total estimado para principios de 2018 según la fuente consultada. El resto de las viviendas destinan sus efluentes principalmente a cámara séptica o pozo ciego. 
La abrasión de piezas metálicas no condujo a la necesidad de cambiarlas pero sí se debieron adelantar los mantenimientos. Las rejas primarias y secundarias son los únicos filtros que poseen pero no presentaron problemas de obstrucción dado que sólo retienen los grandes residuos.

Si bien no hay datos disponibles acerca de los operativos de limpieza realizados en la planta $^{11}$, se sabe que aproximadamente el reactor perdió un metro de volumen. Las cenizas colectadas del sistema tuvieron tres destinos: parte fue al vertedero municipal, parte quedó en los barros que se destinaron a compostado y parte en las piletas de tratamiento de barros.

Actualmente no cuentan con un plan frente a nuevas erupciones aunque tienen protocolos básicos de actuación como, por ejemplo, cortar las bombas. Para continuar operando frente a posibles cortes de energía -algo frecuente en episodios de caída de ceniza volcánica-, cuentan con dos generadores (grupos electrógenos) sobre todo para garantizar la salida de efluentes al lago.

La ceniza volcánica de Calbuco en 2015 no condujo problemas de funcionamiento en la planta, sobre todo, por el escaso material piroclástico caído en el entorno a San Carlos de Bariloche. Actualmente la planta se encuentra en proceso de ampliación para cubrir todas las necesidades de la población creciente que tiene esta localidad.

En lo que respecta a los desagües pluviales, las localidades de Villa La Angostura y Dina Huapi poseen mayormente un escurrimiento superficial, que facilitó la limpieza de la ceniza (sólo algunas alcantarillas forman parte de la red, sobre todo, en aquellos sectores atravesados por algún curso de agua o una ruta).

San Carlos de Bariloche, la localidad más extensa y poblada, posee una red de desagüe más compleja, donde combinan un sistema a cielo abierto en las afueras de la localidad con un sistema de redes de cañerías y alcantarillas en área comprendida por el casco urbano.

Entre las cinco delegaciones (Sur, Cóndor, lago Moreno, Cerro Otto y servicios públicos -microcentro-) totalizaron 100 personas abocadas a las tareas de limpieza (sólo en servicios públicos trabajaron 30 personas entre maquinistas y cuadrilla). Estas tareas implicaron un trabajo sostenido de dos meses donde se combinó el trabajo de camiones municipales y privados, aunque luego sólo quedaron trabajando los municipales, dando prioridad a la limpieza del microcentro y al recorrido del transporte público.

\footnotetext{
${ }^{11}$ Hacia el 24 de junio de 2011, la Agencia de Noticias Bariloche (ANB) sostenía que unos "40.000 kilos de ceniza reducen la capacidad operativa de la planta depuradora" (ANB, 24 de Junio de 2011).
} 
El destino que le dieron al material recolectado fue principalmente la cantera municipal: se hizo acopio en la delegación El Cóndor (sobre calle Esandi) y en la cantera municipal (Barrio Omega).

Entre los impactos se cuenta el incremento en el mantenimiento de los vehículos de trabajo: cada dos días se hacía cambio de filtros de toda la flota (filtro de aire, aceite, combustible). Asimismo, estiman desde el área que la ceniza en el sistema permaneció por lo menos un año luego de iniciada la erupción. A diferencia de la situación previa, en la actualidad se cuenta con 40 contenedores (volquetes) y un Vactor (camión desobstructor con agua a presión) que fue adquirido por la municipalidad luego de iniciada la erupción.

Similar a lo sucedido en la planta depuradora, en los sistemas pluviales tampoco se registraron problemas en 2015 con la erupción del Volcán Calbuco en abril de ese año.

\subsubsection{Efectos en la actividad turística}

El turismo es la principal actividad económica de la región del Nahuel Huapi. El comienzo de la erupción del Cordón Caulle en 2011 prácticamente coincidió con el inicio de la temporada invernal, la cual se vio seriamente afectada por la caída de cenizas. Por ejemplo, las excursiones lacustres, algunas de las cuales se realizan desde Puerto Pañuelo hacia Puerto Blest, Bosque de Arrayanes e Isla Victoria debieron suspenderse. La ceniza y piedras pómez suspendidas en el lago dificultaron la navegación, siendo su presencia un elemento altamente abrasivo para las hélices de los motores. Desde una de las empresas prestatarias del servicio de transporte lacustre se informó que desde el 4 de junio (día que comenzó la erupción) dejaron de operar hasta el día 15 de ese mes, cuando restituyeron la conexión con Puerto Blest. Recién hacia el día 18 de julio, restituyeron el servicio a Isla Victoria. La diferencia de más de un mes entre el servicio hacia ambos sitios se debió a dos motivos: a través de Puerto Blest se realiza el Cruce Andino (es decir, que había que llevar pasajeros a la vez que traer personas que viajan hacia Chile o Argentina a través del paso Internacional Vicente Pérez Rosales) y, además, casi no había turistas para transportar a Isla Victoria. Como la ceniza afectaba los motores, las embarcaciones salían en tándem: se partía en un barco y de ahí se realizaba un trasbordo a otro barco de modo tal que el material piroclástico que estaba acumulado en la costa no afectaba significativamente a los motores de las embarcaciones principales. Entre los efectos secundarios se cuenta el mantenimiento más frecuente de las unidades, sobre todo el cambio permanente de filtros. 
Las pérdidas económicas estimadas por la caída de ceniza en las localidades más impactadas de la región (Cuadro $\mathrm{N}^{\circ} 4$ ) y publicadas por diferentes periódicos se resumen a continuación.

\begin{tabular}{|c|c|c|}
\hline \multicolumn{1}{|c|}{ Estimación de las pérdidas } & Fuente & $16-06-2011$ \\
100 millones de dólares en Bariloche & Infobae on line & \\
$\begin{array}{c}109 \text { millones de dólares, según Confederaciones Rurales } \\
\text { Argentinas (CRA), en el sector agropecuario de Neuquén, Río } \\
\text { Negro y Chubut. }\end{array}$ & El Mercurio on line & $18-06-2011$ \\
145 millones de dólares en el sector turístico de Bariloche y \\
Villa La Angostura. & & $4-08-2011$ \\
\hline $\begin{array}{c}1.200 \text { millones de pesos, sólo en Bariloche. } \\
\text { 1.476 millones de pesos en ingresos por turismo entre Junio y } \\
\text { Diciembre de } 2011, \text { según el Centro de Estudios Regionales de } \\
\text { la Universidad FASTA. }\end{array}$ & Cronista on line & $16-03-2012$ \\
\hline $\begin{array}{c}\text { 1.200 millones de pesos (277 millones de dólares), sólo en } \\
\text { Bariloche, según el Colegio de Graduados en Ciencias } \\
\text { Económicas de la Zona Andina. }\end{array}$ & $\begin{array}{c}\text { Agencia EFE, en La } \\
\text { Información on line }\end{array}$ & $29-05-2012$ \\
\hline
\end{tabular}

Cuadro $\mathrm{N}^{\circ}$ 4: Pérdidas económicas estimadas para la erupción del Cordón Caulle según fuentes periodísticas. Fuente: elaboración propia sobre la base de publicaciones periodísticas.

En primer lugar, se debe destacar la dificultad de contar con datos precisos dado que muchas estimaciones se realizaron en el transcurso de la erupción, es decir que se trata de valoraciones parciales. En segundo lugar, las fuentes coinciden en que los mayores daños se reportaron en los sectores agropecuario -que tienen lugar en el área de la estepa patagónica- y turístico -sobre el área cordillerana-, siendo mayores las pérdidas económicas en este último sector.

\subsubsection{El turismo en San Carlos de Bariloche}

En el período comprendido entre 2005 y 2012, se observa un comportamiento dispar en los indicadores sobre la actividad turística (Cuadro $N^{\circ} 5$ ). El número de plazas disponibles se incrementó un 9,2\% alcanzando su máximo valor en 2008. La ocupación anual alcanzó su mayor valor en 2006 y 2007, correspondiendo su mínimo al año 2011 en coincidencia con la erupción del Cordón Caulle. 
La cantidad de turistas alojados alcanzó su máximo en 2006 y a partir de allí comenzó a descender. La caída en el número de turistas se prolongó en los años 2008 y 2009. Sorpresivamente, el 2 de Mayo de 2008 el volcán Chaitén entra en erupción afectando principalmente a la ciudad de Esquel, en la provincia de Chubut, distante 300 kilómetros al sur de Bariloche. Esto puso en evidencia la capacidad de las erupciones volcánicas para afectar las economías locales incluidas las de Villa La Angostura y San Carlos de Bariloche, donde debieron suspenderse varios vuelos programados. Por último, la aparición y difusión de la Gripe A en 2009 condujo a un nuevo descenso en la cantidad de turistas alojados.

El valor mínimo de turistas alojados se alcanzó en 2011 como consecuencia de la erupción del Cordón Caulle. En este sentido, las comunicaciones y el tránsito se vieron dificultados, y los aeropuertos cercanos a la región del Nahuel Huapi, como los de Neuquén y Chapelco permanecieron cerrados por largos períodos ${ }^{12}$, viéndose especialmente afectado el aeropuerto de San Carlos de Bariloche donde los vuelos se restituyeron recién el día 13 de enero de 2012, más de siete meses después de iniciada la erupción.

\begin{tabular}{|c|c|c|c|}
\hline AÑO & $\begin{array}{c}N^{\circ} \text { de } \\
\text { Plazas } \\
\text { disponibles }\end{array}$ & $\begin{array}{c}\text { Ocupación } \\
\text { anual (en \%) }\end{array}$ & $\begin{array}{c}\text { Cantidad de } \\
\text { turistas } \\
\text { alojados }\end{array}$ \\
\hline 2005 & 17432 & 54 & 727784 \\
\hline 2006 & 17660 & 55 & 804823 \\
\hline 2007 & 18273 & 55 & 791633 \\
\hline 2008 & 19950 & 52 & 771028 \\
\hline 2009 & 18574 & 46 & 599052 \\
\hline 2010 & 19165 & 51 & 684872 \\
\hline 2011 & 19259 & 39 & 530008 \\
\hline 2012 & 19029 & 45 & 615756 \\
\hline
\end{tabular}

Cuadro $N^{\circ} 5$ : Evolución de las plazas de alojamiento, niveles de ocupación hotelera y cantidad de turistas alojados en la localidad de San Carlos de Bariloche. Período 2005-2012. Fuente: Elaboración propia sobre la base de datos de la Encuesta de Ocupación Hotelera. Secretaría de Turismo. Municipalidad de San Carlos de Bariloche.

Un rasgo sobresaliente de la actividad en Bariloche es el turismo estudiantil, cuya temporada se inicia en junio y finaliza en enero del año siguiente. Si se observa su evolución, la temporada 2005-2006 alcanza su máximo y la correspondiente a 2009-2010 su mínimo, iniciando su recuperación hacia finales del período analizado (Cuadro $\mathrm{N}^{\circ} 6$ ).

\footnotetext{
12 Durante los meses de junio 2011 a marzo de 2012 el Aeropuerto Chapelco permanece cerrado a vuelos comerciales por erupción, registrando sólo movimientos de vuelos particulares, destacándose el mes de agosto de 2011 por el ingreso de vuelos particulares de gran porte, con turistas de diferentes Nacionalidades, a fin de mantener la temporada invernal. Fuente: Dirección Provincial de Estadística y Censos de la Provincia del Neuquén, en base a datos suministrados por la Subsecretaría de Turismo de la Provincia del Neuquén.
} 


\begin{tabular}{|c|c|}
\hline AÑO & $\begin{array}{c}\text { Cantidad de } \\
\text { turistas }\end{array}$ \\
\hline $2005-2006$ & 122830 \\
\hline $2006-2007$ & 118484 \\
\hline $2007-2008$ & 115860 \\
\hline $2008-2009$ & 108529 \\
\hline $2009-2010$ & 105873 \\
\hline $2010-2011$ & 106170 \\
\hline $2011-2012$ & 106245 \\
\hline $2012-2013$ & 115480 \\
\hline
\end{tabular}

Cuadro Nº6: Evolución del turismo estudiantil en San Carlos de Bariloche. Período 2005-2012.

Fuente: Elaboración propia sobre la base de datos de la Encuesta de Ocupación Hotelera. Secretaría de Turismo. Municipalidad de San Carlos de Bariloche.

Se deben destacar dos aspectos de este turismo en particular. En primer lugar, cuando el número total de turistas alcanza su menor valor en el año 2011, el ingreso de estudiantes prácticamente se conservó representando el 20\% del conjunto de turistas que visitó Bariloche ese año. En segundo lugar, es factible que el ingreso de estudiantes no decayera debido a la manera en que se efectúa la compra de los paquetes, la cual se realiza con marcada anterioridad a la fecha de realización del viaje.

\subsubsection{El turismo en Villa La Angostura}

La economía de Villa La Angostura también tiene su eje en el turismo. Si bien esta actividad registró un crecimiento casi permanente en capacidad hotelera, la cantidad de turistas alojados presentó numerosas fluctuaciones (Cuadro №7).

\begin{tabular}{|c|c|c|c|}
\hline AÑO & $\begin{array}{l}N^{\circ} \text { de } \\
\text { Plazas }\end{array}$ & $\begin{array}{c}\text { Ocupación } \\
\text { anual (en \%) }\end{array}$ & $\begin{array}{c}\text { Cantidad de } \\
\text { turistas alojados }\end{array}$ \\
\hline 2005 & 3591 & 32,10 & 75745 \\
\hline 2006 & $3782^{*}$ & 32,50 & 83559 \\
\hline 2007 & $3893^{*}$ & 34,50 & 94456 \\
\hline 2008 & $3954^{\star}$ & 32,20 & 87091 \\
\hline 2009 & $4059^{*}$ & 30,80 & 85238 \\
\hline 2010 & $4177^{\star}$ & 34,50 & 97467 \\
\hline 2011 & $4113^{*}$ & 25,40 & $\star \star 54191$ \\
\hline 2012 & $4161^{\star}$ & 29,20 & 76947 \\
\hline
\end{tabular}

Cuadro N7: Evolución de las plazas de alojamiento, niveles de ocupación hotelera y cantidad de turistas alojados en la localidad de Villa La Angostura (Neuquén). Período 2005-2012.

${ }^{*}$ Mes de enero.

**Datos estadísticos al mes de Mayo de 2011.

Fuente: Elaboración propia sobre la base de datos de la Secretaría de Turismo. Municipalidad de Villa La Angostura. 
Nuevamente, los descensos registrados en 2008 y 2009 reflejan el impacto de la erupción del volcán Chaitén y la aparición de la gripe A en los años 2008 y 2009, respetivamente. En el año 2011, como producto de la erupción del Complejo Volcánico Puyehue-Cordón Caulle, el número de turistas alojados registró una caída de aproximadamente un $45 \%$ con respecto al año anterior.

Como se señaló anteriormente, dado que la erupción se inició el 4 de Junio de 2011 y la prolongación de la emisión de cenizas se extendió por meses, la principal temporada afectada fue el invierno y, en este sentido, la ausencia de datos estadísticos refleja el impacto que tuvo la erupción en el turismo local (Cuadro N8).

\begin{tabular}{|c|c|c|}
\hline Temporada Invernal & Periodo & Plazas (en \%) \\
\hline Julio 2006 & $15 / 07$ al 04/08 & 48,1 \\
\hline Julio 2007 & $07 / 07$ al 03/08 & 40,06 \\
\hline Julio 2008 & $12 / 07$ al 09/08 & 38 \\
\hline Julio 2009 & $06 / 07$ al 01/08 & 38,7 \\
\hline Julio 2010 & $05 / 07$ al 01/08 & 46,25 \\
\hline Julio 2012 & $08 / 07$ al 28/07 & 72,3 \\
\hline Julio 2013 & $08 / 07$ al 28/07 & 58,1 \\
\hline
\end{tabular}

Cuadro №8: Evolución de la ocupación en temporada invernal. Período 2006-2013. Erupción del Cordón Caulle 4 de Junio 2011.

*2011: Sin Datos Estadísticos.

Fuente: Elaboración propia sobre la base de datos de la Secretaría de Turismo. Municipalidad de Villa La Angostura.

Si bien el impacto de la caída de cenizas fue significativo en los niveles de ocupación, resulta interesante señalar que prácticamente no se perdieron plazas hoteleras durante el año 2011. Una de las razones puede encontrarse en que la temporada de verano anterior a la erupción presentó altos niveles de ocupación, situación que permitió sobrellevar la caída de la actividad generada posteriormente por la erupción. Por otra parte, la rápida recuperación de la ciudad cooperó para que en la temporada estival siguiente se eleve la ocupación. Esta situación se consolidó en el invierno de 2012, el cual presentó los niveles de ocupación más altos de los últimos años.

Datos de la Secretaría de Turismo local señalan que en la temporada invernal de 2011 se mantuvieron las tarifas de la temporada media debido a la erupción, aunque los datos indican que en varias categorías de alojamiento se registró un marcado descenso de los valores del alojamiento, en algunos casos muy superiores al $20 \%$. 
En cercanías de Villa La Angostura se encuentra el Paso Internacional Cardenal Samoré, que comunica Argentina con Chile, siendo el paso más importante de la región del Nahuel Huapi por el movimiento de personas que registra esta conexión vial (Figura N8).

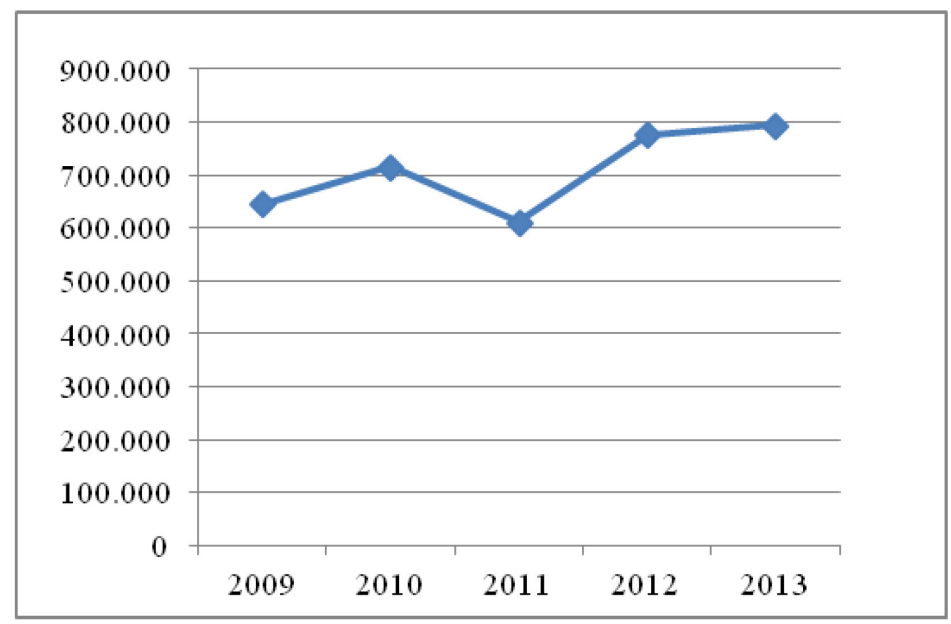

Figura N ${ }^{\circ}$ 8. Movimiento Total de Personas a través del Paso Internacional Cardenal Samoré. Período 2009-2013. Fuente: elaboración propia sobre la información suministrada por Dirección Provincial de Estadística y Censos de la Provincia del Neuquén, en base a datos suministrados por Gendarmería Nacional - Agrupación XII "Comahue".

Esta información complementaria refuerza los impactos de la erupción a la actividad turística. En el quinquenio 2009-2013 la tendencia al incremento del flujo de personas se ve interrumpida en el año 2011, momento en el cual se registra un descenso aproximado del $15 \%$ del total de personas que atravesaron el paso internacional.

Los efectos directos de la caída de material piroclástico, expresados en la reducción de la visibilidad, se suman a los indirectos como la posibilidad que se desarrollen avalanchas de nieve y lahares secundarios. Esta última amenaza se concretó, como se señaló en el Capítulo I, cuando a una semana de iniciada la erupción, la ruta que conecta Argentina con Chile a través del paso internacional Cardenal Samoré quedó destruida por una avalancha de cenizas y arena volcánica, provocada por las fuertes lluvias que afectaron la región (Los Andes, edición digital, 11 de Junio de 2011).

\subsection{Impactos en la ganadería}

En términos generales, como resultado de la erupción del Cordón Caulle en 2011, las consecuencias más importantes a la ganadería (Figura $\mathrm{N}^{\circ} 9$ ) fueron las pérdidas por inanición, bloqueos del rumen y desgaste de la dentadura de los animales (Wilson et al., 2013, p. 57). 


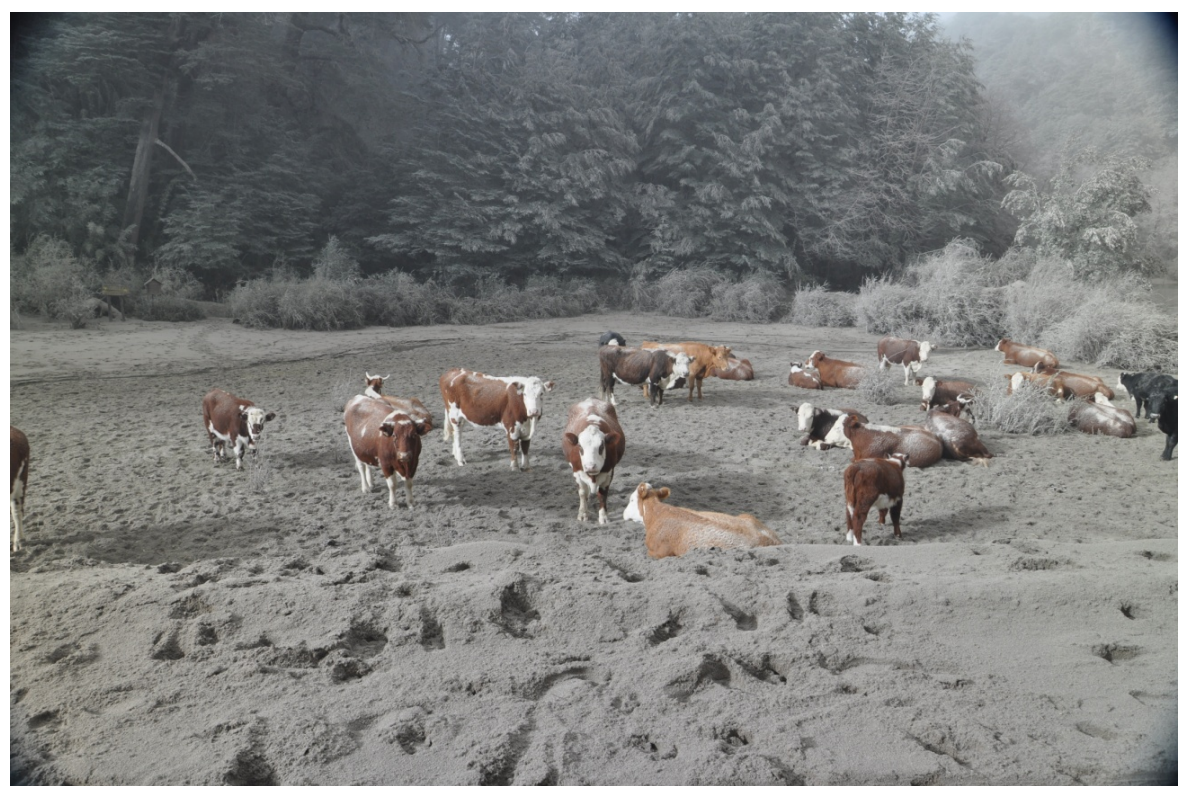

Figura $\mathrm{N}^{\circ}$ 9. Impacto de las caídas de ceniza volcánica. Grandes depósitos de cenizas y pómez cubrieron la vegetación en áreas cercanas a Villa La Angostura, departamento Los Lagos, Neuquén. La erupción del Cordón Caulle en 2011 afectó también los departamentos cordilleranos de Bariloche (Río Negro) y Lácar (Neuquén). Fuente: imagen captada por Villarosa y Outes, 3 de Octubre de 2011.

En la estimación de las consecuencias de la erupción en el departamento Los Lagos, Anselmi et al. (2012) sostienen que el índice de mortandad promedio ascendió a $21 \%$ de vientres (madres) considerando ovinos, bovinos y caprinos ${ }^{13}$ (p. 20) pero los autores agregan que la situación en la zona de los Parques Nacionales es compleja. Para el caso de Los Lagos, tanto la capacidad productiva como la tenencia precaria de la tierra, por encontrarse en jurisdicción de Parques Nacionales, los limita para acceder a créditos que les permitan ampliar la producción (p. 13).

\subsection{Aspectos metodológicos: indicadores censales y estimación de la vulnerabilidad}

En el Capítulo I se analizaron diferentes acepciones para el término vulnerabilidad, destacándose la importancia que tienen las condiciones socioeconómicas anteriores a un evento de desastre. Dado que la erupción del Cordón Caulle se inicia en el año 2011, emerge la oportunidad de evaluar el estado antecedente tomando los datos proporcionados por el Censo Nacional de Población, Hogares y Viviendas realizado en todo el territorio nacional en el año 2010, unos meses antes de iniciado el proceso eruptivo antes desarrollado.

\footnotetext{
${ }^{13}$ Las pérdidas ganaderas en el departamento Los Lagos totalizaron 865 bovinos -22\%-, 357 ovinos - $19 \%$ - y 88 caprinos -20\%- (Anselmi et al., 2012, p. 20).
} 
Los censos nacionales de población constituyen una fuente inagotable de información que resulta sumamente relevante para evaluar aspectos sociales de diversa naturaleza, entre los que se encuentra la vulnerabilidad social. La peligrosidad volcánica, y particularmente la caída de cenizas, comprenden un conjunto de características particulares que requieren de una serie de indicadores que se complementan entre sí para evaluar la vulnerabilidad de una comunidad frente a esta amenaza.

En sintonía con las diferenciaciones espaciales tratadas también en el Capítulo I, sobresale que la aplicación más interesante de estos datos se encuentra a una escala de radios censales, lo que permite una mejor diferenciación de los distintos indicadores en cada localidad, a la vez que permite una aproximación los barrios que conforman un determinado espacio urbano.

En síntesis, la metodología a la que se recurrió consiste la selección de indicadores censales, su posterior procesamiento y clasificación utilizando intervalos naturales, definiéndose cinco intervalos: muy alto, alto, medio, bajo, muy bajo. Dichos indicadores fueron representados cartográficamente por radios censales en un sistema de información geográfica $^{14} \mathrm{y}$, de este modo, se confeccionaron mapas de la vulnerabilidad social frente a la caída de ceniza volcánica a partir de diversas estrategias metodológicas.

4.4.1 El rol de las condiciones demográficas y habitacionales en la vulnerabilidad frente a la caída de ceniza volcánica

Las diferenciaciones territoriales al interior de las localidades costeras del lago Nahuel Huapi son relevantes para la comprensión de la vulnerabilidad social. Los diferentes indicadores presentados en esta sección se representan según radios censales ${ }^{15}$, haciendo factible un acercamiento al problema según los barrios que componen cada localidad (Figuras $\mathrm{N}^{\circ} 10$ y $\left.\mathrm{N}^{\circ} 11\right)$.

\footnotetext{
${ }^{14}$ Se utilizó el software libre GVSIG versiones 1.11 .0 y 1.12.0.

15 Los datos utilizados para este trabajo, obtenidos del Censo Nacional de Población, Hogares y Viviendas 2010 , se encuentran disponibles en el Anexo.
} 


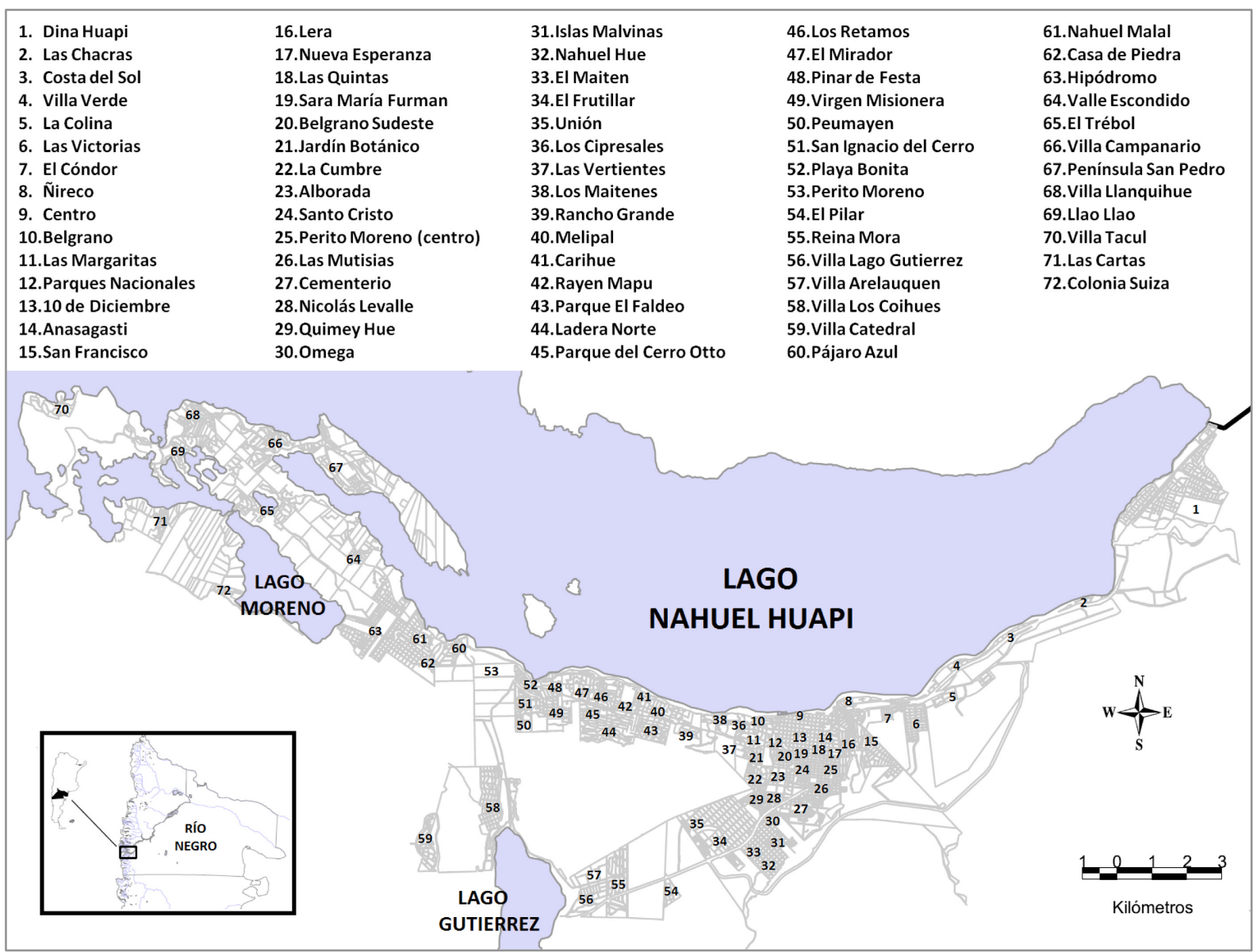

Figura $N^{\circ} 10$. Barrios y localidades que componen el espacio urbano de Bariloche y Dina Huapi. Cerca de un centenar de barrios y pequeñas localidades configuran un amplio espacio urbano, con aproximadamente 50 kilómetros de costa sur sobre el lago Nahuel Huapi desde Dina Huapi, en el extremo oriental, hasta Villa Tacul, en el sector más occidental. Fuente: elaboración propia. 


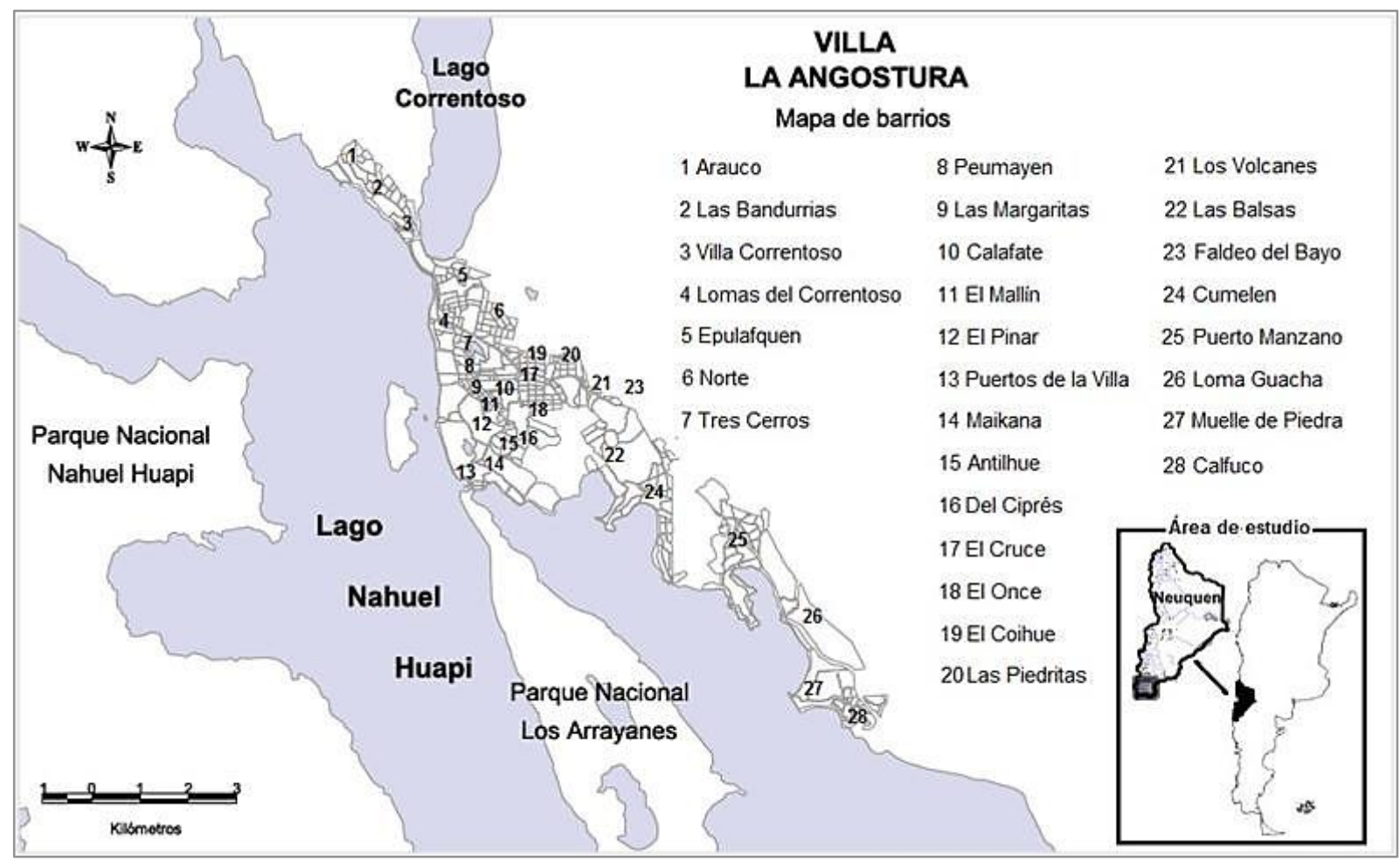

Figura $\mathrm{N}^{\circ}$ 11. Barrios que componen la localidad de Villa La Angostura. Villa La Angostura, la localidad más austral de la provincia de Neuquén, tiene un área urbana con un trazado general en sentido Noroeste-Sudeste. Se encuentra rodeada por los Parques Nacionales Arrayanes y Nahuel Huapi y está compuesta por más de una veintena de barrios que se extienden a lo largo de unos $16 \mathrm{~km}$. acompañando las costas de los lagos Nahuel Huapi y, en menor medida, Correntoso. Fuente: elaboración propia.

\subsubsection{Tasa de desocupación}

Un indicador socioeconómico importante es la tasa de desocupación (Figuras $\mathrm{N}^{\circ} 12$ y $N^{\circ} 13$ ) la cual representa, según el INDEC, el porcentaje entre la población desocupada y la población económicamente activa brindando información sobre la proporción de personas que están demandando trabajo y no lo consiguen (INDEC, 2013, p. 2). Si bien es conveniente emplear el concepto de desocupación ${ }^{16}$, Natenzon y González (2010) sostienen que el desempleo y sus variantes, señalan diferentes grados de carencia respecto a un sostén económico del hogar y, por lo tanto, una mayor vulnerabilidad frente a los desastres (p. 201).

\footnotetext{
${ }^{16}$ Las estadísticas miden desocupación.
} 


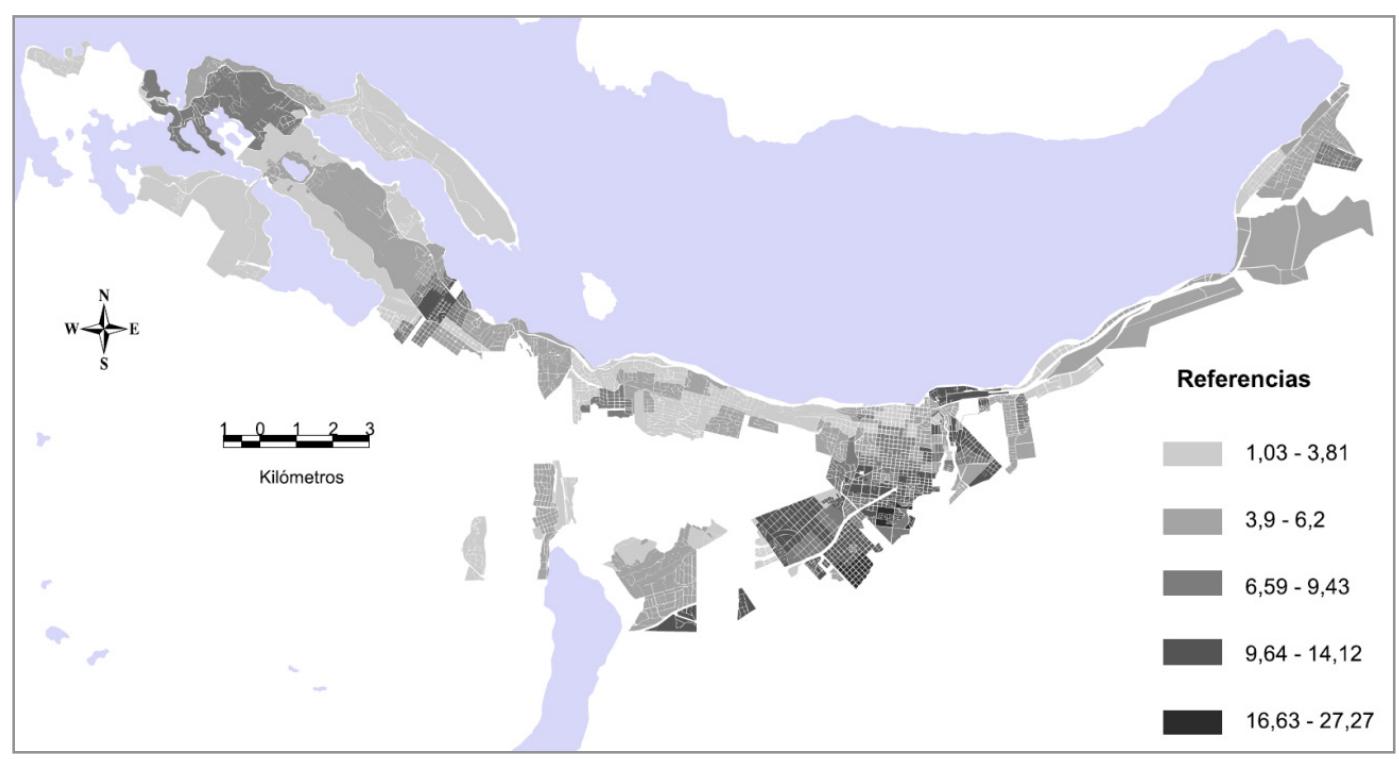

Figura №12. Desocupación (en \%). San Carlos de Bariloche y Dina Huapi. 2010. Los valores más altos de desocupación se encuentran en los sectores Sur (barrios Malvinas, Nahuel Hue, El Maitén, El Pilar, El Frutillar, Cementerio) y centro-Oeste (Nahuel Malal, Casa de Piedra). En el Este (parte de Dina Huapi) y el Oeste (Llao Llao, Villa Llanquihue) los valores de desocupación son intermedios. Fuente: elaboración propia en base a datos del INDEC. Censo Nacional de Población, Hogares y Viviendas 2010, procesado con Redatam +SP.

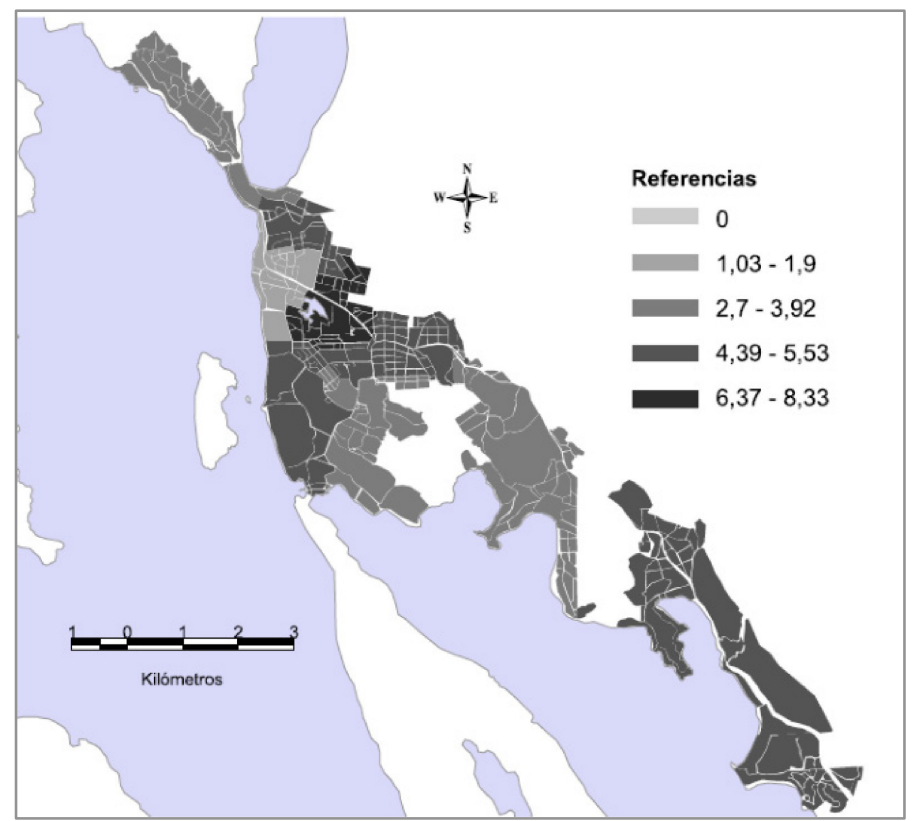

Figura N¹3. Desocupación (en \%). Villa La Angostura. 2010. En términos generales, si bien la desocupación en Villa La Angostura es baja, los barrios Norte, Peumayen y Las Margaritas muestran los valores más elevados. Le siguen en importancia Los Volcanes, Las Piedritas, El Cruce, El Once, Epulafquen, El Mallín, Calafate, Loma Guacha, Muelle de Piedra, Calfuco y Puerto Manzano. Fuente: elaboración propia en base a datos del INDEC. Censo Nacional de Población, Hogares y Viviendas 2010, procesado con Redatam +SP. 


\subsubsection{Jefe de hogar femenino}

Los hogares cuyo jefe es femenino (Figuras $N^{\circ} 14$ y $\left.N^{\circ} 15\right)$ poseen una condición de vulnerabilidad intrínseca dado que la mujer asume sola las responsabilidades y los trabajos domésticos y extradomésticos (Barrenechea et al., 2010, p. 8). La fragilidad en estos hogares está asociada al campo económico, siendo fundamental en este esquema el desigual acceso al mercado de trabajo que presentan las mujeres en comparación con los hombres. Para el año 2007, el ingreso laboral de las mujeres era menor que el de los varones, producto de una inserción laboral más precaria, con menos participación en el mercado de trabajo, mayores tasas de desempleo, menor acceso al empleo asalariado registrado y menor ingreso por hora trabajada (Rojo Brizuela y Tumini, 2008, p. 53).

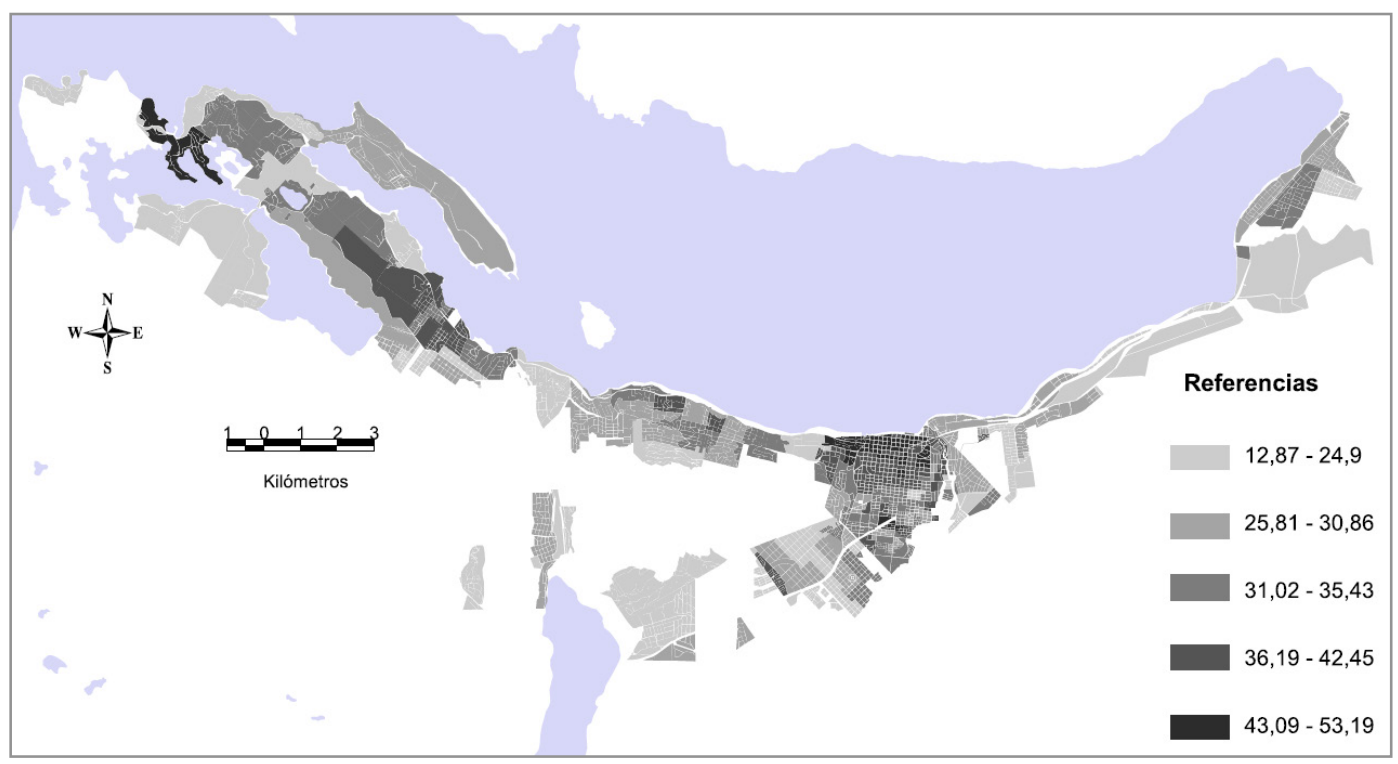

Figura $N^{\circ} 14$. Hogares con Jefe de hogar femenino (en \%). San Carlos de Bariloche y Dina Huapi. 2010. La situación de hogares con jefe femenino es muy dispar en toda el área urbana: es fuerte su presencia en el centro de la ciudad y el Oeste (Llao Llao, Villa Llanquihue y Valle Escondido) y baja en Villa Lago Gutiérrez, Reina Mora, Villa Arelauquen, Perito Moreno, Las Chacras, Costa del Sol, El Frutillar, Unión, entre otros. Fuente: elaboración propia en base a datos del INDEC. Censo Nacional de Población, Hogares y Viviendas 2010, procesado con Redatam +SP. 


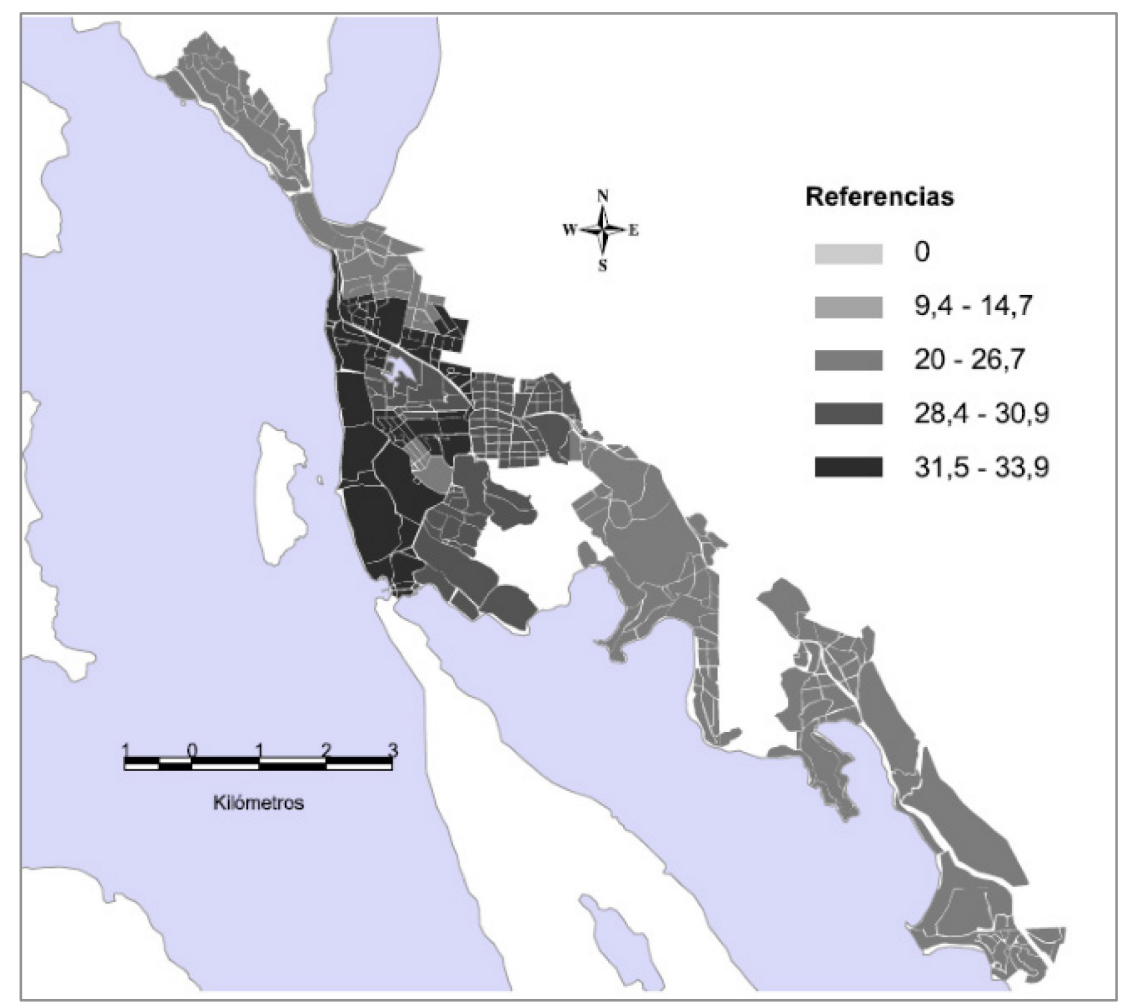

Figura $\mathrm{N}^{\circ} 15$. Hogares con Jefe de hogar femenino (en \%). Villa La Angostura. 2010. La franja central del área urbana muestra los mayores resultados -entre 28 y 34\%-, correspondiendo a los barrios Norte, Tres Cerros, Lomas del Correntoso, Las Margaritas, Peumayen, El Mallín, El Pinar y Calafate (Figura N5). Menores valores pero relevantes también- poseen los barrios Los Volcanes, Las Piedritas, Ciprés, Antilhue, Maikana, El Once y El Cruce. Fuente: elaboración propia en base a datos del INDEC. Censo Nacional de Población, Hogares y Viviendas 2010, procesado con Redatam +SP.

\subsubsection{Analfabetismo}

Si bien el analfabetismo es el porcentaje de la población de 10 años y más que no sabe leer y escribir (INDEC, 2013, p. 2), este indicador es presentado en términos absolutos (Figuras $\mathrm{N}^{\circ} 16$ y $\mathrm{N}^{\circ} 17$ ). La población analfabeta tiene, entre otros aspectos, menor capacidad para tomar mejores decisiones frente a situaciones extremas, de hacer valer sus derechos a un ambiente saludable o aprovechar indicaciones en momentos críticos (Natenzon y González, 2010, p. 201). 


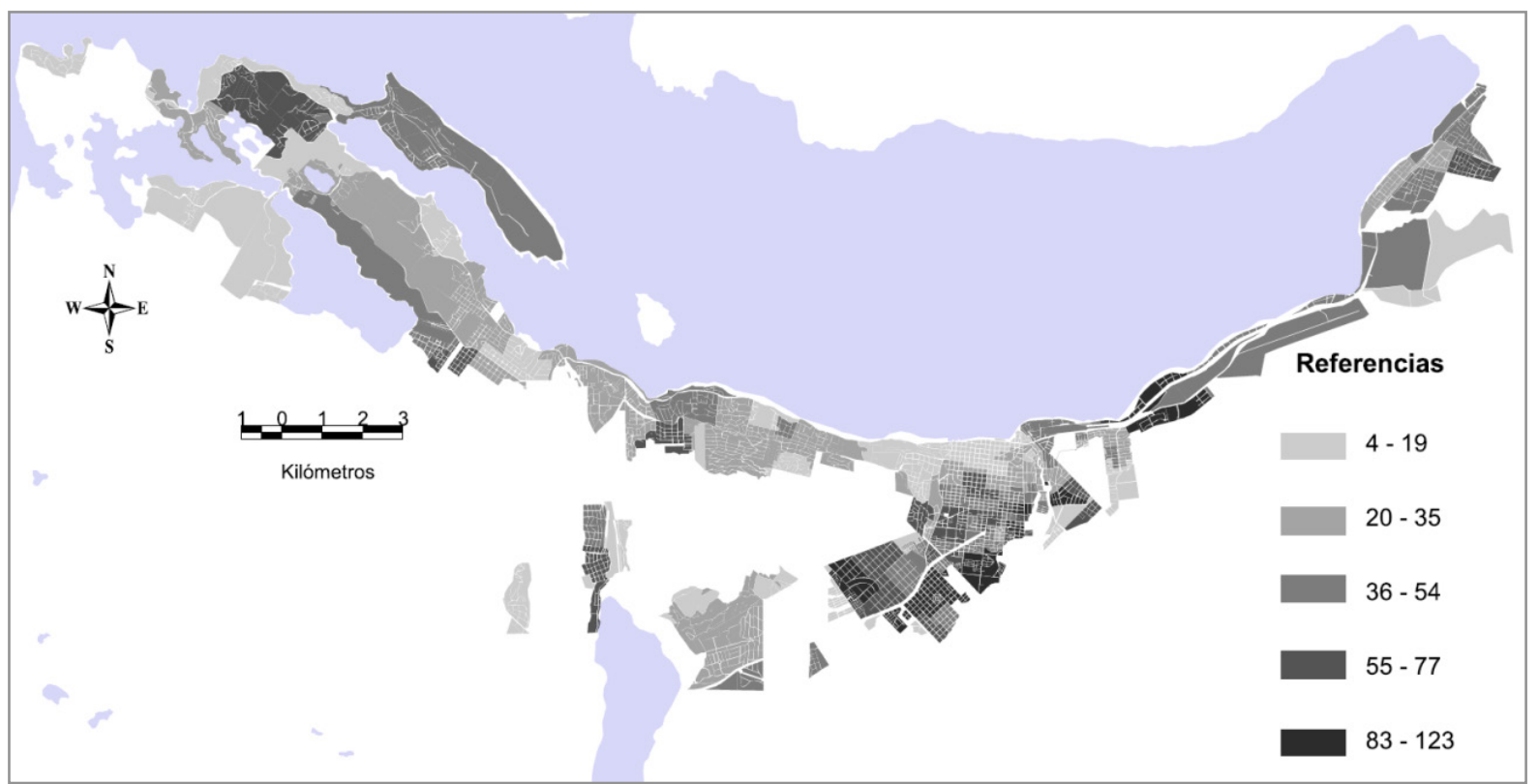

Figura $N^{\circ} 16$. Personas con Analfabetismo. San Carlos de Bariloche y Dina Huapi. 2010. Los barrios con valores elevados de personas con analfabetismo son Villa Llanquihue, en el Oeste; Cementerio y Unión en el Sur; Villa Verde y la Colina en el sector centro-oriental; el sector Sudoeste de Dina Huapi también presenta valores considerables. Fuente: elaboración propia en base a datos del INDEC. Censo Nacional de Población, Hogares y Viviendas 2010, procesado con Redatam +SP.

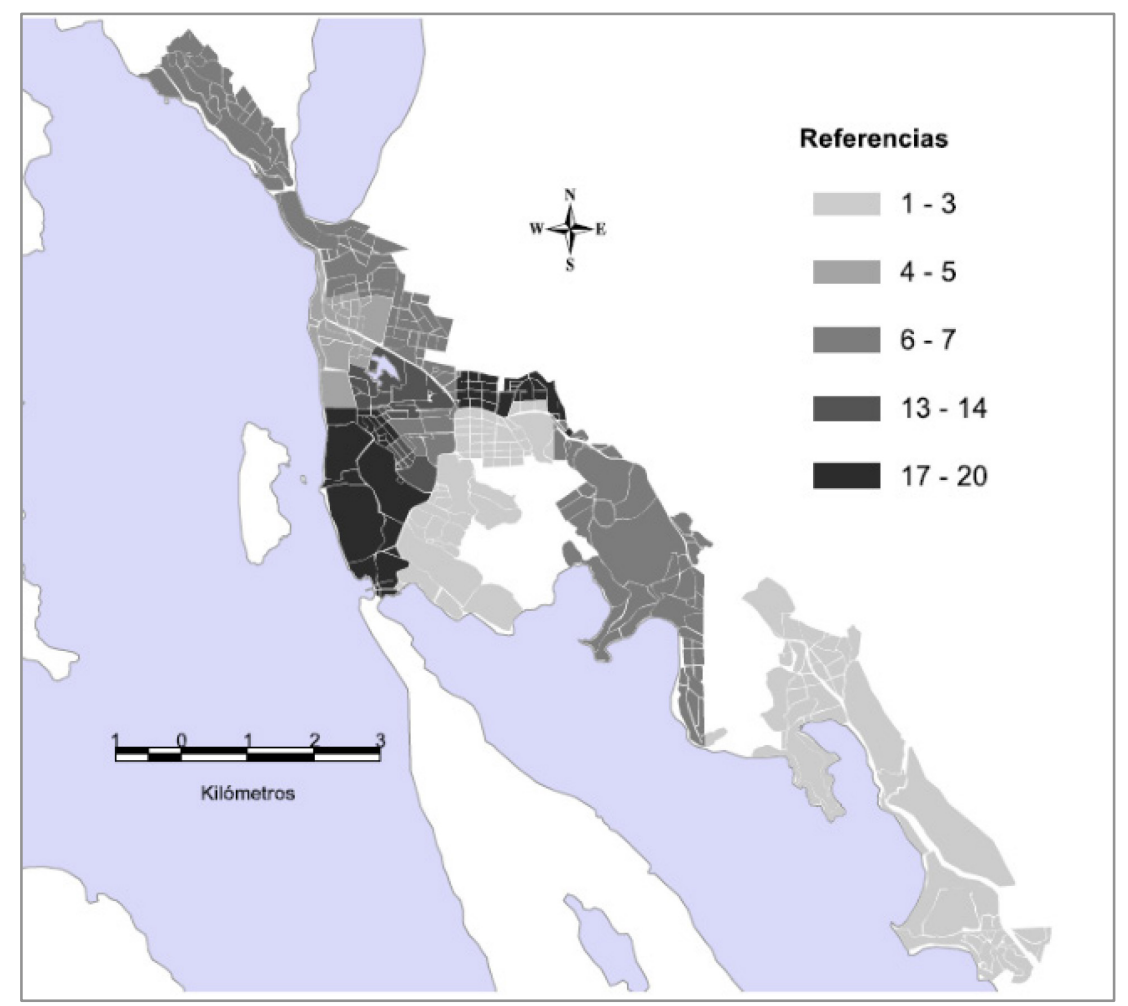

Figura N¹7. Personas con Analfabetismo. Villa La Angostura. 2010. El analfabetismo en el Departamento Los Lagos alcanza el 1,25\% de la población. En Villa La Angostura, los mayores valores absolutos de analfabetismo los presentan los barrios Los Volcanes, Las Piedritas, El Coihue, El Cruce, El Mallín y Calafate. Fuente: 
elaboración propia en base a datos del INDEC. Censo Nacional de Población, Hogares y Viviendas 2010, procesado con Redatam + SP.

\subsubsection{Necesidades Básicas Insatisfechas (NBI)}

El Instituto Nacional de Estadísticas y Censos (INDEC) considera hogares con $\mathrm{NBI}^{17}$ aquellos en los que está presente al menos uno de los siguientes indicadores de privación: Hogares que habitan viviendas con más de 3 personas por cuarto (hacinamiento crítico), Hogares que habitan en una vivienda de tipo inconveniente (pieza de inquilinato, vivienda precaria u otro tipo), Hogares que habitan en viviendas que no tienen retrete o tienen retrete sin descarga de agua, Hogares que tienen algún niño en edad escolar que no asiste a la escuela, Hogares que tienen 4 o más personas por miembro ocupado y en los cuales el jefe tiene bajo nivel de educación (sólo asistió dos años o menos al nivel primario).

A los fines de determinar grados de vulnerabilidad social frente a la caída de ceniza volcánica se analizan, por un lado, el Hacinamiento (Figuras $\mathrm{N}^{\circ} 18$ y $\mathrm{N}^{\circ} 19$ ), en la medida que representa condiciones de fragilidad de las personas que habitan una vivienda, suministrando una información valiosa a las organizaciones competentes en la gestión del riesgo, por ejemplo, ante posibles evacuaciones (protección civil, bomberos, gendarmería, ONGs, entre otras).

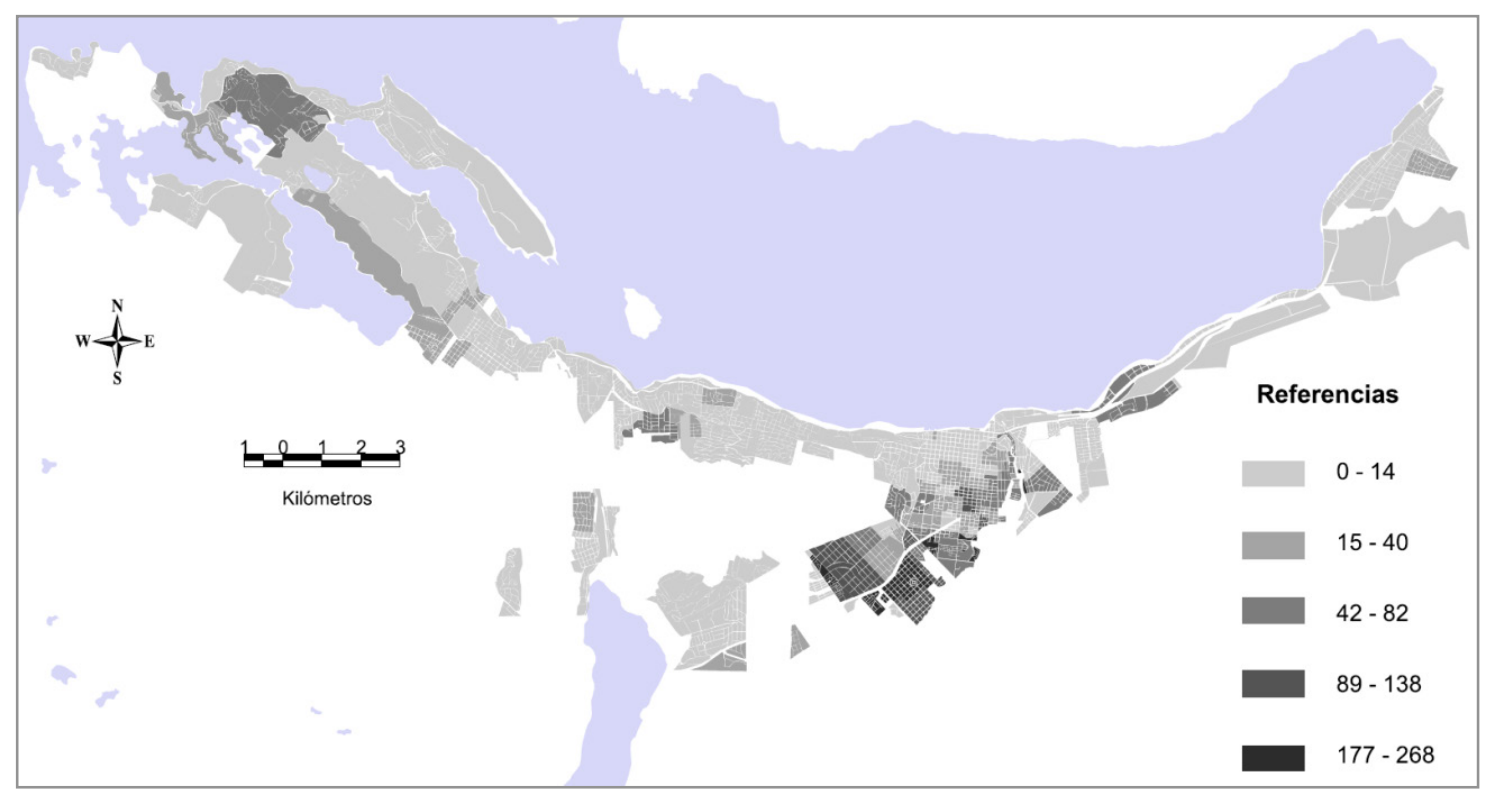

Figura N¹8. Personas con Hacinamiento. San Carlos de Bariloche y Dina Huapi. 2010. Villa Llanquihue, Virgen Misionera, El Frutillar, El Maitén, Unión, Cementerio, Islas Malvinas, Nahuel Hue, Omega son los barrios con más hogares con hacinamiento. Le siguen en importancia, Villa Verde, La Colina, San Francisco, Lera, Nueva

\footnotetext{
${ }^{17}$ En http://www.indec.mecon.ar/glosario/textos_glosario.asp?id=39. Consultada el 20 de mayo de 2014.
} 
Esperanza, Las Mutisias, La Cumbre, Levalle y Quimey Hue. Fuente: elaboración propia en base a datos del INDEC. Censo Nacional de Población, Hogares y Viviendas 2010, procesado con Redatam +SP.

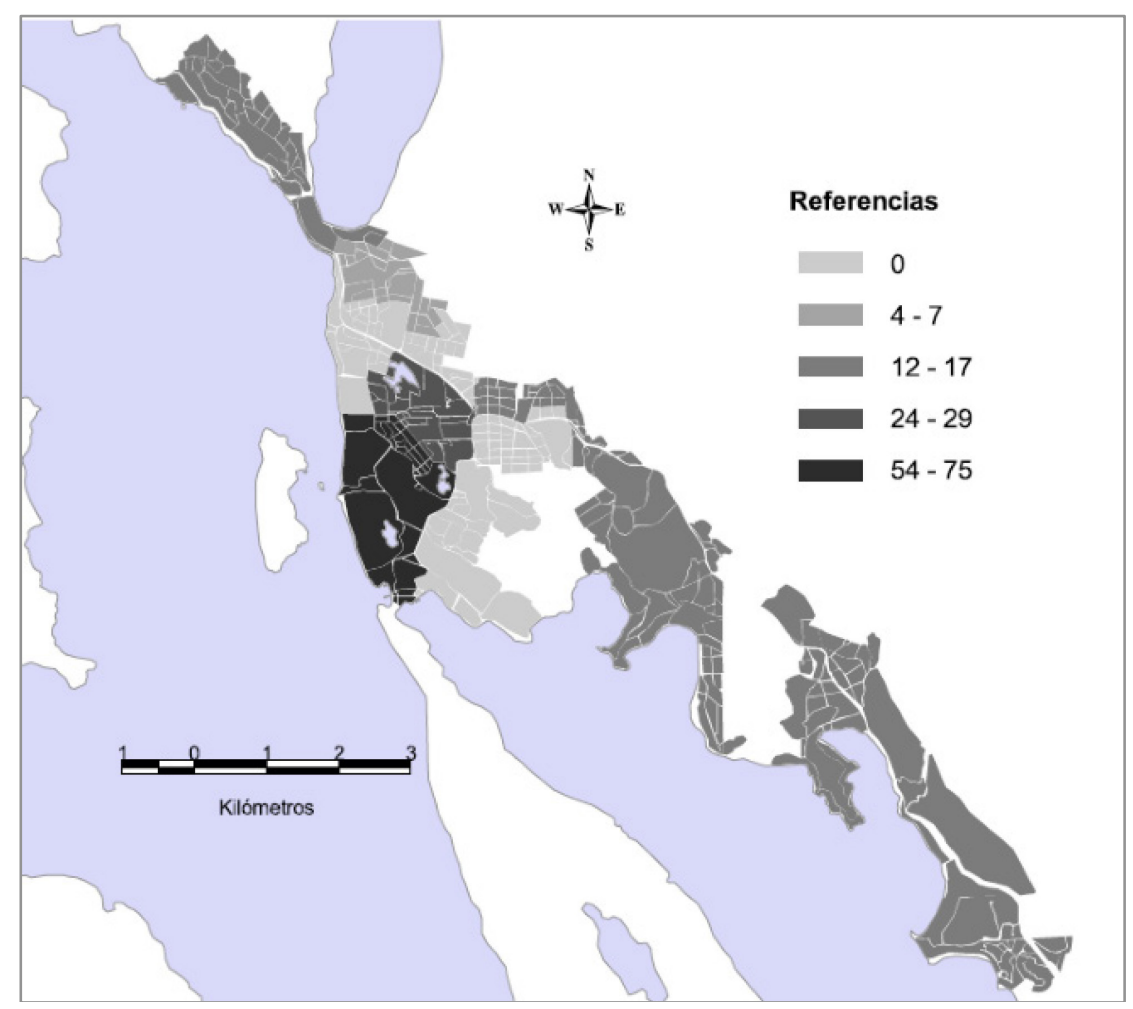

Figura N¹9. Personas con Hacinamiento. Villa La Angostura. 2010. Si bien la localidad no presenta valores elevados de personas con hacinamiento, los mayores registros se encuentran en los barrios El Mallín, El Pinar y Calafate y le sigue en importancia el barrio Las Margaritas. Fuente: elaboración propia en base a datos del INDEC. Censo Nacional de Población, Hogares y Viviendas 2010, procesado con Redatam +SP.

Por otro, se analiza también la Vivienda Inconveniente (Figuras $\mathrm{N}^{\circ} 20$ y $\mathrm{N}^{\circ} 21$ ), que incluye pieza de inquilinato, pieza de hotel o pensión, casilla, local no construido para habitación o vivienda móvil, excluyendo casa, departamento y rancho; en cierta medida refleja la capacidad de la vivienda de afrontar una caída de cenizas (especialmente para los casos de viviendas precarias). 


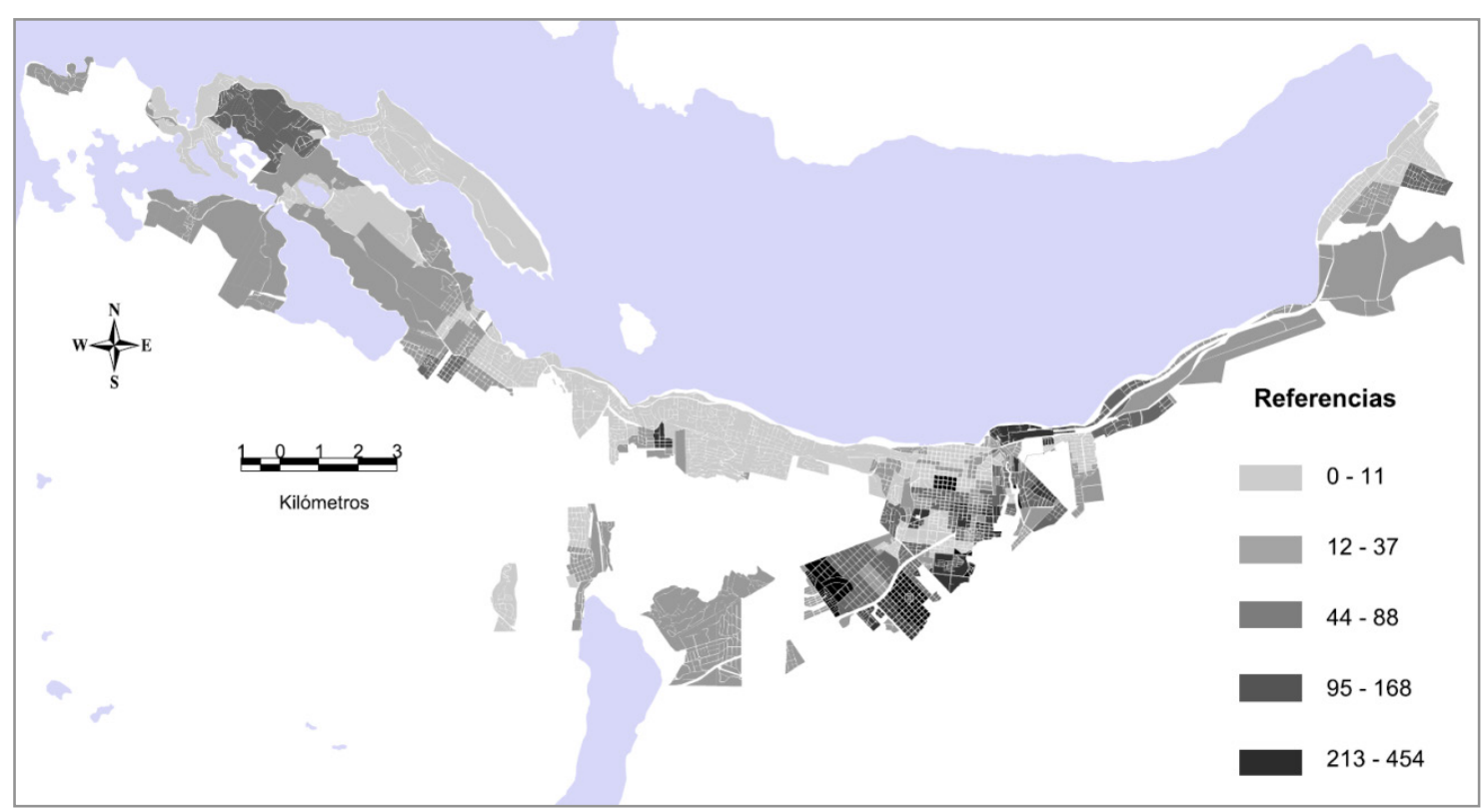

Figura N²0. Personas en Vivienda inconveniente. San Carlos de Bariloche y Dina Huapi. 2010. Los barrios Unión, Islas Malvinas, Nahuel Hue, El Maitén, 10 de Diciembre, Alborada, Santo Cristo, Perito Moreno (centro), Las Mutisias, San Francisco, Ñireco, La Colina y Virgen Misionera muestran los valores más elevados. Con menor nivel, pero importantes también, se encuentran Villa Verde, Villa Llanquihue y un sector de Dina Huapi. Fuente: elaboración propia en base a datos del INDEC. Censo Nacional de Población, Hogares y Viviendas 2010, procesado con Redatam $+\mathrm{SP}$.

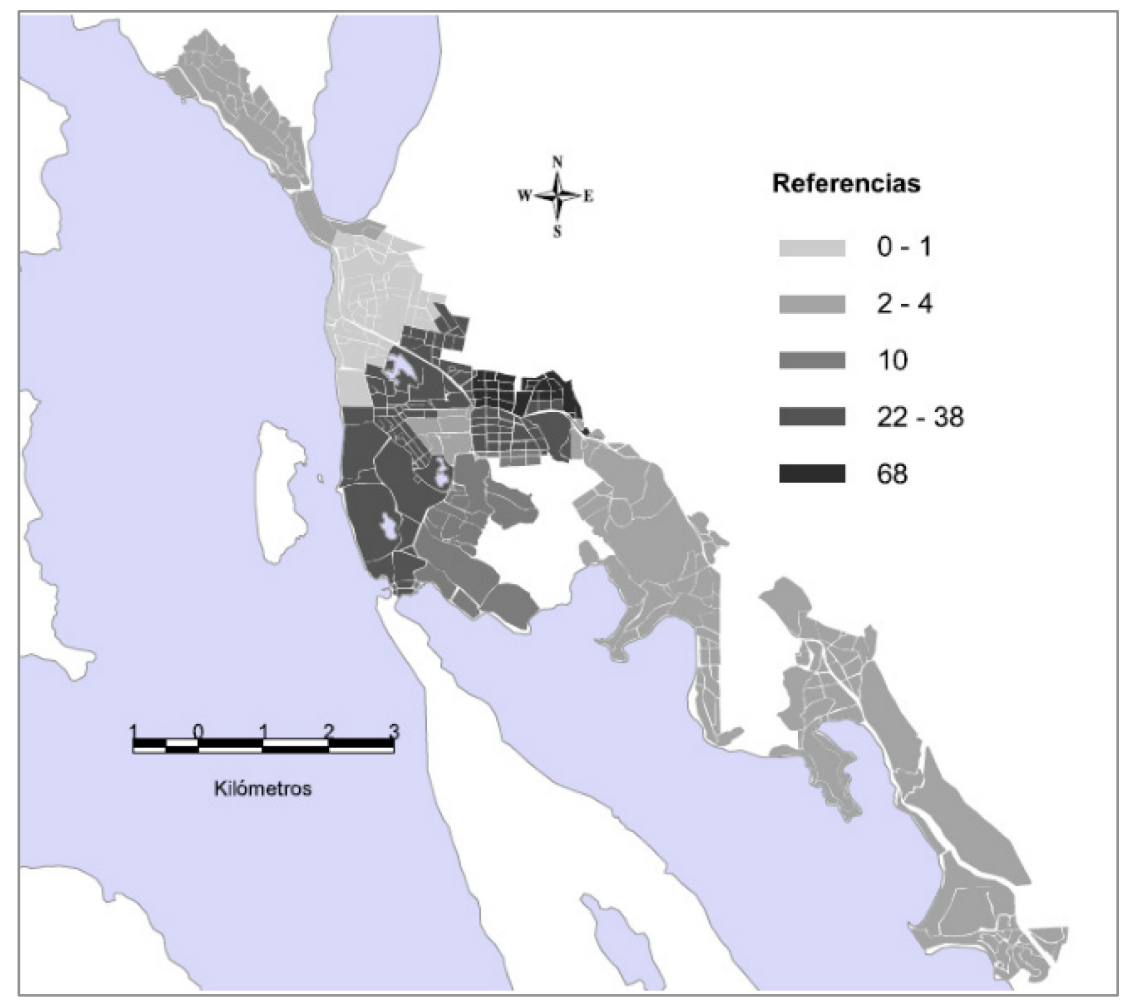

Figura $N^{\circ} 21$. Personas en Vivienda inconveniente. Villa La Angostura. 2010. Al interior de Villa La Angostura, los barrios Las Piedritas, El Coihue, Los Volcanes, El Coihue y El Cruce poseen los números más elevados de 
cantidad de personas en viviendas inconvenientes. Le siguen en importancia los barrios El Once, Norte, Las Margaritas Calafate y El Mallín. Fuente: elaboración propia en base a datos del INDEC. Censo Nacional de Población, Hogares y Viviendas 2010, procesado con Redatam +SP.

\subsubsection{Material predominante de la cubierta exterior del techo}

El peso de la ceniza acumulada, en especial si está húmeda, genera una carga que tiene un gran potencial de causar daños, en caso de sobrepasar la capacidad de ciertas estructuras, visible frecuentemente en los daños a los techos.

De acuerdo a las densidades que presentaron las tefras de la erupción de 2011, el peso que ejerce una capa de ceniza de unos $10 \mathrm{~cm}$ de espesor varía entre 40 y $70 \mathrm{Kg}$ por metro cuadrado, para el material seco. En cambio, para la ceniza húmeda los valores aumentan sensiblemente alcanzando pesos que varían entre los 100 y $125 \mathrm{Kg}$ por metro cuadrado (Tilling, 1993; en Villarosa et al. 2012, p. 46).

De acuerdo a las densidades que presentaron las tefras de la erupción de 2011 obtenidas en el Laboratorio de Tefrocronología y Limnogeología (GEA, IPATEC) sobre muestras de diversa granulometría, desde ceniza gruesa colectada durante los primeros días de la erupción en Villa La Angostura y sectores aledaños, hasta ceniza muy fina como la caída en Villa Traful o eventos puntuales en Villa La Angostura, indican valores que varían entre $0,66 \mathrm{~g} / \mathrm{cm}^{3}$ hasta $0,84 \mathrm{~g} / \mathrm{cm}^{3}$ (es decir, entre 66 y $84 \mathrm{~kg}$ por metro cuadrado para un espesor de $10 \mathrm{~cm}$ de tefra). Los valores de densidad húmeda para las mismas muestras varían entre $1,05 \mathrm{~g} / \mathrm{cm}^{3}$ hasta $1,49 \mathrm{~g} / \mathrm{cm}^{3}$ (es decir, entre 105 y 149 kilogramos por metro cuadrado para un espesor de $10 \mathrm{~cm}$ de tefra).

Este aspecto adquiere mayor relevancia cuando entra en consideración la carga adicional que puede presentar la nieve en temporada invernal, como sucedió en el caso de la erupción de 2011, donde se verificaron daños por la caída de techos por el excesivo peso.

El Censo Nacional de Población, Hogares y Viviendas contempla los siguientes materiales para la cubierta exterior del techo: a) Cubierta asfáltica o membrana, b) baldosa o losa (sin cubierta), c) pizarra o teja, d) chapa de metal (sin cubierta), e) chapa fibrocemento o plástico, f) chapa de cartón, g) caña, palma, tabla o paja con o sin barro, h) otro.

Se consideran como los más propensos a sufrir daños por una caída de ceniza los techos de chapa de cartón (Figuras $\mathrm{N}^{\circ} 22$ y N²3) y los techos de caña, palma, tabla o paja con o sin barro (este último no se aborda en detalle por su escasa presencia). 


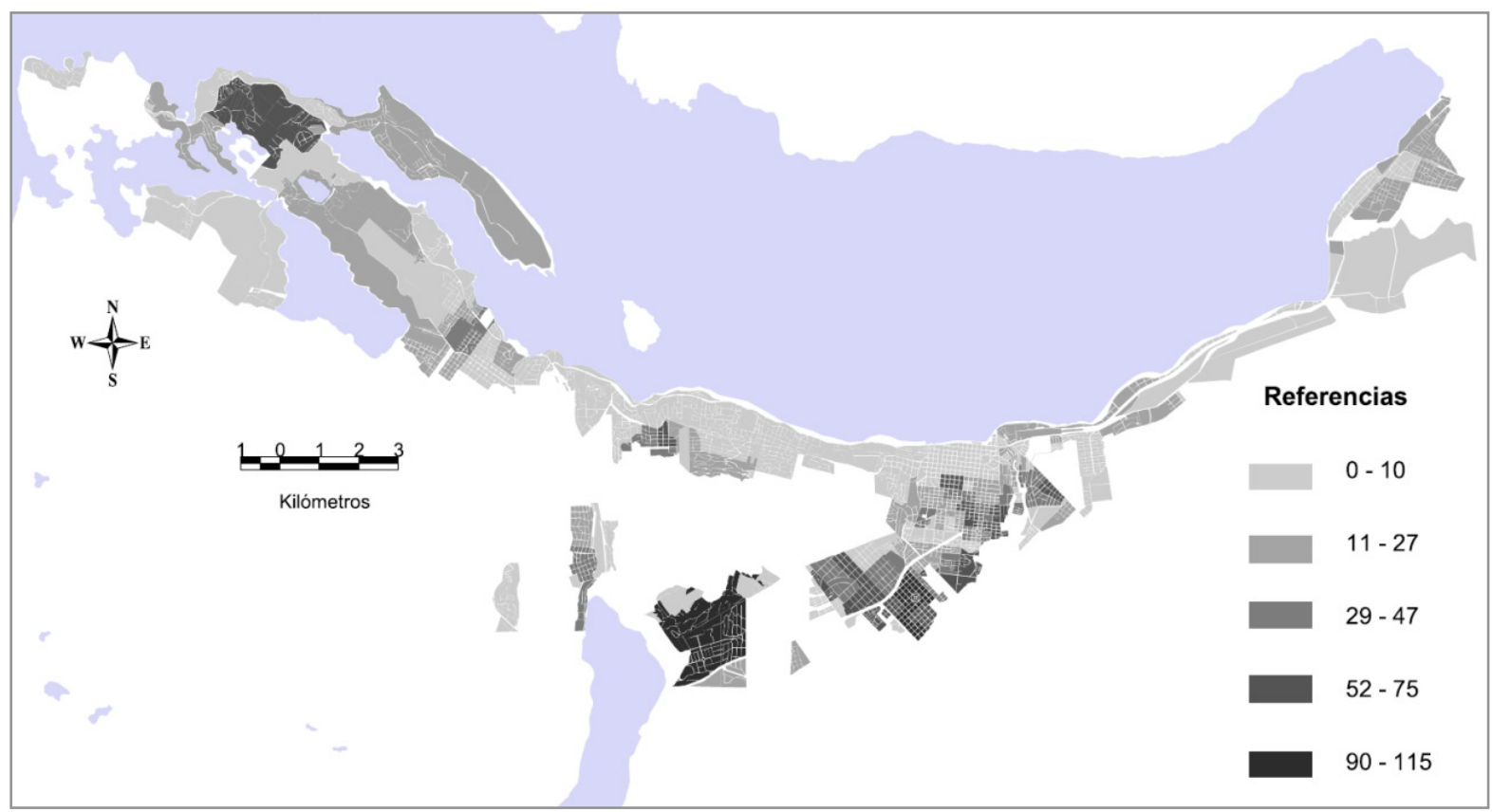

Figura $N^{\circ} 22$. Hogares con techo de chapa de cartón. San Carlos de Bariloche y Dina Huapi. 2010. En la zona es muy frecuente encontrar viviendas con techos de chapa de cartón, presentando altos valores los barrios del Sur como Reina Mora, Villa Lago Gutiérrez, Villa Arelauquen, El Frutillar, Unión, Malvinas, El Maitén, Nahuel Hue y Cementerio. Los barrios del área central como 10 de Diciembre, San Francisco, Lera, Mutisias, Perito Moreno también presentan valores altos. Hacia el sector centro-occidental, aparece con indicadores altos Virgen Misionera y Villa Llanquihue (más hacia el Oeste). Fuente: elaboración propia en base a datos del INDEC. Censo Nacional de Población, Hogares y Viviendas 2010, procesado con Redatam +SP.

Dado que las ciudades de San Carlos de Bariloche y Dina Huapi corresponden a unidades administrativas diferentes, cada una de ellas cuenta con su propio código de edificación en los que se definen, entre otros detalles, los materiales constructivos. Para el caso de los techos resulta relevante no sólo el material sino también la inclinación de los mismos.

En el caso de Bariloche, se especifican algunos materiales admitidos (fibrocemento, chapa de cobre o hierro galvanizado, cerámico, madera, asfalto y techado fluido), no explicitándose la prohibición del uso de chapa de cartón el cual, como se ha visto en el mapa, está ampliamente difundido.

El Decreto provincial 840/2005, en su Art. $2^{\circ}$ aprueba el Código de Planeamiento Urbano y Edificación de Dina Huapi, donde no se especifica la prohibición o admisión de ningún material constructivo. Sin embargo, en ambos códigos se sostiene que "el sentido de composición de techos tiene el mismo fundamento que se observa en la composición de fachadas respecto a su acatamiento a principios de estética pública" (apartado 3.7.1 del Código de Edificación de San Carlos de Bariloche y art. 104 del Código de Planeamiento Urbano y Edificación de Dina Huapi). 
Tanto para Bariloche como para Dina Huapi la inclinación mínima de los techos es de $18^{\circ}$, ubicándose en un rango de $18^{\circ}$ a $35^{\circ}$ sólo en el radio urbano de San Carlos de Bariloche. Esta información es sumamente útil para conocer la predisposición de las viviendas frente a la amenaza que pueden significar las grandes nevadas a la estructura edilicia, pero también frente a la caída de ceniza volcánica.

La propensión al daño en los techos está determinada no sólo por el material sino también por la inclinación de los mismos. El "Código de Edificación" (Ordenanza Municipal 1415/03) aclara que en el área "R" (centro de Villa La Angostura) y "R1" (Avenida Arrayanes) definidas por el Código de Planeamiento Ambiental Urbano (Ordenanza Municipal No 2659/12), no se permitirá la chapa acanalada traslúcida ni la de cartón. Por otra parte, en el ítem 4.2.2 se estipulan los materiales permitidos para la construcción de los techos: Chapas galvanizada o de aluminio, de cobre, de fibras, tejas cerámicas, gravilladas, tejuelas de madera, asfálticas, pizarra hormigón armado. En edificaciones de uso comercial no se permite la chapa de cartón. El apartado 4.3.6 del Código de Edificación referido a las pendientes de los techos sostiene que todos los elementos que componen una cubierta de techos tendrán una pendiente mínima de $25^{\circ}$ (veinticinco grados sexagesimales) o 46,67\% para un mínimo de la mitad de la superficie de los techos; la otra mitad deberá tener como mínimo un $80 \%$ de cubierta con pendiente no menor a $12^{\circ}$ (medidas en proyección perpendicular sobre un plano horizontal que pase por el punto más alto de la cubierta). 


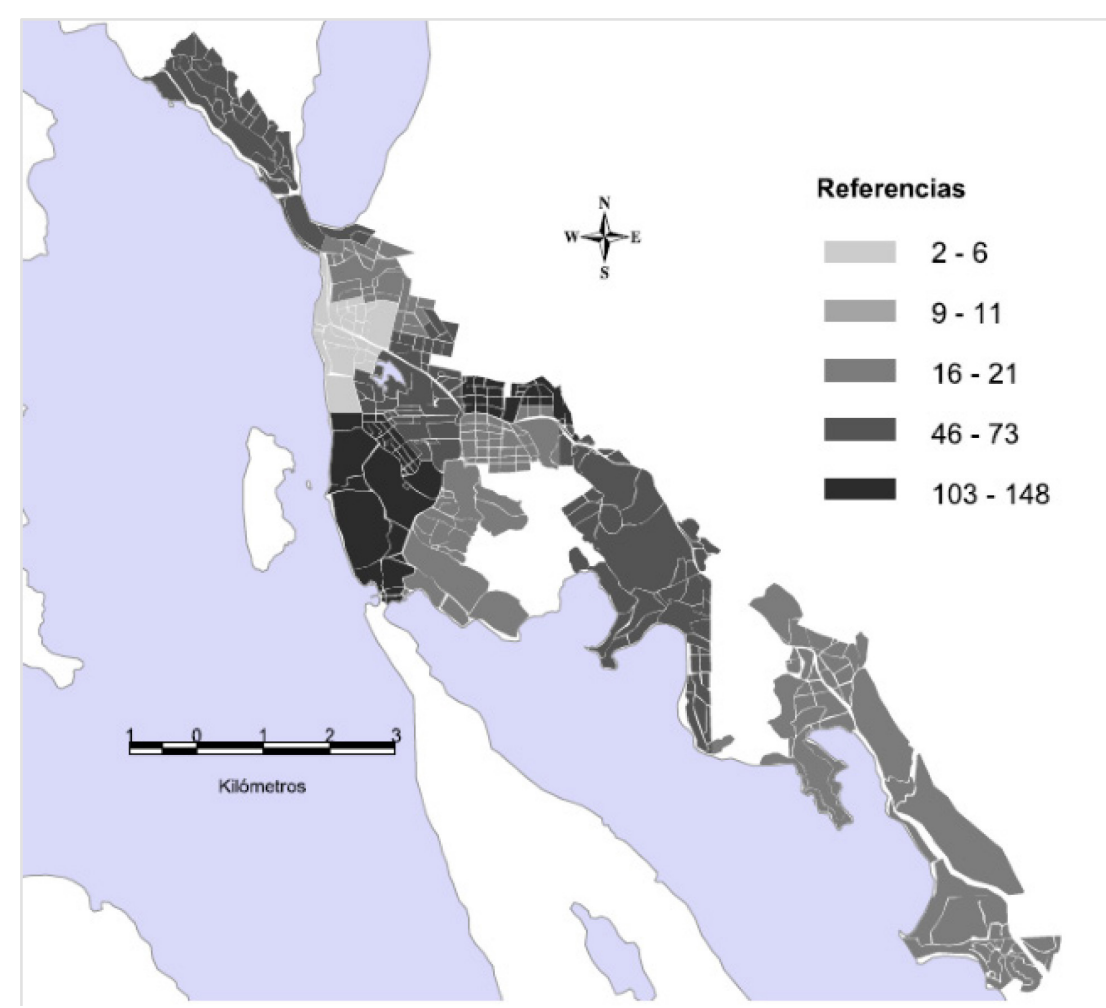

Figura $N^{\circ} 23$. Hogares con techo con chapa de cartón. Villa La Angostura. 2010. El mayor número de hogares que presenta este tipo de material en su cubierta exterior se encuentra en los barrios Los Volcanes, Las Piedritas, el Coihue, El Cruce, El Pinar, El Mallín y Calafate. También es elevado en los barrios Norte, Las Margaritas, Las Balsas y Cumelén. Fuente: elaboración propia en base a datos del INDEC. Censo Nacional de Población, Hogares y Viviendas 2010, procesado con Redatam +SP.

Ambos aspectos (material e inclinación) no han sido suficientes para reducir los impactos de la erupción, dado que la mayoría de los techos que presentaron daños eran de chapa de cartón y la inclinación de los mismos era escasa para el tipo de amenaza que se está abordando.

Durante la emergencia volcánica generada por la erupción del Cordón Caulle, se conformó un Grupo del Ejército que fue destinado a la limpieza, reparación y apuntalamiento de techos (Figura $\mathrm{N}^{\circ} 24$ ). La mayor parte del trabajo de este grupo, con más de una veintena de casas asistidas ${ }^{18}$, se concentró en los barrios El Mallín (6 viviendas), Las Piedritas (5 viviendas), Calafate (4 viviendas) y Norte (3 viviendas) y, en menor orden, en los barrios Peumayen, Epulafquen, Los Volcanes, Las Margaritas, Villa Correntoso y Las Balsas (todos ellos con una vivienda).

\footnotetext{
${ }^{18}$ Totalizaron 25 viviendas (una de ellas sin domicilio definido).
} 

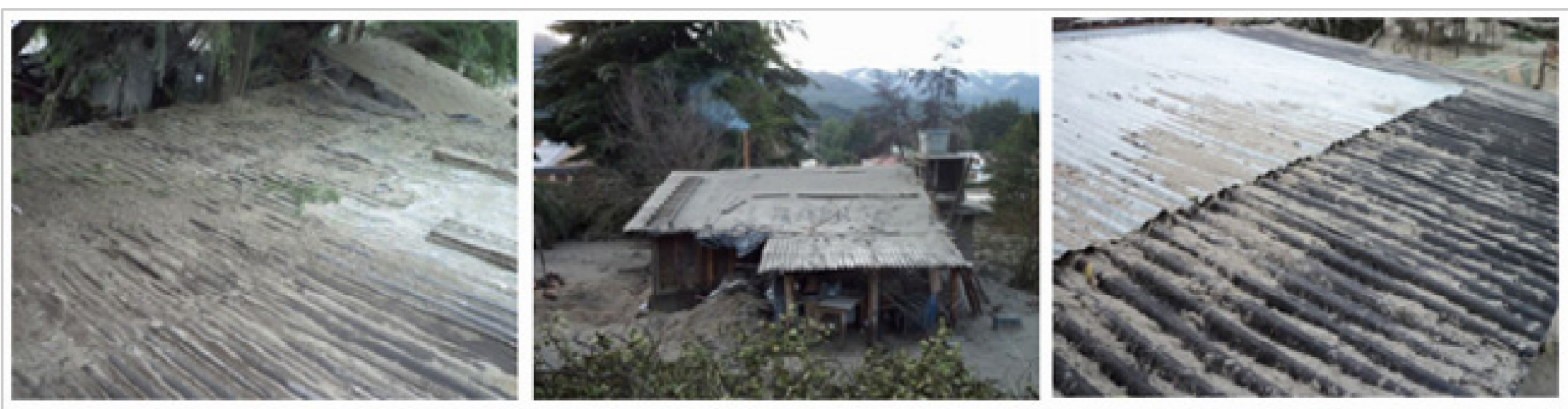

Figura $\mathrm{N}^{\circ} 24$. Viviendas con techos de chapa de cartón visiblemente deteriorados por la ceniza volcánica acumulada, potenciados por la escasa inclinación. Por los daños reportados, estas viviendas debieron recibir asistencia durante la emergencia. Fotos: gentileza del Comando de Operaciones en Emergencias (COE) de Villa La Angostura.

\subsubsection{Procedencia del agua de beber y cocinar}

El Censo reconoce diversas fuentes de agua para beber y cocinar: red pública, por perforación (con bomba manual o a motor), de pozo, transporte por cisterna y agua de lluvia, río, canal, arroyo o acequia. A este último, se deben agregar los lagos, lagunas y vertientes.

La caída de ceniza volcánica eleva rápidamente la turbidez del agua tanto en los cursos como en los cuerpos superficiales, por lo que el acceso al agua potable emerge como un indicador de suma importancia no sólo para el consumo humano sino también para la limpieza y la humidificación de la ceniza caída, lo que evita la removilización por el viento.

Entre las fuentes de provisión de agua menos susceptibles de ser afectadas por una caída de cenizas se destacan:

- Agua de red pública (Figuras $\mathrm{N}^{\circ} 25$ y N²6): si bien el sistema se abastece principalmente de lagos altamente expuestos a la caída de material piroclástico, los controles bromatológicos a los que se somete el agua con regularidad debería asegurar ciertos estándares de calidad, considerando como complemento un análisis químico que garantice su potabilidad. 


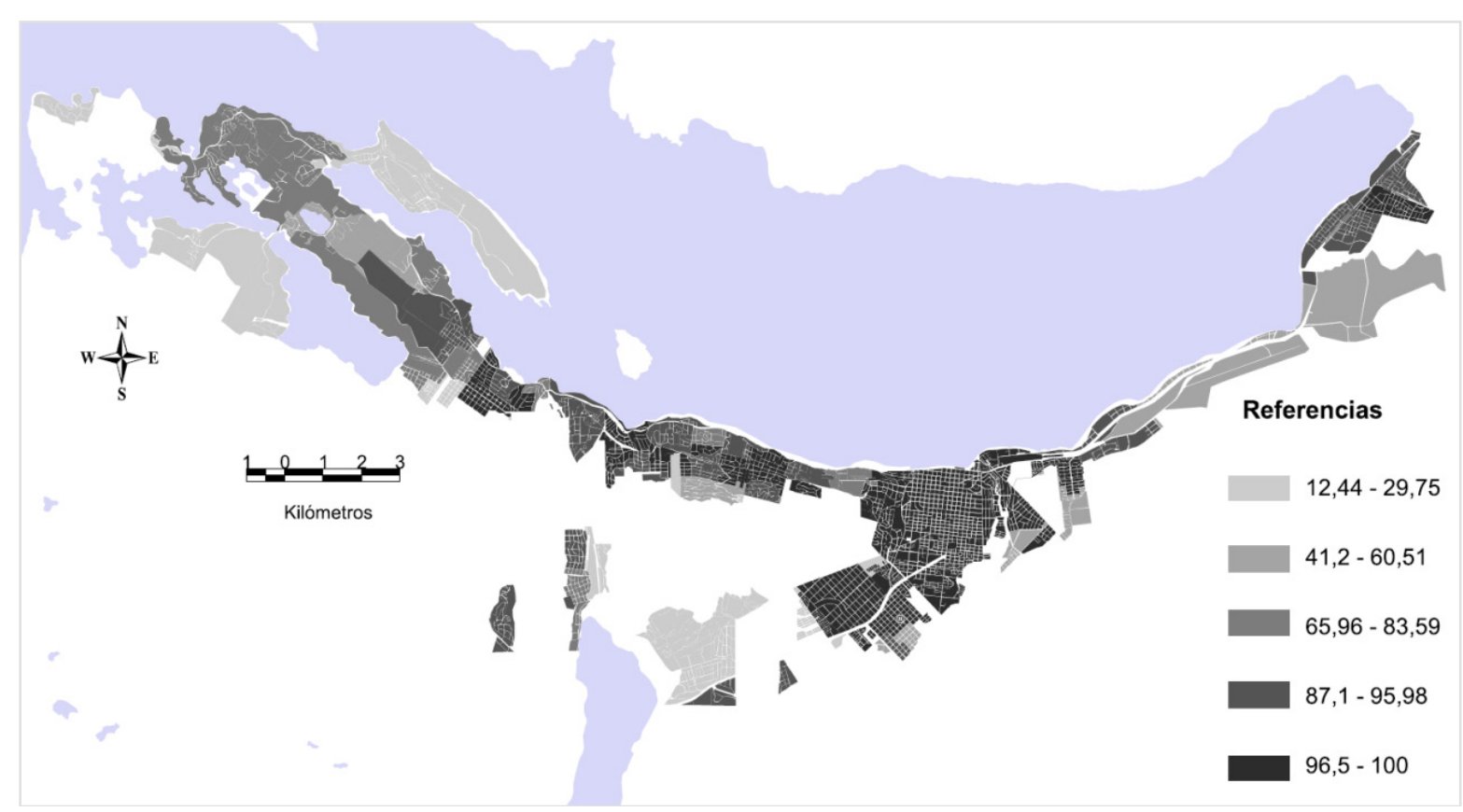

Figura $\mathrm{N}^{\circ} 25$. Hogares con agua de red pública (en \%). San Carlos de Bariloche y Dina Huapi. 2010. En el sector occidental, los barrios con menor presencia de agua de red son Península San Pedro, Las Cartas y Villa Tacul; en el sector oriental los barrios Las Chacras y Costa del Sol; en el Sur, Reina Mora, Villa Arelauquen y Villa Lago Gutiérrez. El área central del espacio urbano tiene una presencia elevada de agua de red. Fuente: elaboración propia en base a datos del INDEC. Censo Nacional de Población, Hogares y Viviendas 2010, procesado con Redatam $+S P$.

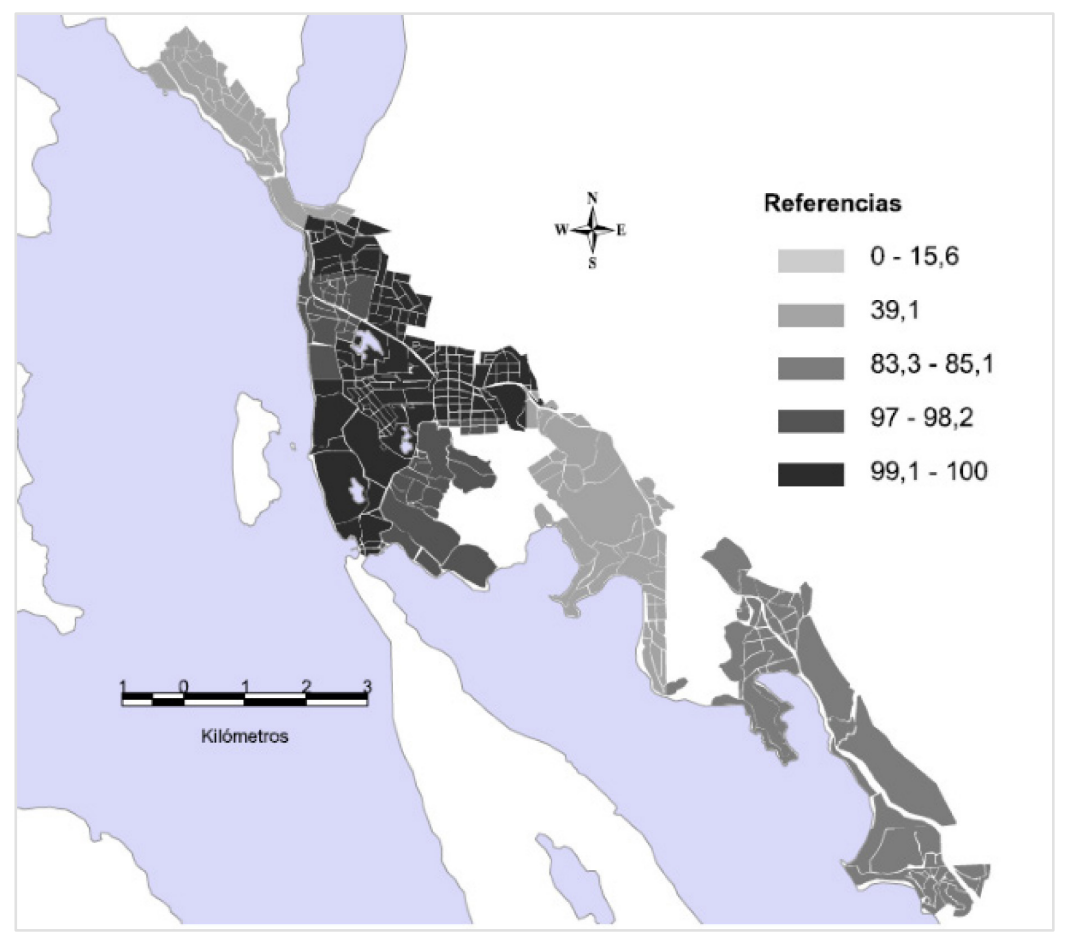

Figura $N^{\circ} 26$. Hogares con agua de red pública (en \%). Villa La Angostura. 2010. El área centro de Villa la Angostura tiene una cobertura casi total de agua de red. Fuente: elaboración propia en base a datos del INDEC. Censo Nacional de Población, Hogares y Viviendas 2010, procesado con Redatam +SP. 
- Agua de perforación (Figuras $N^{\circ} 27$ y ํ28): es una fuente con una baja vulnerabilidad aunque puede suponer algún riesgo. Si bien no presenta una exposición directa al material piroclástico, esta fuente aprovecha el agua de acuíferos freáticos que podrían estar expuestos al aporte rápido de aguas de recarga que estuvieron en contacto con el material volcánico y, por ende, presentar algún nivel de exposición a la contaminación química, mayor al que tendrían las aguas de acuíferos confinados que se explotan en otras áreas del país.

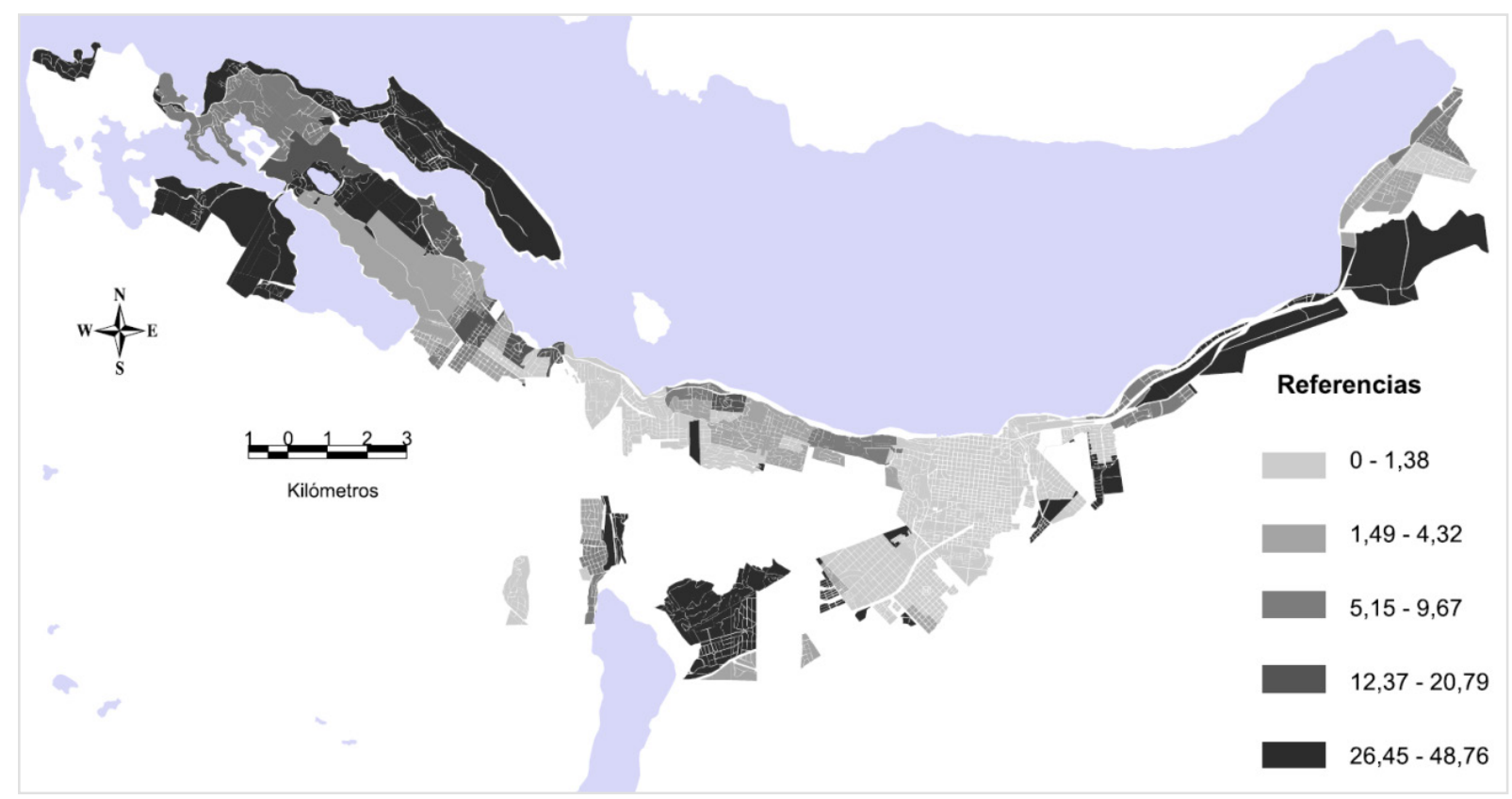

Figura $N^{\circ} 27$. Hogares con agua por perforación manual y mecánica (en \%). San Carlos de Bariloche y Dina Huapi. 2010. Los barrios que presentan bajos valores de hogares con agua de red, poseen los niveles más altos de agua por perforación: Península San Pedro, Las Cartas, Villa Tacul, Reina Mora, Villa Arelauquen, Villa Lago Gutiérrez, Las Chacras y Costa del Sol. Fuente: elaboración propia en base a datos del INDEC. Censo Nacional de Población, Hogares y Viviendas 2010, procesado con Redatam +SP. 


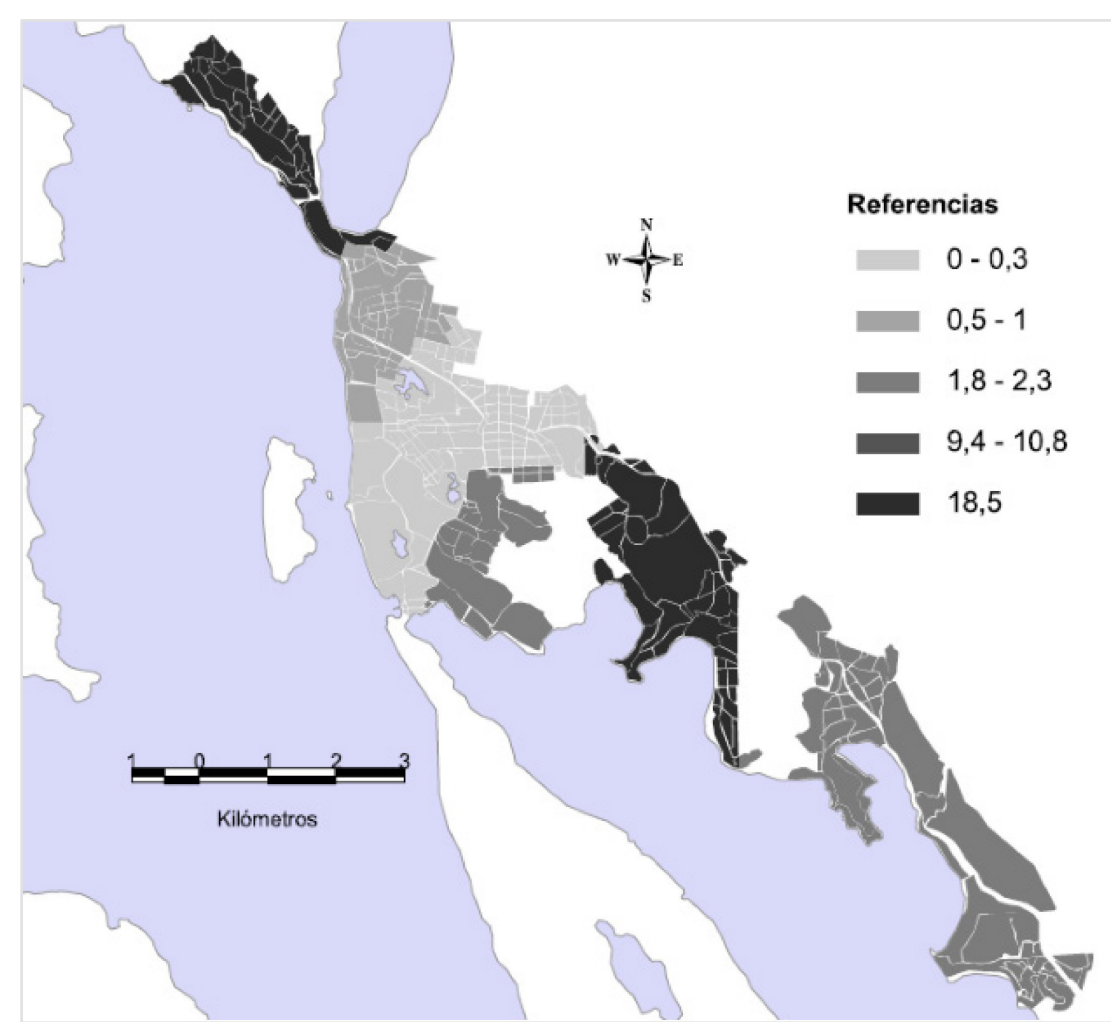

Figura $\mathrm{N}^{\circ} 28$. Hogares con agua por perforación manual y mecánica (en \%). Villa La Angostura. 2010. La periferia de la ciudad presenta los mayores valores, de hasta casi un $20 \%$ de los hogares. Fuente: elaboración propia en base a datos del INDEC. Censo Nacional de Población, Hogares y Viviendas 2010, procesado con Redatam +SP.

- El transporte por cisterna: su origen en fuentes seguras garantizaría la calidad del agua transportada. Tanto en Bariloche y Dina Huapi como en Villa La Angostura su presencia es de escasa relevancia, por lo cual no se trata en detalle.

- El pozo, como fuente de provisión sin protección, presenta una situación intermedia de vulnerabilidad. Si bien su exposición es directa, se trata de una fuente fácil de proteger. Dado que su presencia es baja en las tres localidades, no se analiza en detalle.

- Las tomas directas de agua de lluvia, río, canal, arroyo o acequia -y lagos- (Figuras $\mathrm{N}^{\circ} 29$ y $\mathrm{N}^{\circ} 30$ ) son las más vulnerables por la carga sedimentaria que normalmente transportan los cursos y la exposición directa a la caída de cenizas y la consecuente carga en suspensión adicional que una erupción puede añadir. 


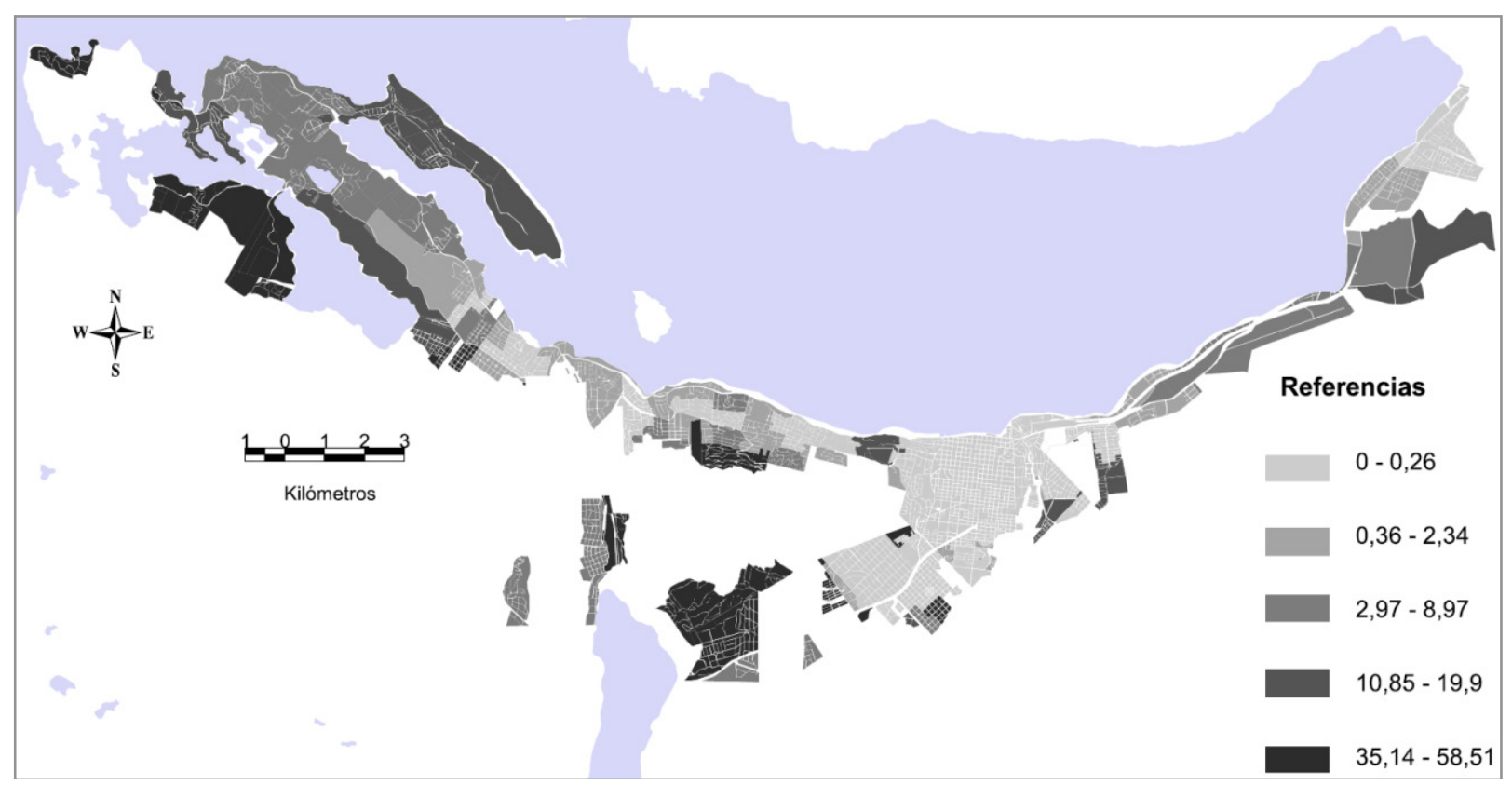

Figura $N^{\circ} 29$. Hogares con agua de lluvia, río, canal, arroyo o acequia (en \%). San Carlos de Bariloche y Dina Huapi. 2010. Los barrios del Oeste, como Península San Pedro, Villa Tacul, Llao Llao, Las Cartas, Colonia Suiza y del Sur, como Villa Arelauquen, Reina Mora y Villa Lago Gutiérrez presentan los valores más altos de hogares con este sistema de abastecimiento de agua. En cambio. El área central del espacio urbano, concentra los valores más bajos. Hacia el sector oriental, se observa que los valores vuelven a aumentar (Las Chacras, Costa del Sol). Fuente: elaboración propia en base a datos del INDEC. Censo Nacional de Población, Hogares y Viviendas 2010, procesado con Redatam +SP.

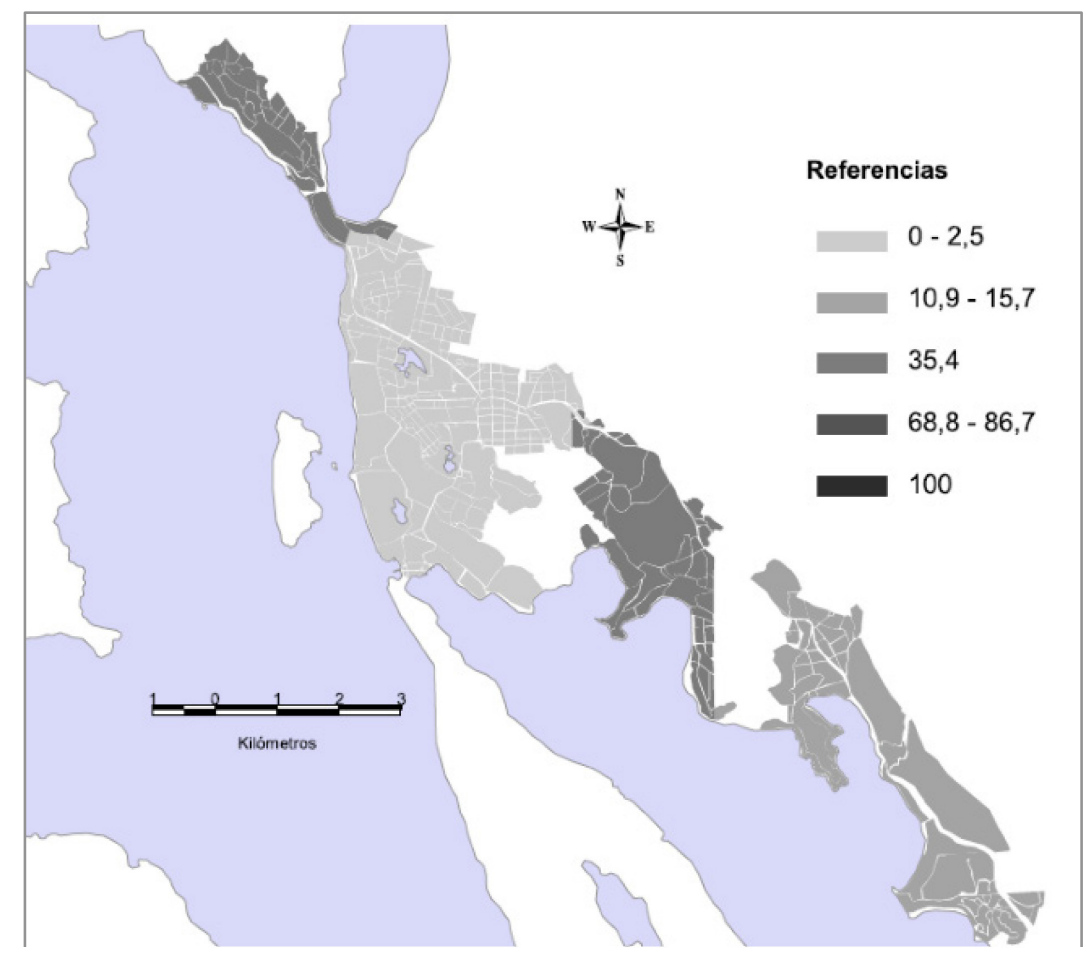

Figura N³0. Hogares con agua de lluvia, río, canal, arroyo o acequia (en \%). Villa La Angostura. 2010. Los barrios Villa Correntoso, Bandurrias, Las Balsas y Cumelén presentan los mayores valores de hogares con este 
abastecimiento de agua. Fuente: elaboración propia en base a datos del INDEC. Censo Nacional de Población, Hogares y Viviendas 2010, procesado con Redatam +SP.

Según información suministrada por el Honorable Concejo Deliberante de Villa La Angostura, en registros que constan en el Informe final de donaciones (Exp. $N^{\circ} 49 / 2011$ ) que se distribuyeron durante la emergencia volcánica de 2011, se destaca que desde el inicio de la entrega de agua (29 de Junio de 2011) hasta su culminación (19 de Agosto de 2011) en el centro de acopio, Gimnasio Barbagelata, se asistieron 4600 familias. Los registros comprobables (Cuadro $\mathrm{N}^{\circ} 9$ ) totalizaron la suma de 4.303 entregas de agua, las cuales se clasificaron según los barrios a los que se destinó dicha asistencia:

\begin{tabular}{|l|c|}
\hline \multicolumn{1}{|c|}{ Barrio } & Participación (en \%) \\
\hline Las Piedritas & 19,1 \\
\hline El Mallín & 17,9 \\
\hline Norte & 9,7 \\
\hline Las Margaritas & 9,0 \\
\hline El Once & 6,4 \\
\hline Puerto Manzano & 4,2 \\
\hline Los Volcanes & 4,1 \\
\hline Las Balsas & 3,6 \\
\hline Peumayen & 3,3 \\
\hline El Cruce & 3,2 \\
\hline El Pinar & 2,2 \\
\hline Calafate & 2,1 \\
\hline Epulafquen & 1,6 \\
\hline Otros & 13,6 \\
\hline
\end{tabular}

Cuadro $N^{\circ} 9$. Distribución de la asistencia de agua potable durante la emergencia volcánica de 2011. * Incluye: si bien la mayoría son domicilios no especificados, comprende también el centro de la ciudad, Muelle de piedra, Calfuco, Quetrihué, Parque Industrial, Huemul, Inalco, COE, Ciprés, Parque Huemul, Paso Coihue, Ejército, Puertos de la Villa, Villa Correntoso, Lomas del Correntoso, Tres Cerros, Maikana, Bandurrias, Cumelén, Brazo Rincón, perilago, Lago Espejo, entre otros). Fuente: elaboración propia sobre la base de información suministrada por el Honorable Concejo Deliberante de la localidad de Villa La Angostura.

Asimismo, entre los días 14 de Julio y 12 de Agosto de 2011, en el Centro del Día se repartió no sólo agua potable sino también leche (Cuadro $N^{\circ} 10$ ). La información procesada por barrio, sobre un total de 2.619 registros, arrojaron los siguientes resultados:

\begin{tabular}{|l|c|}
\hline \multicolumn{1}{|c|}{ Barrio } & Participación (en \%) \\
\hline El Mallín & 34,6 \\
\hline Las Margaritas & 16,5 \\
\hline Las Piedritas & 9,2 \\
\hline Norte & 7,4 \\
\hline El Cruce & 4,7 \\
\hline Calafate & 4,7 \\
\hline Peumayen & 4,4 \\
\hline
\end{tabular}




\begin{tabular}{|l|c|}
\hline El Once & 3,1 \\
\hline Epulafquen & 2,3 \\
\hline Otros $^{*}$ & 13,2 \\
\hline
\end{tabular}

Cuadro N¹0. Distribución de la asistencia de agua potable durante la emergencia volcánica de 2011. * Incluye: El Pinar, Las Balsas, Puerto Manzano, Tres Cerros, Lomas del Correntoso, Los Volcanes, Puertos de la Villa, Cumelén, Villa Correntoso, El Coihue, Muelle de Piedra, laderas del Bayo, Antilhue, Arauco, perilago, Ejército, Hogar de Ancianos, COE, Brazo Rincón, Paso Coihue, Lago Espejo, 7 Lagos, Inalco, Arroyo Colorado, domicilios sin especificar, entre otros). Fuente: elaboración propia sobre la base de información suministrada por el Honorable Concejo Deliberante de la localidad de Villa La Angostura.

El abastecimiento de agua potable fue un problema general a toda la localidad de Villa La Angostura, principalmente durante los inicios del proceso eruptivo. A diferencia de los registros de agua potable (Cuadro $\mathrm{N}^{\circ} 6$ ), la mayor demanda de agua y leche se concentró en los barrios El Mallín y Las Margaritas, hecho que resulta esperable dado que los radios censales que incluyen, entre otros, a estos barrios poseen la mayor población relativa y absoluta de niños de entre 0 y 14 años de edad, según datos del Censo Nacional de Población, Hogares y Viviendas 2010.

El análisis del abastecimiento de agua potable y su interacción con la ceniza volcánica debe abordarse con un criterio espacio-temporal y a nivel de cuenca hidrográfica: la carga sedimentaria producida por la removilización de material piroclástico en los cursos superficiales se puede prolongar por un largo período de tiempo, dependiendo del volumen de ceniza caída y la superficie de la cuenca drenada.

\subsubsection{Combustible usado principalmente para cocinar}

En momentos de emergencia volcánica por caída de ceniza, una de las principales recomendaciones que se sugiere es proteger las viviendas para evitar el ingreso de material piroclástico a las mismas, por ejemplo, sellando aberturas y chimeneas. Por esta razón, cualquier procedimiento que implique un proceso de combustión interna genera un riesgo implícito al verse reducida la ventilación de la vivienda, exponiendo a sus habitantes a una intoxicación por monóxido de carbono y es en este contexto que adquiere relevancia el combustible utilizado para cocinar. El Censo reconoce diferentes combustibles para cocinar, entre ellos: 1) gas de red, 2) gas a granel, 3) gas de tubo, 4) gas de garrafa, 5) electricidad, 6) leña o carbón y 7) otro (INDEC, 2013, p. 7).

El combustible que más relevancia adquiere para el estudio de la vulnerabilidad en el marco de caída de ceniza volcánica es la leña o carbón, el cual en muchas ocasiones suele utilizarse también para calefaccionar las viviendas. Las Figuras $N^{\circ} 31$ y $N^{\circ} 32$ exhiben la 
distribución del número viviendas con combustible de leña o carbón utilizados preferentemente para cocinar.

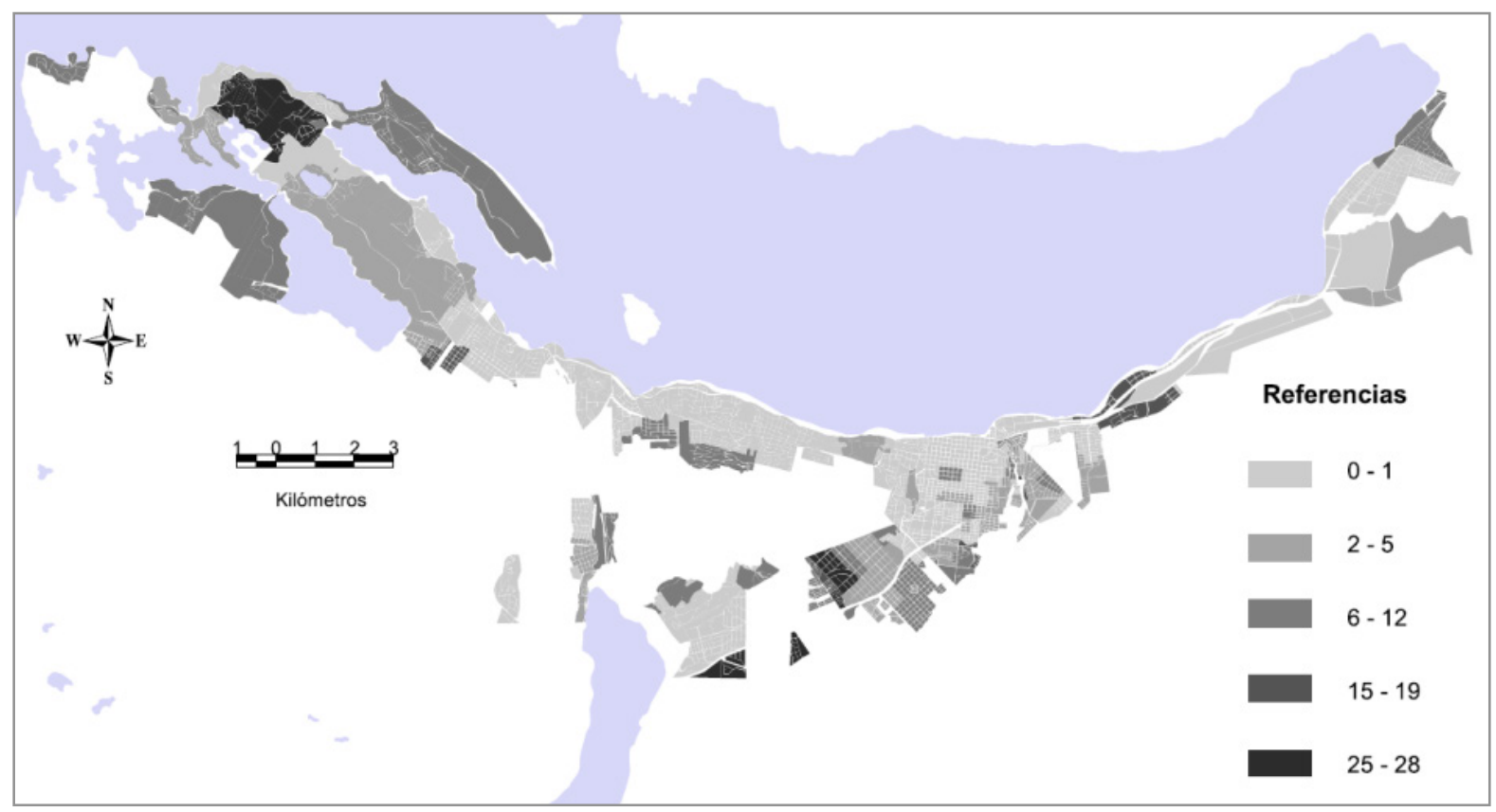

Figura $N^{\circ} 31$. Combustible usado principalmente para cocinar: leña o carbón (viviendas). San Carlos de Bariloche y Dina Huapi. 2010. Los barrios del sur como El Frutillar y Unión, Reina Mora y El Pilar así como algunos del oeste como Villa Llanquihue y Península San Pedro, presentan los valores más elevados. Fuente: elaboración propia en base a datos del INDEC. Censo Nacional de Población, Hogares y Viviendas 2010, procesado con Redatam + SP. 


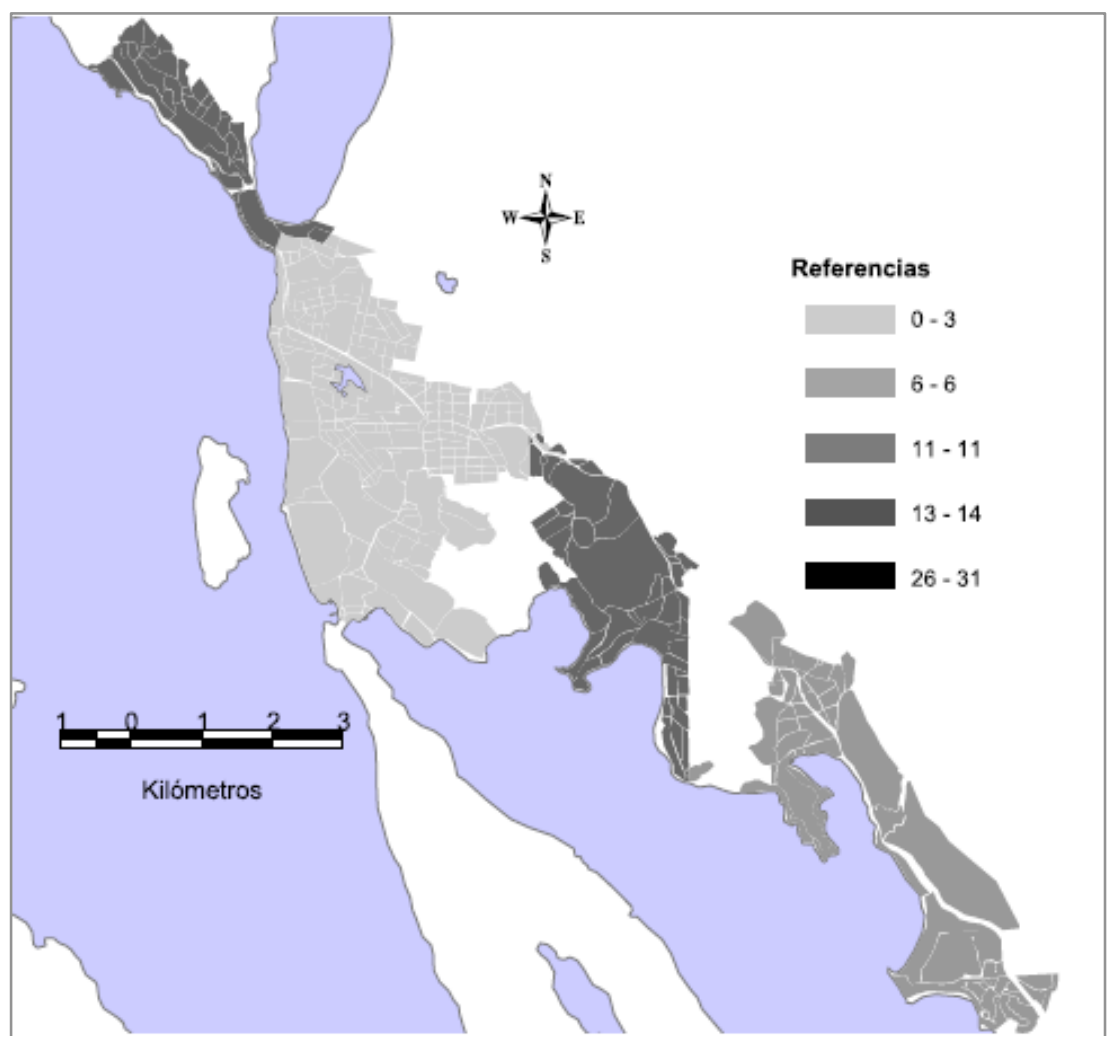

Figura N³2. Combustible usado principalmente para cocinar: leña o carbón (viviendas). Villa La Angostura. 2010. Los barrios Las Balsas, Cumelén, Arauco, Las Bandurrias y Villa Correntoso, presentan valores medios. Puerto Manzano, Loma Guacha, Muelle de Piedra y Calfuco presentan valores bajos, siendo la zona central del ejido urbano la que presenta los valores más bajos. Fuente: elaboración propia en base a datos del INDEC. Censo Nacional de Población, Hogares y Viviendas 2010, procesado con Redatam +SP.

\subsubsection{Mapas de vulnerabilidad social para las localidades costeras del lago Nahuel Huapi}

En función de los impactos conocidos para las caídas piroclásticas y de la importancia intrínseca que presenta cada indicador, se procedió a la construcción de posibles escenarios de vulnerabilidad social frente a la caída de ceniza volcánica (vale recordar que la construcción de escenarios ha sido uno de los aspectos desarrollados en el marco teórico). En relación a esto, surge un interrogante clave ¿cuál es el criterio metodológico correcto para construir un escenario de vulnerabilidad que mejor represente la realidad? Para poder llegar a resultados más consistentes es necesario aplicar diferentes criterios metodológicos. Dado que la mayoría de los registros de la erupción de 2011 corresponden a Villa La Angostura, resulta oportuno realizar la discusión metodológica en esta localidad ya que es aquí donde se puede visualizar la correspondencia entre las condiciones previas de vulnerabilidad y la ayuda prestada a la población. 


\section{Propuesta metodológica del PIRNA}

El mapa final de vulnerabilidad social presentaba la opción de adoptar un criterio clasificatorio cuantitativo o bien uno cualitativo. En cuanto al primero, se puede tomar como ejemplo el interesante trabajo desarrollado por el PIRNA (Natenzon y González, 2010) para establecer un Índice de Vulnerabilidad Social (IVS) a partir de 10 indicadores, a saber:

- Población menor o igual a 14 años

- Población de mayores o igual a 65 años

- Hogares con jefatura de hogar femenino

- Población sin cobertura de salud (obra social y/o plan de salud privado o mutual)

- Población de 10 años o más analfabeta

- Población desocupada

- Población en hogares con NBI

- Población en hogares sin presencia de agua corriente en red

- Población en hogares sin presencia de servicio de cloacas

- Población en hogares sin presencia de transporte público

Las autoras, sistematizaron estos indicadores utilizando el criterio de cortes naturales y estableciendo cinco rangos o intervalos. A través de la herramienta de clasificación de datos tipificaron esta información en cinco número de clases, asignándoles un valor correlativo ( muy bajo=1, bajo=2, Medio=3, Alto=4, muy alto=5). Estos puntajes se sumaron para cada subíndice y para el IVS. Sobre los valores obtenidos por sumatoria se volvió a aplicar el criterio de los cinco rangos, estableciendo nuevamente la valoración de 1 a 5 . (Natenzon y González, 2010, p. 206).

La Figura $N^{\circ} 33$ muestra el IVS aplicado a la localidad de Villa La Angostura por radios censales $^{19}$.

\footnotetext{
${ }^{19}$ Los datos utilizados para determinar el IVS para Villa La Angostura se encuentras disponibles en el anexo.
} 


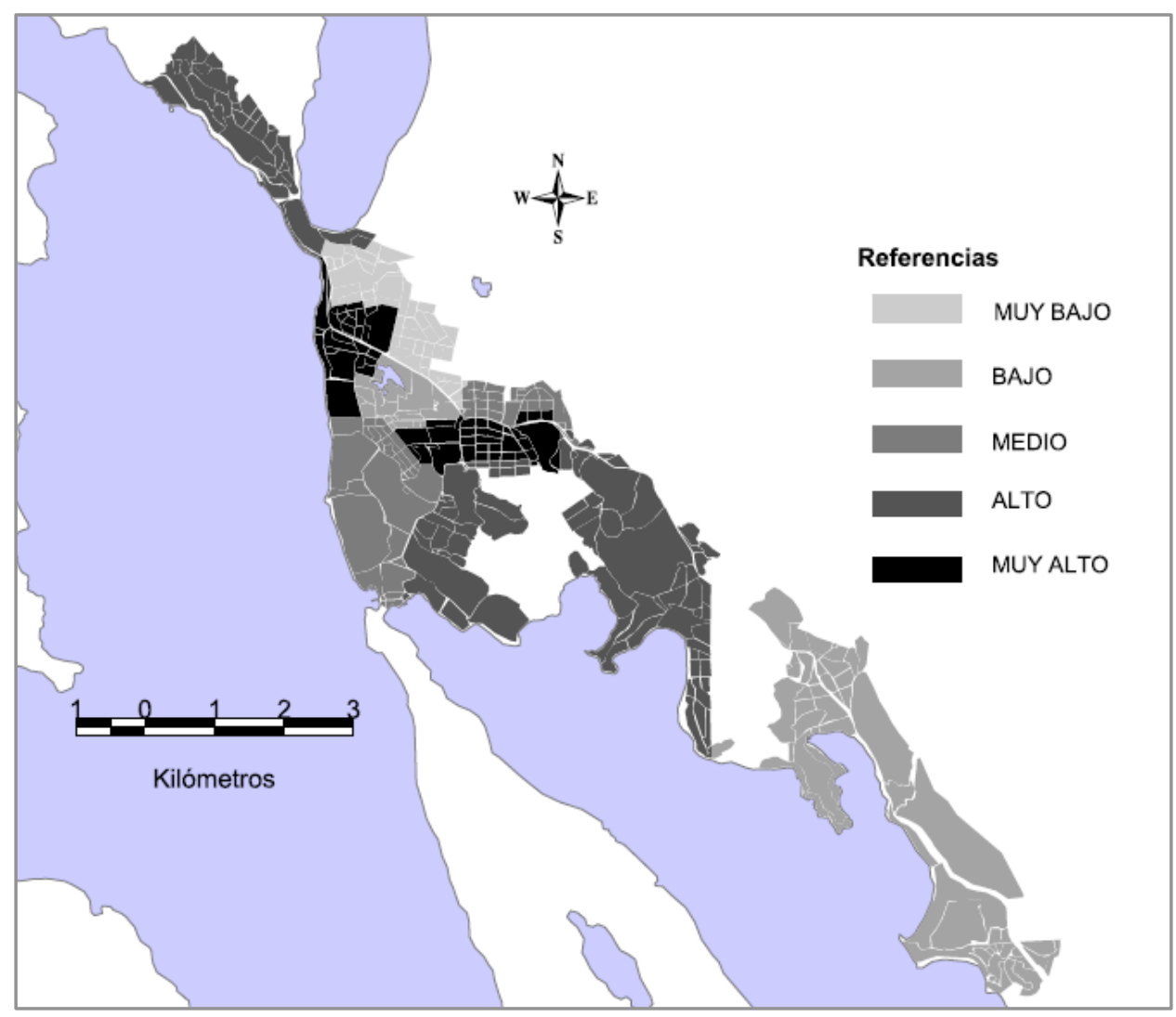

Figura N³3. IVS. Villa La Angostura. Barrios del área central del ejido municipal como El Cruce, El Once y Calafate así como también del noroeste como Lomas del Correntoso y Epulafquen presentan los índices más elevados siendo escasos los barrios con baja vulnerabilidad, como Epulafquen y Norte. Fuente: adaptado de Natenzon y González (2010).

\section{Propuesta metodológica a partir del Proceso Analítico Jerárquico de Saaty}

A partir de los ocho indicadores considerados a lo largo del capítulo, se procedió a ponderarlos a partir de la metodología elaborada por Saaty, conocida como Analytical Hierarchy Process - AHP (Proceso Analítico Jerárquico - PAJ). En primer lugar, el Cuadro $N^{\circ} 11$, presenta la ponderación de los factores o rangos que componen las variables más relevantes para la vulnerabilidad frente a la caída de ceniza volcánica, ponderación que se realiza según el criterio de autor.

\begin{tabular}{|c|c|}
\hline \multicolumn{1}{|c|}{ Intervalo } & Valor \\
\hline Muy Alto & 9 \\
\hline Alto & 7 \\
\hline Medio & 5 \\
\hline Bajo & 3 \\
\hline Muy Bajo & 1 \\
\hline
\end{tabular}

Cuadro $N^{\circ} 11$. Ponderación de los intervalos que se asignarán a cada variable o indicador seleccionado. 
La forma más efectiva de concentrar el juicio es tomar un par de elementos y compararlos en una sola propiedad sin preocuparse por otras propiedades $u$ otros elementos (Saaty, 1990, p. 12). El Método de Comparación por Pares de Saaty $(1977,1990)$ es uno de los métodos de ponderación, dentro del método de Jerarquías Analíticas, donde a cada una de las clasificaciones que se efectuaron para cada factor se le asignó un valor de entre 1 y 9 (Saaty, 1990, p. 15), donde:

$1=$ Igual importancia.

$3=$ moderada importancia de uno sobre otro.

$5=$ =importancia esencial o fuerte.

$7=$ importancia muy fuerte.

$9=$ importancia extrema.

2, 4, 6, 8=valores intermedios entre los dos juicios adyacentes.

En Cuadro $\mathrm{N}^{\circ} 12$ muestra los pesos calculados en el proceso de ponderación de las variables, es decir, de la relación de importancia entre ellas. La Razón de Consistencia (CR) permite verificar los resultados de la asignación de juicios de valor y se considera aceptable si el valor es igual o inferior a 0,1 .

\begin{tabular}{|c|c|c|c|c|c|c|c|c|c|}
\hline & $\begin{array}{l}\text { Mat. } \\
\text { Cub. Ext. } \\
\text { techo }\end{array}$ & $\begin{array}{l}\text { Proc. agua } \\
\text { de beber y } \\
\text { cocinar }\end{array}$ & $\begin{array}{l}\text { Viv. } \\
\text { inconv. }\end{array}$ & Hacin. & Desoc. & $\begin{array}{l}\text { J. de } \\
\text { hogar } \\
\text { fem. }\end{array}$ & Analf. & $\begin{array}{l}\text { Comb. } \\
\text { cocina }\end{array}$ & Peso \\
\hline $\begin{array}{c}\text { material cubierta } \\
\text { exterior techo }\end{array}$ & 1 & & & & & & & & 0,3297 \\
\hline $\begin{array}{l}\text { procedencia del } \\
\text { agua de beber y } \\
\text { cocinar }\end{array}$ & $1 / 2$ & 1 & & & & & & & 0,2129 \\
\hline $\begin{array}{c}\text { vivienda } \\
\text { inconveniente }\end{array}$ & $1 / 3$ & $1 / 2$ & 1 & & & & & & 0,1290 \\
\hline hacinamiento & $1 / 5$ & $1 / 3$ & $1 / 2$ & 1 & & & & & 0,0842 \\
\hline desocupación & $1 / 5$ & $1 / 3$ & $1 / 2$ & 1 & 1 & & & & 0,0926 \\
\hline $\begin{array}{l}\text { Jefe de hogar } \\
\text { femenino }\end{array}$ & $1 / 5$ & $1 / 3$ & $1 / 2$ & 1 & $1 / 2$ & 1 & & & 0,0687 \\
\hline analfabetismo & $1 / 5$ & $1 / 5$ & $1 / 3$ & $1 / 3$ & $1 / 3$ & $1 / 2$ & 1 & & 0,0454 \\
\hline $\begin{array}{c}\text { combustible usado } \\
\text { principalmente para } \\
\text { cocinar }\end{array}$ & $1 / 5$ & $1 / 5$ & $1 / 3$ & $1 / 3$ & $1 / 3$ & $1 / 2$ & $1 / 2$ & 1 & 0,0374 \\
\hline
\end{tabular}

Cuadro $\mathrm{N}^{\circ} 12$. Ponderación de las variables implicadas en la metodología. El material de la cubierta exterior del techo, la procedencia del agua de beber y cocinar y la vivienda inconveniente son los tres factores más relevantes para este estudio.

A partir del procedimiento de Combinación Lineal Ponderada (CLP) cada factor estandarizado es multiplicado por su correspondiente peso, son sumados y luego la suma es dividida por el número de variables. Luego, se realiza la superposición espacial de los criterios, calculando para cada radio censal (Cuadro $\mathrm{N}^{\circ} 13$ ) el valor de capacidad a partir de 
la ecuación a) $\mathrm{li}=\sum \mathrm{p}_{\mathrm{i}} \mathrm{x}_{\mathrm{i}}$, correspondiente a los valores de las alternativas $\left(\mathrm{X}_{\mathrm{ij}}\right)$ y a los pesos de los criterios $\left(\mathrm{P}_{\mathrm{ij}}\right)$.

\begin{tabular}{|c|c|c|c|c|c|c|c|c|c|}
\hline \multirow{3}{*}{$\begin{array}{c}\text { Radios de la } \\
\text { Fracción } 1 \\
\text { implicados }\end{array}$} & \multicolumn{6}{|c|}{ NBI } & \multirow{3}{*}{$\begin{array}{c}\text { Proc. Agua } \\
\text { para Beber } \\
\text { y Cocinar } \\
0,2129\end{array}$} & \multirow{3}{*}{$\begin{array}{l}\text { Comb. } \\
\text { Cocina } \\
0,0374\end{array}$} & \multirow{3}{*}{ Totales } \\
\hline & Desoc. & $\begin{array}{l}\text { J. De Hogar } \\
\text { Fem. }\end{array}$ & Analf. & Hacin. & $\begin{array}{l}\text { Viv. } \\
\text { Incon. }\end{array}$ & $\begin{array}{l}\text { Mat. Cub. } \\
\text { Ext. Techo }\end{array}$ & & & \\
\hline & 0,0926 & 0,0687 & 0,0454 & 0,0842 & 0,129 & 0,3297 & & & \\
\hline 3 & 5 & 5 & 5 & 5 & 3 & 7 & 5 & 5 & 5,4009 \\
\hline 4 & 3 & 7 & 3 & 1 & 1 & 1 & 1 & 1 & 1,6881 \\
\hline 5 & 7 & 7 & 9 & 5 & 9 & 9 & 1 & 1 & 6,3373 \\
\hline 6 & 7 & 7 & 1 & 1 & 7 & 5 & 1 & 1 & 4,0605 \\
\hline 7 & 7 & 9 & 9 & 7 & 7 & 9 & 1 & 1 & 6,3851 \\
\hline 8 & 7 & 5 & 5 & 3 & 1 & 5 & 1 & 1 & 3,4991 \\
\hline 9 & 7 & 9 & 5 & 7 & 3 & 7 & 1 & 1 & 5,0281 \\
\hline 10 & 7 & 5 & 1 & 5 & 3 & 5 & 3 & 3 & 4,2445 \\
\hline 11 & 9 & 7 & 7 & 7 & 7 & 7 & 1 & 1 & 5,6827 \\
\hline 12 & 5 & 7 & 1 & 1 & 5 & 5 & 1 & 1 & 3,6173 \\
\hline 13 & 9 & 9 & 5 & 1 & 7 & 7 & 1 & 1 & 5,2241 \\
\hline 14 & 5 & 5 & 7 & 9 & 7 & 9 & 1 & 1 & 6,0027 \\
\hline
\end{tabular}

Cuadro N¹3. Combinación lineal ponderada. Cada radio censal que forma parte del ejido urbano de Villa La Angostura muestra un valor total que es el resultado tanto de la ponderación de rangos como así también de la ponderación de las variables utilizadas.

De este modo, a cada radio censal le corresponderá un valor, los cuales a su vez, serán clasificados en muy alto, alto, medio, bajo o muy bajo (Figura $N^{\circ} 34$ ), siguiendo el criterio de los intervalos naturales. 


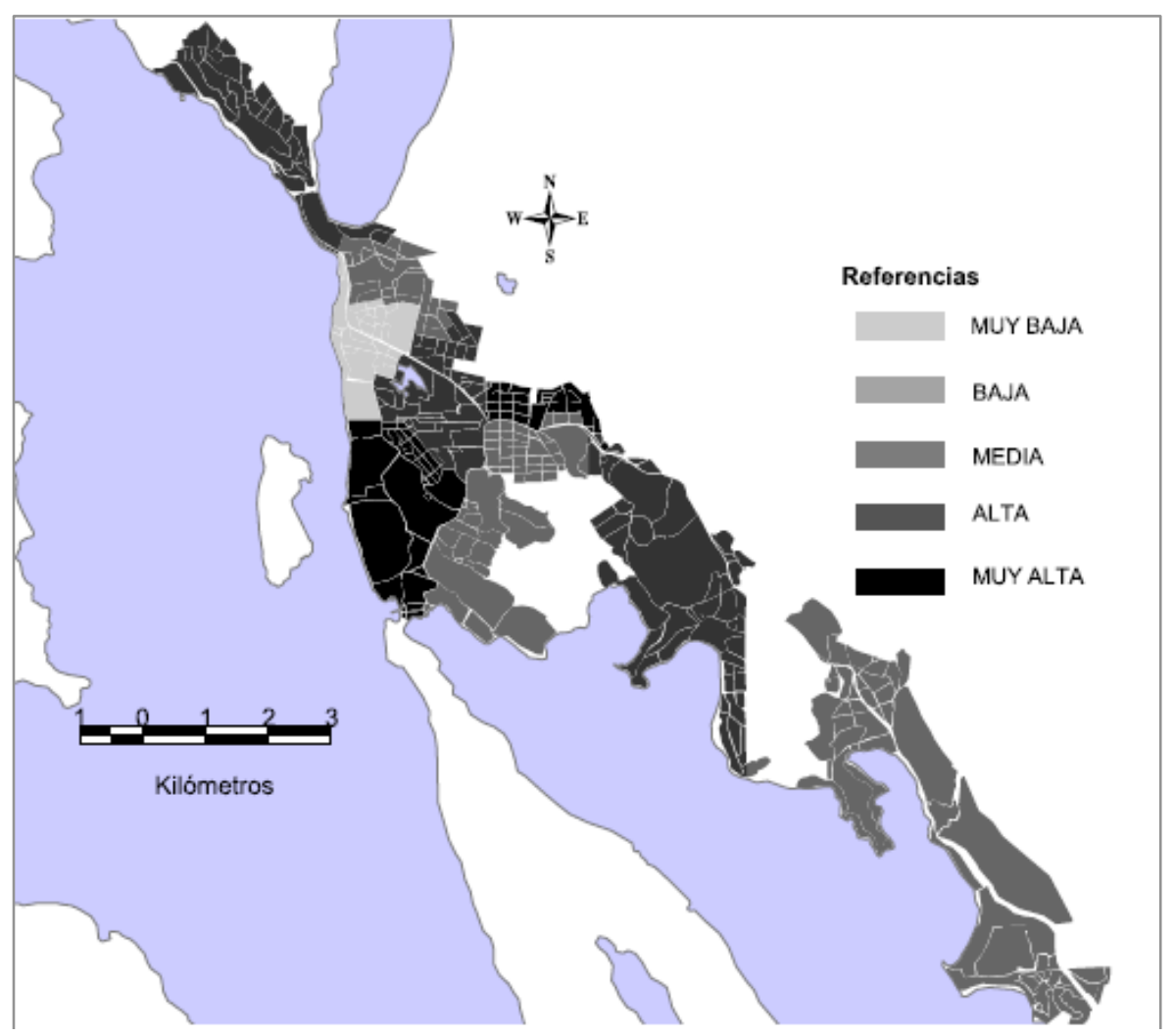

Figura N³4. Mapa de Vulnerabilidad de Villa La Angostura según el Método Analítico Jerárquico de Saaty.

\section{Propuesta cuali-cuantitativa}

Para obtener un mapa final de vulnerabilidad se optó por la adopción de un criterio cuali-cuantitativo. Es decir, una vez definidos y justificados a lo largo del capítulo los principales indicadores en función de su relevancia frente a la caída de ceniza, se procedió a definir un criterio cuantitativo para establecer categorías de vulnerabilidad alta, media y baja, donde la reducción a tres rangos expresen espacial y visualmente las diferencias al interior de la localidad. Estos criterios se detallan a continuación:

- Vulnerabilidad Alta: si la mitad o más indicadores son altos-muy altos (en el caso de la procedencia del agua, se considera como vulnerable sólo la provisión a través agua de lluvia, río, canal, arroyo o acequia).

- Vulnerabilidad Media:

- si tres indicadores son altos-muy altos ó

- si dos indicadores son altos-muy altos y ambos pertenecen a las condiciones habitacionales, es decir, corresponden a las NBI o bien al material predominante de la cubierta exterior del techo.

- Vulnerabilidad Baja: 
- si como máximo un indicador es alto-muy alto ó

- si dos indicadores altos-muy altos no corresponden a las condicionales habitacionales, ya sean referidas a las NBI o bien al material predominante de la cubierta exterior del techo.

A partir de este criterio metodológico, el mapa de vulnerabilidad social (Figura $\mathrm{N}^{\circ} 35$ ) para Villa La Angostura muestra una vulnerabilidad social con importantes diferencias con respecto a la metodología anterior.

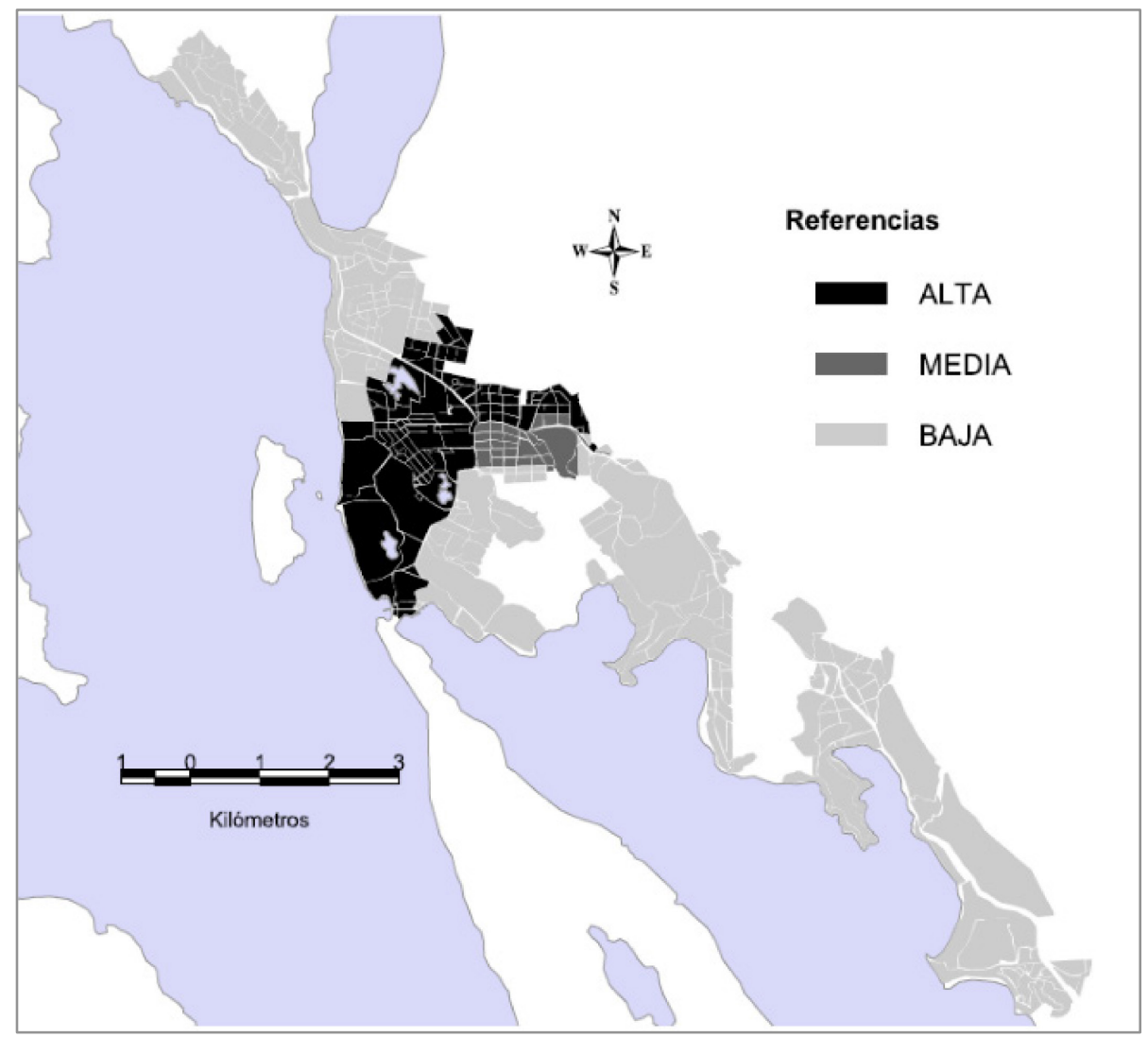

Figura N³5. Mapa de vulnerabilidad. Villa La Angostura. Los barrios Los Volcanes, Las Piedritas, El Cruce, El Mallín, Las Margaritas, Peumayén, Norte y Calafate presentan los niveles de vulnerabilidad más elevados dentro del área urbana correspondiente a la localidad de Villa La Angostura y sólo el barrio El Once presenta condiciones de vulnerabilidad media. Fuente: elaboración propia.

\section{Discusión}

La discusión inicial acerca de qué criterio metodológico representa mejor la realidad da lugar a nuevos interrogantes ¿por qué los resultados son tan variables? ¿a qué obedecen esas diferencias? 
En primer lugar, el trabajo desarrollado por el PIRNA es un índice de vulnerabilidad social, un referente y punto de partida importante, motivo por el cual se encuentra abordado en esta tesis pero, al ser concebida para analizar la vulnerabilidad social en general, no hay un conjunto de indicadores particularmente relevantes y específicos para la caída de ceniza volcánica. A su vez, los indicadores considerados en esa propuesta no se encuentran ponderados, es decir, se hallan todos en el mismo plano de igualdad. La especificidad de los indicadores referidos a la vulnerabilidad frente a la caída de piroclastos, sumada a la ponderación de las mismas, son dos aspectos metodológicos clave a tener en cuenta en la construcción de una metodología para evaluar la vulnerabilidad social frente a la caída de ceniza volcánica.

En segundo lugar, aun cuando se aplicó una metodología cuantitativa como el Proceso Analítico Jerárquico y otra de corte más cualitativo como el propuesto en este capítulo, las diferencias en los resultados obtenidos son considerables. En efecto, cuando se observa con detalle el resultado de la aplicación del Proceso Analítico Jerárquico, algunos radios censales con población que goza de cierto bienestar (entre ellos un barrio privado), ubicados en el sudeste y noroeste de la localidad, aparecen con vulnerabilidad media y alta, cuando la metodología cuali-cuantitativa aquí propuesta señala que dichos radios censales presentan una vulnerabilidad baja. Vale recordar que esta metodología también fue creada con la finalidad de representar en buena medida las acciones llevadas a cabo durante la emergencia volcánica de 2011 contemplando hacia qué sitios se orientó la ayuda. Entonces, ¿Por qué ciertos radios censales aparecen como vulnerables cuando podría pensarse que no lo son? La respuesta radica en el carácter temporal de la respuesta a las necesidades de la población que fueron expuestas por la emergencia.

El mapa que presenta la metodología cuali-cuantitativa señala los espacios más vulnerables con inmediatez a la emergencia volcánica, es decir, que los barrios con la población más necesitada en el momento de la emergencia se ubicaban en esos radios censales. En cambio, el mapa que presenta la metodología cuantitativa señala la presencia de sitios vulnerables que requirieron (y requieren aún) de cambios mediatos, más bien estructurales, como por ejemplo, mejoras en el sistema de provisión de agua, que según se mostró, efectivamente se llevaron a cabo y fueron detalladas precedentemente. Por último, estas diferencias de resultados ponen una vez más en relieve lo planteado desde la Teoría Social del Riesgo, esto es, que el concepto de vulnerabilidad elimina la dicotomía pobre-no pobre y los cambios implementados a partir de los aprendizajes de la erupción de 2011, 
hacen suponer que la vulnerabilidad se ha reducido sustancialmente, y lo será más aún cuando ciertas infraestructuras como la red de gas natural se extiendan a toda la localidad.

\section{Vulnerabilidad social en San Carlos de Bariloche y Dina Huapi}

A partir de las metodologías basadas en el Proceso Analítico Jerárquico y la Propuesta cuali-cuantitativa desarrollada en esta tesis, presentada y discutida anteriormente, se presentan los mapas de vulnerabilidad social frente a la caída de ceniza volcánica para las localidades de San Carlos de Bariloche y Dina Huapi (Figuras №36 y №37).

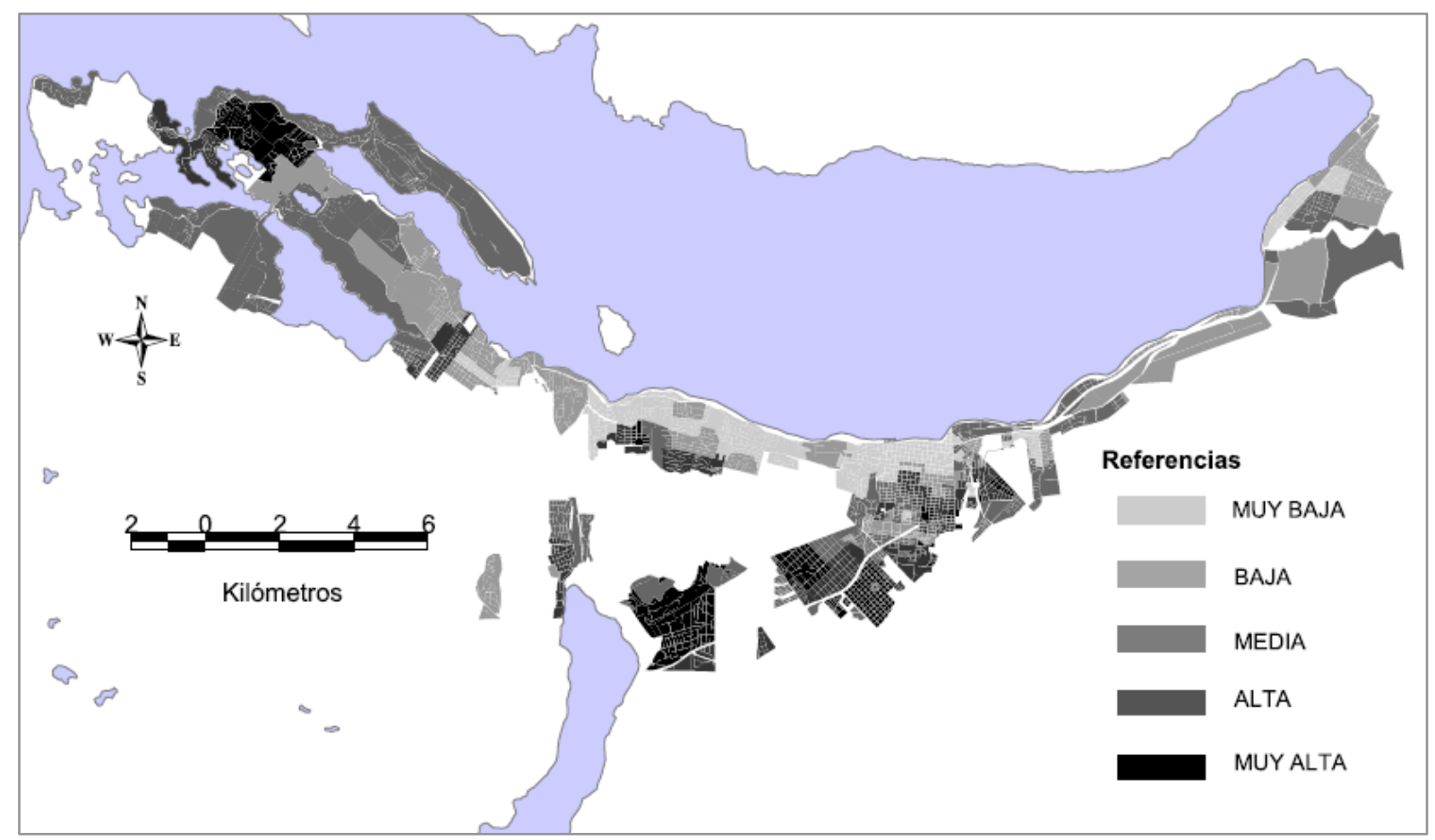

Figura N³6. Mapa de Vulnerabilidad. San Carlos de Bariloche y Dina Huapi. Los indicadores ponderados en función del Proceso Analítico Jerárquico, muestran grandes espacios urbanos del ejido San Carlos de Bariloche y Dina Huapi con vulnerabilidad media o superior. A los barrios del sur, que recibieron la mayor asistencia durante la emergencia de 2011 según Protección Civil Municipal, se deben agregar los del oeste. La ponderación de variables fue expuesta en el caso de Villa La Angostura. La información relativa a la Combinación Lineal Ponderada se encuentra disponible en el Anexo. Fuente: elaboración propia. 


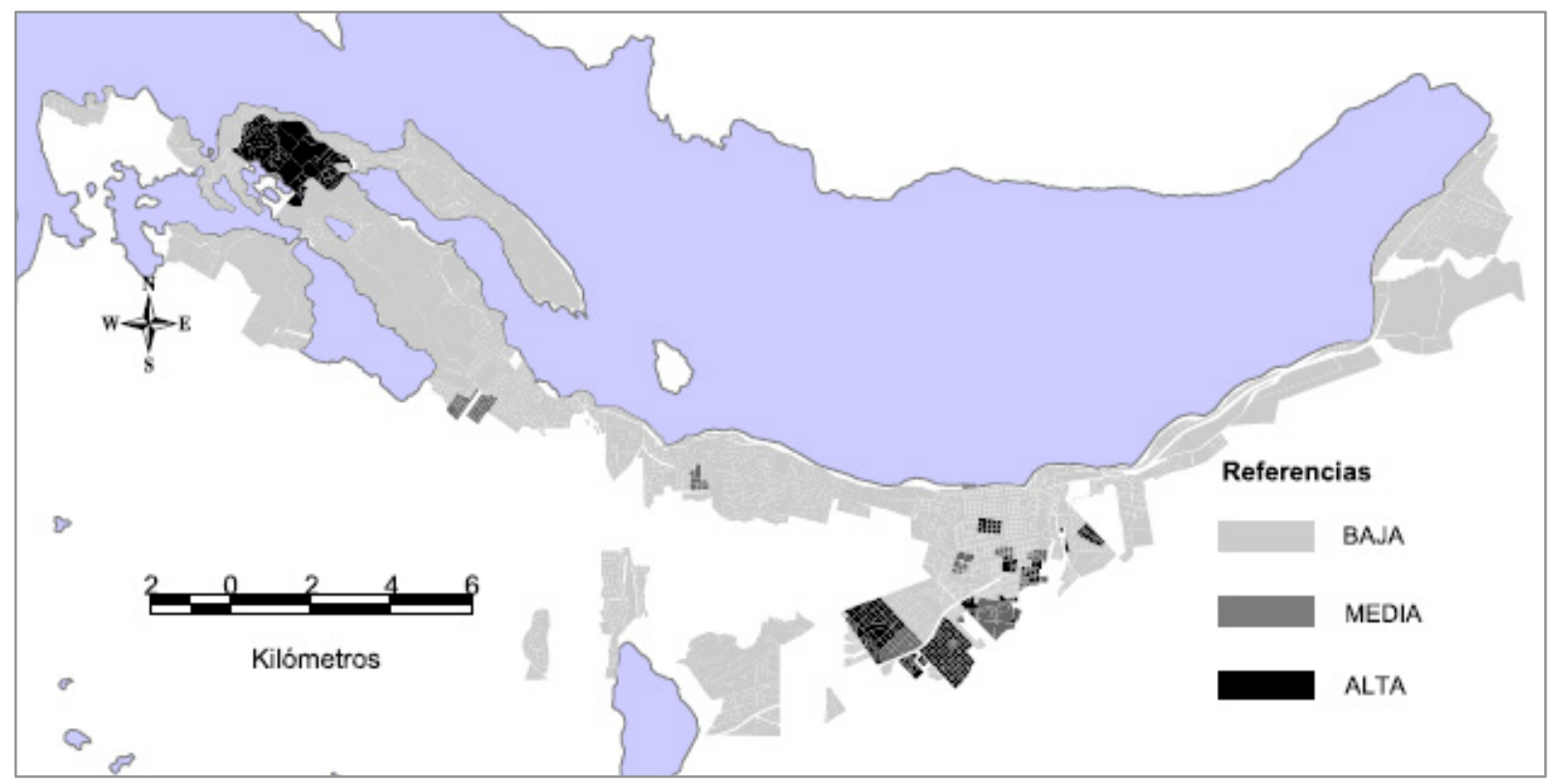

Figura №37. Mapa de Vulnerabilidad. San Carlos de Bariloche y Dina Huapi. Las áreas más vulnerables se presentan en sector Sur del área urbana comprendiendo los barrios Unión, Islas Malvinas, Nahuel Hue y un sector del Frutillar. En el sector occidental del ejido urbano, se encuentra Villa Llanquihue. Más cercano al centro de la ciudad de San Carlos de Bariloche, los barrios 10 de Diciembre, Santo Cristo, Perito Moreno y las Mutisias también presentan valores elevados. Por último, un sector de los barrios Cementerio y San Francisco presentan similares condiciones. Fuente: elaboración propia. 


\subsection{Bibliografía del capítulo}

ALLOWAY B. V.; PEARCE N. J. G.; VILLAROSA G.; OUTES V.; MORENO P. I. 2015. Multiple melt bodies fed the AD 2011 eruption of Puyehue-Cordón Caulle, Chile. Sci. Rep. 5, 17589; doi: 10.1038/srep17589. 8 Págs.

ANDRADE M. I. 2013. Ocurrencia de inundaciones en el Gran La Plata Abril de 2013. IV Congreso Nacional de Geografía de Universidades Públicas y XI Jornadas Cuyanas de Geografía. Facultad de Filosofía y Letras de la Universidad Nacional de Cuyo. Mendoza, 23 al 26 de octubre 2013, p. 1-10.

ANDRADE M. I; PLOT B.; INFESTA M. E.; SCARPATTI O. E.; PINTOS P.; PAPALARDO M. M.; VALLEJOS V. H.; MONTES M. del C.; GRATTI P.; LOSANO G.; CARUT C.; BENITEZ M.; DEL RÍO, J. P. 2003. Problemática de inundaciones en el Gran La Plata: mapa de riesgo hídrico desde la teoría social del riego. En PINTO P. (Comp.). Pensar La Plata. Políticas públicas, Sociedad y Territorio en la década de los noventa. Ed. Al Margen; La Plata; p 7199.

ANSELMI F.; VALOT N.; SPINELLI G. 2012. Diagnóstico y propuestas de diversificación productiva Departamento Los Lagos. Informe técnico. Inédito. p. 1-33.

BARRENECHEA J.; GENTILE E.; GONZÁLEZ S.; NATENZON C. 2000. Una propuesta metodológica para el estudio de la vulnerabilidad social en el marco de la Teoría Social del Riesgo. IV Jornadas de Sociología. Facultad de Ciencias Sociales. UBA. Buenos Aires, 6 al 9 de Noviembre de 2000, p. 1-13.

BECK U. 2007. Vivir en la sociedad del riesgo mundial. En: http://www.cidob.org/es/publicaciones/documentos/dinamicas_interculturales/vivir_en_la_soci edad_del_riesgo_mundial_living_in_the_world_risk_society. Documentos CIDŌB, $\bar{N}^{\circ}$, Barcelona, Julio de 2007, p. 1-57.

BENGTSSON L. y ENELL M. 1986. Chemical Analysis. En BERGLUND B. E. Handbook of Holocen Palaeoecology and Palaeohydrology. John Wiley \& Sons, Chichester, Inglaterra, Reino Unido. Págs. 423-451.

BLAIKIE P.; CANNON T.; DAVID I.; WISNER B. 1996. Vulnerabilidad. El entorno social, económico y político de los desastres. En http://www.desenredando.org, La Red, Julio de 1996, p. 1-290.

BRONK RAMSEY C. (2008). Deposition models for chronological records. Quaternary Science Reviews, 27(1), pp. 42-60.

CAPUTO M. G.; HARDOY J. E.; HERZER, H. M. 1985. La inundación en el Gran Resistencia (Provincia del Chaco, Argentina) 1982-1983. Desastres Naturales y Sociedad en América Latina, Vol. 4, Grupo Editor Latinoamericano, Buenos Aires, p. 129-156.

CARDONA O. D. 1993. Evaluación de la amenaza, la vulnerabilidad y el riesgo. "Elementos para el Ordenamiento y la Planeación del Desarrollo". En MASKREY A. (Comp.). 1993. Los desastres no son naturales. La Red. En: http://www.desenredando.org, Págs. 45-65.

CÓRDOBA G.; VILLAROSA G.; SHERIDAN M.; VIRAMONTE J. G.; BEIGT D.; SALMUNI G. 2015. Secondary lahar hazard assessment for Villa La Angostura, Argentina, using TwoPhase-Titan modelling code during 2011 Cordón Caulle eruption. Natural Hazards and Earth System Sciences Discussions, 15, p. 757-766. 
CRAIG H.; WILSON T.; STEWART C.; VILLAROSA G.; OUTES V.; CRONIN S.; JENKINS S. 2016. Agricultural impact assessment and management after three widespread tephra falls in Patagonia, South America. Natural Hazards. June 2016, Vol. 82, Issue 2, pp. 1167-1229.

CRUZ REYNA S. de la. 1996. Estimación del riesgo volcánico en términos de la distribución estadística de erupciones explosivas. México, D.F; México. Sistema Nacional de Protección Civil. Centro Nacional de Prevención de Desastres (CENAPRED); feb. 1996. (Cuadernos de Investigación, 38). 27 Págs.

DELMÉNICO A.; VILLAROSA G.; BEIGT D.; OUTES V. 2015. "Pensando el volcanismo en términos de vulnerabilidad: la construcción de escenarios como herramienta de gestión de riesgos frente a la caída de ceniza volcánica en Bariloche y Dina Huapi (Patagonia, Argentina)". En actas del Seminario Internacional "Ciencias Sociales y Riesgo de Desastres en América Latina: un encuentro inconcluso". Bs. As., 15-17 de Septiembre de 2015. En: http://www.pirna.com.ar/files/pirna/SICSYRD_PON_DELMENICO_Agustin.pdf

DELMÉNICO A.; VILLAROSA G.; BEIGT D.; OUTES V.; ANDRADE M. I.; MANZONI C. (2016) Census indicators as a tool to assess social vulnerability to ashfall events in Argentina: the case of Villa La Angostura during 2011 Cordón Caulle eruption. En Actas del Congreso "Cities on volcanoes 9". Puerto Varas, Chile, 20-25 de Noviembre de 2016.

DELMÉNICO A.; VILLAROSA G.; BEIGT D.; OUTES V.; ANDRADE M. I.; MANZONI C. Los indicadores censales como herramienta para evaluar la vulnerabilidad social frente a la caída de ceniza volcánica. El caso de Villa La Angostura (Argentina) durante la erupción del Cordón Caulle 2011. Revista Universitaria de Geografía de la Universidad Nacional del Sur. En prensa.

DZENDOLETAS M. I. 2012. "Determinación y análisis de áreas de potencial conflicto en el uso del suelo en el ejido municipal de San Carlos de Bariloche utilizando la tecnología de los Sistemas de Información Geográfica". Tesis de Maestría en Gestión Ambiental del Desarrollo Urbano. Inédito.

EIRD/ONU. 2004. Vivir con el Riesgo. Informe mundial sobre iniciativas para la reducción de desastres. ONU. Ginebra. En http://www.eird.org/vivir-con-el-riesgo/index2.htm; p. 1-624.

GELLERT-DE PINTO G. I. 2012. El cambio de paradigma: de la atención de desastres a la gestión del riesgo. Boletín Científico Sapiens Research, 2 (1), p.13-17.

GIDDENS A. 1993. Consecuencias de la Modernidad. Madrid, Alianza, Sec. I: págs. 15-59.

GÓMEZ A. R. 2005. Espectrometría de masas con aceleradores (AMS): aplicación a la datación por radiocarbono. Isagogé, (2), 4. pp. 19-22.

GONZALEZ S. 2001. Gestión del riesgo por inundaciones en la ciudad de Buenos Aires. Situación actual y alternativa. Realidad Económica, N¹77, p. 1-14.

HEIRI O.; LOTTER A. F.; LEMCKE G. 2001. Loss on ignition as a Method for Estimating Organic and Carbonate Content in Sediments: Reproducibility and Comparability of Results. Journal of Paleolimnology 25. Págs. 101-110.

HERZER H. y GUREVICH R. (a). 1996. Construyendo el riesgo ambiental en la ciudad. Desastres y sociedad, № 7, Año 4. La red. Julio/Diciembre 1996, Págs. 9-17.

HERZER H. y GUREVICH R. (b). 1996. Degradación y desastres: parecidos y diferentes: tres casos para pensar y algunas dudas para plantear. En FERNANDEZ M. A. (Comp.) Ciudades en riesgo. Degradación Ambiental, Riesgos Urbanos y Desastres. La Red, Lima, p. 75-91. 
INDEC. 2013. Censo Nacional de Población Hogares y Viviendas 2010. Censo del Bicentenario. Base de Datos REDATAM. Definición de los indicadores. Serie Base de datos Censo 2010. Abril 2013. Versión Digital; p. 1-2.

LAVELL A. 1993. Ciencias Sociales y desastres naturales en América Latina: un encuentro inconcluso. En MASKREY A. Comp. 1993. Los desastres no son naturales. La Red. En http://www.desenredando.org; p. 111-127.

LAVELL A. 1996. Degradación ambiental, riesgo y desastre urbano. Problemas y conceptos: hacia la definición de una agenda de investigación. En FERNANDEZ M. A (Comp.) Ciudades en riesgo. Degradación Ambiental, Riesgos Urbanos y Desastres. La Red, Lima, p. 12-42.

LAVELL A. 2009. Reducción del Riesgo de Desastres en el Ámbito Local: Lecciones desde la Subregión Andina. Serie: Experiencias significativas de desarrollo local frente a los riesgos de desastres. Primera Edición. Comunidad Andina. Lima, Perú.

LEE S.; BRONK RAMSEY C.; HARDIMAN M. 2013. Modeling the age of the Cape Riva (y-2) tephra. 21st International Radiocarbon Conference. A J T Jull \& C Hatté (Eds.). RADIOCARBON, Vol. 55, N²-3, pp. 741-747.

MASKREY A. (Comp.). 1993. Los desastres no son naturales. En http://www.desenredando.org. La Red, p. 1-140.

NATENZON C. E. 1995. Catástrofes naturales, riesgo e incertidumbre. Serie de Documentos e Informes de Investigación, N 197; FLACSO; p. 1-19.

NATENZON C. E. 2003. Inundaciones catastróficas, vulnerabilidad social y adaptaciones en un caso argentino actual. Cambio climático, elevación del nivel medio del mar y sus implicancias. En: Climate Change Impacts and Integrated Assessment EMF (Energy Modeling Forum) Workshop IX. Stanford University. Snowmass, Colorado. July 28 - August 7; p. 1-16.

NATENZON C. E. y GONZALEZ S. G. 2010. Riesgo, vulnerabilidad social y construcción de indicadores. Aplicaciones para Argentina. En ARROYO M. y ZUSMAN P. (Coords.) 2010. Argentina e Brasil. Posibilidades e obstáculos no proceso de integração territorial. São Paulo, Humanitas, p. 195-217.

OUTES V.; VILLAROSA G.; DELMÉNICO A.; GÓMEZ LISARAGUE M.; BEIGT D.; MANZONI C.; ARRETCHE M. 2015. La erupción del Cordón Caulle 2011 en Villa La Angostura: una experiencia de cooperación entre los sistemas científico y de protección civil. En VIAND J. y BRIONES F. (Comps.). 2015. Riesgos al sur. Diversidad de riesgos de desastres en Argentina. Imago Mundi/La Red. Págs. 229-256.

POLANCO E; CLAVERO J. 2003. Análisis estadístico de erupciones del volcán Villarrica [39o.25' S], Andes del Sur, Chile [artículos de congresos]. En actas del Congreso Geológico Chileno, 10, Concepción, Chile, 6-10 Octubre.

ROJO BRIZUELA S. y TUMINI L. Inequidades de género en el mercado de trabajo de la Argentina: las brechas salariales. Revista de Trabajo Nueva Época 4, N 6, 2008, p 53-70.

ROMERO G. y MASKREY A. 1993. "Cómo entender los desastres naturales". En MASKREY A. Comp. Los desastres no son naturales. La Red. http://www.desenredando.org

RUBINOS PEREZ A. 2009. Límites de la geocronología en el estudio de yacimientos de época histórica. Munibe Antropologia-Arkeologia 60. Págs. 331-347.

SAATY T. 1977. A Scaling Method for Priorities in Hierarchical Structures", Journal of Mathematical Psychology, Vol. 15. Págs. 234-281. 
SAATY T. L. 1990. How to make a decision: The Analytic Hierarchy Process. European Journal of Operational Research 48, Págs. 9-26.

SERRA M. N., GARCÍA M. L., MAIDANA N., VILLAROSA G., LAMI A., MASSAFERRO J. 2016. Little Ice Age to present paleoenvironmental reconstruction based on multiproxy analyses from Nahuel Huapi Lake (Patagonia, Argentina). Ameghiniana, Vol. 53, p. 58-73.

STEWART C.; CRONIN S.; WILSON T.; BICKERTON H.; VILLAROSA G.; OUTES V.; BAXTER P. 2012. Volcanic ashfall, drinking water and public health - recent experiences from the 2011 Puyehue-Cordón Caulle and 2012 Tongariro eruptions. En Cities on Volcanoes, Colima, 19-23 de Noviembre de 2012, p. 1.

VILLAROSA G. 2008. Tefrocronología postglacial de la Región del Nahuel Huapi, Patagonia, Argentina. Tesis doctoral. Inédito.

VILLAROSA G. y OUTES V. 2013. Distribución, características de la ceniza volcánica caída en la región e impactos en la comunidad. En Convenio de Asistencia Técnica, Centro Regional Universitario Bariloche (Universidad Nacional del Comahue)-Legislatura de Neuquén: Efectos de la caída de cenizas del CPCC sobre la región del lago Nahuel Huapi. Informe Final, Diciembre de 2013, p. 12-59.

VILLAROSA G.; OUTES V.; GÓMEZ, E. 2012. La erupción del CC del 4 de junio de 2011: Mapa de distribución, características de la ceniza volcánica caída en la región e impactos en la comunidad. Convenio CRUB, UNCOMA-Legislatura de Neuquén. Mayo de 2012, p. 12-59.

VILLAROSA G.; SCHNEIDER M.; OUTES V.; LÓPEZ E.; DZENDOLETAS M. A.; BEIGT D.; VILLAROSA F.; GALOSI C.; RUIZ M. 2012. Estudio de Peligrosidad de avalanchas en el Parque Nahuel Huapi vinculados a la erupción del Cordón Caulle (CC). Informe Inédito. Convenio de Asistencia Técnica INIBIOMA (CONICET-Universidad Nacional del Comahue)Administración de Parques Nacionales, Diciembre 2012, p. 1-81.

WILCHES-CHAUX G. 1993. La vulnerabilidad global. En MASKREY A. (Comp.). 1993. Los desastres no son naturales. La Red. En http://www.desenredando.org, p. 11-44.

WILSON T.; STEWART C.; BICKERTON H; BAXTER P.; OUTES V.; VILLAROSA G.; ROVERE E. 2013. Impactos en la salud y el medioambiente producidos por la erupción del Complejo Volcánico Puyehue-Cordón Caulle del 4 de Junio de 2011: Informe de un equipo de investigación multidisciplinario. GNS Science Report 2012/20, enero de 2013, p. 1-88.

\section{Otras fuentes}

AGENCIA DE NOTICIAS BARILOCHE (ANB). "40 mil kilos de cenizas reducen la capacidad operativa de la planta depuradora". En http://www.anbariloche.com.ar/noticias/2011/06/24/22115-40-mil-kilos-de-cenizas-reducen-lacapacidad-operativa-de-la-planta-depuradora. Consultada el 29 de enero de 2018.

ALERTA EPIDEMIOLÓGICO, Semana 15 de 2008. Actualización de Diarrea Aguda desde la vigencia de la Salud, Provincia del Neuquén. Situación Provincial relacionada a Diarrea Aguda. Dirección de Epidemiología y Estadística, Subsecretaría de Salud.

Código de Edificación de San Carlos de Bariloche. Municipalidad de San Carlos de Bariloche. Ordenanza 211-I-1979 aprobada por Decreto $N^{\circ} 654 / 80$. Disponible en http://www.digestobariloche.gov.ar/detalleOrd.php?hdnldOrd=3055\&hdnSiglaOrd=.

Consultada el 9 de Abril de 2015. 
DIRECCIÓN PROVINCIAL DE ESTADÍSTICAS Y CENSOS / NEUQUÉN. http://www.estadisticaneuquen.gob.ar/DatosCenso2010.html. Consultada el 21 de Mayo de 2014.

EIRD/ONU. http://www.eird.org/vivir-con-el-riesgo/index2.htm. Consultada el 15 de Mayo de 2014.

GLOBAL VOLCANISM PROGRAM. INSTITUTO SMITHSONIANO. http://volcano.si.edu/. Volcanoes of the World, v. 4.6.6. VENZKE, E (ed.). Disponible el 16 de Marzo 2018. https://dx.doi.org/10.5479/si.GVP.VOTW4-2013

INDEC. http://www.indec.mecon.ar/glosario/textos_glosario.asp?id=39. Consultada el 20 de Mayo de 2014.

INDEC. http://www.censo2010.indec.gov.ar/index.asp. Consultada el 20 de Mayo de 2014.

INDEC. Censo Nacional de Población, Hogares y Viviendas 2010. Censo del Bicentenario. Base de datos REDATAM.

LA RED. http://www.desenredando.org. Consultada el 2 de Mayo de 2014.

CÓDIGO DE EDIFICACIÓN. Ordenanza N¹415/03. Municipalidad de Villa La Angostura.

CÓDIGO DE PLANEAMIENTO AMBIENTAL URBANO DE VILLA LA ANGOSTURA. Ordenanza No 2659/12. Municipalidad de Villa La Angostura.

Código de Planeamiento Urbano y Edificación de Dina Huapi, aprobado por Decreto 840/2005. Viedma, 14 de julio de 2005. Disponible en http://www.estrucplan.com.ar/Legislacion/Rio\%20Negro/Decreto/Dec00840-05.asp.

Consultada el 9 de Abril de 2015.

Departamento de Digesto Municipal e informática Legislativa. San Carlos de Bariloche. http://www.digestobariloche.gov.ar/detalleOrd.php?hdnldOrd=3055\&hdnSiglaOrd= Consultada el 14 de Abril de 2015.

Diario Río Negro (Edición on line). "Los datos de cada ciudad que muestra el censo" (03/05/2013). En http://www.rionegro.com.ar/diario/los-datos-de-cada-ciudad-que-muestra-elcenso-1155176-9574-nota.aspx. Consultada el 3 de Septiembre de 2014.

ENCUESTA DE COYUNTURA HOTELERA (ECH). Municip. de San Carlos de Bariloche. Disponible en http://www.bariloche.gov.ar/turismo_desarrollo.php?id_contenido=47 el 9 de Abril de 2014.

Ordenanza N²188-CM-11. Municipalidad de San Carlos de Bariloche, Río Negro.

OxCal. Universidad de Oxford. Disponible https://c14.arch.ox.ac.uk/embed.php?File=oxcal.html. el 6 de Mayo de 2016.

Rock-Color Chart with genuine Munsell color chips. 1991. The Geological Society of America. Séptima impresión.

TURISMO ESTUDIANTIL. INFORME ESTADÍSTICO. Municipalidad de San Carlos de Bariloche. Disponible

en http://www.bariloche.gov.ar/turismo_desarrollo.php?id_contenido=55 el 9 de Abril de 2014 .

"Una avalancha de cenizas volcánicas cortó el paso a Chile en Neuquén". Sábado, 11 de junio de 2011. Diario Los Andes, edición digital. http://www.losandes.com.ar/notas/2011/6/11/avalancha-cenizas-volcanicas-corto-paso-chileneuquen-573950.asp. Consultada el 1 de Junio de 2013. 


\section{CAPÍTULO V}

\section{VULNERABILIDAD FRENTE A PROCESOS TSUNAMIGÉNICOS EN EL LAGO NAHUEL HUAPI}

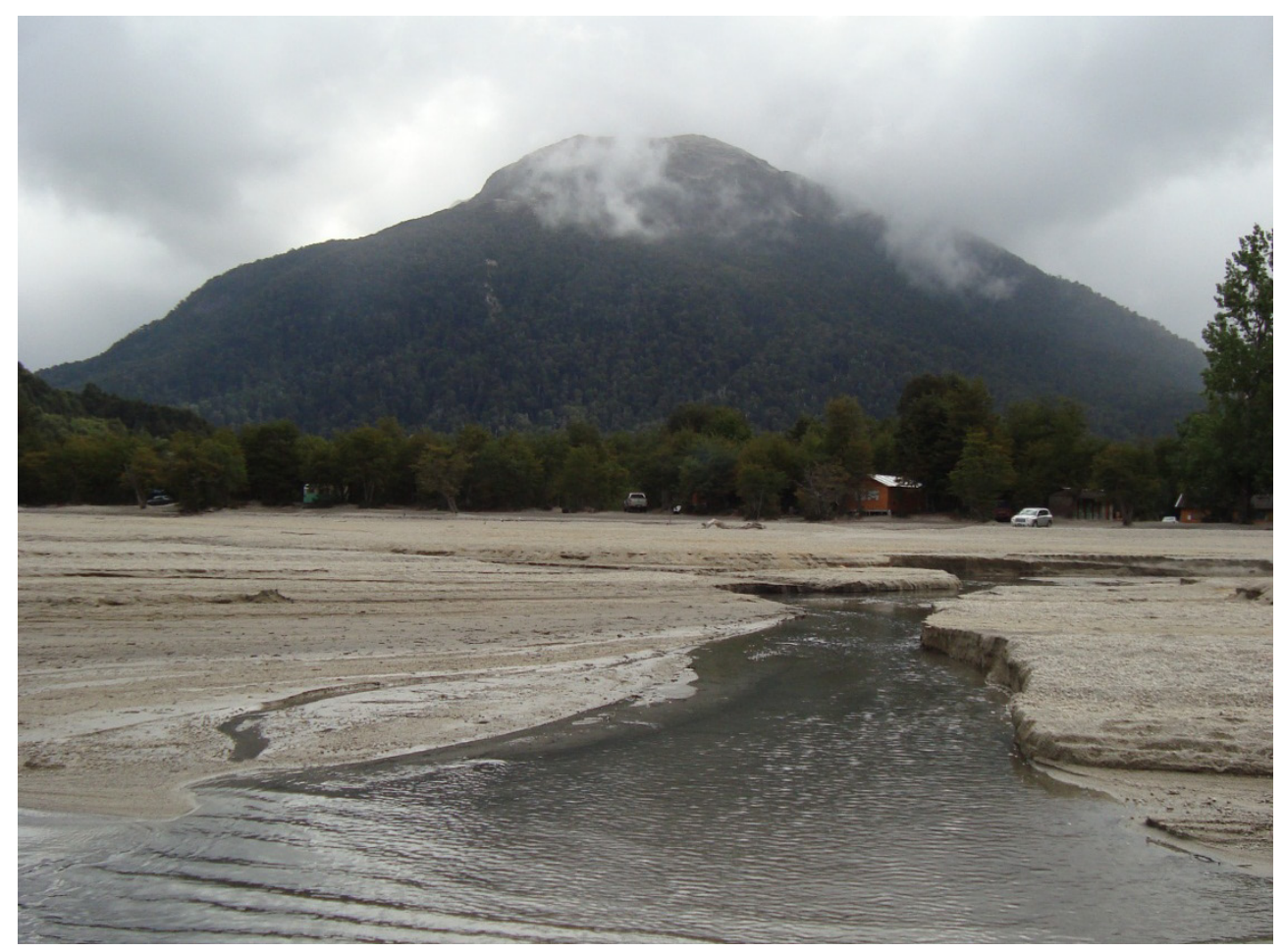

Arroyo Pireco. Vista de su desembocadura en el Brazo Rincón del Lago Nahuel Huapi, en un delta fuertemente progradado por la removilización de ceniza volcánica proveniente de la erupción del Cordón Caulle 2011 Lago Nahuel Huapi, 14 de marzo de 2014. Foto del autor. 


\subsection{Introducción}

El origen de la palabra tsunami es japonés: Tsu significa puerto y nami, ola (UNDHA/GENEVA, 1994, p. 7). Se trata de una onda o serie de ondas que se producen en una masa de agua al ser empujada violentamente por una fuerza que la desplaza verticalmente. Las fuentes tsunamigénicas se categorizan básicamente en cuatro fenómenos naturales de gran magnitud (sismos y movimientos de fallas en el lecho lacustre, remoción en masa, actividad volcánica e impacto de asteroides) y actividad antropogénica (e.g. explosiones atómicas, actividades desestabilizadoras en las costas o en los lechos de los cuerpos de agua) (Bryant, 2010; en Velasco y López, 2016, p. 82).

Los terremotos pueden desencadenar movimientos de masas de sedimentos del lecho (deslizamientos subacuáticos), o en sectores de laderas adyacentes (deslizamientos subaéreos, que introducen grandes volúmenes de rocas en el cuerpo de agua) (BØe et al., 2000; Smoot et al., 2000; Villarosa et al., 2009; Beigt et al., 2013). Este tipo de eventos afecta la topografía del fondo lacustre y puede desplazar verticalmente un volumen de agua, induciendo una onda en la superficie (Beigt et al., 2013, pp. 10-11). Los procesos tsunamigénicos en su totalidad comprenden tanto las fuentes tsunamigénicas como así también la onda resultante, es decir, un tsunami.

Numerosas publicaciones sobre tsunamis que impactaron o pueden impactar en una zona litoral determinada se centran en las costas marítimas (Velásquez et al., 2002; Brink et al., 2006; Lagos, 2012; Lastras et al., 2013; Velasco y López, 2016). Si bien también son numerosos los estudios de casos de tsunamis en lagos (Smoot et al., 2000; Wagner et al., 2003; Freundt et al., 2007; Villarosa et al., 2009; Garduño-Monroy et al., 2011; Marshall, 2012; Kremer, et al., 2012), muchos de ellos se orientan desde un enfoque retrospectivo, es decir, recabando la evidencia necesaria para identificar las causas de dichas olas extraordinarias.

En Patagonia Norte, existen numerosos reportes de ondas en diferentes lagos andinos como Moquehue y Huechulafquen en el año 2010 (concomitante al sismo de Concepción) y Nahuel Huapi en diferentes oportunidades (en 1960 con el terremoto de Valdivia, en 2010 con el sismo de Concepción y en 2014 en el Brazo Rincón, a lo que se añade una playa deslizada en el Brazo Huemul en 2009).

En virtud de los objetivos planteados en esta tesis, el enfoque adoptado se centrará en aquellas ondas inducidas por deslizamientos subacuáticos. Los sedimentos que componen el lecho del lago Nahuel Huapi son de variada naturaleza, entre ellos glaciarios, fluviales y piroclásticos. Los depósitos de ceniza volcánica, de baja consolidación, podrían actuar como 
posibles planos de deslizamiento induciendo procesos de remoción en masa subacuáticos (Beigt et al., 2014b, p. 248). En los ambientes deltaicos del lago Nahuel Huapi se desarrollan eventos de remoción en masa que involucran grandes volúmenes de sedimentos siendo altamente probable que estos eventos de magnitud considerable generen ondas en la superficie del lago (Beigt et al., 2014b, p. 258). Gran parte de estos deslizamientos se encuentran en ambientes deltaicos, los cuales presentan tres ambientes subacuáticos, entre ellos un frente deltaico con pendientes pronunciadas (Beigt et al., 2012a,b, 2014a,b; 2016). Dichas pendientes, así como las altas tasas de sedimentación que caracterizan a los ambientes deltaicos, son factores propiciantes de deslizamientos subacuáticos.

Para comprender los tsunamis y sus efectos es necesario no sólo revisar las causas que dan origen a estos eventos sino también aquellas que potencian o atenúan sus efectos destructivos. La exposición al peligro de olas extraordinarias, desde una perspectiva física, está directamente vinculada a la morfología costera. Las costas con escasas pendientes son áreas donde las olas de tsunami disipan gran parte de su energía. Las bahías en formas de $\mathrm{U}, \mathrm{V} \circ \mathrm{W}$ son sitios donde aumenta la altura de la ola mientras que bahías con entradas estrechas pueden atenuar el efecto de la onda. Por último, la existencia de zonas con amplias playas constituye un factor que atenúa el grado de afectación de un tsunami en las zonas construidas (Velásquez et al., 2002, p. 6; UNDHA/GENEVA, 1994, p. 14); pero cuando estas presentan muy escasa pendiente, el ingreso del agua se dará a mayor distancia.

El lugar de generación del tsunami y la presencia de islas, provocarán alteraciones en el impacto de la ola en la costa dado que estos componentes modifican sustancialmente la dirección del desplazamiento de la onda. Además, de acuerdo con Velázquez et al. (2002), existen otros factores que cobran relevancia: la distancia a la playa, la topografía y la existencia de protección por bosque, son factores que modifican el grado de afectación de un asentamiento. Una población que esté alejada de la playa y localizada en sitios topográficamente altos, con barreras de vegetación boscosa, se verá menos afectada que una sin estas características (p. 6).

La problemática de los posibles impactos de un tsunami reviste de gran complejidad, particularmente en el caso del lago Nahuel Huapi con aproximadamente $550 \mathrm{~km}^{2} \mathrm{de}$ superficie y siete ramificaciones (brazos Campanario, de la Tristeza, Blest, Machete, Rincón, de la Última Esperanza y Huemul) en un contexto de gran dinamismo poblacional y expansión de la urbanización costera. Por este motivo, es necesaria la identificación de los sectores costeros con distintos grados de vulnerabilidad según diferentes parámetros entre 
los que se encuentran la vegetación, la infraestructura vial y edilicia, la población y las morfologías costeras más destacadas (Manzoni et al., 2013).

Las fuentes de información utilizadas fueron varias, entre ellas se cuentan los recursos cartográficos, artículos y fotos publicados en diversas fuentes periodísticas, observaciones de campo en las costas urbanizadas y batimetrías de alta resolución confeccionadas a partir de un Sonar Batimétrico por Medición de Fase (SBMF). También se contó con fotos aéreas de 1940 que permitieron comparar los cambios en el trazado urbano en los últimos setenta años. Toda la información fue procesada en Sistemas de Información Geográfica (Software libre gvSIG versión 1.11 y 1.12) para la elaboración de los distintos mapas temáticos. Por último, se recurrió al testimonio de personas que vivían en Bariloche en 1960 y recuerdan el sismo y posterior tsunami, ya sea por experiencia propia o a través del recuerdo de sus conocidos

En función de estos aspectos, el capítulo propone un acercamiento al tsunami de 1960 desde el recuerdo de los pobladores de ese entonces aspirando a, entre otros aspectos, conocer la ciudad en ese entonces, rescatar los testimonios y recuerdos tanto del sismo como de las erupciones de 1960 y de 1961. Por otra parte, a partir de variables seleccionadas como indicadoras de vulnerabilidad costera frente a tsunami lacustre y su ponderación, junto a una estimación de la altura de la ola de tsunami de 1960, se efectuó una zonificación del área costera urbanizada desde el río Limay hasta Puerto Pañuelo en función de distintos grados de vulnerabilidad.

\subsection{El tsunami lacustre de 1960 en el Lago Nahuel Huapi}

\subsubsection{Bariloche en 1960}

El Puerto San Carlos, llamado "el muelle" por los pobladores locales, era sumamente importante en ese entonces para el pueblo de Bariloche, como parte de su identidad y atractivo:

"El muelle si bien se había incendiado unos años anteriores lo que se había hecho estaba bien, y era el gran atractivo del pueblo. Todo el mundo iba al muelle y más un fin de semana, día lindo. Era el paseo como cualquier otro lado, acá ibas a caminar por el muelle. Era re lindo ver la llegada de la Modesta Victoria que llegaba con todos los pasajeros que venían especialmente del cruce. No te olvides que en esa época el único cruce con Chile era a través del barco, por Blest, entonces era el atractivo de 
Bariloche. Creo que no debe haber ningún barilochense de esa época que no tenga una foto sacadas cuando era chico en el muelle porque era el atractivo".

Los testimonios de residentes de aquel entonces sostienen que las condiciones meteorológicas imperantes el día del tsunami eran muy estables:

"Era un día de esos soñados, o sea el cielo estaba azul. No corría una brisa, no había nada, no te digo que estaba calentito, pero estaba agradable, era un sol espectacular".

"Era un día hermosísimo, de sol viste, no hacía frío ni nada y todo el mundo salió a caminar o a pasear".

\subsubsection{El sismo de Valdivia del 22 de mayo de 1960}

El 22 de mayo 1960 se produjo el sismo de Valdivia de $9.5 \mathrm{MW}$, el más grande jamás registrado, que en Bariloche se sintió con gran fuerza:

"Se veía la calle Mitre como una ola, una ola, ondas. No fue horizontal sino vertical el movimiento y eso favoreció a que no se rompieran las casas (...) En el cine había mucha gente, en el cine coliseo. Había muchísima gente en el cine y salieron todos a la Mitre".

"Mi hermano estaba mirando, él estaba subido a un cerco, mirando como jugaban los chicos del vecino de la casa donde estábamos y de repente siente que se le mueve el cerco y mira así y dice pero no hay viento porque no se movían las ramas entonces, por las dudas, se bajó y fue al lado donde estaba nuestro papá y tranquilitos sin decir nada todos nos fuimos acercando y nos paramos debajo del dintel porque yo estaba en una habitación y el piso es como que entro a ondular. Fue una sensación así muy fuerte".

"Bueno yo me agarre del ciprés que está pegado a Primo Capraro, el monumento, ese que está pagadito y veo como se retiró la ola, se retiró el lago, se fue para atrás y se empezó a levantar. En ese momento, cuando veo eso, veo que la Cristina encaro para lago adentro, lo mismo que la modesta, alcanzaron a hacer ese movimiento pero una quedo ahí, se ve que no había nadie, fue la que se hundió después, quedo hundida justo al borde de una grieta que se formó ahí cerca del muelle”. 


\subsubsection{El tsunami del lago Nahuel Huapi}

Concomitante al sismo, se produjo un tsunami en las costas del lago Nahuel Huapi frente a la ciudad de San Carlos de Bariloche, siendo éste el primero registrado en el país. Esta ola inducida por un deslizamiento subacuático (Villarosa et al, 2009) dejó un saldo de dos muertes, sumado a la destrucción del Puerto San Carlos, cuyo muelle fue arrastrado por el movimiento en masa, hundiendo varias embarcaciones que se encontraban amarradas al mismo, Algunas embarcaciones fueron depositadas sobre la costa (Villarosa et al., 2009, p. 593); en Puerto Pañuelo. Hacia fines de marzo de 1958 un incendio destruyó el muelle por completo. De inmediato se inició su reconstrucción, colocando nuevamente el estacado, lo que requirió del hincado de postes. El tsunami ocurrió cuando la reconstrucción estaba prácticamente concluida, es decir que durante más de dos años previo al tsunami hubo intervención antrópica continua en la zona aumentando la inestabilidad del material sedimentario (Villarosa et al., 2009, p. 596).

Las excelentes condiciones climáticas del día, sumado al atractivo que representaba el puerto para la localidad, con la presencia permanente de personas, podría dar lugar a pensar en un desastre más grande. Es aquí donde emerge un tercer factor, que explica por qué la tragedia no fue aún mayor.

"no hubo más gente accidentada y no hubo más desgracias que la de estas dos personas, que no estaban en el muelle sino estaban en un bote, era porque la banda del Ejército estaba tocando música y era una banda que se dedicaba a tocar Jazz y música de ese momento también y que estaba todo el mundo en lo que era en esa época el picadero que es ahora donde está el Bariloche Centre. Ese era el picadero de Gendarmería".

“No había gente en el muelle porque ese día gendarmería había cedido donde ahora está el Bariloche Centre, era un picadero, ellos tienen unos caballos y había algunos gendarmes que andaban estos caballos, hacian una exhibición con sus caballos y estaba la banda militar".

No todos los relatos de la época coinciden en la altura de la ola:

"El comentario, lo que yo recuerdo es que se hablaba de 7 metros de alto, de lo que contaba la gente que la ha visto".

"Hablaban de muchos metros, que pueden ser 4 otros dijeron que eran 7. Era una ola que vino así paso por encima del muelle y arrastró todo. Esto lo confirmaron todos" 


\begin{abstract}
"La altura era fácilmente la mitad de la Modesta Victoria, la altura de la Modesta Victoria, la mitad del casco, un poquito más quizás es lo que yo podía presenciar. A la lancha Juana de Arco la tapaba y a la otra también. Y cuando vino la ola pego contra la pared del muelle que está pegado a la tierra y cuando se retiró no quedo nada. No quedo muelle ni de madera ni de hormigón, nada".
\end{abstract}

En base a estos testimonios y a las mediciones realizadas a la embarcación Modesta Victoria se trató de estimar la altura de la ola, reforzando estos cálculos a partir de fotos de la época. Un indicador clave es la medida del Francobordo, es decir, la distancia existente entre la proa y el agua. En el caso de la Modesta Victoria dicha medida alcanza los 3 metros de longitud y por el testimonio antes expuesto y fotos de la embarcación, la ola habría tenido al menos la mitad de esa medida. Esta información permitió inferir una altura de la ola de entre 1,5 y 2 metros. Aunque la altura parezca escasa hay que tener en cuenta dos aspectos: es una altura considerable para un cuerpo de agua (sobre todo en condiciones de tiempo calmo) a la vez que es muy importante el volumen de agua implicado en este tipo de olas y su capacidad destructiva cuando golpea una costa.

Los medios de comunicación eran escasos, siendo preponderante el lugar que ocupaba la radio (como Radio Bariloche, e incluso algunas de Chile). El medio gráfico que ya existía en ese entonces era Diario Río Negro (Figuras $\mathrm{N}^{\circ} 1$ y $\mathrm{N}^{\circ} 2$ ), que se hacía eco de los sucesos en la cordillera.

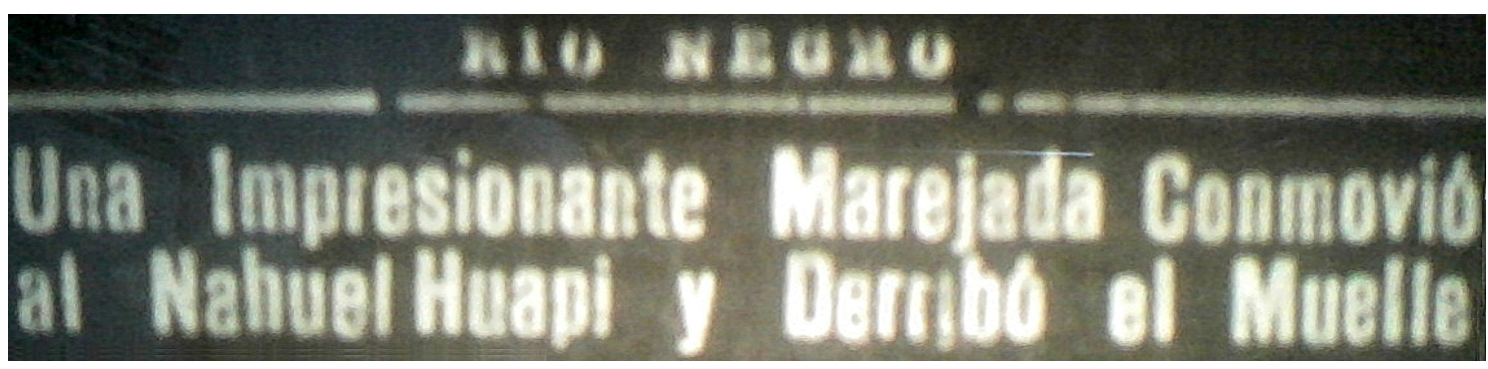

Figura N¹. Titular del Diario Río Negro del 23 de mayo de 1960. En referencia al Tsunami lacustre, en los diarios de esa época sólo se pudieron encontrar los negativos correspondientes a este ejemplar del 23 de mayo de 1960. Según esta fuente periodística, "el golpe de agua -que alcanzó dos metros de altura- hizo impacto sobre el muelle y lo derribó en parte abriendo una inmensa brecha".

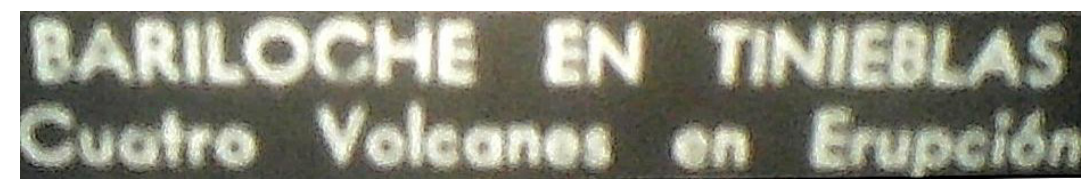


Figura N². Titular del Diario Río Negro del 25 de mayo de 1960. A sólo 3 días del sismo, y ya iniciada la erupción del Cordón Caulle con la consecuente emisión de cenizas, este diario informó que en San Carlos de Bariloche se registró “... un espeso manto de esta materia que llegaron a alcanzar hasta 10 centímetros de espesor".

\subsubsection{Las erupciones del Cordón Caulle y Calbuco}

El 24 de mayo de 1960, a menos de 2 días del sismo, se inicia una erupción del Cordón Caulle.

"Eran las 7 de la mañana cuando estaba en la estación de tren esperando que llegue el tren, el cielo estaba totalmente despejado y veo un hongo en la cordillera, en la parte del Puyehue, o por ahí”.

"Todos los actos se hacían en la calle Mitre, ese año se decidió que se hiciera en la calle Onelli para darle más vida a la Onelli que tiene más movimiento que la Mitre. Entonces estaba la banda, la banda del ejército la mandaron acá por la calle Tiscornia y Onelli y ahí estaban tocando música, no solamente marcha, música de todo. Justo ese día es que yo pase por ahí y estaba todo lo de la banda como si estuviera nevado, viste, por la ceniza y ellos seguían con su música”.

En referencia a los espesores registrados, no hay recuerdo de medidas precisas por parte de los entrevistados, aunque se observan algunas discrepancias en la cantidad:

"Cayó muy poquito, si para juntar en una latita o un frasquito tenías que barrer. Era apenitas nada que ver con lo que cayó hace pocos años" (en referencia a la erupción del año 2011).

"Cayó ceniza pero no fue significante".

“Llegamos a Bariloche, el aeropuerto, la pista tenía arena, pero arena no muy gruesa. La pista estaba bastante limpia pero a los bordes había y los pilotos bajaban corriendo, sacaban sobres y cosas y metían arena adentro porque era todo un acontecimiento (...) En el 60 cayo mucho porque vivía en el departamento de arriba y había una terraza abierta y tenía su linda cantidad de arena”.

"Esta vuelta (2011) fue mucho más grande, la cantidad, el volumen que cayó y el tema de que cayó tanto tiempo la emisión de ceniza”.

Como se vio en el capítulo anterior, el registro sedimentario de laguna El Trébol mostró un nivel muy delgado de ceniza correspondiente al evento de 1960, de unos 2-3 mm según 
medición de la muestra en laboratorio. Sin embargo, debe tenerse en cuenta que parte del material piroclástico, al ingresar en un cuerpo de agua, es suspendido, removilizado y transportado hacia la costa por acción del oleaje. Ello sumado a la compactación de este material en el lecho lacustre provoca una subestimación del espesor del depósito original.

El 1 de febrero de 1961 el volcán Calbuco inicia un proceso eruptivo cuya emisión de cenizas alcanzó la región del Nahuel Huapi. Esta erupción no es recordada por todos los entrevistados, sino sólo por algunos de ellos.

\begin{abstract}
"Y después tengo el recuerdo de cuando en el 61, cuando fue lo del Calbuco. Nosotros estábamos pasando unos días en el refugio del Cerro López, estábamos ahí arriba, también un día re lindo. Tiene que haber sido enero, febrero, la fecha. Es cuestión de ver cuándo fue la fecha, porque eso está registrado. Estábamos ahí afuera y de repente, sobre el filo norte, empezó a acercarse así a aparecer una nube re contra negra, cada vez que oscurecía más, más, más y de repente empezó a caer así también algo, y bueno automáticamente bueno, ceniza de nuevo. Fue mucho menos, el sismo no se sintió, por menos ahí arriba nosotros no lo sentimos y la ceniza que cayó era muy muy muy finita, muy finita, un polvo muy muy finito. Fue mucho menos que la del sesenta".
\end{abstract}

Un recuerdo generalizado se da en relación al cambio en la coloración del lago:

\begin{abstract}
"Si había después con toda la remoción del lago, quedo el lago mucho tiempo de un color turquesa, así medio verdoso, como se suele poner el brazo del Mascardi, la punta esta de acá cuando la que se une, cerca del Gutiérrez, después en primavera se suele poner de un tono lechoso. Bueno, cuando fue lo de ahora lo del Caulle también, había lugares donde estaba con ese color. Y después tenía muchísima piedra pómez, una piedra pómez grande, que flotaba en el lago, como que se había transformado el lago".
\end{abstract}

"El lago estuvo verde durante meses. Viste como el lago frías? Un verde claro, bueno estuvo meses, porque todo lo de abajo flotó".

"El lago era más verdoso, muchos meses. Muchos pensaban que era malo, y se veía hermoso turquesa esmeralda".

La turbidez generada por 1) la movilización de los sedimentos del fondo del lago producto del deslizamiento subacuático inducido por el movimiento sísmico y 2) la ceniza en suspensión derivada de la erupción del Cordón Caulle en 1960, indujo a una modificación en 
los procesos de absorción, reflexión y dispersión de la luz solar, lo que explica los cambios en la coloración de las aguas del lago.

En otro aspecto que los entrevistados coinciden es que no hubo un caos generalizado en el pueblo ya sea por el sismo, el tsunami o la caída de ceniza (a diferencia de la erupción del Cordón Caulle en 2011):

"En el momento sí, pero yo después los vi a todos tranquilos porque yo vine dos días después".

"No quedaron traumados como este último. Y después sabes qué? Los medios de comunicación como no eran tantos no te machacaban como ahora con cualquier estupidez que pasan".

"Yo creo que fue más el shock de todo lo que pasó, fue más impactante la movida en el lago con el tema de la desaparición del muelle y la muerte de estas dos personas. Ya te digo, las anécdotas de cada uno, como vivió y donde estaba, y como vivió ese momento (...) y nadie salió corriendo y huyó porque a ver si venia algo más (...) No vivíamos enloquecidos ni nada y ya te digo, siguió todo, yo no recuerdo de que se hayan suspendido clases. Yo no tengo para nada esa imagen de locura esquizofrenia que pasamos en el 2011".

\subsubsection{Conclusiones de las entrevistas}

Este apartado permitió suministrar información más certera acerca cómo era la vida en la ciudad y de cómo se sucedieron los acontecimientos que sacudieron San Carlos de Bariloche. Luego del Sismo de Valdivia de 1960, una ola de tipo tsunami golpeó las costas de la ciudad cobrándose dos vidas humanas, pérdidas materiales (destrucción del muelle y naufragio de embarcaciones) y, pocas horas después, la erupción del Cordón Caulle arrojó cenizas a la atmosfera que cubrieron la región trayendo inconvenientes en la vida cotidiana.

De toda esta información se desprende que la altura de la ola alcanzó los 2 metros, y es aquí donde la fuente periodística coincide con la información aportada por uno de los informantes calificados que presenció el evento. Asimismo esto se cotejó con las fotos y las medidas de la motonave Modesta Victoria presente en el momento del tsunami y que sirvió de referencia para comprobar la altura de la ola.

En relación a la cantidad de ceniza acumulada, hay discrepancias entre las fuentes, aunque por las evidencias de los registros sedimentarios de Laguna El Trébol que muestran un espesor muy delgado para esta erupción, pareciera que estarían más cercanas a la realidad las fuentes consultadas que indican que la caída fue muy escasa (quizás unos poco centímetros). 
Tanto las olas de tipo tsunamis como las caídas de ceniza volcánicas no eran fenómenos conocidos en ese entonces y, pese a ellos, los informantes sostuvieron que la normalidad retomó pronto a Bariloche.

\subsection{Aspectos regionales relevantes en relación a la vulnerabilidad frente a tsunamis}

La región del Nahuel Huapi presenta numerosos cuerpos de agua: además del homónimo, los lagos Moreno Este y Moreno Oeste, Gutiérrez y Correntoso. Dada su menor superficie y la reducida extensión de los espacios urbanos sobre sus costas, el trabajo se centrará en el Lago Nahuel Huapi.

\subsubsection{San Carlos de Bariloche-Dina Huapi}

El área urbana comprendida por las localidades de San Carlos de Bariloche (ejido con 22.652 hectáreas de superficie) y Dina Huapi (1.216 hectáreas) se extiende preferentemente en un sentido Este-Oeste con costa en tres lagos: Nahuel Huapi, Moreno y Gutiérrez.

- Lago Nahuel Huapi

Con una superficie de aproximadamente $550 \mathrm{~km}^{2}$, es el lago más grande del Parque Nacional Nahuel Huapi, con un frente costero urbanizado que alcanza la extensión de unos 50 kilómetros. Numerosos cursos vierten sus aguas en este lago, algunos ellos formando prominentes deltas: Gutiérrez, Ñireco y Ñirihuau (Figura Nㅜ3). 


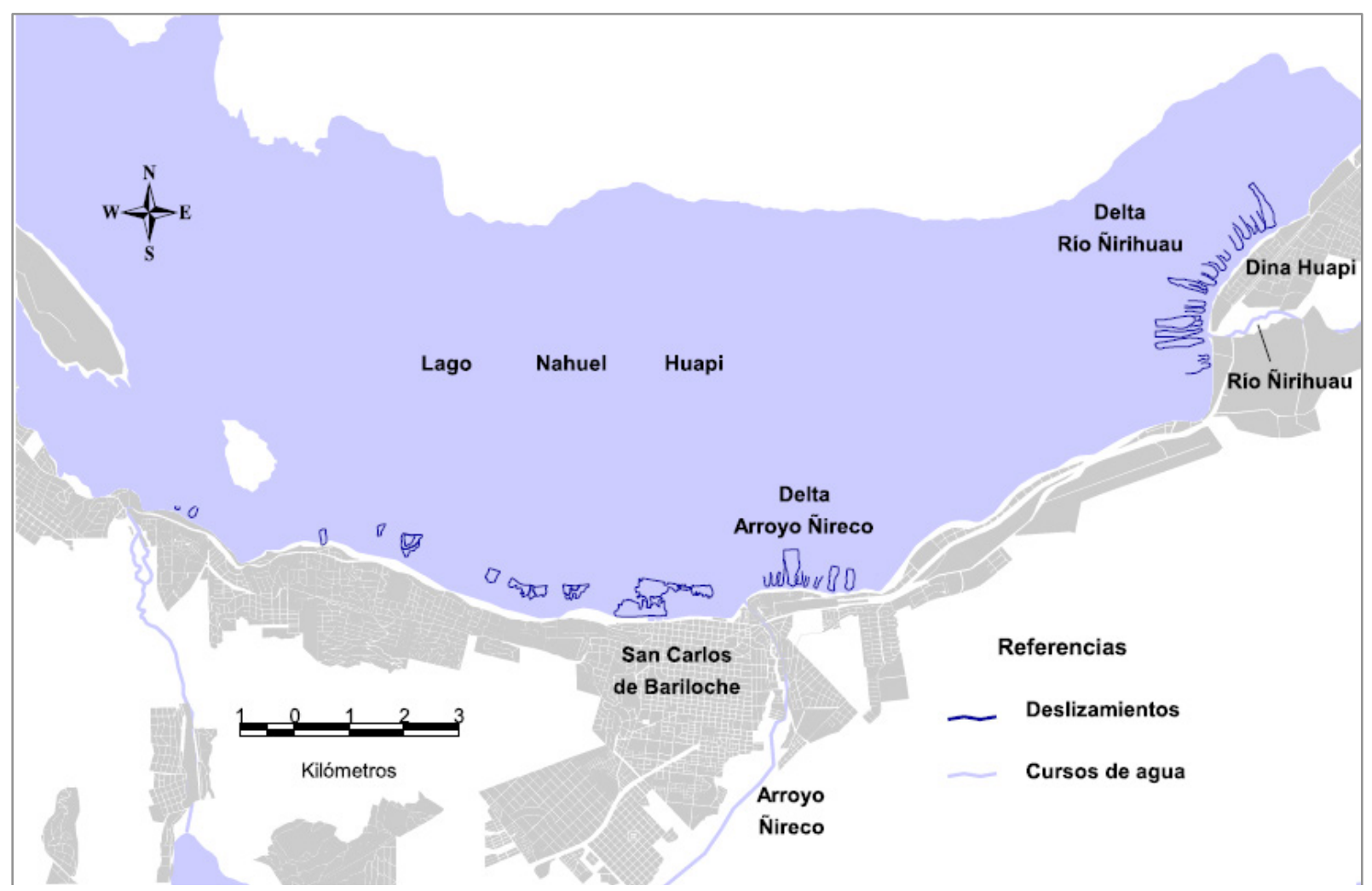

Figura $\mathrm{N}^{\circ}$ 3. Deslizamientos subacuáticos en torno a San Carlos de Bariloche y Dina Huapi. Los deltas del arroyo Ñireco y sobre todo el río Ñirihuau presentan frentes muy activos, con numerosos deslizamientos subacuáticos. Fuente: modificado de Beigt et al., 2014b y 2016.

\section{- Lago Gutiérrez}

Se trata de un cuerpo de agua reducido en su extensión, apenas $16 \mathrm{~km}^{2}$, pero con población costera en ascenso. Presenta numerosos deltas menores constituidos por los arroyos que descienden de la Sierra de la Ventana, aunque el más importante es el que forma el arroyo Van Titter, curso que desciende del Cerro Catedral.

\section{- Lago Moreno Este y Oeste}

Ambos cuerpos, en conjunto suman una superficie aproximada de $16 \mathrm{~km}^{2}$. En él desembocan numerosos cursos de agua, algunos de ellos de gran relevancia por formar un delta en su desembocadura: son los casos de los arroyos Casa de Piedra, Cascada de la Virgen y Goye; sobre este último se asienta Colonia Suiza.

\subsubsection{Villa La Angostura}

La localidad de Villa La Angostura presenta un ejido urbano de 4.540 hectáreas de superficie, con un desarrollo costero en torno a los lagos Nahuel Huapi y Correntoso. 


\section{- Lago Nahuel Huapi}

En torno a Villa La Angostura, dos ambientes deltaicos que presentan numerosos deslizamientos subacuáticos a partir de los cuales podría generarse un tsunami lacustre son los deltas de los arroyos Pireco y Totoral y el río Bonito (Beigt et al., 2012a. Beigt et al., 2016).

\section{- Lago Correntoso}

Es un cuerpo de agua de unos $27 \mathrm{~km}^{2}$ de superficie, si bien su población escasa está en crecimiento presenta una playa turística en su extremo sur y es una de las fuentes de provisión de agua potable para la localidad de Villa La Angostura. Si bien este cuerpo de agua se encuentra en el entorno urbano de Villa La Angostura, no será estudiado en profundidad.

\subsection{Factores desencadenantes de procesos tsunamigénicos}

\subsubsection{Sismicidad}

Como se mencionó al comienzo del capítulo, uno de los más importantes desencadenantes de procesos tsunamigénicos en cuerpos lacustres son los terremotos. Según el Instituto Nacional de Prevención Sísmica (INPRES), el peligro sísmico es la probabilidad de que ocurra una determinada amplitud de movimiento del suelo en un intervalo de tiempo fijado. Dicha probabilidad depende del nivel de sismicidad de cada zona (Figura N4). San Carlos de Bariloche, Dina Huapi y Villa La Angostura se encuentran en un área de peligrosidad sísmica de Nivel 2 (moderado). 


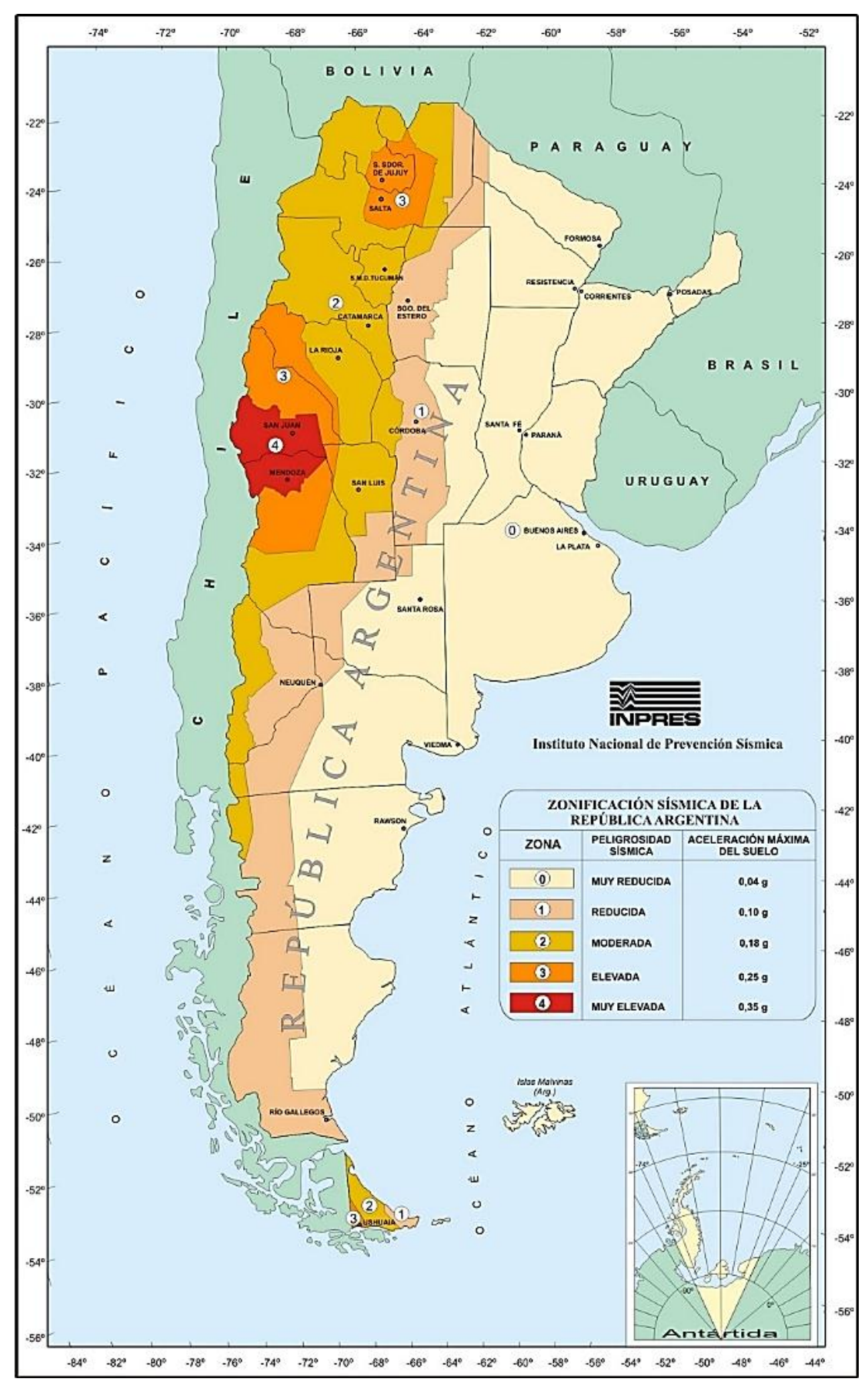

Figura № 4. Zonificación sísmica de la República Argentina. Fuente: INPRES.

El Centro Sismológico Nacional de Chile dispone de una base de datos desde el año 2012 de los principales eventos sísmicos en ese país, entre los que se destacan por su cercanía a la región del Nahuel Huapi los que se presentan en el Cuadro $\mathrm{N}^{\circ}{ }^{1}$, a los que se agregaron los grandes sismos de Valdivia en 1960 y Concepción en 2010. 


\begin{tabular}{|c|c|c|c|}
\hline Fecha & Latitud ['] & Longitud [ $\left.{ }^{\circ}\right]$ & Magnitud [*] \\
\hline $22-05-1960$ & -38.14 & -73.41 & 9.5 \\
\hline $27-02-2010$ & -36.12 & -72.90 & 8.8 \\
\hline $30-08-2012$ & -37.24 & -73.86 & 5.2 \\
\hline $29-09-2013$ & -37.47 & -73.88 & 5.5 \\
\hline $04-11-2014$ & -41.23 & -73.83 & 4.9 \\
\hline $22-11-2014$ & -40.77 & -73.13 & 4 \\
\hline $13-04-2015$ & -40.25 & -73.68 & 4.7 \\
\hline $03-10-2015$ & -37.56 & -73.74 & 6.1 \\
\hline $25-10-2015$ & -41.93 & -73.55 & 4.5 \\
\hline $07-01-2016$ & -41.72 & -74.15 & 5.3 \\
\hline $08-01-2016$ & -41.71 & -74.12 & 4.5 \\
\hline $16-01-2016$ & -41.73 & -73.99 & 4 \\
\hline $05-07-2016$ & -41.69 & -73.6 & 4.5 \\
\hline $12-07-2016$ & -42.2 & -73.38 & 4.5 \\
\hline $12-08-2016$ & -40.36 & -72.96 & 4.1 \\
\hline $25-12-2016$ & -43.52 & -74.39 & 7.6 \\
\hline $03-01-3017$ & -43.41 & -74.56 & 5.7 \\
\hline $29-05-2017$ & -37.34 & -71.8 & 5.8 \\
\hline
\end{tabular}

Cuadro $\mathrm{N}^{\circ}$ 1. Sismos con epicentro cercano a la Región del Nahuel Huapi. El cuadro muestra la fecha, ubicación del epicentro y magnitud de los principales fenómenos,. Fuentes: elaboración propia sobre la base de datos del Centro Sismológico Nacional. Universidad de Chile (Datos disponibles desde 01-01-2012 en http://evtdb.csn.uchile.cl/events. Consultada el 16 de agosto de 2017) y Earthquake Hazards Program, USGS (Servicio Geológico de los Estados Unidos), disponible en https://earthquake.usgs.gov/earthquakes/browse/. Consultada el 25 de agosto de 2017.

Si bien las causas estructurales están presentes de manera directa, constituyen disparadores de fenómenos de remoción subaéreos y subacuáticos. En el lago Nahuel Huapi las evidencias halladas apuntan a los deslizamientos subacuáticos como mecanismo de generación de tsunamis lacustres (Villarosa et al., 2009, Beigt et al., 2014, 2016), por lo tanto es en este punto en que se va a ahondar.

\subsubsection{Deslizamientos subacuáticos y corrientes de densidad}

El concepto de corrientes o flujos de densidad puede resultar apropiado para comprender los procesos sedimentarios presentes en el delta de los arroyos Pireco y Totoral localizado en el Brazo Rincón del lago Nahuel Huapi. Mulder y Alexander (2001) presentan diferentes clasificaciones de los flujos de densidad sedimentarios (p. 274). Una de estas clasificaciones se basa precisamente en la densidad, distinguiendo entre: 
- Flujos hipopicnales, donde el flujo es menos denso que el agua circundante, siendo importantes en la desembocadura de muchos ríos donde el sedimento se dispersa en plumas flotantes.

- Flujos homopicnales, donde son iguales la densidad del flujo y el agua circundante.

- Flujos hiperpicnales, el flujo es más denso que el agua circundante y se utilizan para referirse a los flujos inferiores generados directamente por efluentes fluviales.

- Flujos mesopicnales (intraflujo o intrusivo), se hacen presentes si la densidad del flujo está entre la densidad de dos capas en una columna de agua estratificada de manera que el flujo viaja por encima de una picnoclina. Son particularmente relevantes en las cuencas marinas fuertemente estratificadas donde son grandes los contrastes de densidad entre las capas de agua y en lagos con capas térmicas. Este sistema de clasificación es una simplificación, ya que la turbulencia ambiental puede convertir los flujos hiperpicnales o hipopicnales en flujos homopicnales.

Uno de los conceptos más recurridos en la literatura es el de corrientes de turbidez que son, por definición, movimientos descendentes de agua densa, cargada de sedimentos. Las capas depositadas por estas corrientes se denominan turbiditas, donde cada evento produce una capa caracterizada, en principio, por una disminución del tamaño de los sedimentos de arriba a abajo, estructura conocida con el nombre de estratificación gradada (Tarbuck, et al., 2005, p. 223).

Chapron et al., 2006 y 2007 observaron turbiditas post-sísmicas en lagos andinos de Argentina y Chile originadas por flujos hiperpicnales, generados por removilización fluvial de deslizamientos de detritos sísmicamente inducidos en la cuenca. La erupción del Cordón Caulle en 1960 dejó un depósito subáereo de tefra compuesta por fragmentos pumíceos claros, sobre la cual se asienta un nivel oscuro constituido de escoria en la llanura aluvial del río Gol Gol, en Chile (Chapron et al., 2006, p. 64, Chapron et al., 2007, p. 369). Estos depósitos han sido reelaborados encontrándose sucesivos niveles mixtos. Sin embargo, en los registros subacuáticos del Lago Puyehue (Chile) se encontraron depósitos de una mega inundación hiperpicnal sobre la cual se asientan sucesivos depósitos de inundación que se destacan por el cambio de coloración en el sedimento y por el contenido fluctuante de agua (Chapron et al., 2007, p. 369).

Bouma (1962) estableció una secuencia típica de depósitos turbidíticos, caracterizándolos desde el punto de vista sedimentológico Si bien estas secuencias fueron establecidas para ambientes marinos, las turbiditas están presentes también en lagos con características particulares. Los eventos de remoción en masa pueden ocurrir tanto en tierra 
firme e ingresar a un lago como así también dentro de un cuerpo de agua y pueden ser lo suficientemente grandes como para causar un tsunami lacustre y potencialmente un seiche (van Daele et al., 2015, p. 1482).

La metodología para identificar turbiditas en sedimentos lacustres comprende una serie de variables e indicadores (Moernaut et al., 2014; Van Daele et al., 2015). A continuación se presentan algunos de ellos y su importancia en el reconocimiento de estos fenómenos:

- En función de la estratificación gradada que presentan los depósitos turbidíticos, la granulometría del sedimento es un indicador clave.

- Imágenes de Rayos X, para reconocer tanto niveles de ceniza volcánica que sirven de marcadores estratigráficos como así también niveles minerales en el perfil estratigráfico del testigo.

- Sísmica de alta resolución, para reconocer niveles disturbados en el sedimento del fondo lacustre.

- LOI (Loss On Ignition/pérdidas por calcinación), para establecer proporción de materia orgánica presente en el sedimento.

- La susceptibilidad magnética (MagSus), expresa en qué medida un material es susceptible de ser magnetizado por un campo magnético dado.

- La presencia de diatomeas, que permite reconocer los distintos tipos de turbiditas en lagos en función del ambiente lacustre en que se encuentre el depósito turbidítico.

Moernaut et al. (2014) y Van Daele et al. (2015) reconocen dos tipos de turbiditas lacustres que denominan LT1 (en inglés, lacustrine turbidite 1) y LT2 (en inglés, lacustrine turbidite 2). Una secuencia completa de un LT1 se caracteriza por una base arenosa delgada, una unidad media gruesa homogénea limosa y una parte superior arcillosa delgada. La unidad central principal de un LT1 tiene una composición sedimentaria y un tamaño de grano medio similar a los sedimentos de fondo. La base arenosa y los techos arcillosos consisten en granos más detríticos, en comparación con dicha unidad principal. En algunas áreas, también se arrastran algunos materiales costeros poco profundos en las corrientes de turbidez, lo que resulta en un ligero enriquecimiento de granos arenosos y valores mayores de MagSus a lo largo de la turbidita. El segundo tipo de turbidita (LT2), se compone de una mezcla heterogénea no gradada de arena fina detrítica y materia orgánica en partículas. Los patrones de tamaño de grano y MagSus no siempre permiten una discriminación inequívoca entre LT1s y LT2s. Por lo tanto, el mejor criterio es el contenido de microfacies, que muestra una cantidad significativamente menor de diatomeas y mayor cantidad de granos detríticos y 
partículas de materia orgánica en LT2s en comparación con LT1s (Moernaut, et al. 2014, pp. 1616-1617).

Depósitos de flujos de densidad en el lago Nahuel Huapi

En el mes de febrero de 2017 se extrajo el testigo sedimentario denominado TOT90217 (Figuras $N^{\circ} 5$ y N6) obtenido en el Brazo Rincón del Lago Nahuel Huapi (Lat. 40 43,959' S / Long. $71^{\circ} 46,444^{\prime} \mathrm{O}, 93$ metros de profundidad). El mismo contaba con una longitud original de $63,5 \mathrm{~cm}$ (medido en campo) pero post-extrusión, su longitud final se redujo a $51 \mathrm{~cm}$ (medido en laboratorio).

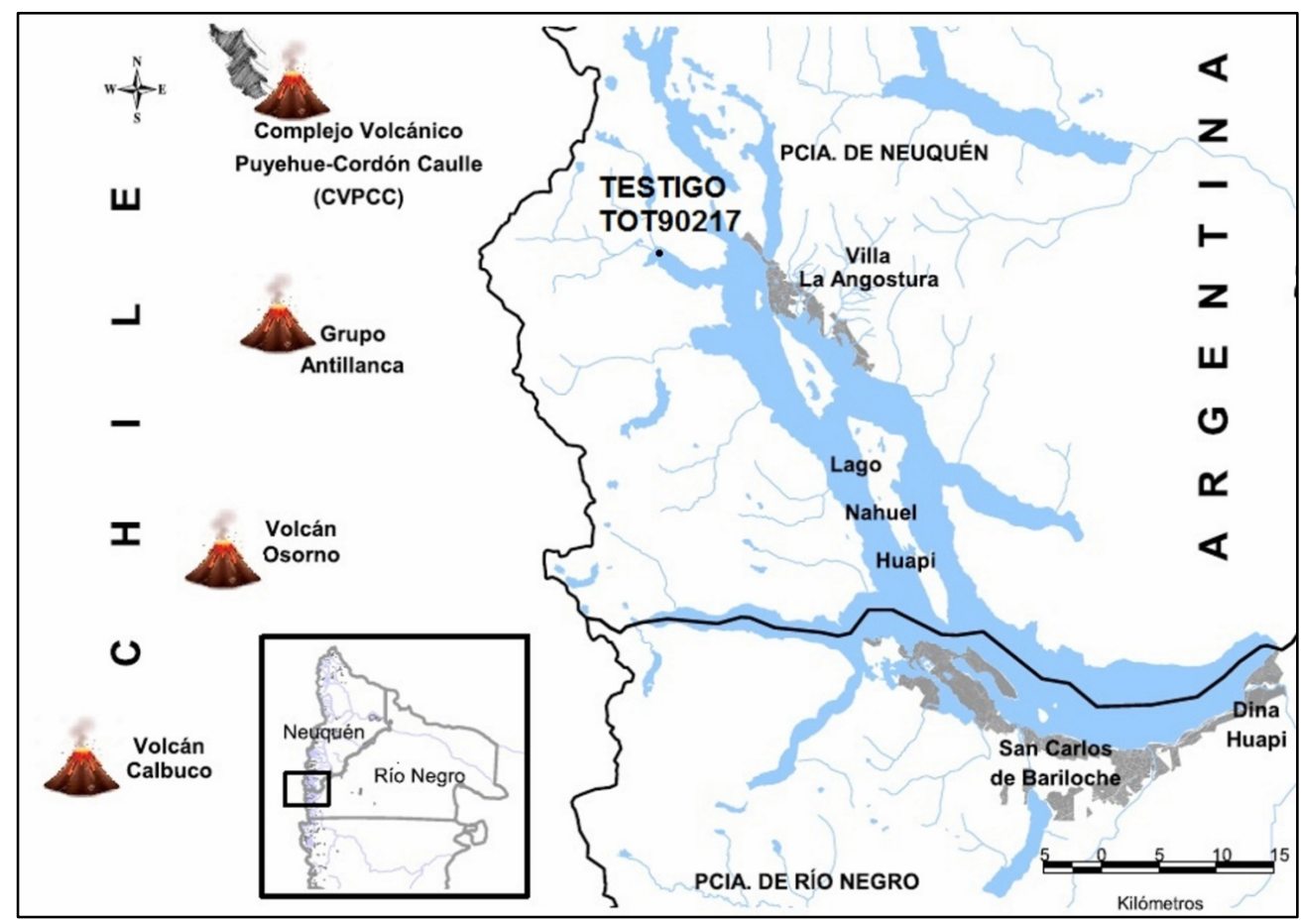

Figura $N^{\circ} 5$. Mapa de localización del sitio de extracción del testigo lacustre en la zona distal del delta de los arroyos Pireco-Totoral. 


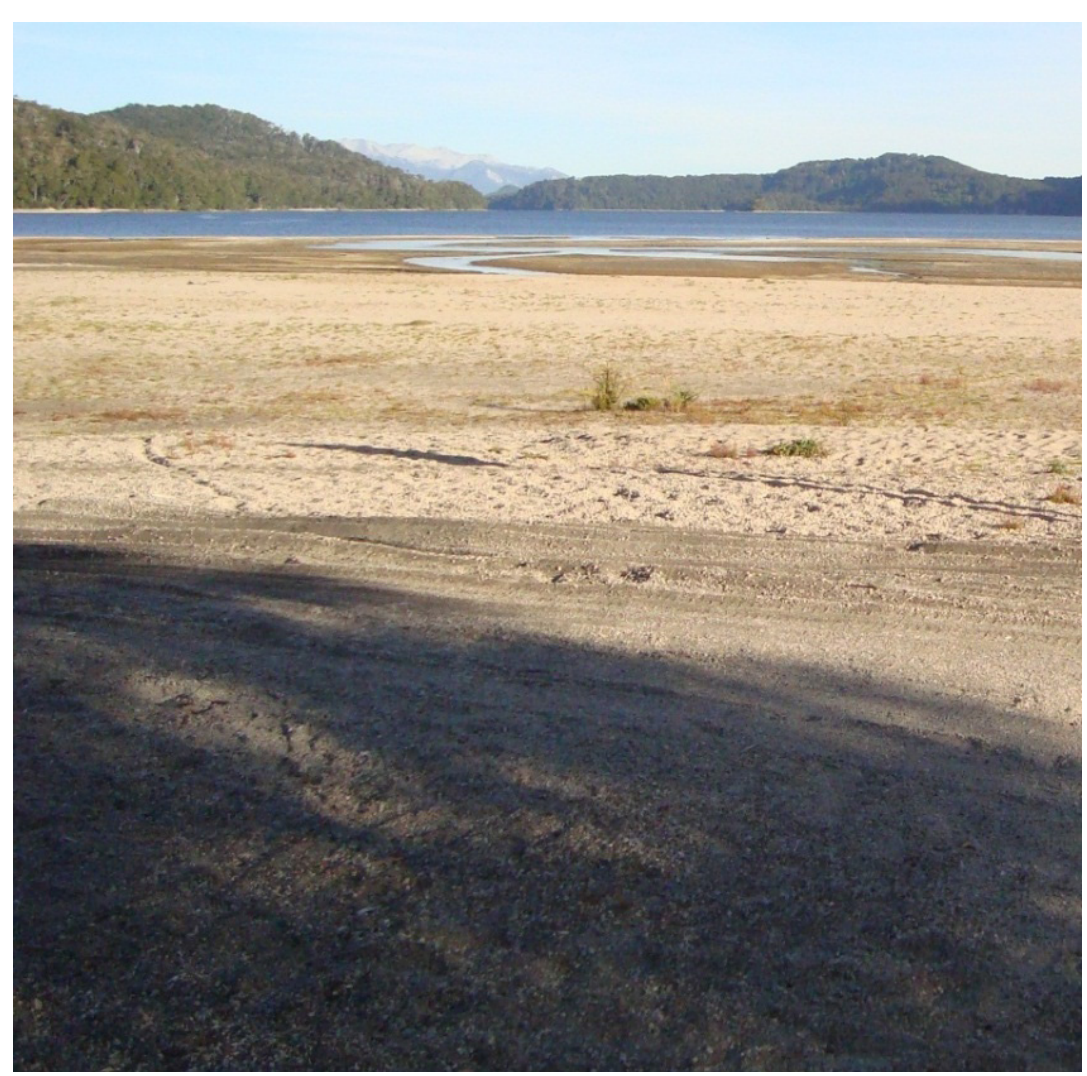

Figura $N^{\circ} 6$. Delta de los arroyos Pireco y Totoral. Vista general del sitio de extracción del testigo, donde se aprecia la gran cantidad de material piroclástico transportado y depositados por estos cursos de agua. Foto del autor, 9 de febrero de 2017.

\section{Descripción del testigo}

El procedimiento de trabajo con testigos sedimentarios lacustres en laboratorio ya fue explicado en el capítulo anterior. Lo que se observa en el testigo (Figura $N^{\circ} 7$ ) es que su base, ubicada a los $51 \mathrm{~cm}$ de profundidad en la columna de sedimentos muestra una coloración oscura, seguida inmediatamente por un nivel delgado de tefra clara, gruesa, granodecreciente y conspicua, entre los 50 y $48 \mathrm{~cm}$. 


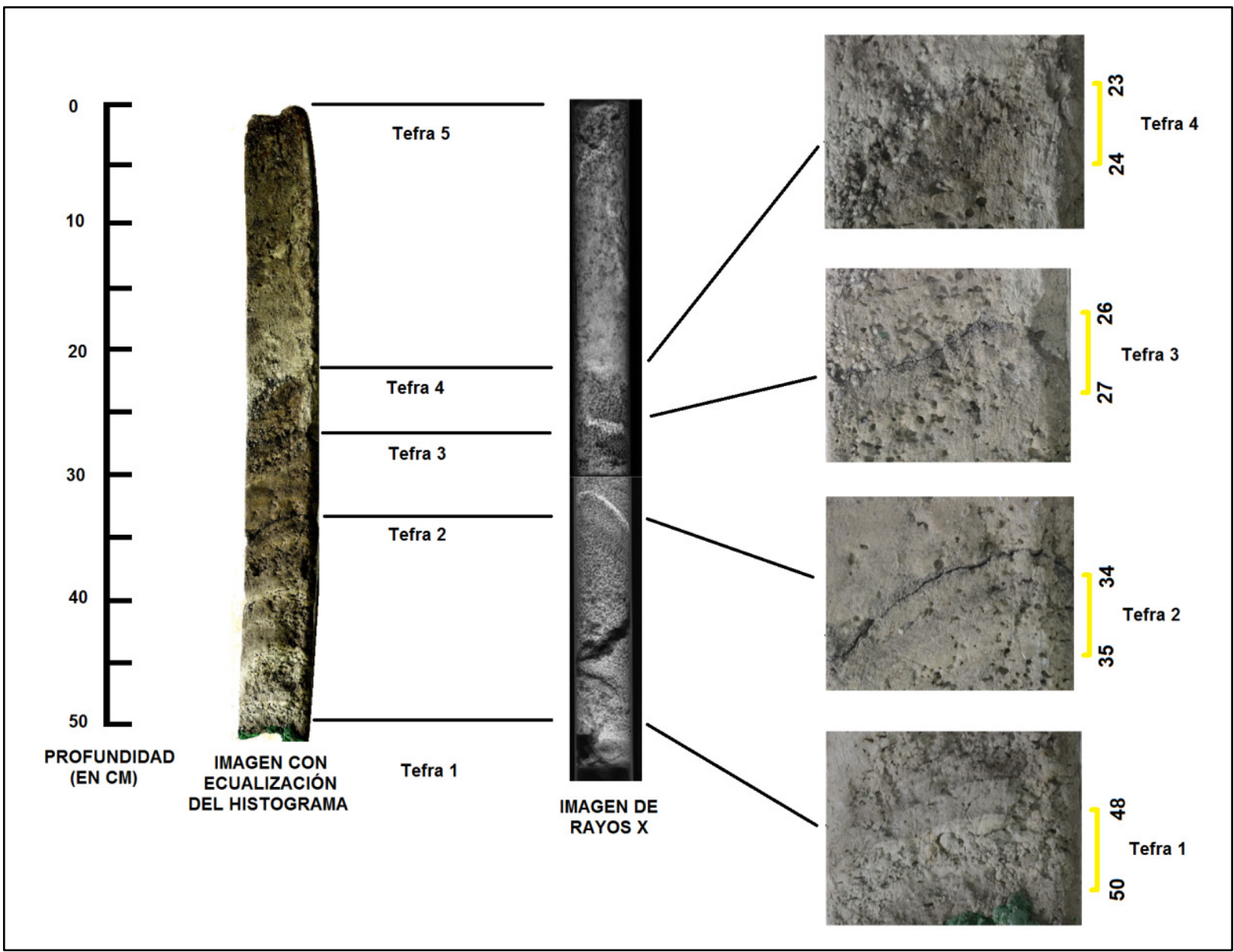

Figura $N^{\circ} 7$. Perfil esquemático del Testigo TOT90217. Esquema comparativo entre la fotografía con ecualización del histograma y la imagen de Rayos X. Las diferencias en la longitud obedecen a la extrusión, proceso que lo compactó $12,5 \mathrm{~cm}$.

Luego de este depósito piroclástico, entre los 48 y $38 \mathrm{~cm}$, se destaca un cambio de coloración con alternancia de láminas oscuras y claras, mostrando todo el conjunto tonalidades más claras y una granulometría más fina. Todas las láminas claras son "castaño amarillento pálido" (pale yellowish brown) y las láminas oscuras son de color "castaño amarillento oscuro" (dark yellowish brown), según la cartilla de color del Servicio Geológico de Estados Unidos (Rock-Color Chart, The Geological Society of America, 1991). Esta laminación está acompañada no sólo por un cambio en la coloración sino además por un cambio en el tamaño de partículas.

Entre los 38 y $23 \mathrm{~cm}$, la laminación continúa pero de manera más tenue y, en términos generales, esta sección del testigo presenta una coloración más oscura ("castaño amarillento oscuro"). 
A partir de los $23 \mathrm{~cm}$ de profundidad y coincidiendo con la presencia de una tefra de tamaño mediano se observa un cambio marcado de color, predominando el color "castaño amarillento pálido". La Tefra 4 presenta una base neta pero su techo está desdibujado dado que continúa la sedimentación fina con alto contenido de material piroclástico hasta aproximadamente los $10 \mathrm{~cm}$ de profundidad donde se verifica nuevamente cambio de color hacia tonalidades más oscuras (“castaño amarillento oscuro"). En los Rayos X esto se observa con una alta reflectividad que gradualmente pierde intensidad en niveles superiores del testigo, efecto de la disminución del aporte piroclástico desde la cuenca.

Por último, en el techo del testigo se observa la presencia de la Tefra 5, ceniza correspondiente a la erupción del volcán Calbuco en 2015.

\section{Tefras}

Una de las tareas más relevantes realizadas en laboratorio fue el reconocimiento y descripción de los niveles de ceniza volcánica en el testigo descripto precedentemente (Cuadro $\mathrm{N}^{\circ} 2$ ). A partir de la descripción de los niveles de ceniza hallados y la profundidad de los mismos, se determinó, en la medida que fuera posible, el volcán de origen y el año de erupción. Las muestras de ceniza se limpiaron en un lavador ultrasónico y luego se secaron en estufa eléctrica a $38^{\circ} \mathrm{C}$. Una vez secas las muestras, se procedió a su observación en lupa binocular para reconocer tipo de vidrio y atribuir un posible volcán de origen. A partir de estos procedimientos se reconocieron 5 niveles de tefras.

\begin{tabular}{|c|c|c|c|}
\hline Tefra & $\begin{array}{l}\text { Profundidad } \\
(\mathrm{cm})\end{array}$ & Descripción & Origen \\
\hline T5 & $0-2$ & Nivel de tefra fina a mediana, de color gris. & Calbuco 2015 \\
\hline T4 & $22-23$ & $\begin{array}{l}\text { Nivel de tefra gris clara, potente y compacta, } \\
\text { tamaño mediano y granodecreciente de un } \\
\text { centímetro de espesor. }\end{array}$ & Cordón Caulle 2011 \\
\hline T3 & $26,7-27$ & $\begin{array}{l}\text { Nivel de tefra delgado, color gris / gris oscuro, } \\
\text { de tamaño fino a mediano. }\end{array}$ & $\dot{d} ?$ \\
\hline $\mathrm{T} 2$ & $34,8-35$ & $\begin{array}{l}\text { Nivel de tefra muy delgada, coloración oscura, } \\
\text { granulometría mediana. }\end{array}$ & $\dot{d ?}$ \\
\hline T1 & $48-50$ & Nivel potente de tefra color clara. & Cordón Caulle \\
\hline
\end{tabular}

Cuadro N². Descripción de los niveles de ceniza volcánica hallados en el registro sedimentario.

Observaciones: el combamiento del testigo en sus bordes externos, obedece al propio método utilizado para la extracción de la muestra (sacatestigo Uwitec modificado para tubo de $63 \mathrm{~mm}$ de diámetro) sumado al tipo de sedimento, predominantemente fino a mediano. Por ello, los niveles flexurados fueron medidos desde el borde externo derecho, desde base a techo. Fuente: elaboración propia sobre trabajo de laboratorio. 
Contenido de humedad y de materia orgánica.

Para determinar contenido de humedad (Cuadro $\mathrm{N}^{\circ} 3$ ) en el sedimento se procedió a muestrear el testigo sedimentario cada un centímetro, tomando muestras de $1 \mathrm{~cm}^{3}$. Estas muestras fueron sometidas a estufa eléctrica por un período de 24 horas a $105^{\circ} \mathrm{C}$. La diferencia entre los pesos húmedo y seco da como resultado el contenido de humedad. Para determinar el contenido de materia orgánica (Cuadro $\mathrm{N}^{\circ} 2$ ) se recurrió, nuevamente, a la técnica de LOI (pérdidas por calcinación), explicado en el capítulo anterior.

\begin{tabular}{|c|c|c|c|}
\hline $\begin{array}{l}\text { Profundidad } \\
\text { (cm) }\end{array}$ & $\begin{array}{c}\text { Contenido } \\
\text { de agua } \\
(\%)\end{array}$ & $\begin{array}{l}\text { Contenido de } \\
\text { materia } \\
\text { orgánica } \\
\text { (gr) }\end{array}$ & $\begin{array}{c}\text { Contenido de } \\
\text { materia } \\
\text { orgánica } \\
(\%)\end{array}$ \\
\hline $2-3$ & 48,76 & 0,710 & 3,89 \\
\hline $3-4$ & 46,60 & 0,740 & 4,01 \\
\hline $4-5$ & 46,10 & 0,650 & 3,82 \\
\hline $5-6$ & 46,53 & 0,664 & 1,97 \\
\hline $6-7$ & 48,80 & 0,669 & 1,57 \\
\hline $7-8$ & 40,78 & 0,694 & 1,79 \\
\hline $8-9$ & 43,31 & 0,654 & 1,17 \\
\hline $9-10$ & 47,28 & 0,705 & 2,54 \\
\hline $10-11$ & 47,24 & 0,727 & 2,46 \\
\hline $11-12$ & 48,02 & 0,703 & 2,10 \\
\hline $12-13$ & 46,11 & 0,675 & 1,90 \\
\hline $13-14$ & 46,12 & 0,677 & 1,39 \\
\hline $14-15$ & 46,29 & 0,711 & 1,94 \\
\hline $15-16$ & 47,20 & 0,616 & 2,03 \\
\hline $16-17$ & 44,71 & 0,630 & 1,16 \\
\hline $17-18$ & 44,00 & 0,638 & 1,11 \\
\hline 18-19 & 46,62 & 0,711 & 1,11 \\
\hline $19-20$ & 45,63 & 0,695 & 0,85 \\
\hline $20-21$ & 49,62 & 0,776 & 0,89 \\
\hline $21-22$ & 41,47 & 0,647 & 0,77 \\
\hline $22-23$ & 39,33 & 0,560 & 1,50 \\
\hline $23-24$ & 42,23 & 0,617 & 2,13 \\
\hline $24-25$ & 42,74 & 0,595 & 2,26 \\
\hline $25-26$ & 42,03 & 0,591 & 1,84 \\
\hline $26-27$ & 39,43 & 0,528 & 2,22 \\
\hline $27-28$ & 44,04 & 0,602 & 2,61 \\
\hline $28-29$ & 43,80 & 0,586 & 2,53 \\
\hline $29-30$ & 46,02 & 0,618 & 2,21 \\
\hline $30-31$ & 46,73 & 0,615 & 3,28 \\
\hline $31-32$ & 47,27 & 0,649 & 3,04 \\
\hline $32-33$ & 42,40 & 0,589 & 2,38 \\
\hline 33-34 & 45,43 & 0,592 & 2,67 \\
\hline $34-35$ & 45,10 & 0,617 & 1,86 \\
\hline $35-36$ & 44,50 & 0,627 & 2,69 \\
\hline $36-37$ & 44,77 & 0,616 & 2,37 \\
\hline $37-38$ & 44,49 & 0,602 & 1,46 \\
\hline $38-39$ & 44,46 & 0,590 & 1,49 \\
\hline $39-40$ & 42,87 & 0,571 & 1,84 \\
\hline $40-41$ & 42,12 & 0,572 & 2,04 \\
\hline $41-42$ & 42,09 & 0,551 & 1,45 \\
\hline $42-43$ & 43,26 & 0,568 & 1,61 \\
\hline
\end{tabular}

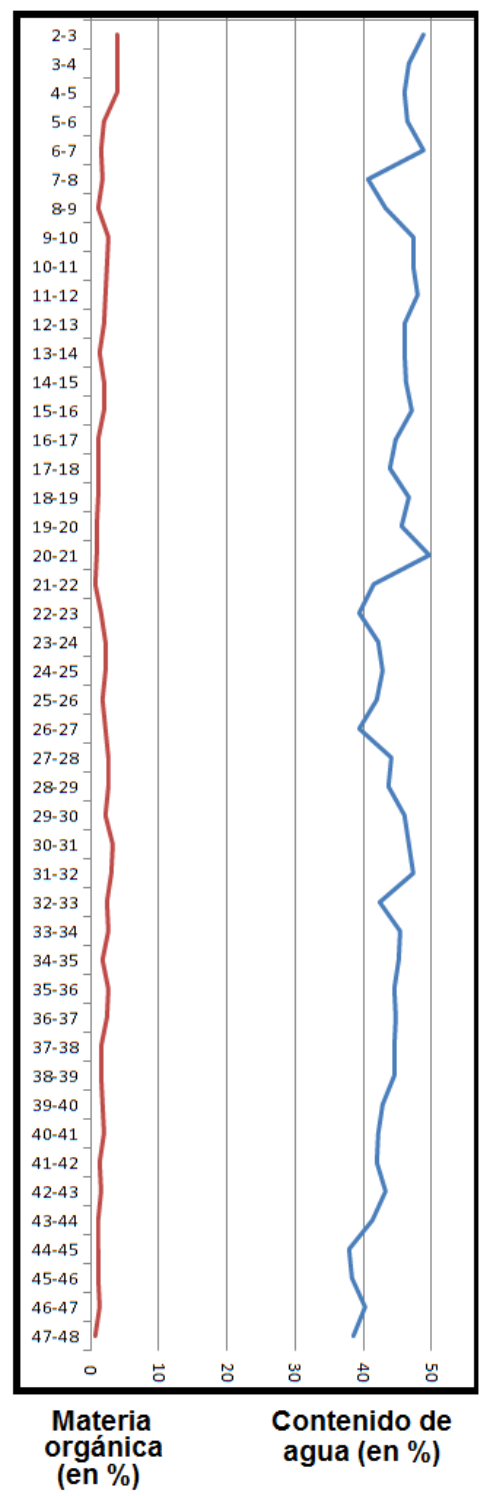




\begin{tabular}{|l|l|l|l|}
\cline { 3 - 3 } $43-44$ & 41,34 & 0,580 & 1,22 \\
\hline $44-45$ & 37,89 & 0,504 & 1,09 \\
\hline $45-46$ & 38,36 & 0,501 & 1,12 \\
\hline $46-47$ & 40,28 & 0,516 & 1,31 \\
\hline $47-48$ & 38,60 & 0,503 & 0,63 \\
\hline
\end{tabular}

Cuadro $N^{\circ} 3$ (y figura asociada). Resultados de contenido de Materia Orgánica y Agua. Fuente: determinaciones de laboratorio de limnogeología del IPATEC, Lic. Valeria Outes.

En términos generales, sobresale el bajo contenido de materia orgánica en toda la longitud del testigo, valores máximos que apenas superan el $4 \%$, cuando los valores máximos obtenidos en el registro de laguna El Trébol superaban el 20\%. Ello responde al fuerte componente piroclástico del sedimento, y a la baja productividad del lago. En cambio, el contenido de agua, presenta variaciones entre 37 y $50 \%$. Si bien a partir de los $34 \mathrm{~cm}$ hacia la porción inferior del testigo sigue presentando variaciones, se pude observar un descenso generalizado atribuible a la compactación que presenta el sedimento a esas profundidades.

\section{Granulometría}

Uno de los indicadores determinantes en el estudio de los depósitos turbidíticos es la granulometría del sedimento (Cuadro $\mathrm{N}^{\circ} 4$ ). Las determinaciones de tamaño de partícula se realizaron en el Instituto Argentino de Oceanografía (IADO, CONICET/UNS, Bahía Blanca) cuyas muestras fueron analizadas mediante la técnica de difracción laser implementando el instrumento Mastersizer 2000, que procesa partículas del rango 0.020 - 2000 micrones. Los datos obtenidos, fueron procesados con el programa Mastersizer 2000 (Malvern Application versión 5.61). Luego, se procedió a clasificar las partículas en rangos conocidos, a saber, el sedimento tamaño arcilla oscila en el rango de 0 y 4 micrones, el limo entre 4 y 63 micrones y la arena entre 63 y 2000 micrones. 


\begin{tabular}{|c|c|c|c|}
\hline $\begin{array}{l}\text { Profundidad } \\
\text { (cm) }\end{array}$ & $\begin{array}{c}\text { Arcilla } \\
(\%)\end{array}$ & $\begin{array}{l}\operatorname{Limo} \\
(\%)\end{array}$ & $\begin{array}{c}\text { Arena } \\
(\%)\end{array}$ \\
\hline $2-3$ & 5,8 & 66,8 & 27,5 \\
\hline $3-4$ & 7,0 & 71,9 & 21,2 \\
\hline $4-5$ & 6,8 & 69,3 & 23,8 \\
\hline $5-6$ & 5,1 & 63,1 & 31,8 \\
\hline $6-7$ & 7,1 & 72,0 & 20,9 \\
\hline $7-8$ & 6,8 & 70,1 & 23,1 \\
\hline $8-9$ & 6,8 & 71,7 & 21,6 \\
\hline $9-10$ & 7,6 & 73,8 & 18,5 \\
\hline $10-11$ & 6,8 & 70,7 & 22,5 \\
\hline $11-12$ & 6,2 & 68,9 & 24,9 \\
\hline $12-13$ & 8,6 & 76,7 & 14,6 \\
\hline $13-14$ & 11,0 & 77,2 & 11,8 \\
\hline $14-15$ & 9,2 & 73,5 & 17,2 \\
\hline $15-16$ & 9,3 & 72,5 & 18,2 \\
\hline $16-17$ & 9,3 & 73,9 & 16,8 \\
\hline $17-18$ & 8,7 & 69,0 & 22,3 \\
\hline $18-19$ & 10,0 & 74,2 & 15,8 \\
\hline $19-20$ & 8,9 & 74,5 & 16,6 \\
\hline $20-21$ & 12,5 & 76,8 & 10,7 \\
\hline $21-22$ & 10,9 & 76,1 & 13,0 \\
\hline $22-23$ & 7,9 & 64,9 & 27,2 \\
\hline $23-24$ & 8,6 & 79,0 & 12,4 \\
\hline $24-25$ & 6,6 & 73,5 & 19,9 \\
\hline $25-26$ & 7,4 & 69,3 & 23,3 \\
\hline $26-27$ & 6,3 & 62,5 & 31,3 \\
\hline $27-28$ & 7,5 & 66,5 & 26,0 \\
\hline $28-29$ & 6,5 & 68,6 & 24,9 \\
\hline $29-30$ & 6,8 & 70,1 & 23,2 \\
\hline $30-31$ & 7,6 & 73,9 & 18,5 \\
\hline $31-32$ & 5,6 & 67,5 & 26,9 \\
\hline $32-33$ & 7,8 & 69,7 & 22,4 \\
\hline $33-34$ & 8,5 & 71,7 & 19,8 \\
\hline $34-35$ & 5,6 & 66,7 & 27,7 \\
\hline $35-36$ & 8,1 & 74,9 & 16,9 \\
\hline $36-37$ & 6,0 & 70,0 & 24,0 \\
\hline $37-38$ & 5,8 & 69,9 & 24,3 \\
\hline 38-39 & 8,7 & 77,1 & 14,2 \\
\hline $39-40$ & 9,7 & 78,5 & 11,8 \\
\hline $40-41$ & 10,8 & 70,7 & 18,6 \\
\hline $41-42$ & 10,9 & 74,6 & 14,6 \\
\hline $42-43$ & 6,5 & 77,5 & 16,0 \\
\hline $43-44$ & 7,0 & 77,9 & 15,1 \\
\hline $44-45$ & 13,4 & 81,6 & 5,0 \\
\hline $45-46$ & 12,7 & 80,2 & 7,1 \\
\hline $46-47$ & 9,5 & 74,8 & 15,8 \\
\hline $47-48$ & 11,0 & 83,3 & 5,8 \\
\hline
\end{tabular}

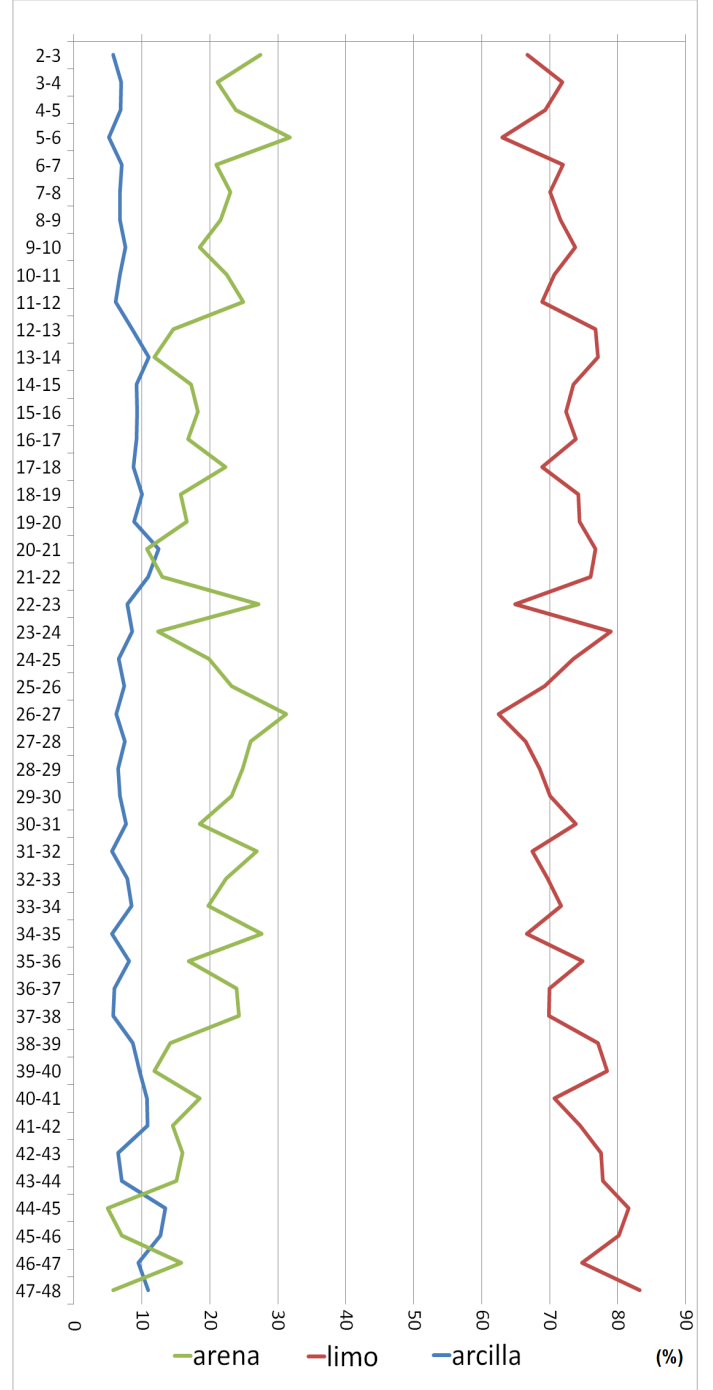

Cuadro $N^{\circ} 4$ (y figura asociada). Granulometría del sedimento. Fuente: determinaciones de laboratorio, gentileza Instituto Argentino de Oceanografía (IADO, CONICET/UNS, Bahía Blanca).

Los resultados señalan que la composición mayoritaria del sedimento corresponde a partículas de tamaño limo (entre 60 y $85 \%$ ), seguido por arena (entre 5 y $32 \%$ ) y arcilla (entre 
5 y 15\%). Todos ellos presentan variaciones a lo largo de la profundidad, sobre todo, en función de la presencia de tefras.

Discusión: hacia un análisis integrado de los parámetros sedimentológicos

La literatura en materia de flujos de corrientes de densidad ha aportado una serie de parámetros sedimentológicos que permiten analizar el testigo lacustre descripto en las secciones previas y que se muestran de manera integrada en la Figura $N^{\circ} 8$.
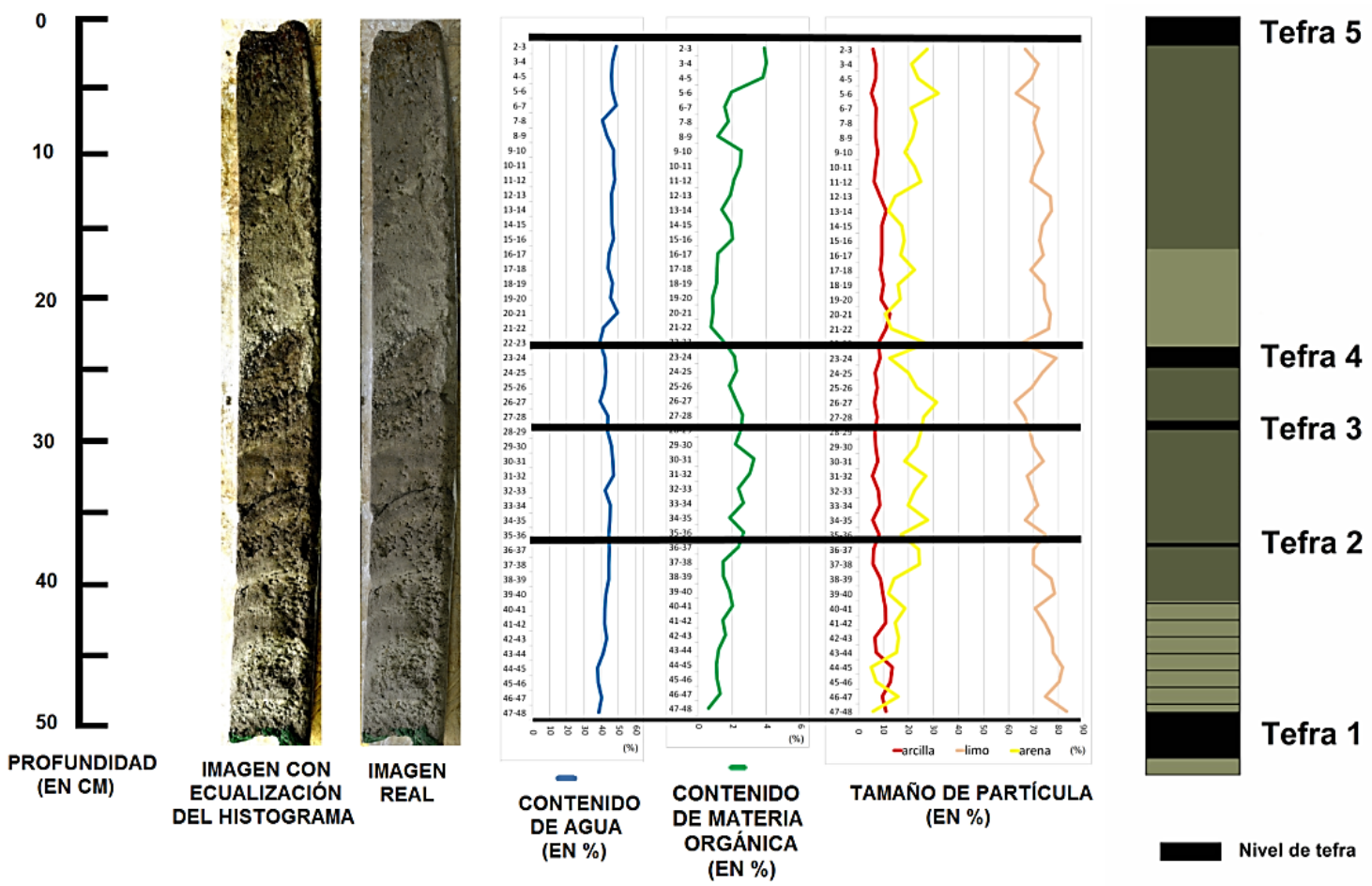

efra 2

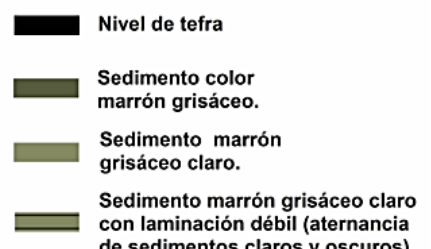

Tefra 1

cedimentos claros y oscuros)

Figura $\mathrm{N}^{\circ} 8$. Figura síntesis de los indicadores para el estudio de depósitos turbidíticos.

La distinción de corrientes de densidad realizadas por Mulder y Alexander (2001) permite comprender el comportamiento de las distintas corrientes a lo largo de la columna de agua y sobre todo, el ambiente en el que se generan, como sucede con los flujos hiperpicnales, comunes en áreas de desembocadura de cursos de agua.

Por otro lado, el análisis puede apoyarse en el reconocimiento de dos tipos diferentes de turbiditas señaladas por Moernaut et al., 2014 y Van Daele et al., 2015 sobre todo en la 
descripción referente a las turbiditas lacustres de tipo 2, las cuales suelen presentarse en ambientes deltaicos y donde es esperable hallar materia orgánica macroscópica en el sedimento (Figura $\mathrm{N}^{\circ}$ ), independientemente del origen de dicha turbidita, la cual puede ser por colapso de delta, flujo del lodo u otro mecanismo.
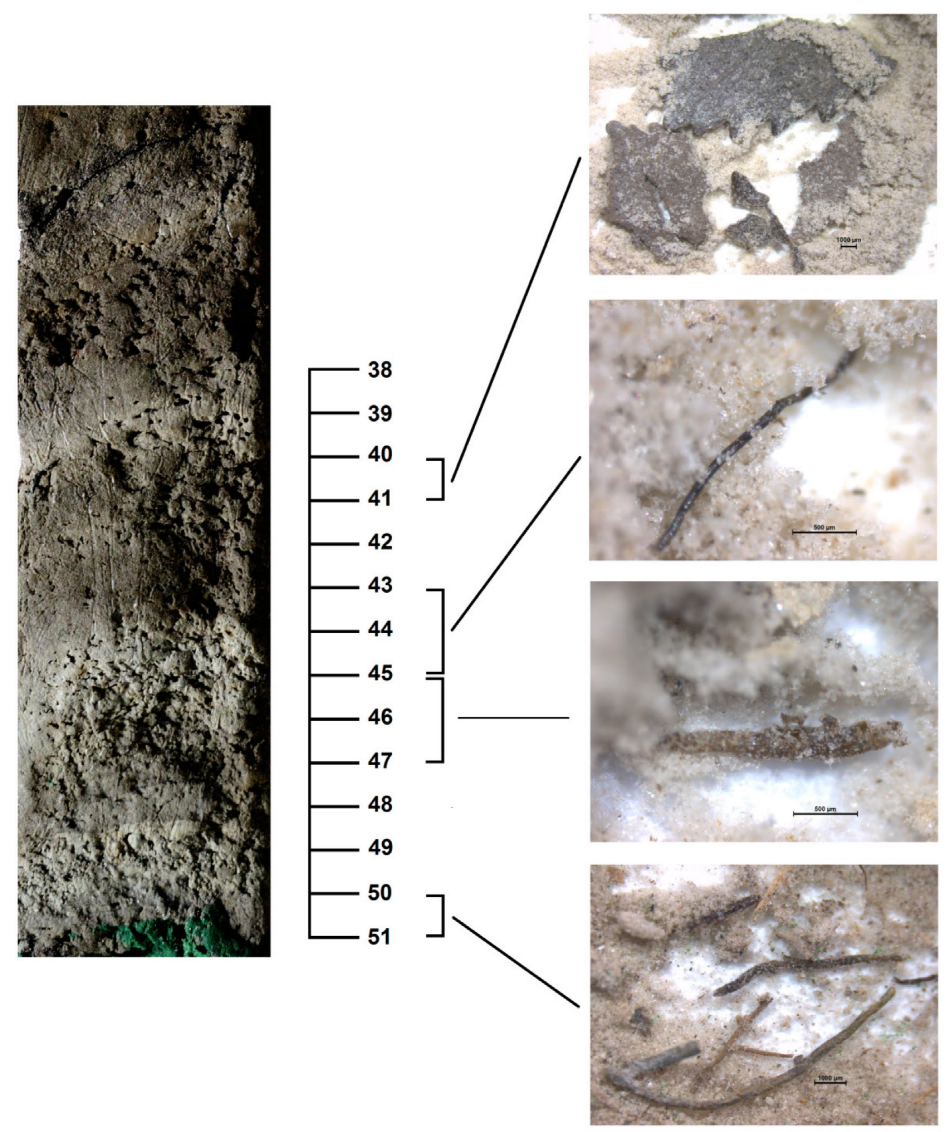

Figura $\mathrm{N}^{\circ} 9$. Esquema de la laminación hallada entre los 48 y 38 centímetros de profundidad. Diferentes láminas claras y oscuras fueron muestreadas para determinar composición y presencia de materia orgánica macroscópica, presente en corrientes de densidad en ambientes deltaicos.

Asimismo, los trabajos de Chapron et al., 2006 y 2007, permitieron interpretar el posible origen de los depósitos laminados ubicados en la sección inferior del testigo sedimentario obtenido en el delta de los arroyos Pireco y Totoral (Cuadro $\mathrm{N}^{\circ} 5$ ).

\begin{tabular}{|c|c|c|c|c|c|c|c|}
\hline $\begin{array}{l}\text { Profundidad } \\
\text { (en cm) }\end{array}$ & Descripción & $\begin{array}{l}\text { Arcilla } \\
\text { (en \%) }\end{array}$ & $\begin{array}{l}\text { Limo } \\
\text { (en\%) }\end{array}$ & $\begin{array}{l}\text { Arena } \\
\text { (en\%) }\end{array}$ & $\begin{array}{l}\text { Total } \\
(\text { en } \%)\end{array}$ & $\begin{array}{c}\text { Contenido } \\
\text { de agua } \\
\text { (en\%) }\end{array}$ & $\begin{array}{c}\text { Materia } \\
\text { Orgánica } \\
\text { (en\%) }\end{array}$ \\
\hline $40-41$ & Lámina Clara & 10,76 & 70,68 & 18,56 & 100,0 & 42,12 & 2,04 \\
\hline $41-42$ & Lámina Oscura & 10,86 & 74,56 & 14,58 & 100,0 & 42,09 & 1,45 \\
\hline $42-43$ & Lámina Clara & 6,48 & 77,54 & 15,97 & 100,0 & 43,26 & 1,61 \\
\hline $43-45$ & Lámina Oscura & 10,22 & 79,73 & 10,04 & 100,0 & 39,62 & 1,15 \\
\hline
\end{tabular}




\begin{tabular}{|c|c|c|c|c|c|c|c|}
\hline $45-47$ & Lámina Clara & 11,09 & 77,49 & 11,42 & 100,0 & 39,32 & 1,21 \\
\hline $47-48$ & Lámina Oscura & 10,96 & 83,28 & 5,76 & 100,0 & 38,60 & 0,63 \\
\hline
\end{tabular}

Cuadro $\mathrm{N}^{\circ} 5$. Depósitos laminados. A partir de la observación en lupa binocular, se determinaron las causas en la diferencia de la coloración de las láminas. Si bien tanto en las láminas claras como en las oscuras predominan los vitroclastos y fragmentos de vitroclastos muy finos, la diferencia en la coloración responde a la presencia diferencial de pequeños fragmentos de materia orgánica, minerales magnéticos y fragmentos piroclásticos máficos.

Estos depósitos laminados hallados en el testigo de Brazo Rincón presentan algunas similitudes con los depósitos limosos de inundación posteriores a la erupción del Cordón Caulle de 1960 hallados por Chapron et al., 2007 en un testigo sedimentario extraído en el delta del río Gol Gol (Lago Puyehue, Chile, Figura Nº10).

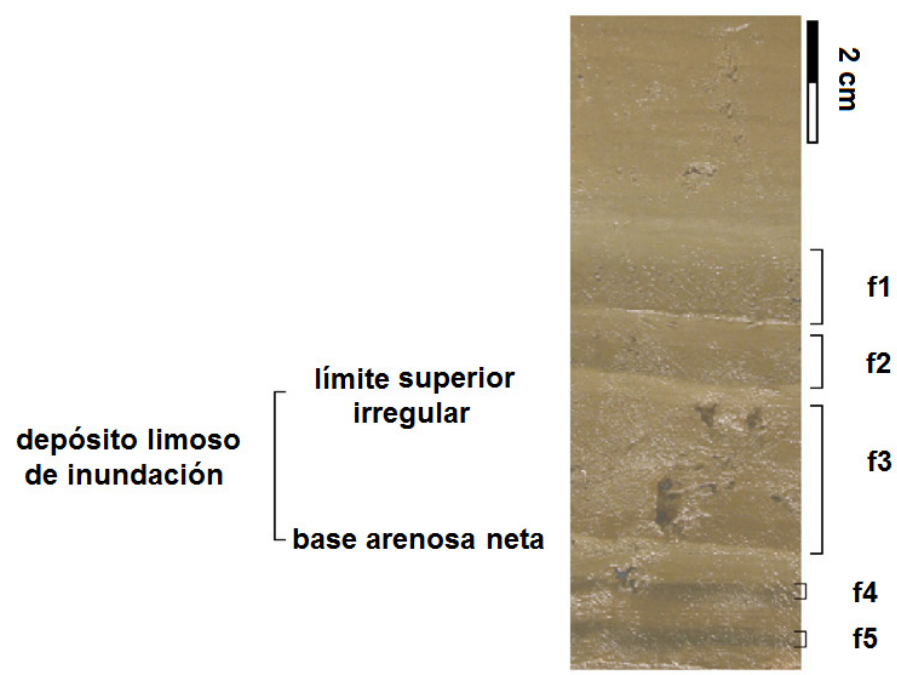

Figura $N^{\circ} 10$. Depósitos limosos de inundación. Laminación hallada en el testigo sedimentario en el delta del río Gol Gol, lago Puyehue, Chile, donde f1 a f5 constituyen los depósitos de flujos de inundación hallados en el sedimento. Fuente: modificado de Chapron et al., 2007, p. 374.

Algunos aportes a la discusión acerca de la asociación entre los depósitos hallados en el detal de río Gol Gol y el testigo sedimentario de Brazo Rincón son los siguientes:

- la presencia de niveles laminados de entre 1 y 2 centímetros de espesor;

- las variaciones en la granulometría, donde si bien la proporción de limos es mayoritaria, la presencia partículas tamaño arena presenta picos puntuales;

- las fluctuaciones en el contenido de agua, aunque muy leves por efecto de la compactación del sedimento en los niveles inferiores del testigo, este contenido se vincula también a la porosidad asociada al tamaño de partículas;

- la presencia de materia orgánica muy baja en términos relativos aunque con presencia de material macroscópico hallado en las diferentes láminas depositadas. 
Asimismo, una visión más amplia a nivel cuenca de los procesos implicados puede desprenderse de los trabajos de Chapron et al., 2006 y 2007. Los depósitos hallados en Chile presenten algunas diferencias en la coloración: a diferencia del río Gol Gol, los arroyos Pireco y Totoral presentan menor caudal, menor superficie de la cuenca y un bosque menos frondoso en su cuenca, a la vez que ambos cursos presentan un cuerpo de agua (la laguna Pire en el curso del arroyo Pireco y el lago Totoral en el trayecto del arroyo homónimo), donde se deposita gran parte material sedimentario de la cuenca antes de sus desembocaduras en el lago Nahuel Huapi.

Estos elementos deber ser considerados en el contexto de su ambiente, que resulta fundamental para entender estos procesos (Figura $\mathrm{N}^{\circ} 11$ ).

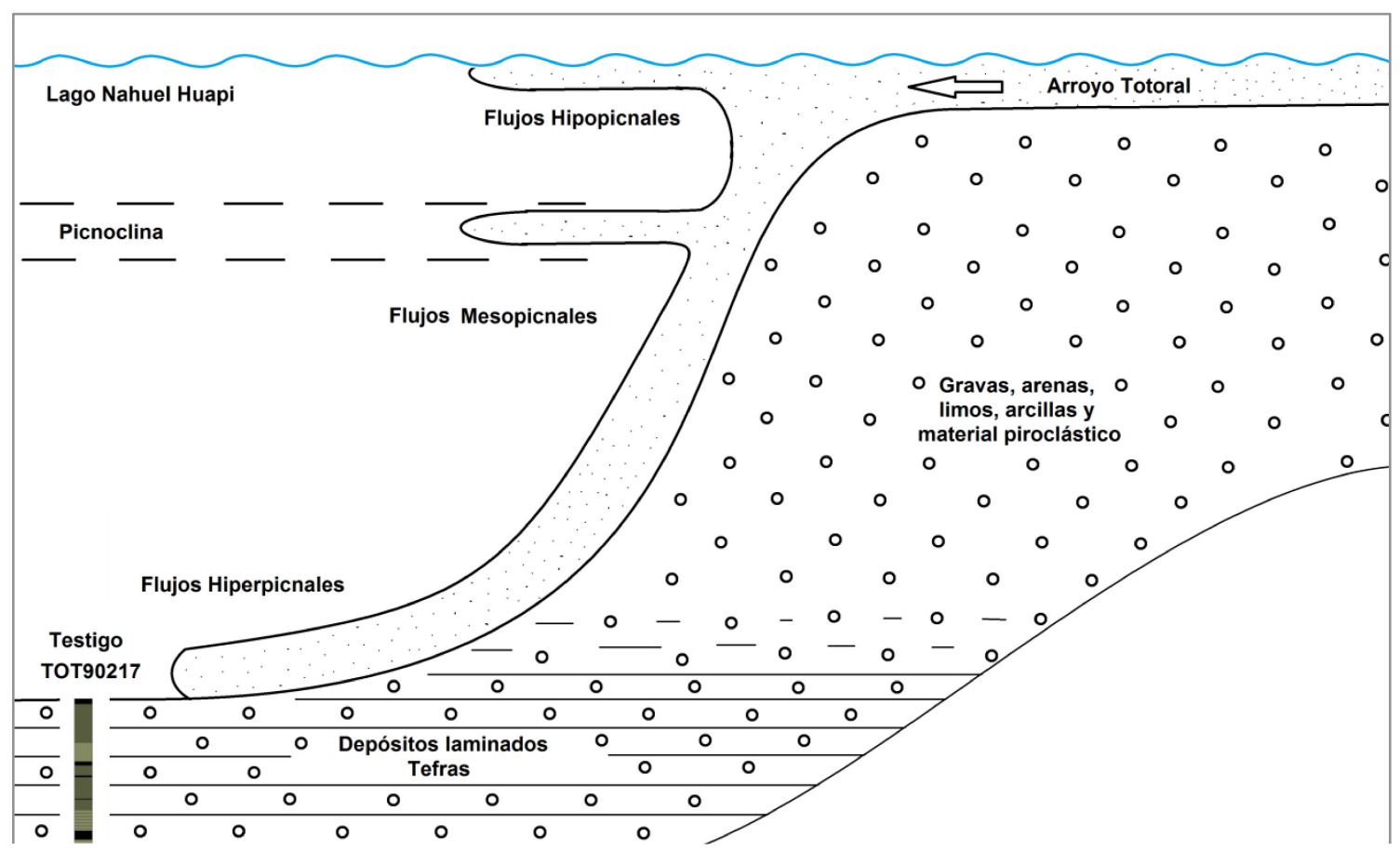

Figura $\mathrm{N}^{\circ} 11$. Esquema que resume el conjunto de aspectos implicados en el estudio de las corrientes de densidad. A partir de los testigos sedimentarios TOT90217 y Pireco 171214, se pudo determinar que el delta se compone de una gran variedad de materiales: gravas, arenas, limos, arcillas y material piroclástico de caída directa así como también retrabajados y transportados por los arroyos Pireco y Totoral. Las corrientes de densidad hiperpicnales, frecuentes en frentes deltaicos, serían las responsables en gran medida de los depósitos hallados en el testigo sedimentario obtenido en el sector distal del delta. Fuente: testigos sedimentarios TOT90217 y Pireco 171214 con base en esquemas presentados por Mulder y Alexander (2001).

En lo que refiere a la sección superior del testigo, a partir de los 23 centímetros de profundidad donde se halla la tefra correspondiente a la erupción del Cordón Caulle de 2011, no se aprecian laminaciones, pero deben considerarse las variaciones en la granulometría, con algunos picos de arenas coincidentes con períodos anuales: entre la tefra de 2011 y la 
tefra de 2015 se observan tres picos, coincidentes posiblemente con cada estación húmeda de los años 2012, 2013 y 2014. Asimismo, la variación gradual de la coloración del sedimento hacia tonalidades más oscuras planteada en la descripción, puede atribuirse a una mayor presencia de materia orgánica, que alcanza los valores máximos en los centímetros superiores del testigo.

De todo lo analizado precedentemente, puede desprenderse la idea de que los flujos de densidad subacuáticos en el delta de los arroyos Pireco y Totoral son frecuentes y, aunque no se puede descartar que tengan como origen un colapso de delta (corrientes densas originadas a partir de deslizamientos) con el potencial de desplazar un volumen de agua considerable e inducir a un tsunami, pueden también deberse a los flujos subaéreos que ingresan al lago o bien a corrientes hiperpicnales, producto de los pulsos estacionales de las precipitaciones invernales y el deshielo primaveral, momento en que el sistema presenta mayor energía capaz de incrementar la proporción de arenas y de partículas macroscópicas de materia orgánica.

Cabe señalar que en esta cuenca en particular, la presencia de material piroclástico es sumamente importante en el conjunto de los sedimentos producto de erupciones explosivas de volcanes cercanos como el Cordón Caulle. Por este motivo, las láminas de la sección inferior y los picos de arenas hallados en el tramo superior del testigo post-erupciones de 1960 y 2011 respectivamente, responden a la removilización del material piroclástico depositado en superficie en la cuenca y transportado hacia el lago durante las estaciones húmedas.

\section{Deslizamientos subacuáticos}

Si bien existen diferentes tipos de procesos de remoción en masa, muchos de ellos se dan en ambientes subacuáticos y son capaces de desplazar grandes volúmenes de sedimentos y agua e inducir, de este modo, a la formación de una ola extraordinaria. Las evidencias morfológicas más representativas de los procesos de remoción en masa subacuáticos en el lago Nahuel Huapi las constituyen los canales y las escarpas de deslizamiento. Los canales son evidencia de flujos de detritos y/o corrientes de turbidez y las escarpas de cabecera y laterales son evidencias de los deslizamientos. La batimetría de alta resolución es una herramienta útil para estudiar la morfología subacuática e identificar aquellas áreas que presentan la mayor cantidad de canales y deslizamientos subacuáticos (Figuras $\mathrm{N}^{\circ} 12$ y $\left.\mathrm{N}^{\circ} 13\right)$. 


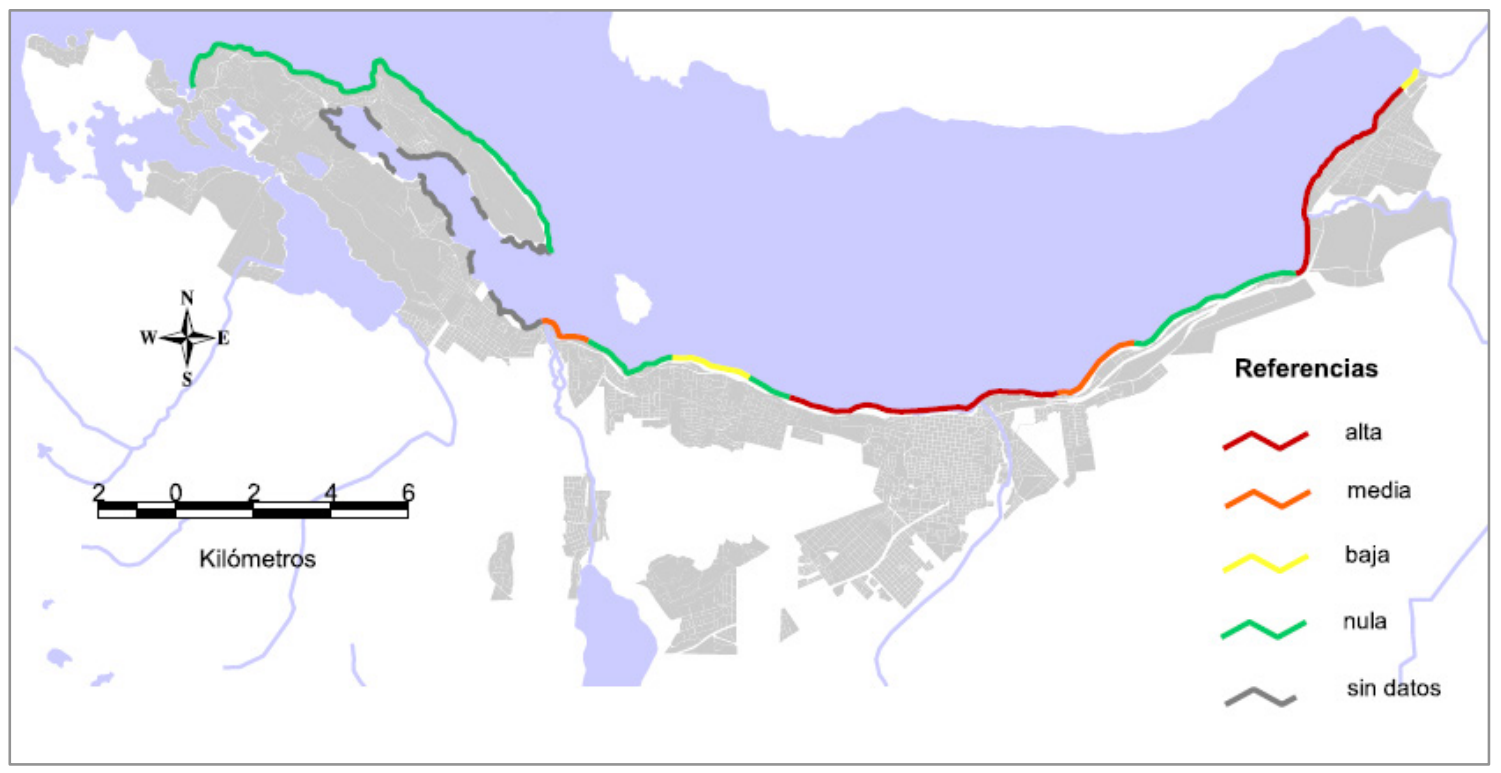

Figura $N^{\circ} 12$. Abundancia de deslizamientos subacuáticos en el Lago Nahuel Huapi (porcentaje de la superficie relevada que ha sido movilizada por deslizamientos). La imagen muestra la abundancia de deslizamientos subacuáticos determinada a partir de la interpretación de grillas batimétricas. Se consideran cualitativamente altamedia-baja-nula en función de la abundancia de deslizamientos. La mayor cantidad de deslizamientos se encuentran en los deltas del río Ñirihuau y arroyo Ñireco y frente a las costas del centro de San Carlos de Bariloche, en cercanías del Puerto. Si bien no todas las costas son susceptibles de deslizar en función de sus condiciones físicas y modificaciones antrópicas, cabe remarcar que amplios sectores del lecho lacustre permanecen sin deslizar entre Dina Huapi y San Carlos de Bariloche y hacia el oeste de esta localidad donde se encuentran playas turísticas y costas pobladas Por este motivo, para el análisis final de vulnerabilidad, los sectores que no presentan deslizamientos (en verde) serán categorizaos con un mayor valor para el evaluación de vulnerabilidad Fuente: modificado de Beigt et al. (2014a, b).

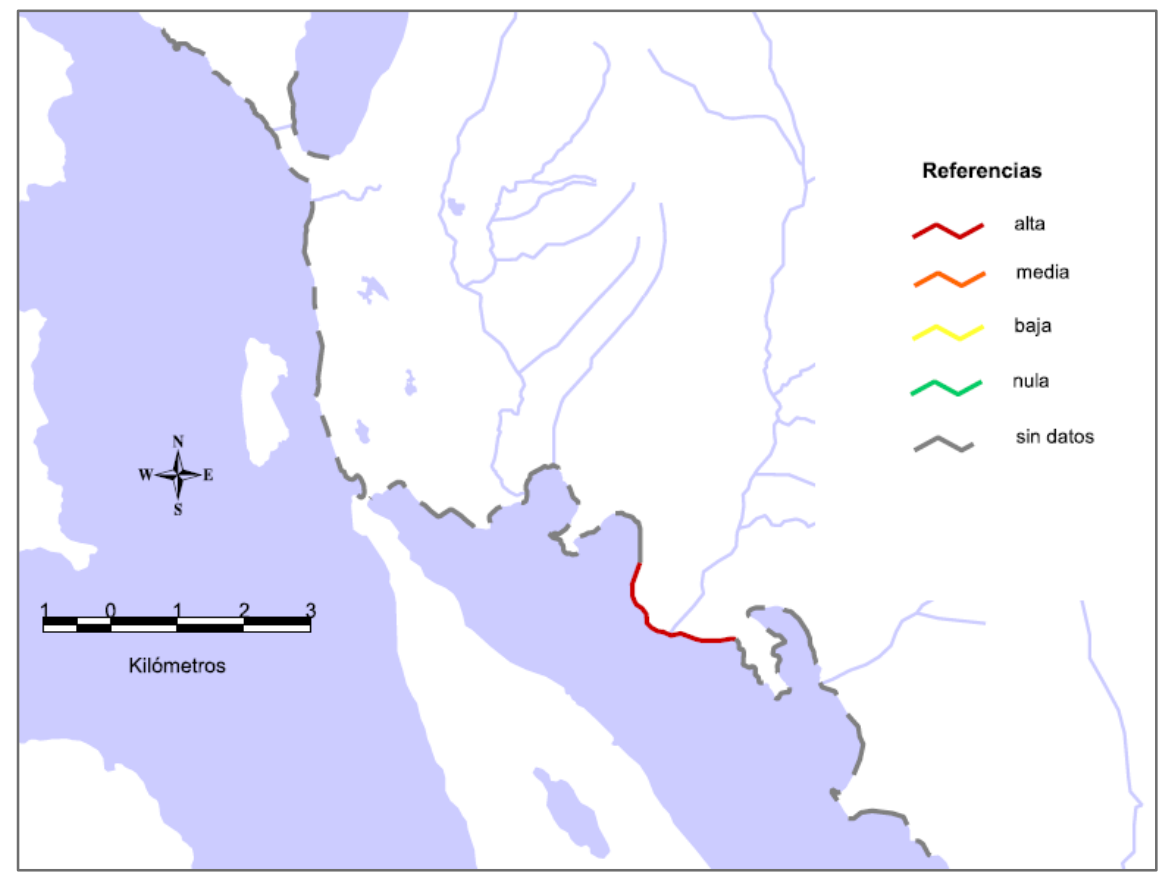


Figura $N^{\circ} 13$. Abundancia de deslizamientos subacuáticos en el Lago Nahuel Huapi. Dado que sólo se cuenta con la batimetría del delta del río Bonito, donde la abundancia de deslizamientos es alta, este indicador no se considerará en la evaluación final de vulnerabilidad en los distintos sectores costeros que comprende el ejido municipal de Villa La Angostura y el amplio sector costero en torno al Villa La Angostura. Fuente: relevamiento de campo procesado en sistemas de información geográfica.

La ocurrencia de deslizamientos subacuáticos principalmente en ambientes deltaicos es favorecida por las elevadas pendientes de los frentes de delta y las altas tasas de sedimentación características en estos ambientes. En particular, es posible que la inestabilidad de los frentes deltaicos en aquellos que recientemente han sido afectados por caídas de ceniza volcánica se incremente debido a la depositación de grandes volúmenes de material piroclástico de baja densidad, débilmente compactados (Beigt et al., 2016, en elaboración) que son removilizados por acción fluvial hacia estos ambientes, generando una progradación significativa de las planicies deltaicas. En este sentido, los reportes de pescadores en el Brazo Machete (lago Nahuel Huapi) acerca de posibles deslizamientos en zonas del veril ocurridos posteriormente a la erupción del Cordón Caulle, así como cartelería instalada por Parques Nacionales en los deltas de los arroyos Pireco y Totoral (Figura N¹4), advirtiendo sobre la inestabilidad costera en los deltas de los arroyos Pireco y Totoral.

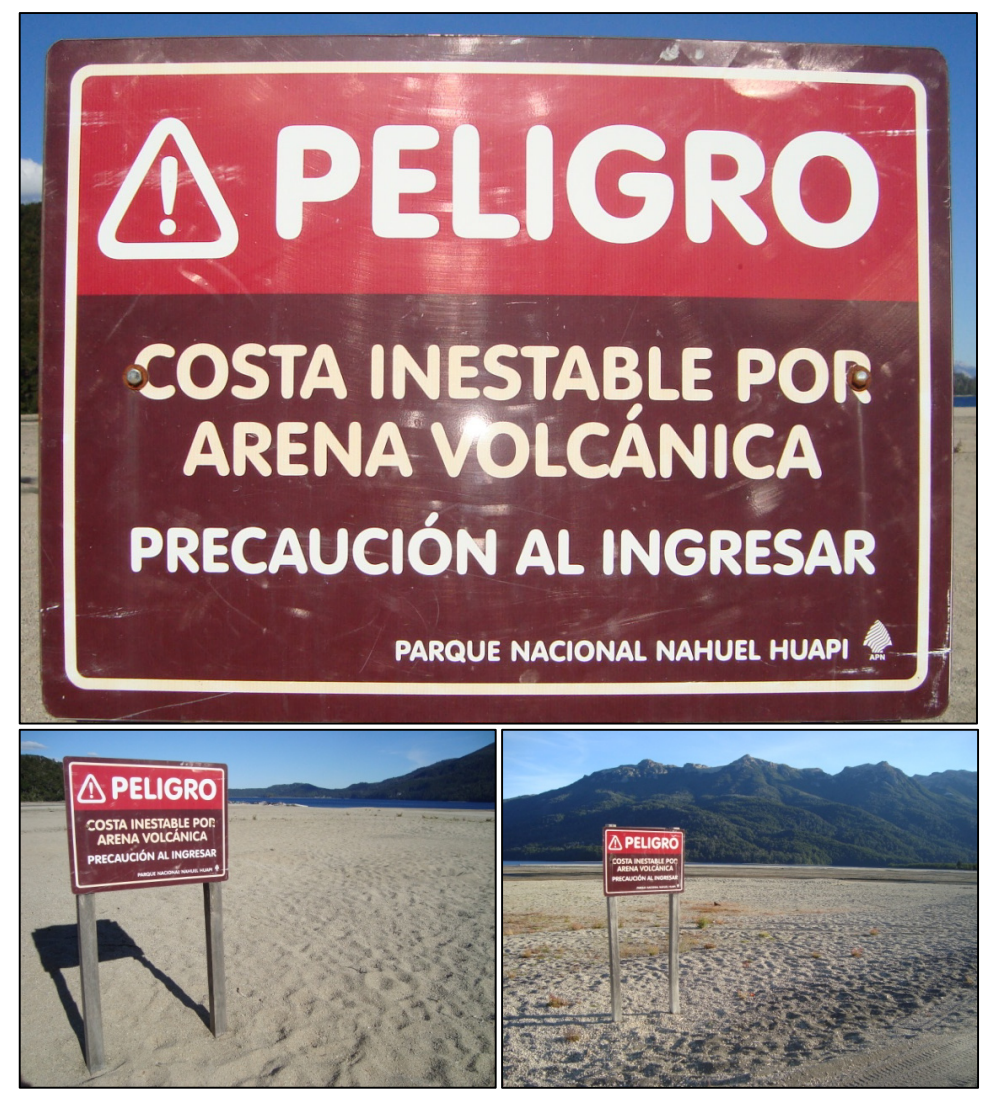


Figura N¹4.Carteles de advertencia en playa occidental del Brazo Rincón, lago Nahuel Huapi. Uno de ellos se ubica en cercanías del arroyo Pireco (abajo, derecha) y el otro se encuentra más cercano al arroyo Totoral (abajo, izquierda). Fotos del autor, 9 de febrero de 2017.

\subsection{Factores precondicionantes de impactos de una ola de tsunami en el lago Nahuel} Huapi

\subsubsection{Vegetación}

El grado de impacto de una ola de tsunami sobre un sector costero se relaciona de manera directa con la vegetación presente en ambientes litorales, la cual podrá atenuar las consecuencias de un tsunami. En un análisis de oeste a este se diferencia claramente una transición del bosque a la estepa, con variadas fisonomías vegetales que abarcan desde bosques húmedos, bosques mixtos, matorrales, humedales, estepas arbustivas y estepas herbáceas (Pereyra et al, 2005, p. 41), variación que está en conformidad con el gradiente de precipitaciones y la altura del relieve.

La vegetación boscosa (Figuras $\mathrm{N}^{\circ} 15$ y $\mathrm{N}^{\circ} 16$ ) se observa en la zona de Llao Llao y Península San Pedro y en todo el ejido urbano de Villa La Angostura, el bosque de transición ocupa una estrecha franja como transición hacia la estepa (Delta del Ñireco, Villa Verde y las Chacras) y la estepa se aprecia en el Delta del Ñirihuau (correspondiente a la localidad de Dina Huapi).

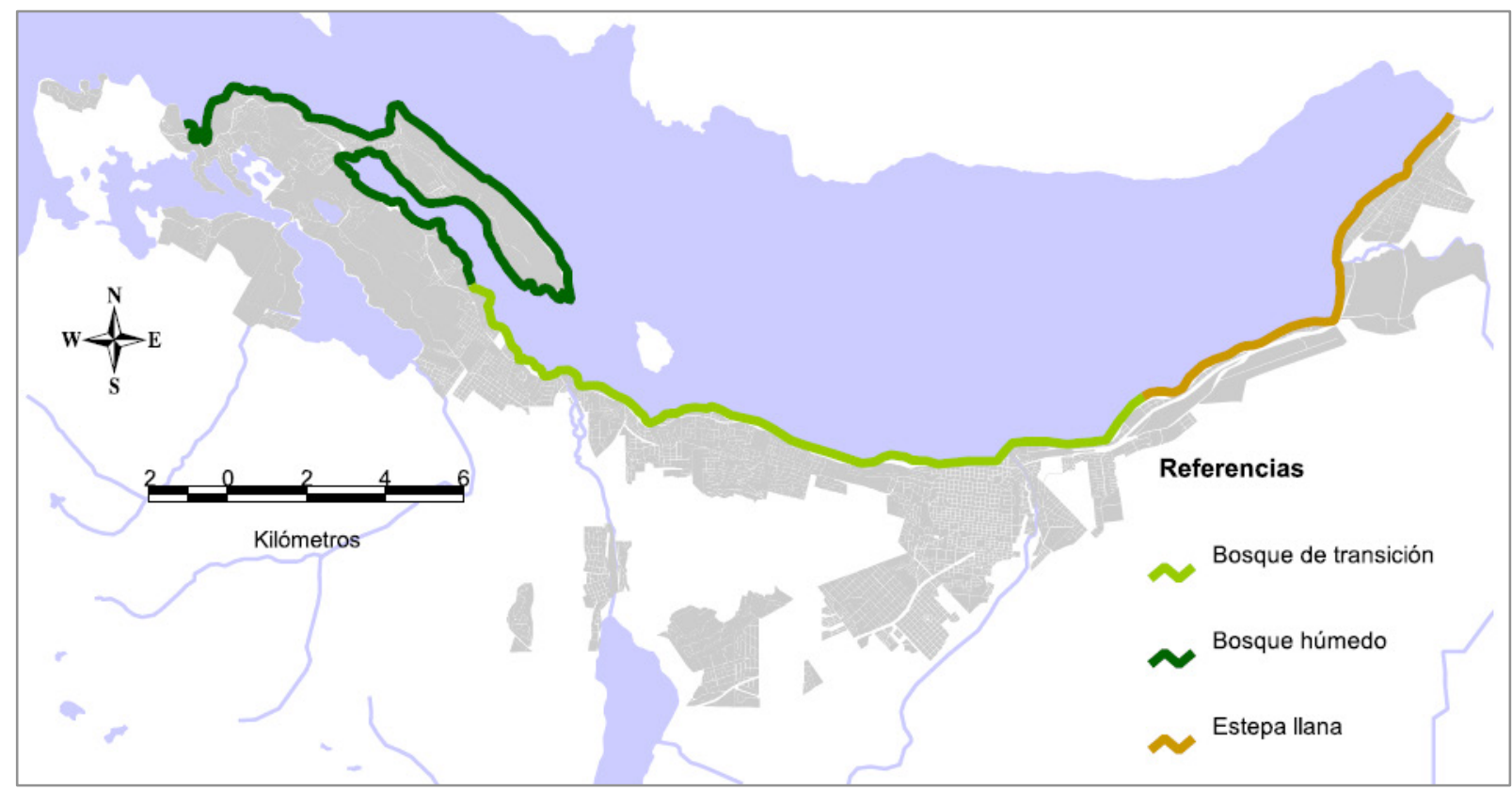

Figura $N^{\circ} 15$. Unidades ecológicas. La vegetación costera nativa actualmente muy alterada por la acelerada urbanización del ejido de San Carlos de Bariloche. Fuente: modificado de Mermoz et al. (2009, p. 10). 


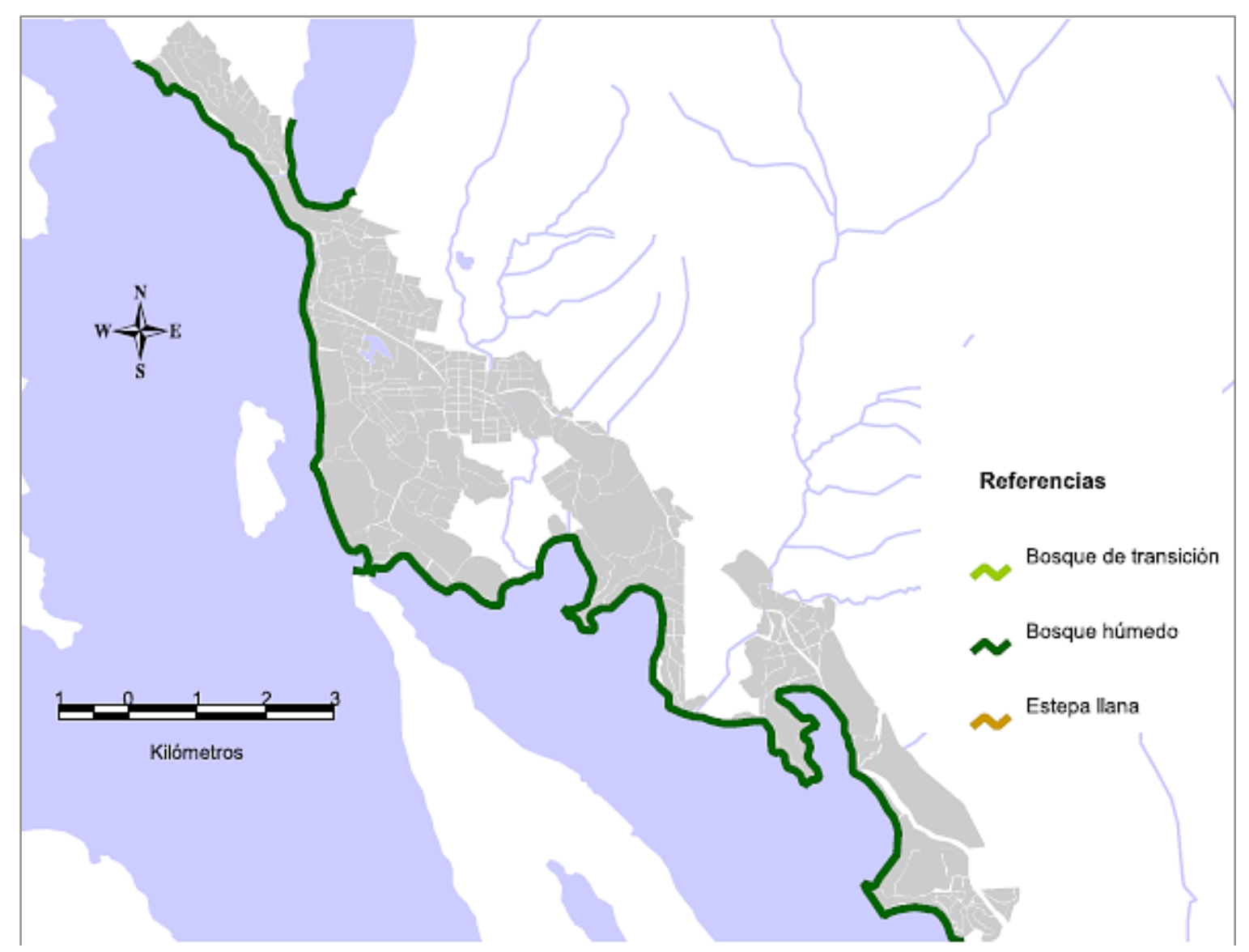

Figura $\mathrm{N}^{\circ} 16$. Unidades ecológicas. La escasa intervención costera mantuvo al bosque húmedo bien conservado en los ambientes costeros urbanizados de Villa La Angostura. Fuente: modificado de Mermoz et al. (2009, p.10).

Si bien la extensión de estas formaciones vegetales era mayor y se encontraba mejor definida, la urbanización fue eliminando las diferentes coberturas, a la vez que diferentes especies exóticas -como la rosa mosqueta, retamas, mimbres, sauces y álamos- ocuparon grandes espacios, particularmente las márgenes de los cursos de agua.

\subsubsection{Morfología costera}

El impacto de una ola también estará en función de las formas costeras, algunas de las cuales podrá atenuar o amplificar una ola extraordinaria (Figuras $\mathrm{N}^{\circ} 17, \mathrm{~N}^{\circ} 18$ y $\mathrm{N}^{\circ} 19$ ). Esta variable se complejiza cuando se contemplan las islas, las cuales pueden originar refracción en las olas modificando su impacto (en el caso de la costa meridional del lago Nahuel Huapi, las Islas Victoria y Huemul, podrían generar este tipo de efectos). 


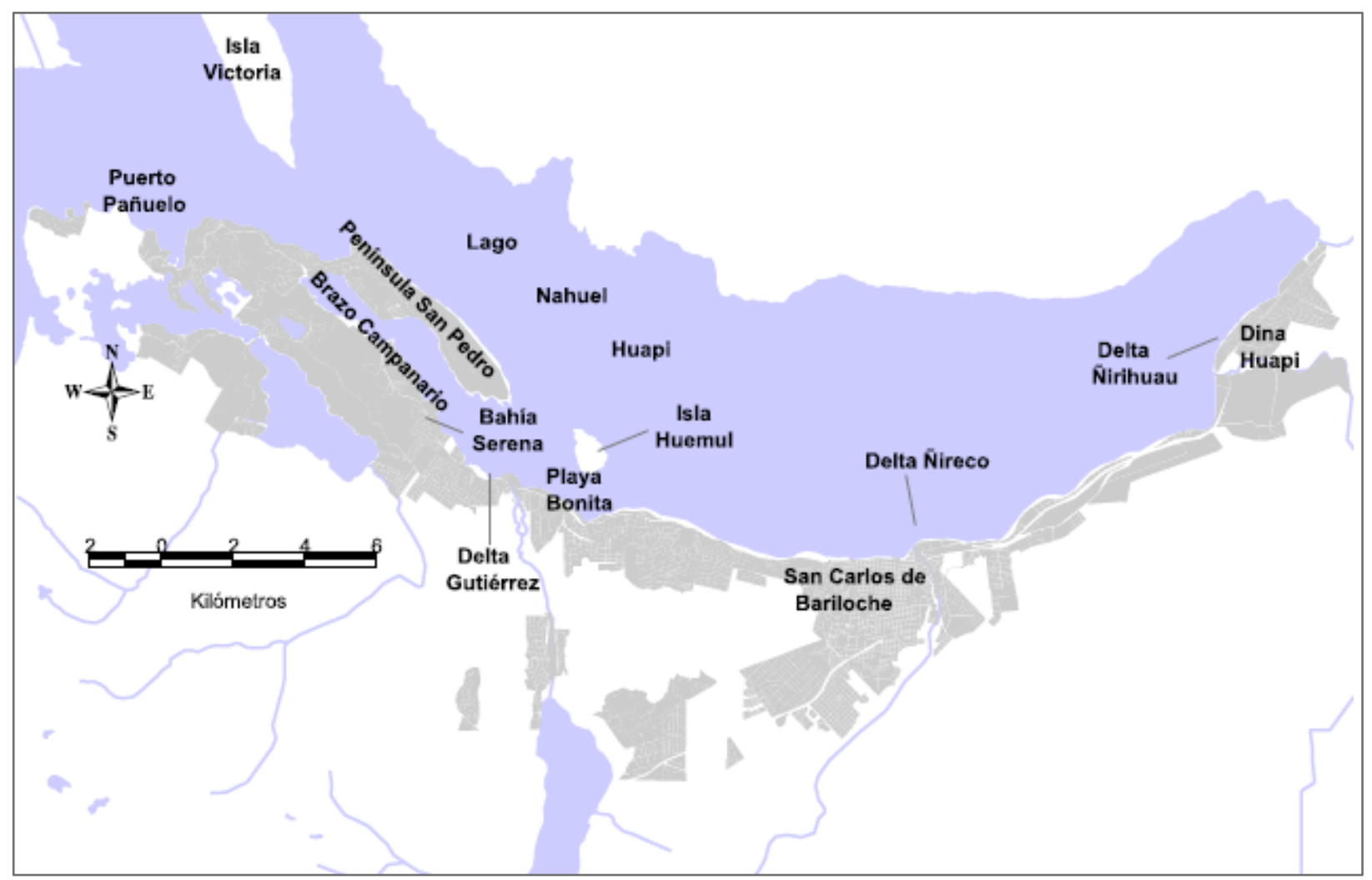

Figura Nº17. Principales morfologías costeras en torno a San Carlos de Bariloche y Dina Huapi. 


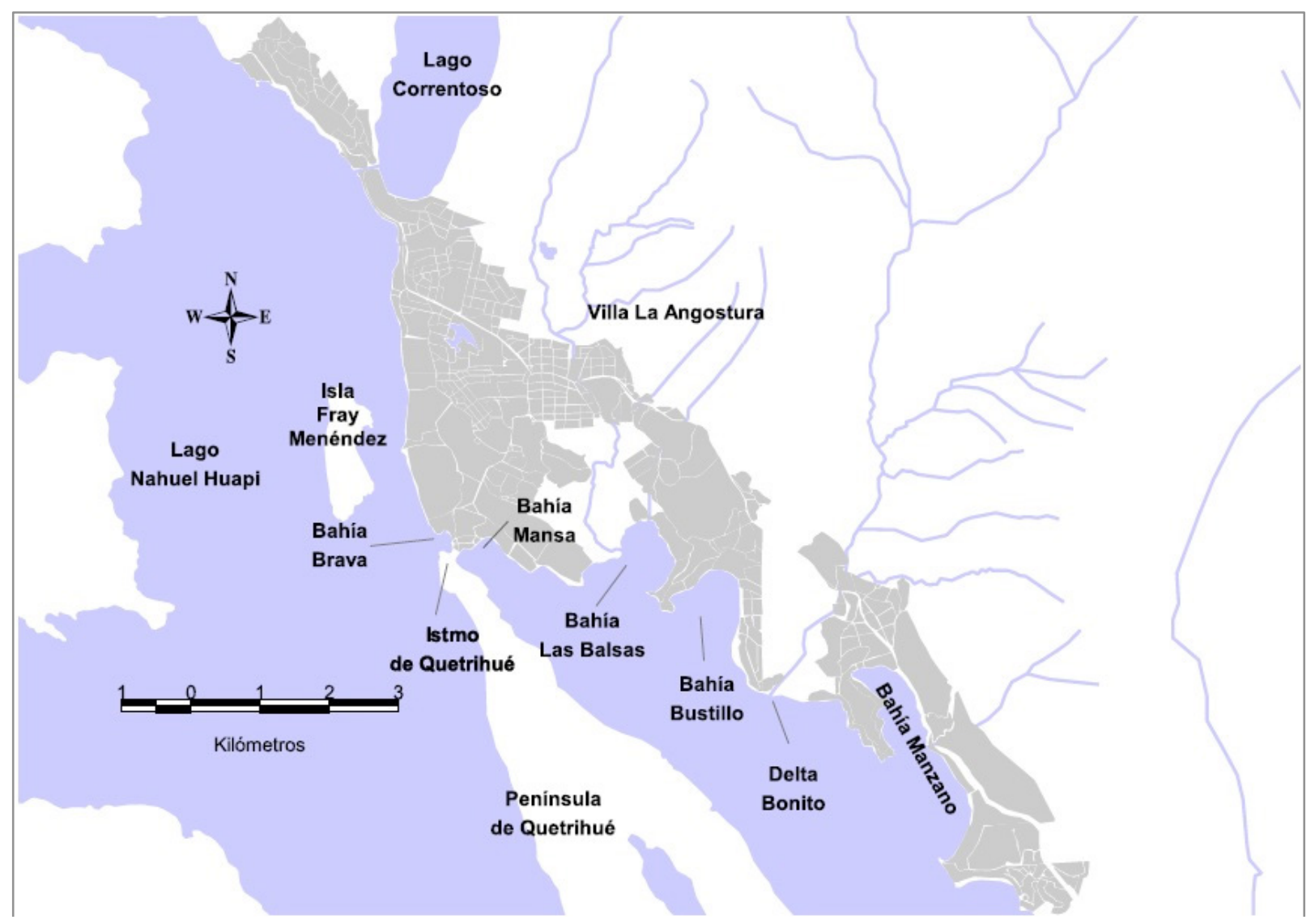

Figura $N^{\circ} 18$. Principales morfologías costeras en torno a Villa La Angostura.

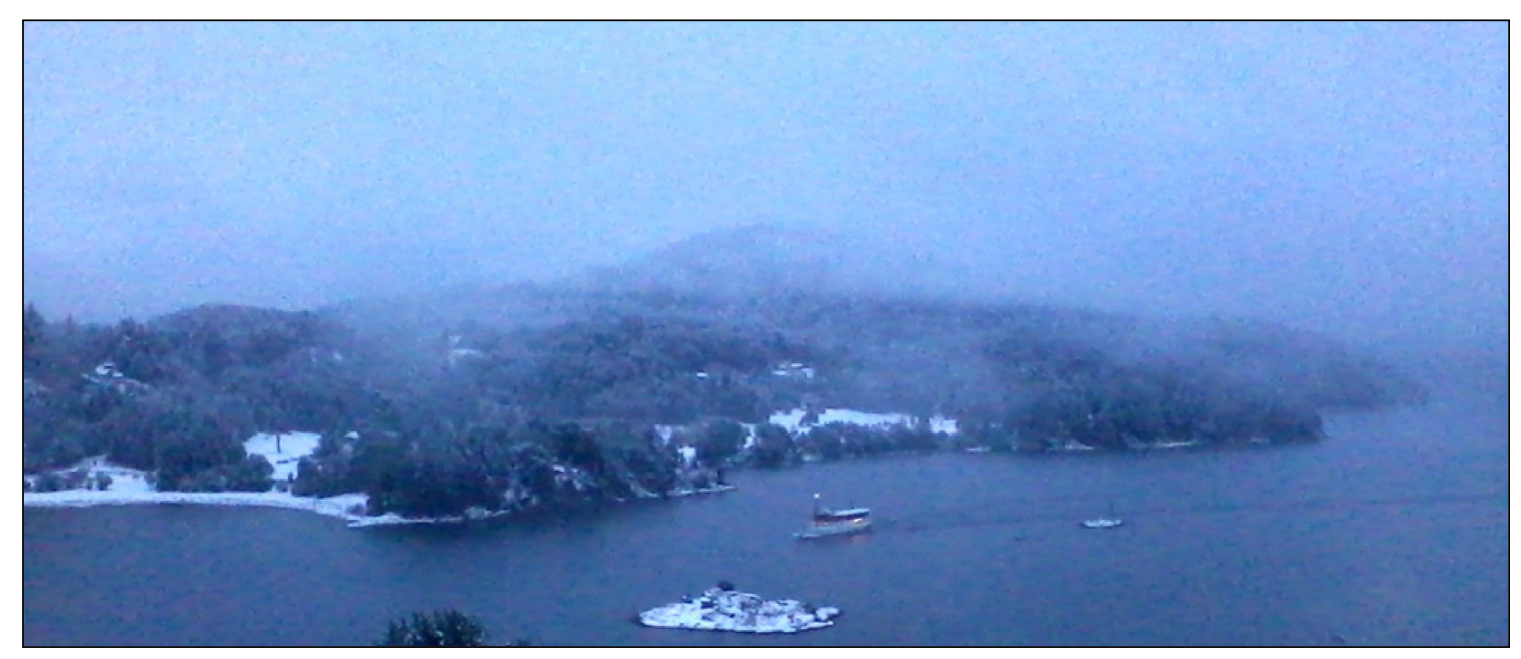

Figura $N^{\circ} 19$. Puerto Pañuelo. Se ubica en una pequeña bahía que le ofrece reparo meteorológico, sin embargo, las bahías en forma de $\mathrm{U}$ o $\mathrm{V}$ pueden potenciar los efectos de una ola de tipo tsunami. Foto del autor, 27 de julio de 2014. 


\subsubsection{Litología}

En términos generales, el sector costero en estudio (Figuras $\mathrm{N}^{\circ} 20$ y $\mathrm{N}^{\circ} 21$ ) se encuentra ubicado en los siguientes depósitos y formaciones geológicas (Giacosa y N. Heredia, 2001):

a. Batolito Patagónico Cordillerano, en la Isla Huemul y de las Gallinas. Bajo este nombre se consideran los granitoides cretácicos que constituyen la mayor parte de las altas cumbres del sector andino (Giacosa y N. Heredia, 2001, p. 17).

b. Formación Ventana, entre Llao Llao y península San Pedro (excluye la península) y parte del Brazo Campanario. Es una Formación de carácter principalmente volcánico con algunas intercalaciones sedimentarias (Giacosa y N. Heredia, 2001, p. 23).

c. Formación Nirihuau, localizada en Península San Pedro y un sector ubicado inmediatamente al oeste del centro de San Carlos de Bariloche. Se trata de depósitos constituidos por rocas clásticas con participación piroclástica y subordinadamente carbonática (Giacosa y N. Heredia, 2001, p. 27).

d. Formación Martín, entre San Carlos de Bariloche y el delta del arroyo Gutiérrez. Litológicamente la unidad se integra con aglomerados, conglomerados y areniscas (Giacosa y N. Heredia, 2001, p. 35).

e. Depósitos glaciales, glacifluviales y glacilacustres, donde actualmente se encuentra el casco urbano de San Carlos de Bariloche. La mayoría de los depósitos son sedimentos de outwash; aunque también los sedimentos glacilacustres alcanzan importancia en la zona (Giacosa y N. Heredia, 2001, p. 36).

f. Depósitos aluviales actuales, desde el delta del arroyo Ñireco hasta la naciente del río Limay y el sector comprendido entre el Delta del arroyo Gutiérrez y el comienzo del Brazo Campanario. Son depósitos de gravas, arenas y limos ubicados en la planicie de inundación actual y en algunos niveles de terrazas más antiguas, situadas a varias decenas de metros de las planicies actuales (Giacosa y $\mathrm{N}$. Heredia, 2001, p. 37).

Las formaciones más importantes, Ventana y Ñirihuau, se encuentran separadas por la Falla del Cerro Otto que atraviesa el Brazo Campanario del lago Nahuel Huapi con rumbo SE-NO.

El tipo de roca predominante en la costa puede propagar la energía de una ola cuando se trata de rocas consolidadas (Batolito Cordillerano Patagónico, Formaciones Ñirihuau, Ventana y Martín) o bien absorber dicha energía cuando la litología se compone 
predominantemente de sedimentos no litificados (presente en los ambientes deltaicos, correspondiente a los sectores con depósitos glaciales y aluviales).

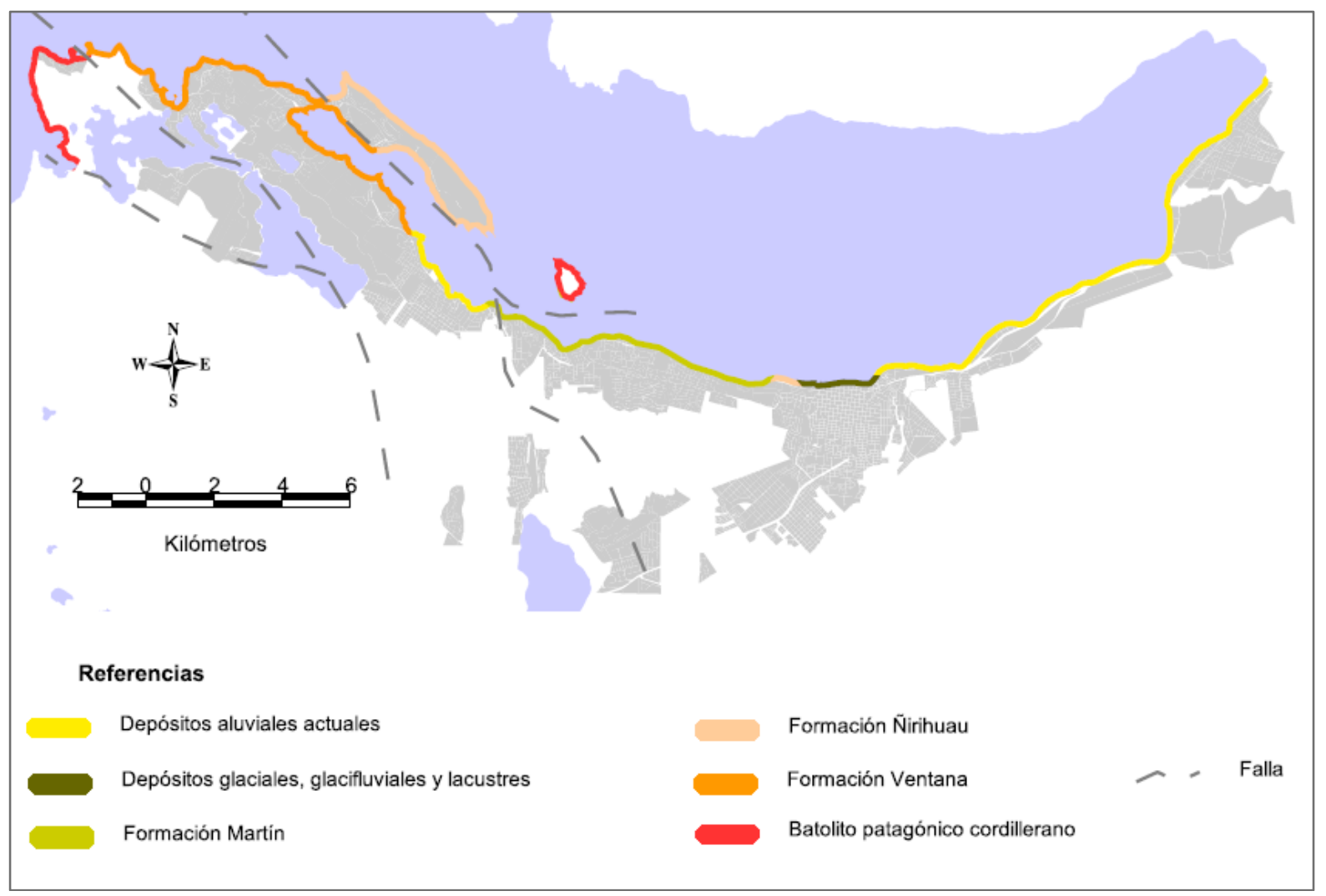

Figura N²0. Geología de la Región del Nahuel Huapi. La litología en torno a San Carlos de Bariloche y Dina Huapi presenta una gran complejidad, donde tienen lugar Formaciones y Depósitos de diferentes edades. Fuente: modificado de González Bonorino (1973) y Giacosa y N. Heredia (2001).
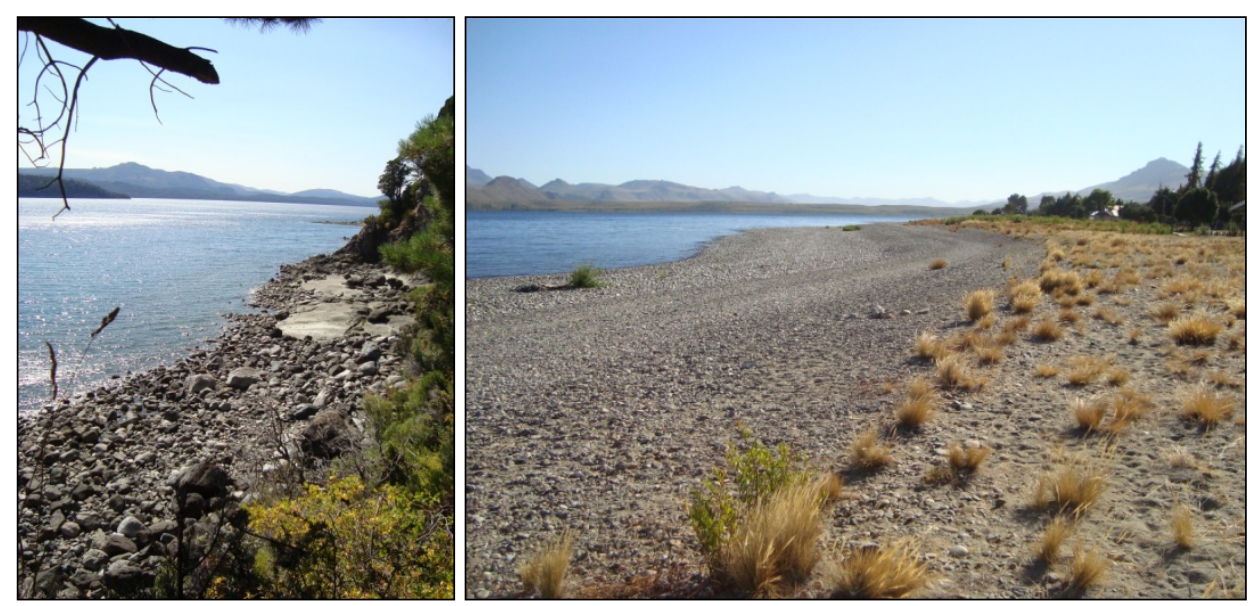
Figura $\mathrm{N}^{\circ} 21$. Costa con fuerte pendiente en Península San Pedro (Oeste), donde la litología predominante corresponde a la Formación Ventana (Izquierda). Escasa pendiente y vegetación en la costa del lago Nahuel Huapi frente a la localidad de Dina Huapi. La composición predominante de arenas, gravas y cantos rodados corresponde a los depósitos aluviales actuales (Derecha). Fotos del autor, 25 y 27 de febrero de 2015.

El área comprendida por el ejido urbano de Villa La Angostura se asienta básicamente sobre tres formaciones geológicas (Escosteguy et al., 2013) similares en su denominación y características a las ya descriptas para la costa austral del Lago Nahuel Huapi (Figura №22):

a. Depósitos aluviales y coluviales indiferenciados, esta unidad está ampliamente distribuida en la región y reúne a los depósitos fluviales que forman parte de las planicies aluviales de generación actual de los principales ríos de la región y algunos abanicos aluviales y deltas. Son depósitos inconsolidados de color castaño claro a gris, constituidos por grava, arena fina y limo, con diferentes proporciones. Algunos depósitos poco extensos que corresponden a pequeños deltas se localizan en las márgenes de algunos lagos, como en el Traful y el Lácar, entre otros. Se les asigna una edad holocena tardía, debido a que estos depósitos están aún en formación (Escosteguy et al., 2013, p. 64).

b. Formación Ventana, antes descripta, aflora en una extensa faja cordillerana que abarca la región de los lagos Nahuel Huapi, Espejo, Totoral y Correntoso, incluyendo la isla Victoria y la península Quetrihue (Escosteguy et al., 2013, p. 35-36).

c. Depósitos glaciarios indiferenciados, unidad constituida por depósitos de till compuestos por material que varía desde limo hasta bloques de rocas plutónicas, volcánicas y piroclásticas. Abundan las gravas sin selección, subangulares y subredondeadas, generalmente con una matriz arenosa. La mayoría de los depósitos están vinculados con morenas terminales, por lo que se presentan como cuerpos cordoniformes, algunos de ellos dispuestos concéntricamente a partir de los extremos orientales de los lagos. Otros, relacionados con morenas de fondo, se encuentran en las partes más bajas de los valles, muy disectados por la erosión fluvial (Escosteguy et al., 2013, p. 57).

En lo que a la situación estructural refiere, la costa NE del Nahuel Huapi coincide con un lineamiento regional de rumbo NO, que se ha interpretado como una falla inversa de inclinación al NE, que junto con el lineamiento NS que discurre por el lago Correntoso, elevan un bloque mayormente constituido por intrusivos de la Formación Los Machis y partes de su caja (Escosteguy et al., 2013, p. 68). 


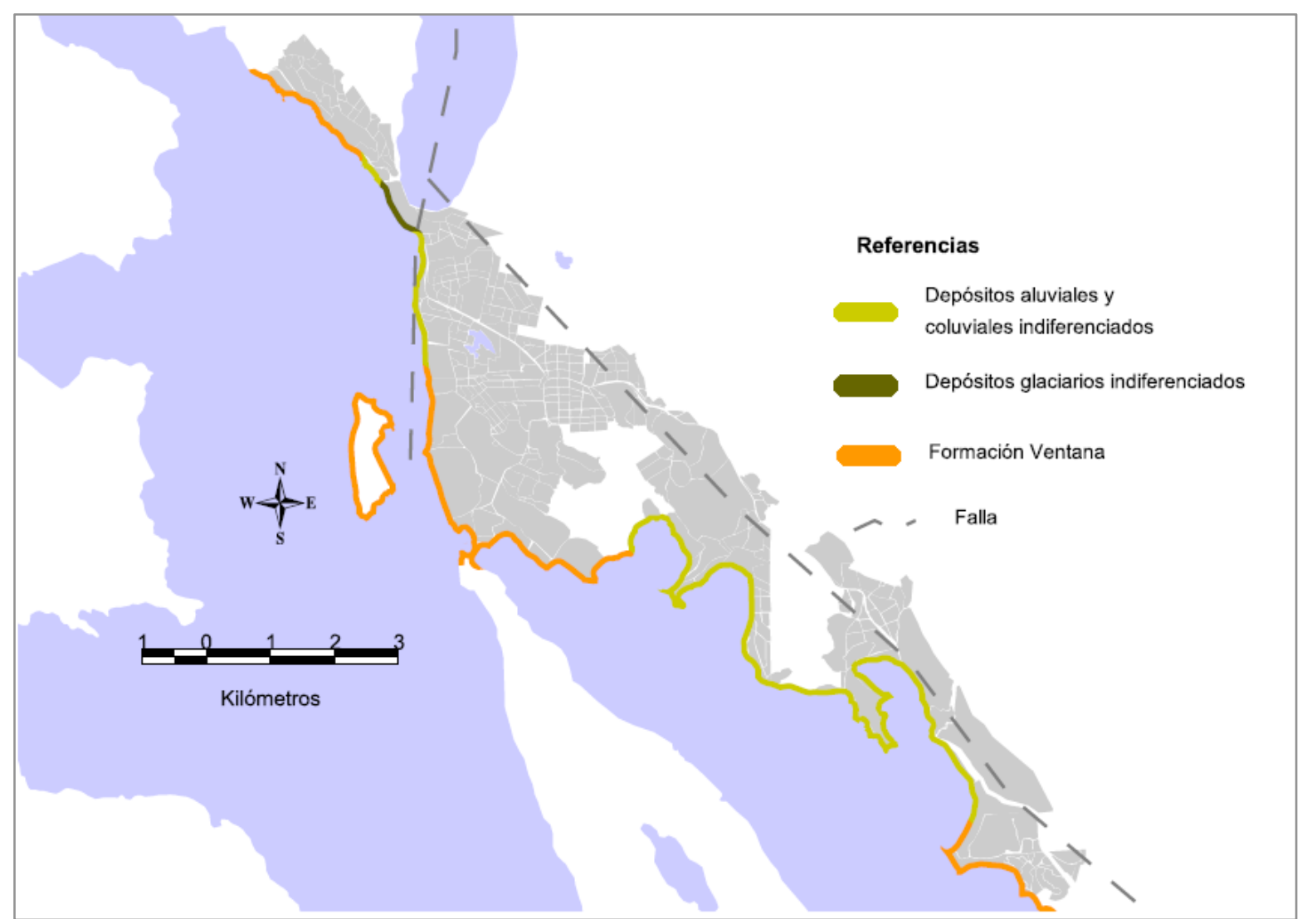

Figura $N^{\circ} 22$. Geología de la Región del Nahuel Huapi. La litología presenta una gran complejidad en torno a Villa La Angostura, donde tienen lugar Formaciones y Depósitos de diferentes edades, algunas de las cuales se presentan en este mapa. Fuente: modificado Escosteguy et al. (2013).

\subsubsection{Nivel del lago}

Los posibles impactos de una ola podrían variar de acuerdo al nivel del agua del lago al momento de registrarse dicho evento. Éste responde a las variaciones estacionales en las precipitaciones y la escorrentía. Los datos suministrados por el Club Náutico Bariloche (Cuadro $N^{\circ} 6$ ), indican para la década 2002-2011 valores más elevados en los meses de primavera, situación que obedece al derretimiento de la nieve en las cuencas altas durante la primavera y comienzos del verano. Si bien este indicador es relevante, es el único que presenta un carácter temporal, razón por la cual se excluye de la ponderación de variables.

\begin{tabular}{|c|c|c|c|c|c|c|c|c|c|c|c|c|}
\hline AÑO/ MES & ENE & FEB & MAR & ABR & MAY & JUN & JUL & AGO & SEP & OCT & NOV & DIC \\
\hline 2002 & 1,58 & 1,23 & 1,28 & 1,38 & 1,81 & 2,30 & 2,27 & 2,30 & 2,52 & 3,29 & 3,59 & 3,36 \\
\hline 2003 & 2,73 & 2,09 & 1,54 & 1,22 & 1,06 & 1,59 & 2,49 & 2,30 & 2,40 & 2,39 & 2,39 & 2,31 \\
\hline 2004 & 2,00 & 1,51 & 1,23 & 1,65 & 1,64 & 1,85 & 3,37 & 2,70 & 2,58 & 2,39 & 2,30 & 2,14 \\
\hline 2005 & 1,81 & 1,42 & 1,22 & 1,17 & 1,47 & 2,50 & 2,83 & 2,65 & 2,40 & 2,41 & 2,55 & 3,20 \\
\hline 2006 & 2,91 & 2,27 & 1,72 & 1,51 & 1,62 & 2,29 & 3,50 & 3,39 & 3,54 & 2,65 & 2,62 & 2,46 \\
\hline 2007 & 2,35 & 1,81 & 1,42 & 1,24 & 1,20 & 1,15 & 1,36 & 1,47 & 1,55 & 1,84 & 2,32 & 2,40 \\
\hline
\end{tabular}




\begin{tabular}{|c|c|c|c|c|c|c|c|c|c|c|c|c|}
\hline 2008 & 2,16 & 1,68 & 1,28 & 1,09 & 1,39 & 1,97 & 2,47 & 2,81 & 2,95 & 2,70 & 2,52 & 2,23 \\
\hline 2009 & 1,66 & 1,25 & 1,09 & 1,17 & 1,73 & 2,45 & 2,31 & 2,36 & 3,15 & 2,66 & 3,00 & 2,78 \\
\hline 2010 & 2,49 & 2,02 & 1,62 & 1,35 & 1,30 & 1,41 & 2,01 & 1,84 & 1,97 & 1,91 & 2,22 & 2,33 \\
\hline 2011 & 1,99 & 1,62 & 1,28 & 1,21 & 1,34 & 1,61 & 1,79 & 2,10 & 2,18 & 2,38 & 2,32 & 1,98 \\
\hline Promedio & $\mathbf{2 , 1 7}$ & $\mathbf{1 , 6 9}$ & $\mathbf{1 , 3 7}$ & $\mathbf{1 , 3 0}$ & $\mathbf{1 , 4 6}$ & $\mathbf{1 , 9 1}$ & $\mathbf{2 , 4 4}$ & $\mathbf{2 , 3 9}$ & $\mathbf{2 , 5 2}$ & $\mathbf{2 , 4 6}$ & $\mathbf{2 , 5 8}$ & $\mathbf{2 , 5 2}$ \\
\hline
\end{tabular}

Cuadro $N^{\circ} 6$. Variaciones estacionales del lago Nahuel Huapi. Período 2002-2011. Si bien se registraron variaciones anuales, en términos generales, el mes de abril presenta, en promedio, los valores más bajos en el nivel del lago mientras que los más elevados corresponden al mes de Noviembre. Analizando los datos suministrados para esta década, los valores extremos corresponden a 0,93 (25, 26 y 27 de marzo de 2009) y 3,84 (16 de julio de 2006), es decir una variación máxima de 3 metros en el período, Las mediciones se toman en referencia a la altura de San Carlos de Bariloche, con línea de ribera establecida en 770,4 m.s.n.m. Fuente: elaboración propia sobre información suministrada por el Club Náutico Bariloche.

\subsubsection{Pendientes}

Los perfiles de costa relevados en sitios puntuales varían a lo largo de la toda la extensión costera involucrada en el trabajo (Figuras $\mathrm{N}^{\circ} 23, \mathrm{~N}^{\circ} 24$ y $\mathrm{N}^{\circ} 25$ ). En materia de seguridad, las pendientes controlan el avance de la ola. Si bien una mayor pendiente brinda mayor seguridad ante una ola extraordinaria, también es cierto una menor pendiente facilita la evacuación (Lagos, 2012, p. 13).

Si bien las costas más extensas pueden disipar una ola, las playas que presentan un perfil de escasa pendiente -sobre todo las ubicadas en sectores deltaicos-, tienen la capacidad de propagar una posible ola, en cambio, las costas más altas tienen la capacidad de moderar el impacto.

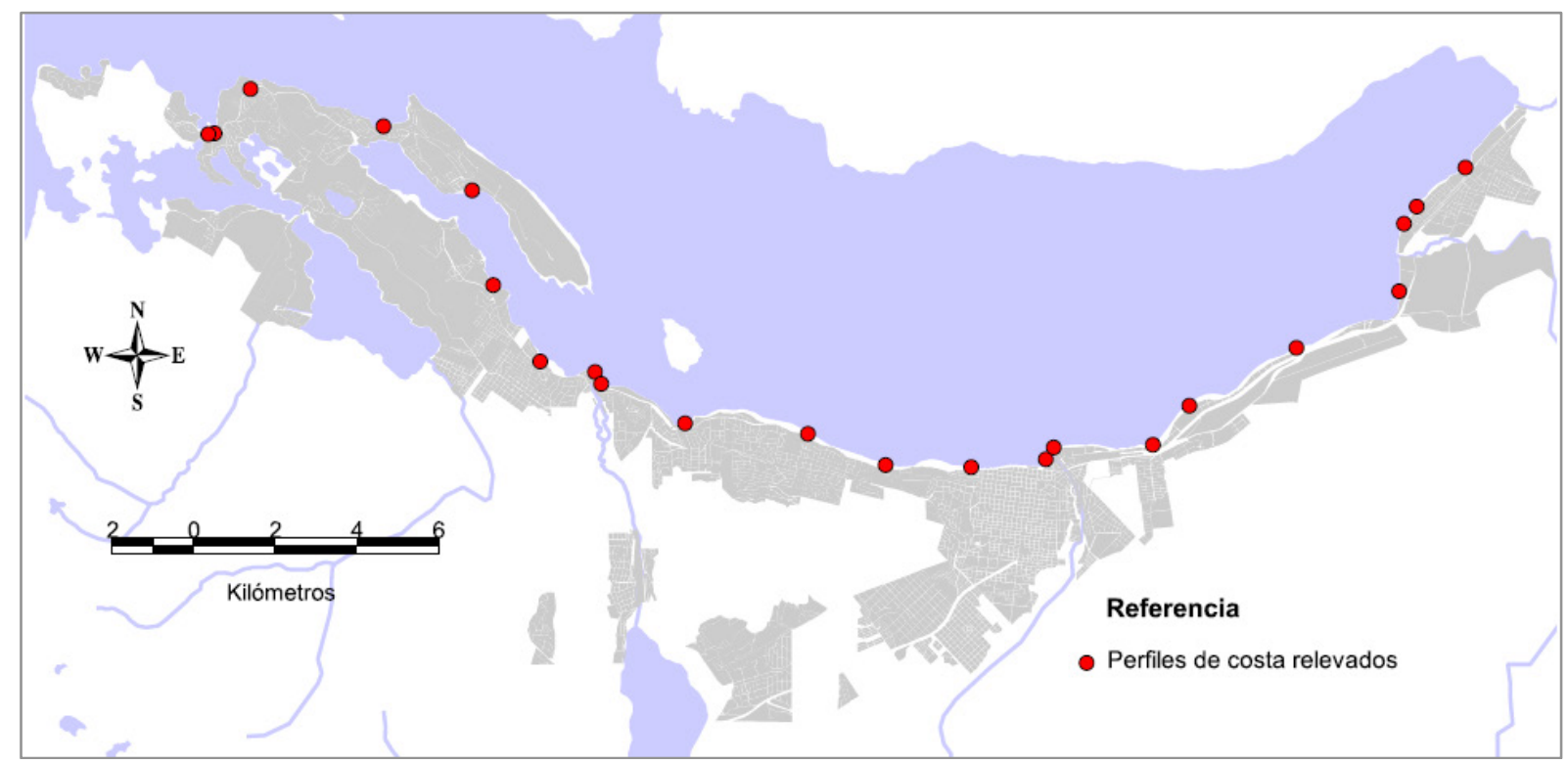

Figura $\mathrm{N}^{\circ} 23$. Perfiles de costa. Se relavaron 22 perfiles a lo largo de toda la costa urbanizada del lago Nahuel Huapi a finales de las temporadas estivales de 2015 y 2016, momento en que el lago tiene su menor altura y se 
exhiben mejor los perfiles de costa. Fuente: elaboración propia sobre la base de imágenes satelitales y observación de campo.

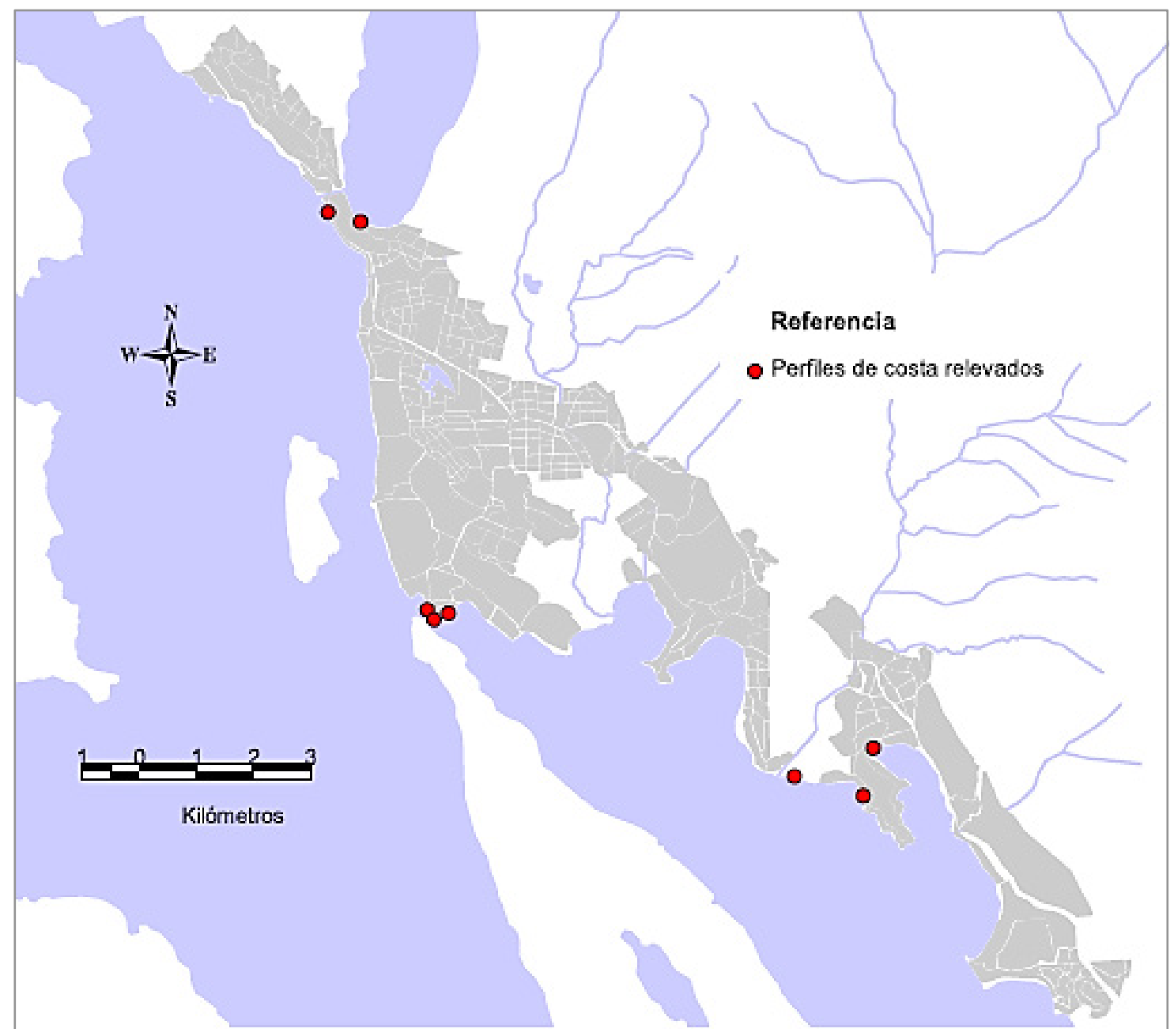

Figura $\mathrm{N}^{\circ} 24$. Perfiles de costa. Se relavaron 8 perfiles a lo largo de toda la costa urbanizada del lago Nahuel Huapi y del Lago Correntoso, a finales de la temporada estival de 2015-2016. Fuente: elaboración propia sobre la base del trabajo de campo.

Existen diferentes clasificaciones para las pendientes según su inclinación, por ejemplo, van Zuidam (1986), Mora et al. (1992), FAO (2009). Por su parte, Lagos (2012) considera que la pendiente del terreno influye en el proceso de escape a zonas seguras (Lagos, 2012, p. 13) y, a partir de una función lineal de forma monotónica incremental, toma dos puntos de control. El primero de ellos corresponde a una superficie plana menor a $1^{\circ}$ de pendiente y el segundo de ellos, de $10^{\circ}$, indica el punto donde aumenta notoriamente el esfuerzo físico (Lagos, 2012, pp.13-14). El Cuadro N7 muestra una simplificación de este criterio que se aplicará para el análisis de la vulnerabilidad costera frente a olas extraordinarias. 


\begin{tabular}{|c|c|}
\hline Ángulo (en grados) & Descripción \\
\hline $0-1$ & bajo \\
\hline $1-10$ & medio \\
\hline$>10$ & alto \\
\hline
\end{tabular}

Cuadro $N^{\circ} 7$. Clasificación de pendientes. Si bien las pendientes más bajas permiten un mayor avance del agua, suponen también un aumento del esfuerzo físico para evacuar a la población hacia zonas seguras. Fuente: adaptado de Lagos (2012, pp. 13-14).

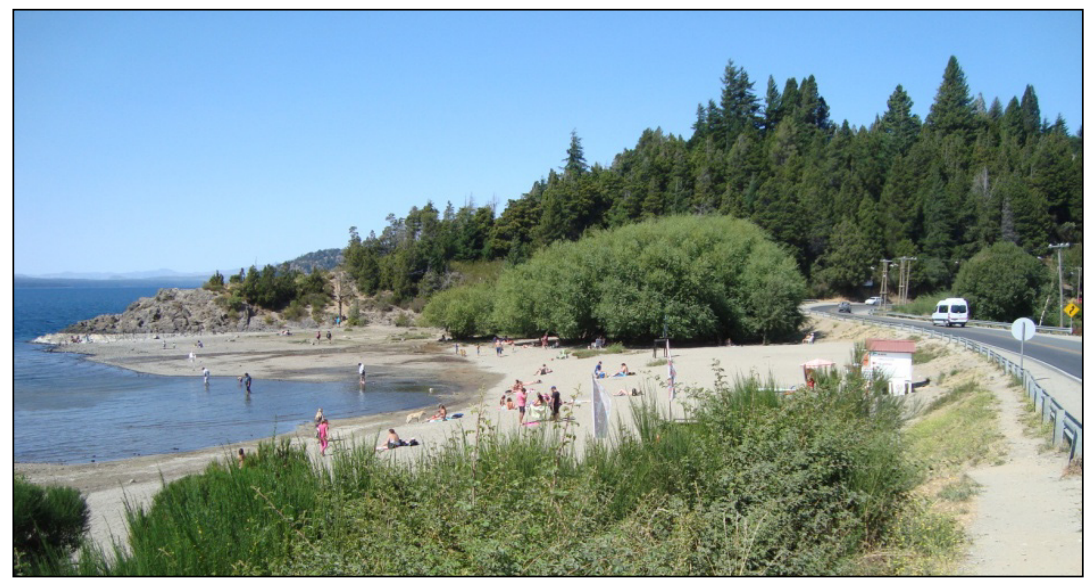

Figura $N^{\circ} 25$. Escasa pendiente en la playa Bahía Serena, a 12 kilómetros del centro de San Carlos de Bariloche, donde la cercanía a la Avenida Bustillo y la escasa vegetación determinan condiciones propicias para importantes impactos. Foto del autor, 25 de febrero de 2015.

\subsubsection{Accesibilidad}

La presencia de vías de comunicación como rutas, caminos asfaltados o consolidados cercanos a la costa (Figuras $\mathrm{N}^{\circ} 26$ y $\mathrm{N}^{\circ} 27$ ) constituye otro componente afectable frente a tsunamis, no sólo por los daños que pueden reportarse a la infraestructura vial sino también por la interrupción en las comunicaciones. 


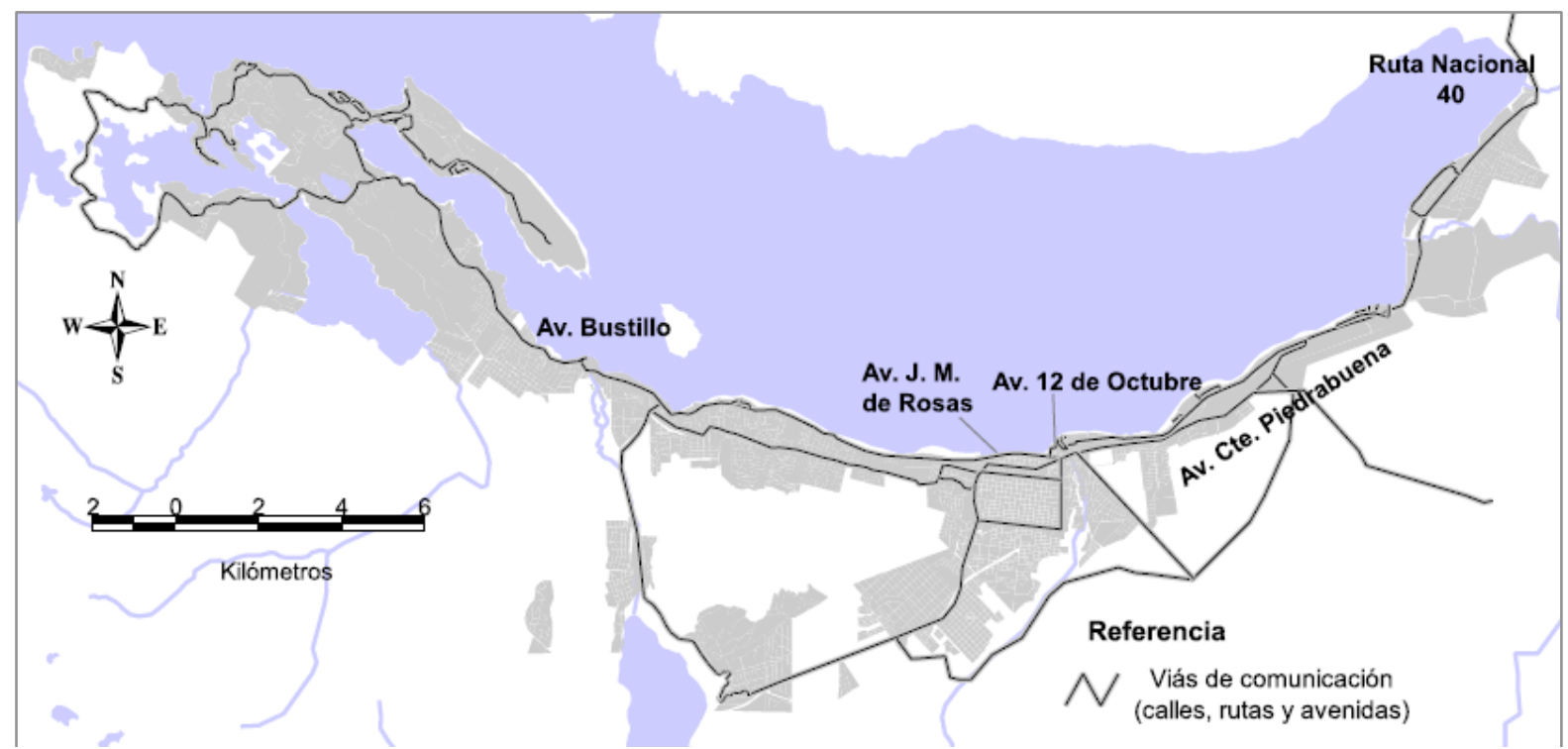

Figura $\mathrm{N}^{\circ} 26$. Accesibilidad. La principal vía de comunicación costera es la ruta nacional 40 (ex ruta nacional 237), desde Dina Huapi hasta Llao Llao. En su trayecto, adquiere diversos nombres: al ingresar a la ciudad de San Calos de Bariloche toma el nombre de Comandante Luis Piedrabuena, luego 12 de octubre, Juan Manuel de Rosas y, finalmente, avenida Bustillo que se continúa como Circuito Chico. En algunos sectores, calles paralelas a esta arteria se encuentran más expuestas a olas extraordinarias, como son las calles Patagonia Argentina (costanera de Dina Huapi), Modesta Victoria y Vereerbrugghen, por nombrar algunas. Fuente: elaboración propia sobre la base de imágenes satelitales y observación de campo.

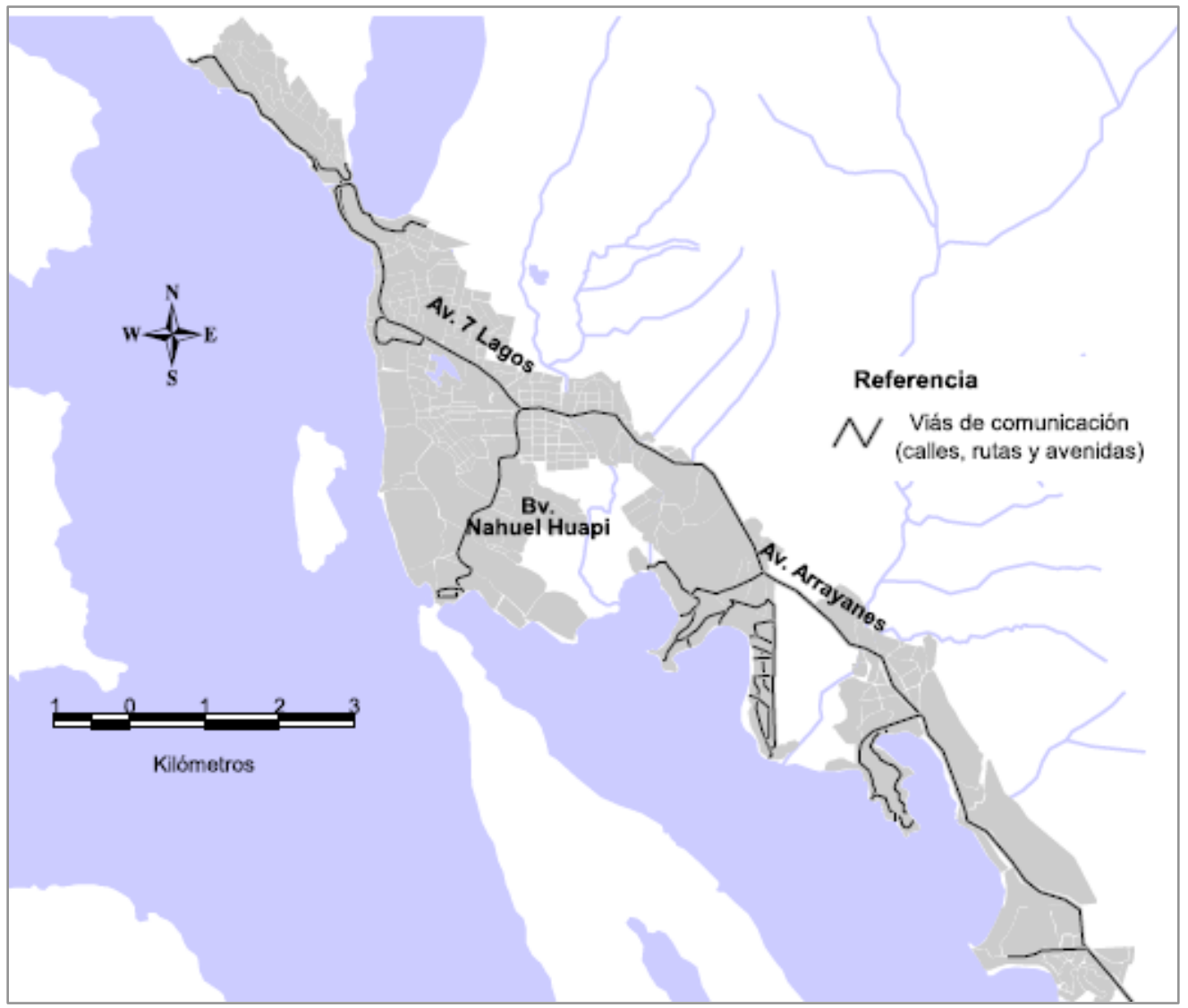


Figura $\mathrm{N}^{\circ} 27$. Accesibilidad. Villa La Angostura tiene la particularidad de no presentar una costanera sobre el lago Nahuel Huapi, sin un acceso a sus dos principales puertos, Bahía mansa y Bahía Brava, a través del Boulevard Nahuel Huapi. Fuente: elaboración propia sobre imágenes satelitales y trabajo de campo.

Fuentes consultadas dentro del área de Gestión Urbana del Municipio de San Carlos de Bariloche sostienen que, según Código de Planeamiento Urbano (apartado 13.2. El cinturón boscoso y los retiros de costas de lago), la construcción a la costa presenta distancias diferenciales en función de su ubicación, asignándose las siguientes áreas:

- Desde río Ñirihuau hasta el arroyo Gutiérrez, 15 metros.

- Desde arroyo Gutiérrez hasta Brazo de la Tristeza, 35 metros.

- Se puede hacer excepciones, siempre y cuando se respete un límite mínimo de 15 metros.

- La cota de referencia de altura del lago es la de 770,4 msnm.

Complementariamente, la Ordenanza-CM-2005 define una línea de crecida media en los 770,4 msnm (Art. 1) y una zona lacustre de ocupación por crecidas ordinarias (ZOC) en los 771,2 msnm (Art. 2).

Por su parte, desde la Dirección de Obras Públicas de Dina Huapi, sostienen que la localidad se rige por la misma normativa establecida en el Código Urbano de Bariloche, con la cota de referencia de 770,4 msnm y una distancia mínima de 15 metros, considerando como zona costera el espacio comprendido entre los ríos Limay y Ñirihuau como área de aplicación.

Por último, desde la Secretaría de Planeamiento, Infraestructura y Medio Ambiente de la Municipalidad de Villa La Angostura sostienen que, según el Código Civil, los retiros de paso libre son de 15 metros desde esa cota y, según código edificación local el retiro a respetar es de 35 metros. Asimismo, la Subsecretaría de Recursos Hídricos de la provincia del Neuquén considera que la cota referencia de restricción es la de 769,32 msnm.

La distancia desde la costa hasta una instalación determinada que requiera ser evacuada eventualmente ante un episodio de tsunami (vivienda, hotel, playa, e incluso un retiro de paso libre) puede ser de entre 15 y 35 metros dependiendo de la línea de ribera. Para evaluar una accesibilidad que contemple dichas distancias, se considerarán los caminos ubicados dentro de una distancia de referencia de 50 metros. 


\subsubsection{Muelles y puertos}

Constituyen parte de la infraestructura costera (Figuras $\mathrm{N}^{\circ} 28, \mathrm{~N}^{\circ} 29$ y $\mathrm{N}^{\circ} 30$ ), expuesta al peligro de tsunami. Daños ocasionados a estas infraestructuras implican asimismo daños potenciales a las comunicaciones lacustres y al sector turístico.

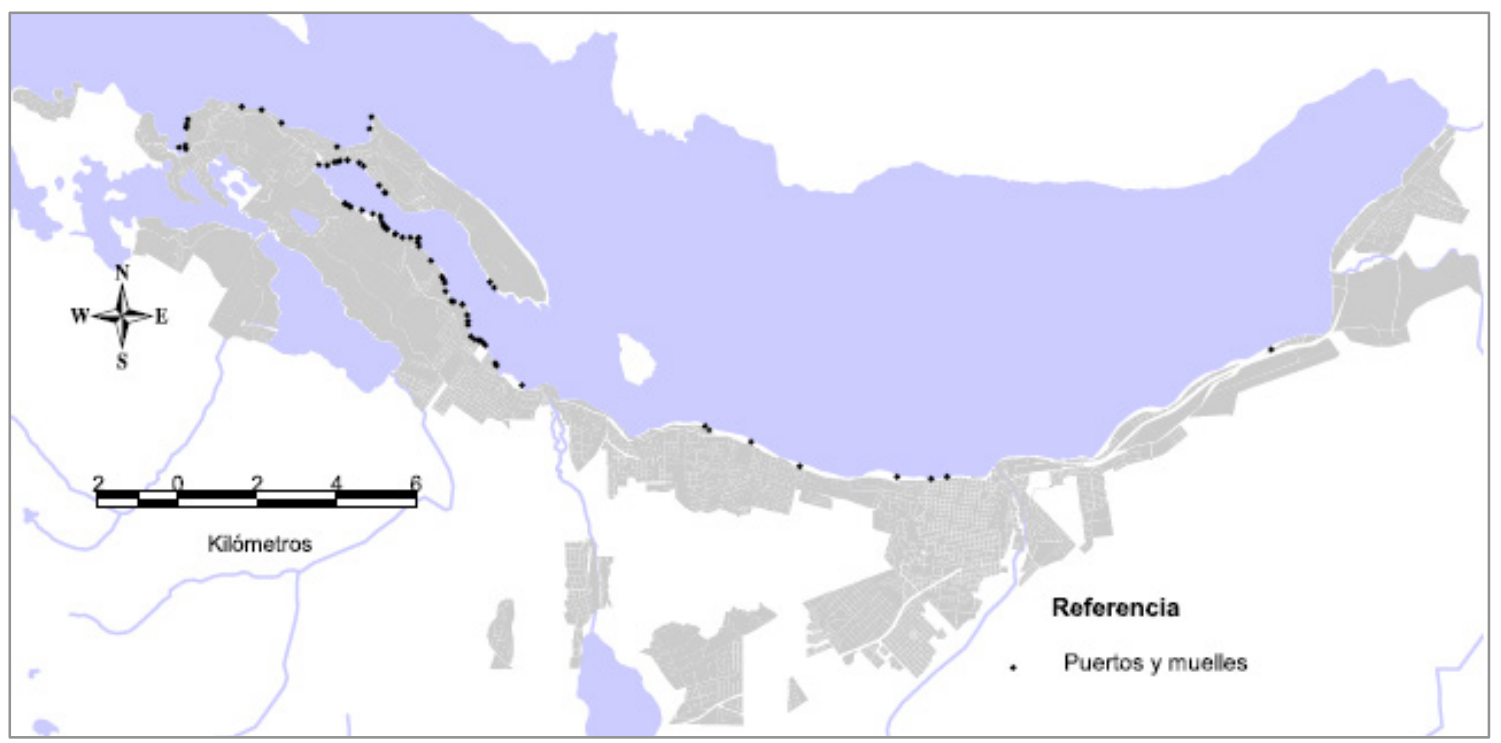

Figura $N^{\circ} 28$. Muelles y Puertos. Los puertos más importantes del área de estudio son San Carlos, en el centro de la ciudad de Bariloche y Pañuelo, a 25 kilómetros de esta localidad. Por el abrigo meteorológico que brinda el sitio, la mayor concentración de muelles se encuentra en el Brazo Campanario, sector comprendido entre los puertos mencionados anteriormente. Fuente: elaboración propia sobre la base de imágenes satelitales. 


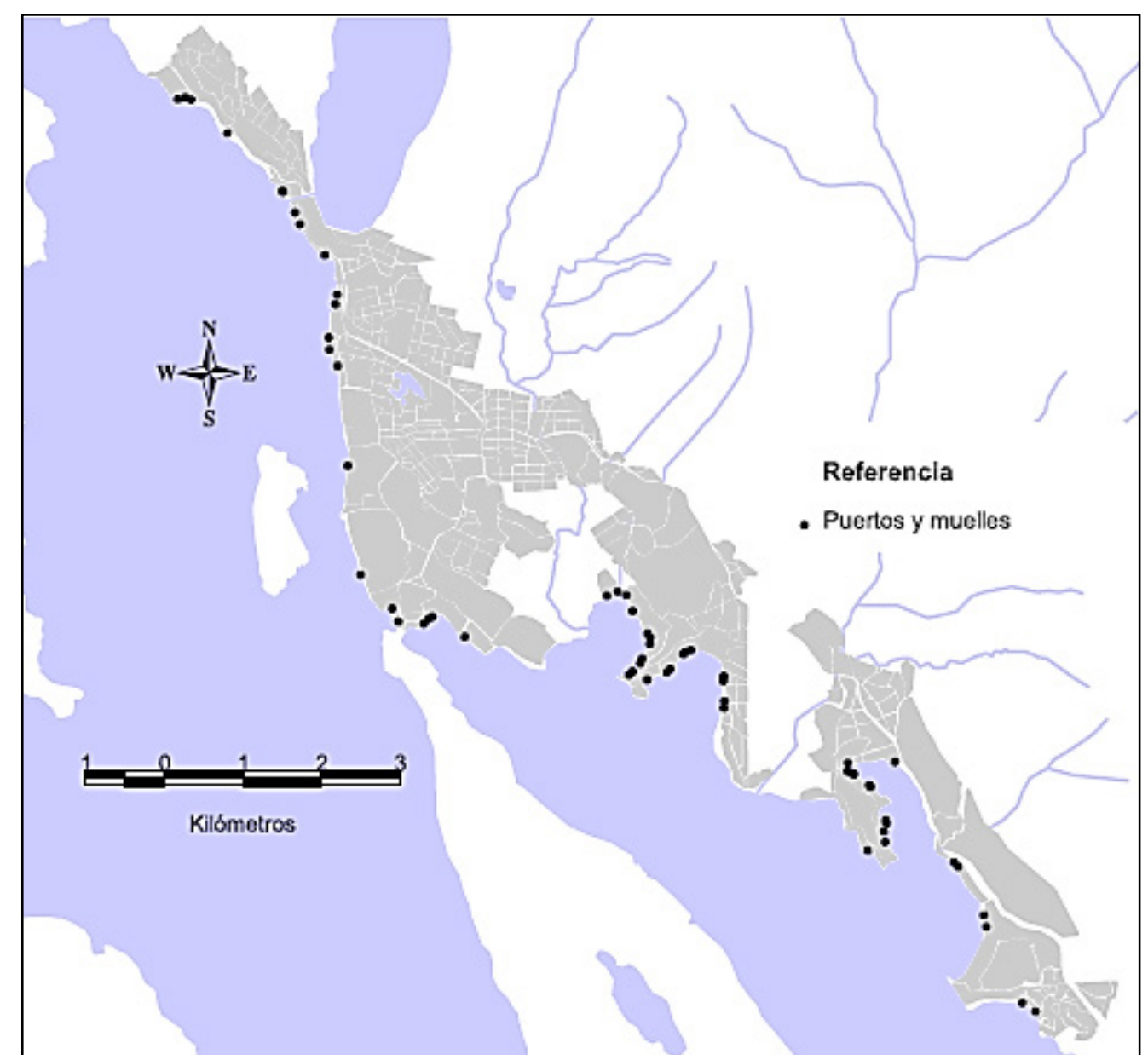

Figura N²9. Muelles y Puertos. Gran cantidad de muelles pueden observarse en las bahías Las Balsas, Bustillo y Manzano, aunque los principales puertos de la localidad se hallan en el Istmo de Quetrihué (Puertos Bahía mansa y Bahía Brava). Fuente: elaboración propia sobre la base de imágenes satelitales y relevamiento de campo.

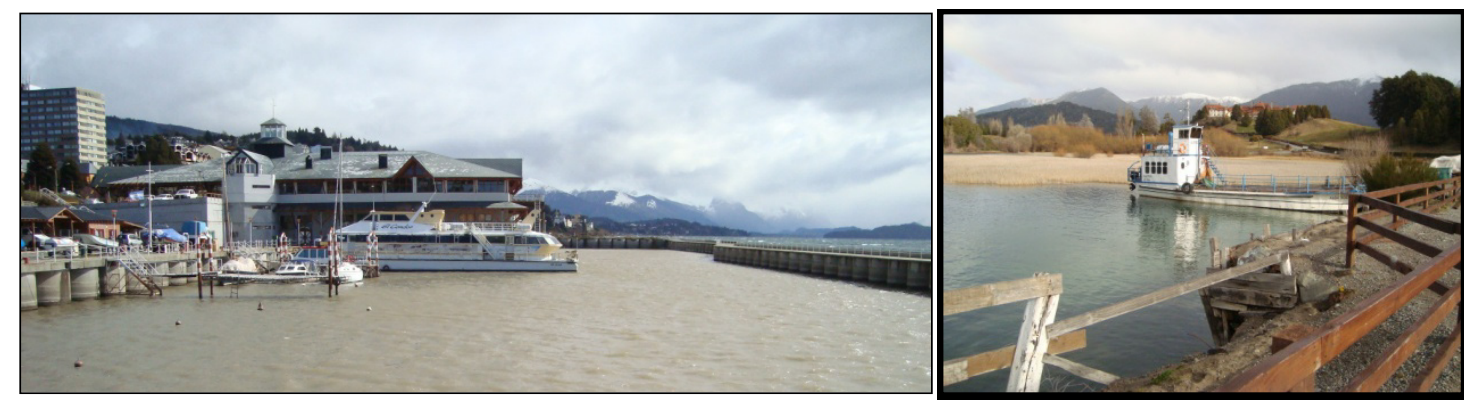

Figura $\mathrm{N}^{\circ} 30$. Infraestructura portuaria y de comunicaciones expuesta a olas extraordinarias en Bariloche (Puerto San Carlos, izquierda) y Llao Llao (Puerto Pañuelo, derecha). Fotos del autor, 1 de septiembre de 2012.

\subsubsection{Playas públicas}

La presencia de playas públicas (Figuras $N^{\circ} 31$ y $\mathrm{N}^{\circ} 32$ ), algunas de ellas muy concurridas en primavera-verano (Figura $\mathrm{N}^{\circ} 33$ ) es un factor a considerar en virtud de la cantidad de personas expuestas, sobre todo en temporada estival. 


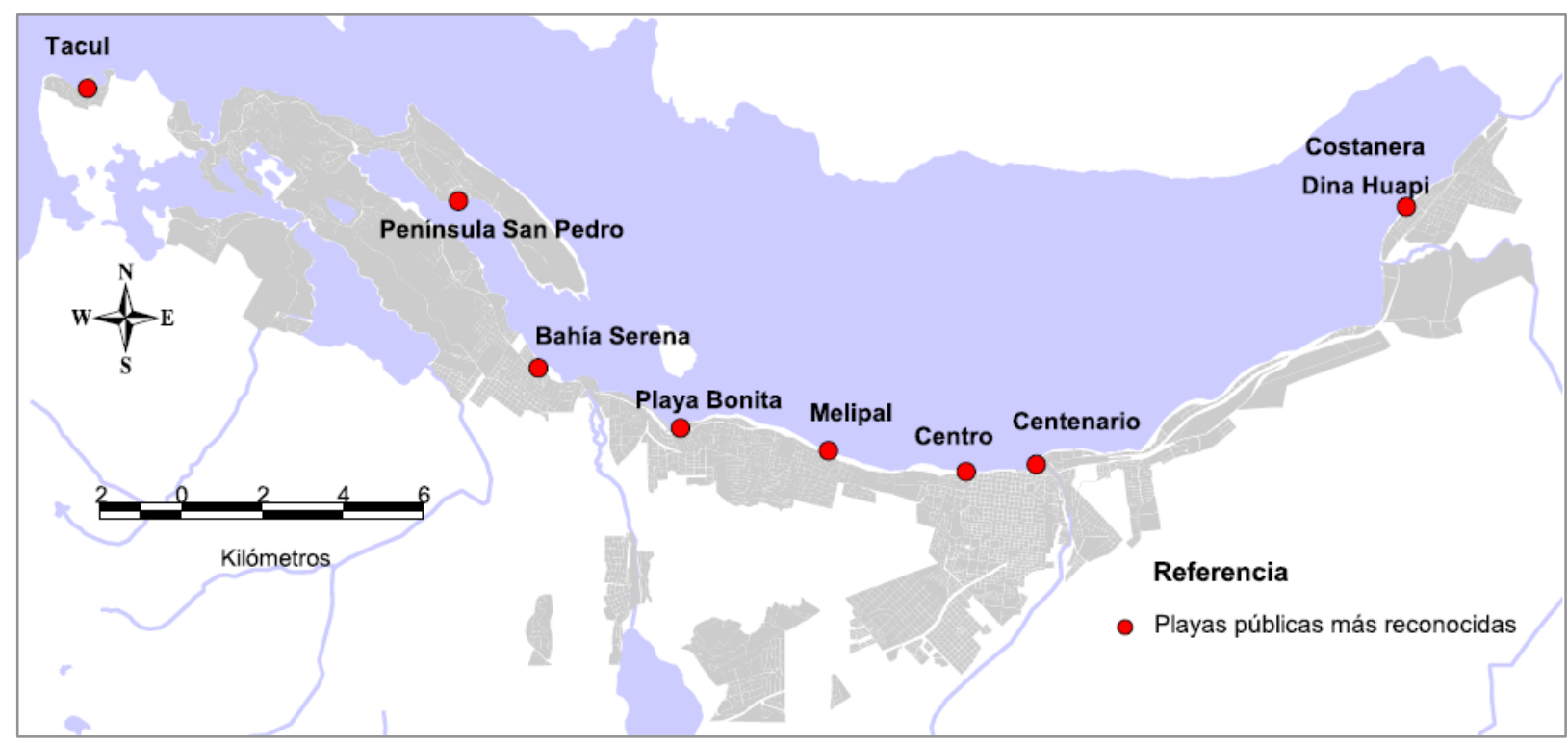

Figura $\mathrm{N}^{\circ} 31$. Playas turísticas. La costa sur del lago Nahuel Huapi, presenta un conjunto de playas muy concurridas en temporada estival, la mayoría de ellas ubicadas en una extensión de 10 kilómetros, entre la playa del Centenario sobre el delta del arroyo Ñireco, hasta la playa ubicada en Bahía Serena. La costanera de Dina Huapi, presenta una playa de uso recreativo-turístico de 1,5 kilómetros de extensión, sobre el delta del río Ñirihuau. Si bien existen otras playas concurridas, como en Villa Tacul, Península San Pedro, las consideradas por la concurrencia, como las más importantes son las representadas en el mapa. Fuente: elaboración propia sobre la base de imágenes satelitales y observación de campo.

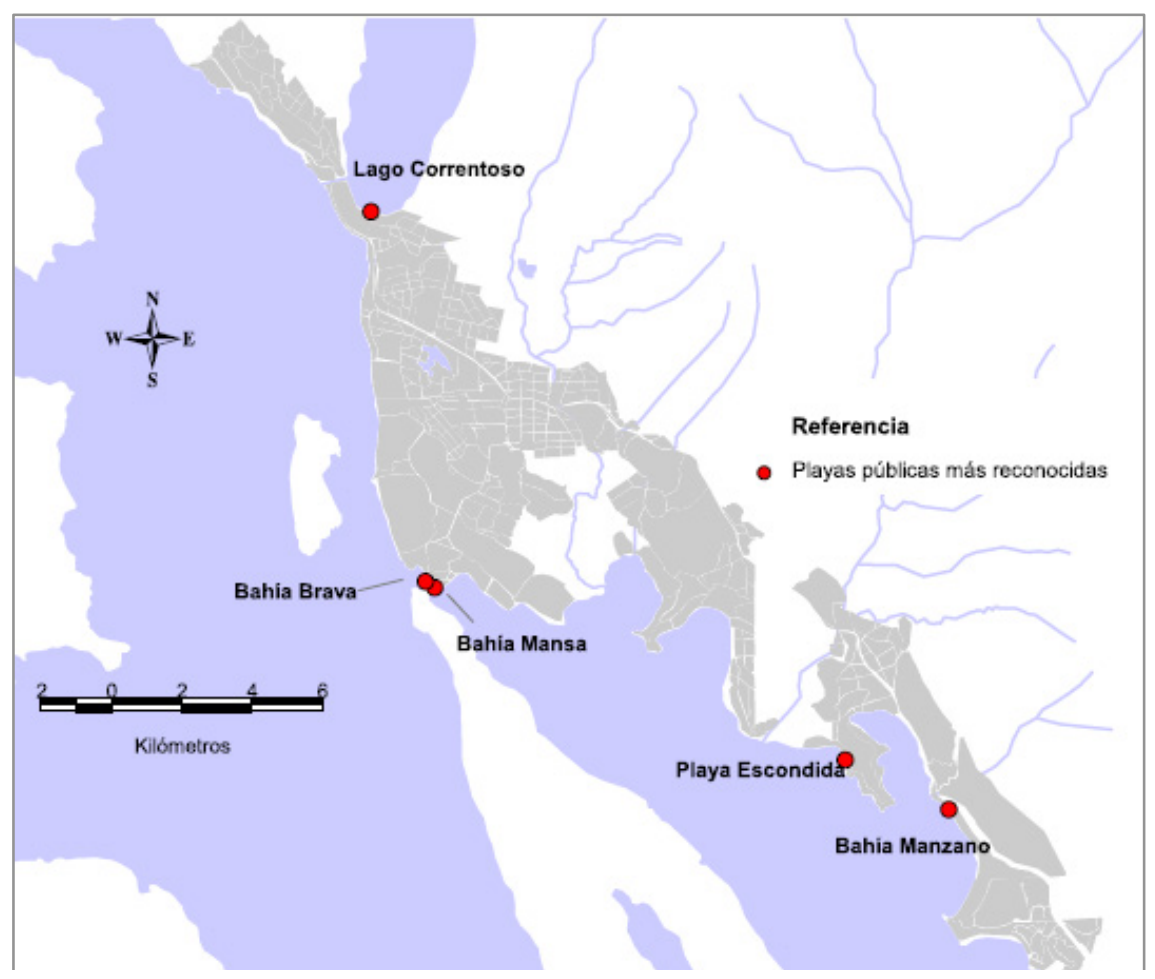


Figura $\mathrm{N}^{\circ} 32$. Playas turísticas. Las playas señaladas en el mapa son muy visitadas por turistas y residentes durante el verano, particularmente en las bahías Mansa y Brava, donde se hallan puertos desde donde parten excusiones lacustres. Fuente: elaboración propia sobre la base de publicidad turística y relevamiento de campo.

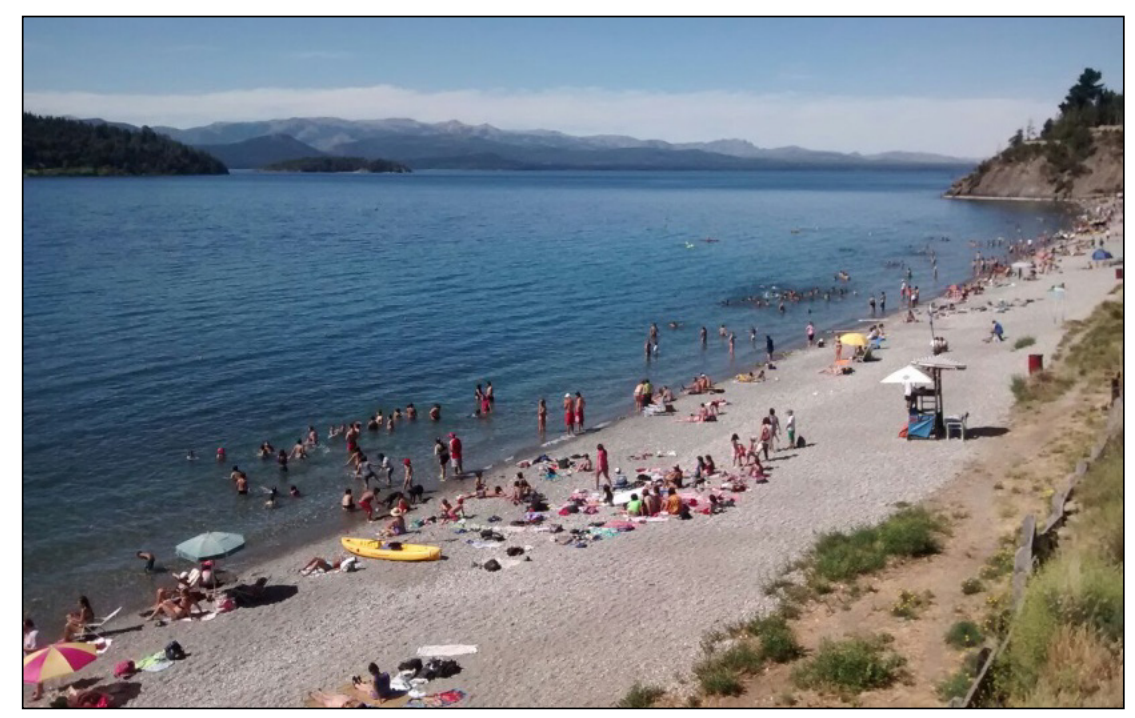

Figura N³3. Playa Bonita. Ubicada a 8 kilómetros del centro de San Carlos de Bariloche es una de las más concurridas por residentes y turistas. Foto del autor, 21 de enero de 2016.

\subsubsection{Densidad de población}

Los mapas de densidad de población (Figuras $N^{\circ} 34$ y №35) muestran las variaciones espaciales del número de personas posiblemente expuestas frente a olas extraordinarias.

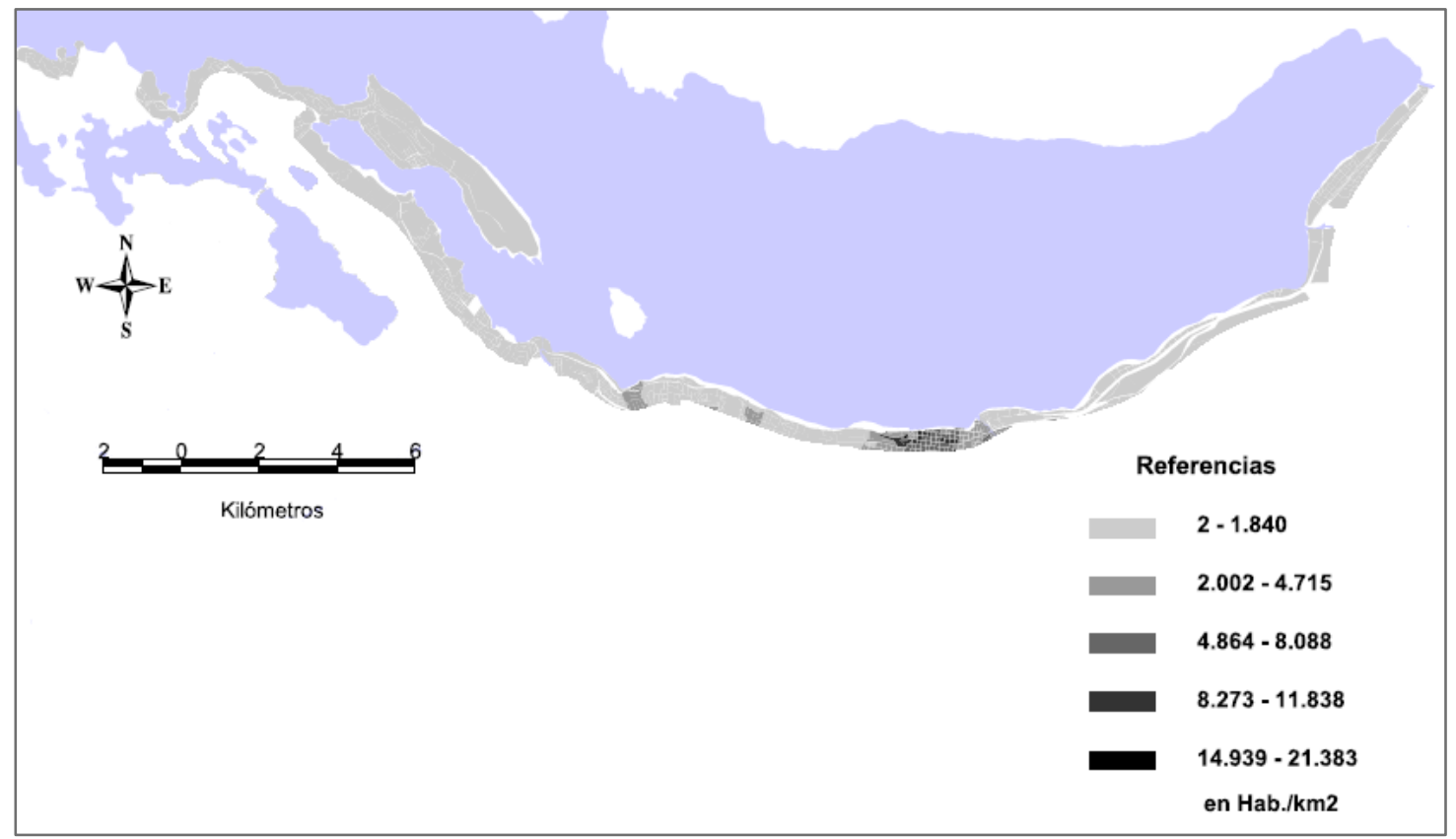

Figura $\mathrm{N}^{\circ} 34$. Mapa de densidad de población. La zona correspondiente al casco fundacional de San Carlos de Bariloche, muy poblada y tradicionalmente turística, exhibe las mayores densidades de población. Fuente: 
elaboración propia sobre la base de información del Censo Nacional de Población, Hogares y Viviendas 2010, clasificada por intervalos naturales en sistema de información geográfica.

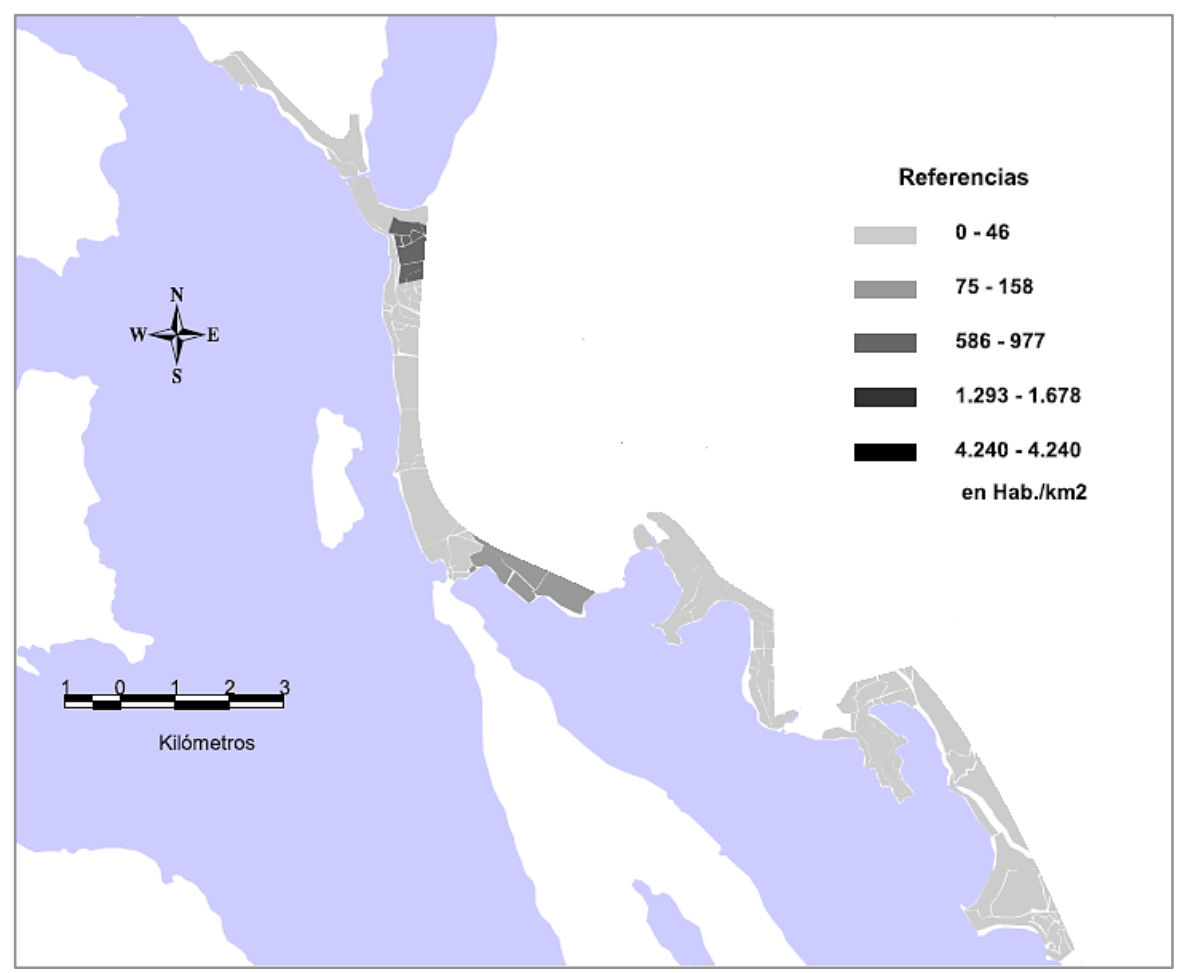

Figura $\mathrm{N}^{\circ} 35$. Mapa de densidad de población. La zona correspondiente al sector costero Noroeste, muestra las mayores densidades de población. Fuente: elaboración propia sobre la base de información del Censo Nacional de Población, Hogares y Viviendas 2010, clasificada por intervalos naturales en sistema de información geográfica.

\subsection{Ponderación de variables}

El procedimiento aplicado en esta instancia se realizó nuevamente (véase Capítulo 4) a partir de la metodología elaborada por Saaty, conocida como Analytical Hierarchy Process AHP (Proceso Analítico Jerárquico - PAJ). En el Cuadro $N^{\circ} 8$, se clasifican y ponderan los factores que componen las variables más relevantes en la determinación de los impactos potenciales de un tsunami.

A partir del Método de Comparación por Pares de Saaty $(1977,1990)$, para cada factor se asignó un valor de entre 1 y 9 (Saaty, 1990, p. 15), donde:

$1=$ Igual importancia.

$3=$ moderada importancia de uno sobre otro.

$5=$ importancia esencial o fuerte.

7=importancia muy fuerte.

9=importancia extrema. 


\section{2, 4, 6, 8=valores intermedios entre los dos juicios adyacentes.}

\begin{tabular}{|c|c|c|c|c|}
\hline Dimensión & Variable & Criterio metodológico & Factor & Valor \\
\hline \multirow{7}{*}{ Social } & \multirow{5}{*}{$\begin{array}{l}\text { densidad de } \\
\text { población }\end{array}$} & \multirow{5}{*}{$\begin{array}{l}\text { Por intervalos naturales, se } \\
\text { calcularon } 5 \text { rangos para } \\
\text { cada espacio urbano, } \\
\text { asignándole a cada uno de } \\
\text { ellos un valor de } 1 \text { a } 9 .\end{array}$} & muy alta & 9 \\
\hline & & & alta & 7 \\
\hline & & & media & 5 \\
\hline & & & baja & 3 \\
\hline & & & muy baja & 1 \\
\hline & \multirow[b]{2}{*}{$\begin{array}{l}\text { playas } \\
\text { turísticas }\end{array}$} & \multirow{2}{*}{$\begin{array}{l}\text { Dado que todas las playas } \\
\text { son de acceso público, a las } \\
\text { turísticas más reconocidas } \\
\text { que convocan más visitantes } \\
\text { presentan una valoración } \\
\text { más elevada. }\end{array}$} & ausencia & 1 \\
\hline & & & presencia & 3 \\
\hline \multirow{7}{*}{ Infraestructura } & \multirow{5}{*}{$\begin{array}{l}\text { muelles y } \\
\text { puertos }\end{array}$} & \multirow{5}{*}{$\begin{array}{c}\text { Por intervalos naturales } \\
\text { aplicados a la cantidad de } \\
\text { muelles y puertos según } \\
\text { cada sector identificado, se } \\
\text { calcularon } 5 \text { rangos } \\
\text { asignándole a cada uno de } \\
\text { ellos un valor de } 1 \text { a } 9 .\end{array}$} & muy alta (51-51) & 9 \\
\hline & & & alta (14-21) & 7 \\
\hline & & & media (4-6) & 5 \\
\hline & & & baja (2-3) & 3 \\
\hline & & & muy baja (0-1) & 1 \\
\hline & \multirow{2}{*}{ accesibilidad } & \multirow{2}{*}{50 metros. } & $\begin{array}{c}\text { Camino a menos de } \\
50 \text { metros de la } \\
\text { costa }\end{array}$ & 3 \\
\hline & & & $\begin{array}{c}\text { Camino a más de } \\
50 \text { metros de la } \\
\text { costa }\end{array}$ & 1 \\
\hline \multirow{15}{*}{ Físico-natural } & \multirow{3}{*}{ pendientes } & \multirow{3}{*}{$\begin{array}{l}\text { Se toma como referencia la } \\
\text { adaptación hecha de Lagos, } \\
2012 .\end{array}$} & $\begin{array}{c}\text { Costas con } \\
\text { pendientes de hasta } \\
1^{\circ} \\
\end{array}$ & 1 \\
\hline & & & $\begin{array}{c}\text { Costas con } \\
\text { pendientes entre } 1^{\circ} \\
\text { y } 10^{\circ}\end{array}$ & 3 \\
\hline & & & $\begin{array}{c}\text { Costas con } \\
\text { pendientes } \\
\text { superiores a los } 10^{\circ} \\
\end{array}$ & 5 \\
\hline & \multirow{2}{*}{ vegetación } & \multirow{2}{*}{$\begin{array}{l}\text { Se considera alta o baja en } \\
\text { función de las observaciones } \\
\text { de campo. }\end{array}$} & $\begin{array}{c}\text { baja presencia de } \\
\text { vegetación }\end{array}$ & 3 \\
\hline & & & $\begin{array}{l}\text { alta presencia de } \\
\text { vegetación }\end{array}$ & 1 \\
\hline & \multirow{4}{*}{ deslizamientos } & \multirow{4}{*}{$\begin{array}{c}\text { Esta clasificación se toma de } \\
\text { Beigt et al. (2014a). }\end{array}$} & alta & 5 \\
\hline & & & media & 3 \\
\hline & & & baja & 1 \\
\hline & & & nula & 0 \\
\hline & \multirow{4}{*}{$\begin{array}{l}\text { formas } \\
\text { costeras }\end{array}$} & \multirow{4}{*}{$\begin{array}{l}\text { Se consideran los } \\
\text { principales aspectos } \\
\text { morfológicos planteados por } \\
\text { Velásquez et al. (2002). }\end{array}$} & $\begin{array}{l}\text { presencia de formas } \\
\text { potenciadoras }\end{array}$ & 3 \\
\hline & & & $\begin{array}{l}\text { ausencia de formas } \\
\text { atenuadoras y } \\
\text { potenciadoras }\end{array}$ & 2 \\
\hline & & & $\begin{array}{l}\text { presencia de formas } \\
\text { atenuadoras y } \\
\text { potenciadoras }\end{array}$ & 2 \\
\hline & & & $\begin{array}{l}\text { presencia de formas } \\
\text { atenuadoras }\end{array}$ & 1 \\
\hline & \multirow{2}{*}{ litología } & \multirow{2}{*}{$\begin{array}{c}\text { A grandes rasgos, se } \\
\text { dividieron en dos grupos en }\end{array}$} & costa rocosa & 3 \\
\hline & & & Depósitos & 1 \\
\hline
\end{tabular}




\begin{tabular}{|l|c|c|c|}
\hline & $\begin{array}{c}\text { función de la fricción que los } \\
\text { materiales pueden aportar a } \\
\text { los flujos reduciendo su } \\
\text { velocidad de avance. }\end{array}$ & $\begin{array}{c}\text { (sedimentos no } \\
\text { litificados) }\end{array}$ & \\
\hline
\end{tabular}

Cuadro N8. Ponderación de factores. Fuente: elaboración propia.

En Cuadro $\mathrm{N}^{\circ} 9$ muestra los pesos calculados en el proceso de ponderación de las variables, es decir, de la relación de importancia entre ellas y el valor calculado para la Razón de Consistencia (CR).

\begin{tabular}{|c|c|c|c|c|c|c|c|c|c|c|}
\hline & $\begin{array}{l}\text { densidad } \\
\text { de } \\
\text { población }\end{array}$ & $\begin{array}{c}\text { playas } \\
\text { públicas }\end{array}$ & $\begin{array}{l}\text { desliza- } \\
\text { mientos }\end{array}$ & $\begin{array}{l}\text { formas } \\
\text { costeras }\end{array}$ & $\begin{array}{l}\text { pendien- } \\
\text { tes }\end{array}$ & $\begin{array}{c}\text { muelles y } \\
\text { puertos }\end{array}$ & $\begin{array}{l}\text { accesi- } \\
\text { bilidad }\end{array}$ & $\begin{array}{l}\text { lito- } \\
\text { logía }\end{array}$ & $\begin{array}{l}\text { vegeta- } \\
\text { ción }\end{array}$ & Pesos \\
\hline $\begin{array}{c}\text { densidad de } \\
\text { población }\end{array}$ & 1 & & & & & & & & & 0,1831 \\
\hline $\begin{array}{c}\text { playas } \\
\text { públicas }\end{array}$ & 1 & 1 & & & & & & & & 0,1807 \\
\hline $\begin{array}{l}\text { deslizamien- } \\
\text { tos }\end{array}$ & $1 / 3$ & 1 & 1 & & & & & & & 0,1427 \\
\hline $\begin{array}{c}\text { formas } \\
\text { costeras }\end{array}$ & 1 & 1 & 1 & 1 & & & & & & 0,1424 \\
\hline pendientes & 1 & $1 / 3$ & 1 & 1 & 1 & & & & & 0,1219 \\
\hline $\begin{array}{c}\text { muelles y } \\
\text { puertos }\end{array}$ & $1 / 3$ & $1 / 3$ & $1 / 3$ & $1 / 3$ & $1 / 3$ & 1 & & & & 0,0810 \\
\hline accesibilidad & $1 / 3$ & $1 / 3$ & $1 / 3$ & 1 & 1 & $1 / 3$ & 1 & & & 0,0715 \\
\hline litología & $1 / 3$ & $1 / 3$ & $1 / 3$ & $1 / 3$ & $1 / 3$ & $1 / 3$ & 1 & 1 & & 0,0453 \\
\hline vegetación & $1 / 5$ & $1 / 5$ & $1 / 5$ & $1 / 5$ & $1 / 3$ & $1 / 3$ & $1 / 3$ & 1 & 1 & 0,0314 \\
\hline
\end{tabular}

Cuadro $\mathrm{N}^{\circ} 9$. Matriz de comparaciones pareadas. Fuente: elaboración propia.

Luego de la ponderación se realizó la Combinación Lineal Ponderada (CLP) y, a partir de ello, la superposición espacial de los criterios, calculando para cada sector costero, el valor de capacidad a partir de la ecuación a) li $=\sum \mathrm{p}_{\mathrm{i}} \mathrm{x}_{\mathrm{i}}$, correspondiente a los valores de las alternativas $\left(\mathrm{X}_{\mathrm{ij}}\right)$ y a los pesos de los criterios $\left(\mathrm{P}_{\mathrm{ij}}\right)$.

A partir de los criterios seleccionados y los nueve sectores identificados por Manzoni et al. (2013) para el área urbana de San Carlos de Bariloche y Dina Huapi en función de una serie de factores entre los que se encuentra el grado de urbanización, la infraestructura vial y costera, la vegetación y la morfología costera, se estimaron los valores de vulnerabilidad (Cuadro $\mathrm{N}^{\circ} 10$ ) para cada uno de ellos en función de la ponderación realizada precedentemente. En el caso de Villa la Angostura, siguiendo dichos criterios, se reconocieron ocho sectores costeros (Cuadro $\mathrm{N}^{\circ} 11$ ). En aquellos casos en que un mismo sector presentara diferentes valores para cada criterio, se seleccionó el valor predominante o bien el valor más alto asignado para cada factor. 


\begin{tabular}{|c|c|c|c|c|c|c|c|c|c|}
\hline Sector & $\begin{array}{c}\begin{array}{c}\text { densidad de } \\
\text { población }\end{array} \\
0,1831\end{array}$ & $\begin{array}{c}\begin{array}{c}\text { playas } \\
\text { turisticas }\end{array} \\
0,1807\end{array}$ & $\begin{array}{c}\text { formas costeras } \\
\qquad 0,1427\end{array}$ & $\begin{array}{c}\text { pendientes } \\
0,1219\end{array}$ & $\begin{array}{c}\text { muelles y } \\
\text { puertos } \\
0,081\end{array}$ & $\begin{array}{c}\text { accesibilidad } \\
0,0715\end{array}$ & $\begin{array}{l}\text { litología } \\
0,0453\end{array}$ & $\begin{array}{c}\text { vegetación } \\
0,0314\end{array}$ & valor \\
\hline \multirow[t]{2}{*}{$\begin{array}{l}\text { Puerto } \\
\text { Pañuelo }\end{array}$} & Muy baja & no & $\begin{array}{l}\text { presencia de } \\
\text { formas } \\
\text { potenciadoras } \\
\text { (bahía) }\end{array}$ & $\begin{array}{c}\text { Entre } 1^{\circ} \mathrm{y} \\
10^{\circ}\end{array}$ & 6 & $\begin{array}{l}\text { Camino a menos } \\
\text { de } 50 \text { metros de } \\
\text { la costa }\end{array}$ & $\begin{array}{l}\text { costa } \\
\text { rocosa }\end{array}$ & alta & \multirow[t]{2}{*}{0,2635} \\
\hline & 1 & 1 & 3 & 3 & 5 & 3 & 3 & 1 & \\
\hline \multirow[t]{2}{*}{$\begin{array}{l}\text { Península } \\
\text { San Pedro } \\
\text { (sector oeste) }\end{array}$} & Muy baja & no & $\begin{array}{l}\text { presencia de } \\
\text { formas } \\
\text { potenciadoras } \\
\text { (bahía) }\end{array}$ & $\begin{array}{c}\text { Entre } 1^{\circ} \mathrm{y} \\
10^{\circ}\end{array}$ & 4 & $\begin{array}{c}\text { Camino a más de } \\
50 \text { metros de la } \\
\text { costa }\end{array}$ & $\begin{array}{l}\text { costa } \\
\text { rocosa }\end{array}$ & alta & \multirow[t]{2}{*}{0,2476} \\
\hline & 1 & 1 & 3 & 3 & 5 & 1 & 3 & 1 & \\
\hline \multirow[t]{2}{*}{$\begin{array}{l}\text { Península } \\
\text { San Pedro } \\
\text { (sector este) }\end{array}$} & Muy baja & no & $\begin{array}{c}\text { presencia de } \\
\text { formas } \\
\text { atenuadoras (islas) }\end{array}$ & $>10^{\circ}$ & 2 & $\begin{array}{c}\text { Camino a más de } \\
50 \text { metros de la } \\
\text { costa }\end{array}$ & $\begin{array}{l}\text { costa } \\
\text { rocosa }\end{array}$ & alta & \multirow[t]{2}{*}{0,2251} \\
\hline & 1 & 1 & 1 & 5 & 3 & 1 & 3 & 1 & \\
\hline \multirow[t]{2}{*}{$\begin{array}{c}\text { Brazo } \\
\text { Campanario }\end{array}$} & Muy baja & $\begin{array}{l}\text { Bahía } \\
\text { Serena }\end{array}$ & $\begin{array}{c}\text { presencia de } \\
\text { formas } \\
\text { atenuadoras } \\
\text { (bahías cerradas) }\end{array}$ & $\begin{array}{c}\text { Entre } 1^{\circ} \mathrm{y} \\
10^{\circ}\end{array}$ & 51 & $\begin{array}{l}\text { Camino a menos } \\
\text { de } 50 \text { metros de } \\
\text { la costa }\end{array}$ & $\begin{array}{l}\text { costa } \\
\text { rocosa }\end{array}$ & alta & \multirow[t]{2}{*}{0,2930} \\
\hline & 1 & 3 & 1 & 3 & 9 & 3 & 3 & 1 & \\
\hline \multirow[t]{2}{*}{ Playa Bonita } & baja & $\begin{array}{l}\text { Playa } \\
\text { Bonita }\end{array}$ & $\begin{array}{c}\text { presencia de } \\
\text { formas } \\
\text { atenuadoras (bahía } \\
\text { con islas y } \\
\text { península cerca) }\end{array}$ & $\begin{array}{c}\text { Entre } 1^{\circ} \mathrm{y} \\
10^{\circ}\end{array}$ & 3 & $\begin{array}{l}\text { Camino a menos } \\
\text { de } 50 \text { metros de } \\
\text { la costa }\end{array}$ & $\begin{array}{l}\text { costa } \\
\text { rocosa }\end{array}$ & baja & \multirow[t]{2}{*}{0,3017} \\
\hline & 3 & 3 & 1 & 3 & 3 & 3 & 3 & 3 & \\
\hline \multirow[t]{2}{*}{ Melipal } & baja & Melipal & $\begin{array}{l}\text { ausencia de formas } \\
\text { atenuadoras y } \\
\text { potenciadoras }\end{array}$ & $>10^{\circ}$ & 5 & $\begin{array}{l}\text { Camino a menos } \\
\text { de } 50 \text { metros de } \\
\text { la costa }\end{array}$ & $\begin{array}{l}\text { costa } \\
\text { rocosa }\end{array}$ & baja & \multirow[t]{2}{*}{0,3943} \\
\hline & 3 & 3 & 2 & 5 & 5 & 3 & 3 & 3 & \\
\hline \multirow[t]{2}{*}{$\begin{array}{l}\text { Casco } \\
\text { urbano }\end{array}$} & alta & $\begin{array}{l}\text { Centro y } \\
\text { Centenario }\end{array}$ & $\begin{array}{l}\text { ausencia de formas } \\
\text { atenuadoras y } \\
\text { potenciadoras }\end{array}$ & $\begin{array}{c}\text { Entre } 1^{\circ} \mathrm{y} \\
10^{\circ}\end{array}$ & 2 & $\begin{array}{l}\text { Camino a menos } \\
\text { de } 50 \text { metros de } \\
\text { la costa }\end{array}$ & $\begin{array}{c}\text { depósito } \\
\text { s }\end{array}$ & baja & \multirow[t]{2}{*}{0,4205} \\
\hline & 7 & 3 & 2 & 3 & 3 & 3 & 1 & 3 & \\
\hline \multirow[t]{2}{*}{ Las Chacras } & baja & no & $\begin{array}{l}\text { ausencia de formas } \\
\text { atenuadoras y } \\
\text { potenciadoras }\end{array}$ & $\begin{array}{c}\text { Entre } 1^{\circ} \mathrm{y} \\
10^{\circ}\end{array}$ & 1 & $\begin{array}{l}\text { Camino a menos } \\
\text { de } 50 \text { metros de } \\
\text { la costa }\end{array}$ & $\begin{array}{c}\text { depósito } \\
\text { s }\end{array}$ & baja & \multirow[t]{2}{*}{0,2086} \\
\hline & 1 & 1 & 2 & 3 & 1 & 3 & 1 & 3 & \\
\hline \multirow[t]{2}{*}{ Dina Huapi } & baja & Costanera & $\begin{array}{l}\text { ausencia de formas } \\
\text { atenuadoras y } \\
\text { potenciadoras }\end{array}$ & $\begin{array}{c}\text { Entre } 1^{\circ} \mathrm{y} \\
10^{\circ}\end{array}$ & 1 & $\begin{array}{l}\text { Camino a menos } \\
\text { de } 50 \text { metros de } \\
\text { la costa }\end{array}$ & $\begin{array}{c}\text { depósito } \\
\text { s }\end{array}$ & baja & \multirow[t]{2}{*}{0,2805} \\
\hline & 1 & 3 & 2 & 3 & 1 & 3 & 1 & 3 & \\
\hline
\end{tabular}

Cuadro $N^{\circ} 10$. Vulnerabilidad frente a tsunamis. Bariloche-Dina Huapi. Fuente: elaboración propia sobre la información recabada en observaciones de campo, imágenes satelitales, fotos aéreas y datos del Censo Nacional de Población, Hogares y Viviendas 2010.

\begin{tabular}{|c|c|c|c|c|c|c|c|c|c|c|}
\hline Sector & $\begin{array}{c}\text { densidad } \\
\text { de } \\
\text { población } \\
0,1831\end{array}$ & $\begin{array}{c}\begin{array}{c}\text { playas } \\
\text { turisticas }\end{array} \\
0,1807\end{array}$ & $\begin{array}{r}\begin{array}{r}\text { desliza } \\
\text { mientos }\end{array} \\
0,1427\end{array}$ & $\begin{array}{c}\text { formas } \\
\text { costeras } \\
0,1424\end{array}$ & $\begin{array}{c}\text { pendientes } \\
0,1219\end{array}$ & $\begin{array}{c}\text { muelles y } \\
\text { puertos } \\
0,081\end{array}$ & $\begin{array}{c}\text { accesibilidad } \\
0,0715\end{array}$ & $\begin{array}{c}\text { litología } \\
0,0453\end{array}$ & $\begin{array}{c}\text { vegetación } \\
0,0314\end{array}$ & valor \\
\hline Noroeste & Muy baja & No & Baja & $\begin{array}{c}\text { ausencia de } \\
\text { formas } \\
\text { atenuadoras } \\
y \\
\text { potenciadora } \\
\mathrm{s}\end{array}$ & $\begin{array}{c}\text { Entre } 1^{\circ} \mathrm{y} \\
10^{\circ}\end{array}$ & 14 & $\begin{array}{l}\text { Camino a } \\
\text { menos de } 50 \\
\text { metros de la } \\
\text { costa }\end{array}$ & depósitos & Alta & 0,2341 \\
\hline
\end{tabular}




\begin{tabular}{|c|c|c|c|c|c|c|c|c|c|c|}
\hline $\begin{array}{l}\text { Bahía } \\
\text { Brava }\end{array}$ & Muy baja & Sí & Baja & $\begin{array}{c}\text { presencia de } \\
\text { formas } \\
\text { potenciadora } \\
\mathrm{s} \text { (bahía) y } \\
\text { atenuadoras } \\
\text { (Isla Fray } \\
\text { Menéndez) }\end{array}$ & $\begin{array}{c}\text { Entre } 1^{\circ} \mathrm{y} \\
10^{\circ}\end{array}$ & 4 & $\begin{array}{l}\text { Camino a } \\
\text { menos de } 50 \\
\text { metros de la } \\
\text { costa }\end{array}$ & $\begin{array}{l}\text { Costa } \\
\text { rocosa }\end{array}$ & Alta & 0,2703 \\
\hline & 1 & 3 & 1 & 2 & 3 & 5 & 3 & 3 & 1 & \\
\hline \multirow[t]{2}{*}{$\begin{array}{l}\text { Bahía } \\
\text { Mansa }\end{array}$} & Baja & Sí & Baja & $\begin{array}{l}\text { presencia de } \\
\text { formas } \\
\text { potenciadora } \\
\mathrm{s} \text { (bahía) }\end{array}$ & $\begin{array}{c}\text { Entre } 1^{\circ} \mathrm{y} \\
10^{\circ}\end{array}$ & 4 & $\begin{array}{l}\text { Camino a } \\
\text { menos de } 50 \\
\text { metros de la } \\
\text { costa }\end{array}$ & $\begin{array}{l}\text { Costa } \\
\text { rocosa }\end{array}$ & Alta & \multirow[t]{2}{*}{0,3339} \\
\hline & 1 & 3 & 1 & 3 & 3 & 5 & 3 & 3 & 1 & \\
\hline \multirow[t]{2}{*}{$\begin{array}{l}\text { Delta } A^{\circ} \\
\text { Las } \\
\text { Piedritas }\end{array}$} & Muy baja & No & Baja & $\begin{array}{c}\text { ausencia de } \\
\text { formas } \\
\text { atenuadoras } \\
y \\
\text { potenciadora } \\
\mathrm{s} \\
\end{array}$ & $\begin{array}{c}\text { Entre } 1^{\circ} \mathrm{y} \\
10^{\circ}\end{array}$ & 0 & $\begin{array}{c}\text { Camino a más } \\
\text { de } 50 \text { metros } \\
\text { de la costa }\end{array}$ & depósitos & Alta & \multirow[t]{2}{*}{0,1733} \\
\hline & 1 & 1 & 1 & 2 & 3 & 1 & 3 & 1 & 1 & \\
\hline \multirow[t]{2}{*}{ Cumelén } & Muy baja & No & Alta & $\begin{array}{l}\text { presencia de } \\
\text { formas } \\
\text { potenciadora } \\
\mathrm{s} \text { (bahía) }\end{array}$ & $\begin{array}{c}\text { Entre } 1^{\circ} \mathrm{y} \\
10^{\circ}\end{array}$ & 21 & $\begin{array}{l}\text { Camino a } \\
\text { menos de } 50 \\
\text { metros de la } \\
\text { costa }\end{array}$ & depósitos & Alta & \multirow[t]{2}{*}{0,2519} \\
\hline & 1 & 1 & 5 & 3 & 3 & 7 & 3 & 1 & 1 & \\
\hline \multirow[t]{2}{*}{$\begin{array}{c}\text { Delta Río } \\
\text { Bonito }\end{array}$} & Muy baja & Sí & Alta & $\begin{array}{c}\text { ausencia de } \\
\text { formas } \\
\text { atenuadoras } \\
y \\
\text { potenciadora } \\
\mathrm{s} \\
\end{array}$ & $\begin{array}{c}\text { Entre } 1^{\circ} \mathrm{y} \\
10^{\circ}\end{array}$ & 1 & $\begin{array}{l}\text { Camino a } \\
\text { menos de } 50 \\
\text { metros de la } \\
\text { costa }\end{array}$ & depósitos & Alta & \multirow[t]{2}{*}{0,2006} \\
\hline & 1 & 3 & 5 & 2 & 3 & 1 & 1 & 1 & 1 & \\
\hline \multirow[t]{2}{*}{$\begin{array}{c}\text { Bahía } \\
\text { Manzano }\end{array}$} & Muy baja & Sí & Baja & $\begin{array}{l}\text { presencia de } \\
\text { formas } \\
\text { potenciadora } \\
\mathrm{s} \text { (bahía) }\end{array}$ & $\begin{array}{c}\text { Entre } 1^{\circ} \mathrm{y} \\
10^{\circ}\end{array}$ & 15 & $\begin{array}{l}\text { Camino a } \\
\text { menos de } 50 \\
\text { metros de la } \\
\text { costa }\end{array}$ & depósitos & Alta & \multirow[t]{2}{*}{0,2970} \\
\hline & 1 & 3 & 1 & 3 & 3 & 7 & 3 & 1 & 1 & \\
\hline \multirow[t]{2}{*}{$\begin{array}{l}\text { Muelle de } \\
\text { Piedra }\end{array}$} & Muy baja & Sí & Baja & $\begin{array}{c}\text { ausencia de } \\
\text { formas } \\
\text { atenuadoras } \\
y \\
\text { potenciadora } \\
\mathrm{s}\end{array}$ & $\begin{array}{c}\text { Entre } 1^{\circ} \mathrm{y} \\
10^{\circ}\end{array}$ & 2 & $\begin{array}{c}\text { Camino a más } \\
\text { de } 50 \text { metros } \\
\text { de la costa }\end{array}$ & $\begin{array}{l}\text { Costa } \\
\text { rocosa }\end{array}$ & Alta & \multirow[t]{2}{*}{0,1870} \\
\hline & 1 & 3 & 1 & 2 & 3 & 3 & 1 & 3 & 1 & \\
\hline
\end{tabular}

Cuadro $N^{\circ} 11$. Vulnerabilidad frente a tsunamis. Villa La Angostura. La matriz presenta la descripción de los sectores costeros en virtud de cada una de las variables y factores seleccionados. Fuente: elaboración propia sobre la información recabada en observaciones de campo, imágenes satelitales, fotos aéreas y datos del Censo Nacional de Población, Hogares y Viviendas 2010.

Los valores estimados para todos los sectores fueron clasificados en muy bajo, bajo, medio, alto y muy alto siguiendo un criterio de clasificación por intervalos naturales y representados cartográficamente, mostrando la localización de los sectores más vulnerables a un tsunami lacustre.

\subsection{Resultados y conclusiones}

El tsunami de 1960 en el lago Nahuel Huapi, permitió una primera aproximación al riesgo de tsunamis contado por los habitantes de ese entonces. La realidad de San Carlos de Bariloche a comienzos de la década de 1960 era completamente distinta: como se 
observó en el Capítulo 3, la población era menor así como también los turistas que llegaban a la región.

El crecimiento que han experimentado las localidades costeras de lago Nahuel Huapi condujo a la ocupación creciente de espacios litorales que las ha vuelto más vulnerables a los efectos de un tsunami lacustre: en la actualidad, aproximadamente el $20 \%$ de la costa de lago Nahuel Huapi se encuentra poblada.

En este contexto, emerge como necesaria la evaluación de la vulnerabilidad a través de distintos factores -condicionantes y precondicionantes- que permitan reconocer grados de vulnerabilidad (Figura $\mathrm{N}^{\circ} 36$ y $\mathrm{N}^{\circ} 37$ ). Los factores que determinan los impactos de una ola extraordinaria, tales como la densidad de población, la infraestructura costera, la vegetación, los deslizamientos subacuáticos (incluyendo sectores deslizados y aún sin deslizar), la presencia de playas públicas, pendientes, entre otros, muestran una valoración diferente, es decir, una mayor o menor importancia relativa priorizando el enfoque social y su interacción con aspectos físicos que atañen a la problemática.

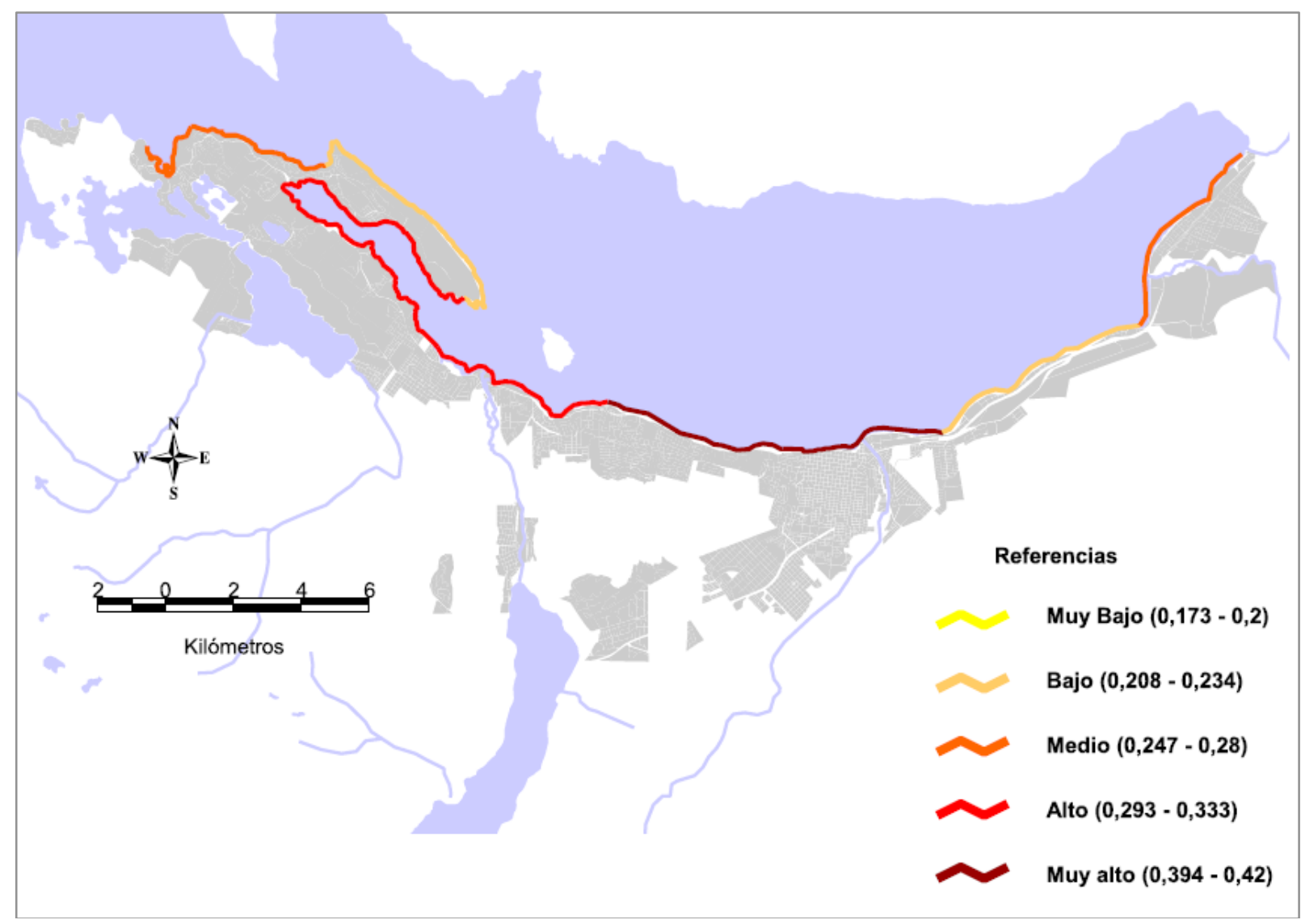

Figura $N^{\circ} 36$. Mapa de vulnerabilidad frente a eventos tsunamis en costas urbanizadas del lago Nahuel Huapi en las localidades de San Carlos de Bariloche y Dina Huapi. Las costas del centro de Bariloche y cercanas a ellas 
presentan los niveles más elevados de vulnerabilidad. Áreas costeras de Dina Huapi y en torno a Playa Bonita presentan valores altos. Fuente: elaboración propia.

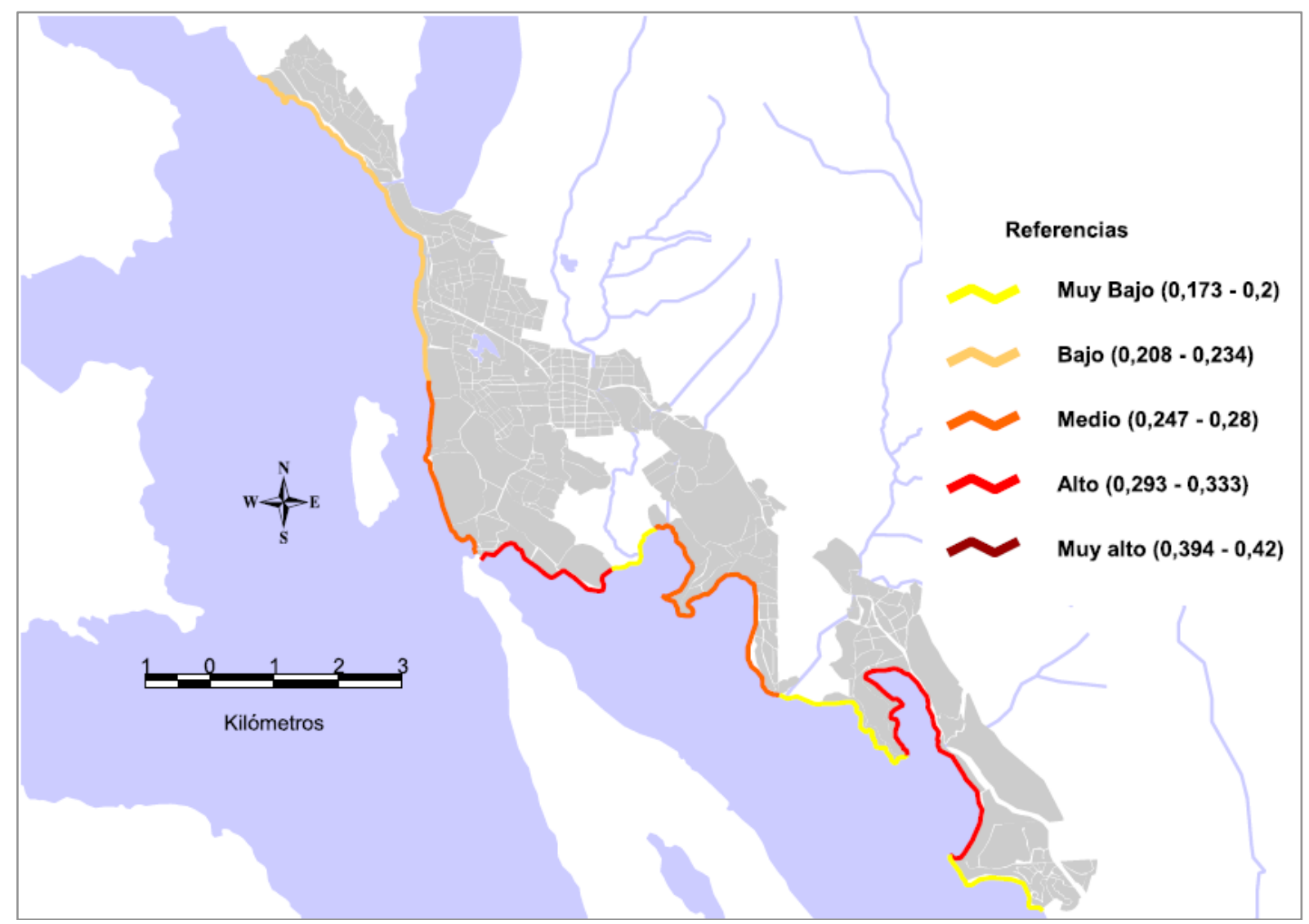

Figura $N^{\circ} 37$. Mapa de vulnerabilidad frente a eventos tsunamis en costas urbanizadas del lago Nahuel Huapi en Villa La Angostura. Si bien no hay registros que alcancen valores muy altos de vulnerabilidad, las costas del sector sur del ejido urbano en torno a las Bahías La Mansa, Las Balsas, Bustillo y Manzano presentan niveles altos de vulnerabilidad. Fuente: elaboración propia.

La aplicación de una metodología que incorpore esta complejidad resultó sumamente propicia para reconocer las franjas litorales más vulnerables a un evento de tsunami. Áreas densamente pobladas, como el centro de San Carlos de Bariloche, otras con playas turísticas y formas costeras que amplifican las olas, como ocurre en Villa La Angostura, o en entornos deltaicos donde los deslizamientos subacuáticos son frecuentes, como el caso de Dina Huapi, muestran valores altos y muy altos de vulnerabilidad frente a olas de tipo tsunami.

La expansión de las localidades implicadas en este estudio, han involucrado espacios costeros de otros lagos adyacentes -Moreno, Gutiérrez, Correntoso-, donde reconocer áreas vulnerables para una planificación urbana que incorpore este riesgo representa un desafío a futuro para toda la región. 


\subsection{Bibliografía del capítulo}

BEIGT D.; MANZONI C.; VILLAROSA G.; GOMEZ E. A. 2014a. Estudio de los deslizamientos subacuáticos en la cuenca distal del lago Nahuel Huapi (Argentina) a partir de batimetrías de alta resolución. XIX Congreso Geológico Argentino, junio 2014, Córdoba. 2 págs.

BEIGT D.; VILLAROSA G.; OUTES V.; DZENDOLETAS M. A.; GOMEZ E. A. 2013. Historias de deslizamientos y erupciones. Tsunamis en el lago Nahuel Huapi. Desde la Patagonia Difundiendo Saberes - Vol. 10 - No $15-2013$.

BEIGT D.; VILLAROSA G.; GOMEZ E. A. 2012(a). Deslizamientos subacuáticos en sistemas deltaicos del lago Nahuel Huapi: resultados preliminares de una evaluación de peligrosidad para la localidad de Villa La Angostura (Neuquén). II Jornadas Nacionales de Investigación y Docencia en Geografía Argentina (2da JONIDGA) y VIII Jornadas de Investigación y Extensión del Centro de Investigaciones Geográficas (8va JIECIG). Tandil, 14-16 de noviembre de 2012.

BEIGT D.; VILLAROSA G.; GOMEZ E. A. 2014(b). Análisis de deslizamientos subacuáticos en deltas lacustres (lago Nahuel Huapi, Argentina) a partir de batimetrías de alta resolución. Cuadernos de Investigación Geográfica. Núm. 40 (1). Págs. 247-259.

BEIGT D.; VILLAROSA G.; GÓMEZ E. A.; MANZONI C. 2016. Subaqueous landslides at the distal basin of Lago Nahuel Huapi (Argentina): Towards a tsunami hazard evaluation in Northern Patagonian lakes GEOMORPHOLOGY; Amsterdam; 2016 vol. 268 p. 197-206.

BEIGT D.; VILLAROSA G.; OUTES V.; DZENDOLETAS M. A.; GOMEZ E. A. 2012b. El lago Nahuel Huapi: un registro de erupciones, deslizamientos y tsunamis. Ciencia Hoy. Vol. 22, Págs. 50 - 56.

BEIGT D.; VILLAROSA G.; OUTES V.; GOMEZ E. A. 2016. Remobilized tephra in lacustrine deltas as a potential factor in landslide susceptibility evaluation: two deltas from northern Patagonia affected by the 2011 Cordón Caulle eruption. En Actas del Congreso "Cities on Volcanoes 9". Puerto Varas, Chile, 20-25 de noviembre de 2016.

BØE R.; HOVLAND M.; INSTANES A.; RISE L.; VASSHUS S. 2000. Submarine slide scars and mass movements in Karmsundet and Skudenesfjorden, southwestern Norway: morphology and evolution. Marine Geology 167, Págs. 147-165.

BRINK U. S. ten; GEIST E. L.; ANDREWS B. D. 2006. Size distribution of submarine landslides and its implication to tsunami hazard in Puerto Rico. Geophysical Research Letters, Vol. 33, Págs. 1-4.

BOUMA A. H. y BROUWER A. (Eds.).1964. Turbidites. Developments in sedimentology. Elsevier. Holanda. 264 Págs.

CHAPRON E., JUVIGNÉ E., MULSOW S., ARIZTEGUI D., MAGAND O., BERTRAND S., PINO M., CHAPRON O. 2007. Recent clastic sedimentation processes in Lake Puyehue (Chilean Lake District, $40.5^{\circ} \mathrm{S}$ ). Sedimentary Geology N²01, p. 365-385.

CORREA N. R. 2009. Evolución de las líneas de ribera y del camino público por efecto de los cambios regionales. Cuarto Simposio Regional sobre Hidráulica de Ríos. Salta, Argentina.

DZENDOLETAS M. I. 2012. "Determinación y análisis de áreas de potencial conflicto en el uso del suelo en el ejido municipal de San Carlos de Bariloche utilizando la tecnología de los Sistemas de Información Geográfica". Tesis de Maestría en Gestión Ambiental del Desarrollo Urbano. Inédito. 
ESCOSTEGUY L.; GEUNA S.; FRANCHI M.; GONZÁLEZ DÍAZ E.; DAL MOLÍN C.; CEGARRA M.; WILSON C.; ETCHEVERRÍA M.; GONZÁLEZ R. 2013. Hoja Geológica 4172II, San Martín de los Andes. Provincias del Neuquén y de Río Negro. Instituto de Geología y Recursos Minerales, Servicio Geológico Minero Argentino. Boletín 409. Buenos Aires.

FAO. 2009. Guía para la descripción de suelos. Organización de las Naciones Unidas para la Agricultura y la Alimentación. Cuarta edición. Roma, Italia. 99 págs. Disponible en http://www.fao.org/3/a-a0541s.pdf, consultada el 16 de Noviembre de 2016.

FREUNDT A.; STRAUCH W.; KUTTEROLF S.; SCHMINCKE H. U. (2007). Volcanogenic Tsunamis in Lakes: Examples from Nicaragua and General Implications. Pure and Applied Geophysics. 164:527-545.

GARDUÑO-MONROY V. H.; SORIA-CABALLERO D. C.; ISRADE-ALCÁNTARA I.; HERNÁNDEZ MADRIGAL V. M.; RODRÍGUEZ-RAMÍREZ A.; OSTROUMOV M.; RODRÍGUEZ-PASCUA M. Á.; CHACON-TORRES A.; MORA-CHAPARRO J. C. 2011. Evidence of tsunami events in the Paleolimnological record of Lake Pátzcuaro, Michoacán, Mexico. Geofísica Internacional, 502: 147-161.

GIACOSA R. y N. HEREDIA C. 2001. Hoja Geológica 4172-IV. San Carlos de Bariloche. Provincias de Río Negro y Neuquén. Instituto de Geología y Recursos Minerales, Servicio Geológico Minero Argentino. Boletín 279. Buenos Aires.

GONZALEZ BONORINO F. 1973. Geología del área entre San Carlos de Bariloche y Llao Llao. Publicación $\mathrm{N}^{\circ}$ 16. Departamento de Recursos Naturales y Energía. Fundación Bariloche.

ICHINOSE G. A.; SATAKE K.; ANDERSON J. G.; SCHWEICKERT R. A. y LAHREN M. M. 2000. The potential hazard from tsunami and seiche waves generated by future large earthquakes within the Lake Tahoe basin, California-Nevada. Geophysical Research Letters 27: 1203-1206.

KREMER K.; SIMPSON G.; GIRARDCLOS S. 2012. Giant Lake Geneva tsunami in AD 563. Nature Geoscience, vol. 5, $\mathrm{n}^{\circ} 11$, p. 756-757.

LAGOS M. 2012. Zonificación del riesgo de tsunami en el centro-sur de Chile. Revista de Geografía Norte Grande N53; Págs. 7-21.

LAGOS M. y CISTERNAS M. 2004. Depósitos de tsunamis como indicadores de riesgo: evidencias sedimentarias. Revista Geográfica de Chile Terra Australis N49; 2004; Págs. 329-351.

LASTRAS G.; AMBLAS D.; CALAFAT A. M.; CANALS M.; FRIGOLA J.; HERMANNS R. L.; LAFUERZA S.; LONGVA O.; MICALLEF A.; SEPÚLVEDA S. A.; VARGAS G.; DE BATIST M.; VAN DAELE M.; AZPIROZ M.; BASCUÑÁN I.; DUHART P.; IGLESIAS O.; KEMPF P.; RAYO X. 2013. Landslides Cause Tsunami Waves: Insights From Aysén Fjord, Chile, Eos Trans. AGU, 94 (34), 297.

MANZONI C.; DELMÉNICO A.; BEIGT D.; VILLAROSA G. 2013. Análisis preliminar de susceptibilidad frente a tsunamis lacustres en costas urbanizadas del lago Nahuel Huapi (Río Negro) en base a la interpretación de imágenes satelitales y fotos aéreas. En NIZ, ORTIZ, RAMOS y CARRIZO (Eds.). 2013. Libro de Resúmenes y Trabajos Completos $1^{\circ}$ Congreso Internacional sobre Riesgos de Desastres y Desarrollo Territorial Sostenible. 1a ed. Catamarca: Editorial Científica Universitaria de la Universidad Nacional de Catamarca. Págs. 428-429. 
MERMOZ M.; ÚBEDA C.; GRIGERA D.; BRION C.; MARTÍN C., BIANCHI E., PLANAS H. 2009. El parque Nacional Nahuel Huapi. Sus características ecológicas y estado de conservación. Administración de Parques Nacionales. Primera Edición. Buenos Aires, Argentina. 80 págs.

MARSHALL J. 2012. Ancient tsunami devastated Lake Geneva shoreline. Nature news. 28 de octubre de 2012. Págs 1-4. En: http://www.nature.com/news/ancient-tsunami-devastatedlake-geneva-sh.

MOERNAUT J.; VAN DAELE M.; HEIRMAN K.; FONTIJN K.; STRASSER M.; PINO M.; R. URRUTIA; DE BATIST M. 2014. Lacustrine turbidites as a tool for quantitative earthquake reconstruction: New evidence for a variable rupture mode in south central Chile, J. Geophys. Res. Solid Earth, 119, 1607-1633, doi:10.1002/2013JB010738.

MORA R.; VAHRSON W.; MORA S. 1992. Mapa de Amenaza de Deslizamientos, Valle Central, Costa Rica. Centro de Coordinación para la Prevención de Desastres Naturales en América Central (CEPREDENAC).

MORA CHINCHILLA R.; CHAVES GAMBOA J.; VÁSQUEZ FERNÁNDEZ M. 2002. Zonificación de la susceptibilidad al deslizamiento: Resultados obtenidos para la península de Papagayo mediante la modificación del método Mora-Vahrson. En III Curso Internacional Microzonificación y su aplicación en la mitigación de desastres (pp. 38-46). Japón. Agencia de Cooperación Internacional del Japón (JICA); Organización Panamericana de la Salud; Centro Panamericano de Ingeniería Sanitaria y Ciencias del Ambiente (CEPIS); Universidad Nacional de Ingeniería. Facultad de Ingeniería Civil; Centro Peruano Japonés de Investigaciones Sísmicas y Mitigación de Desastres (CISMID).

MULDER T. y ALEXANDER J. (2001). The physical character of subaqueous sedimentary density flows and their deposits. Sedimentology 48, p. 269-299

PEREYRA F.; ALBERTONI J.; BRÉARD C.; CAVALIARO S.; COCCIA M.; DUCÓS E.; DZENDOLETAS M.; FOOKES S.; GETINO E.; HELMS F.; KRUCK W.; LÓPEZ R.; MUZIO C.; ROVERANO D.; TOBIO M.; TOLOCZYKI M.; WILSON C. 2005. Estudio geocientífico aplicado al ordenamiento territorial. San Carlos de Bariloche. Anales 42, SEGEMAR. Buenos Aires. 181 Págs.

Proyecto Sirad. Sistema de información sobre recursos para atención de desastres. 2010. Investigación sobre el PELIGRO DE TSUNAMI en el Área Metropolitana de Lima y Callao. Informe de actividades №3. Volumen 14.

SAATY T. 1977. A Scaling Method for Priorities in Hierarchical Structures", Jounal of Mathematical Psychology, Vol. 15. Págs. 234-281

SAATY T. L. 1990. How to make a decision: The Analytic Hierarchy Process. European Journal of Operational Research 48, Págs. 9-26.

SMOOT J. P.; LITWIN R. L.; BISCHOFF J. L.; LUND, S. J. 2000. Sedimentary record of the 1872 earthquake and Tsunami at Owens Lake, SE California. Sedimentary Geology 135. Págs. 241-254.

STRAHLER A. N. y STRAHLER A. H. 1989. Geografía física. Omega. Barcelona. Tercera edición. 636 Págs.

TARBUCK, E. J.; LUTGENS, F. K.; TASA, D. 2005. CIENCIAS DE LA TIERRA. Pearson Educación S. A., Madrid. 
UNDHA/GENEVA. 1994. "Tsunamis". Evaluación de la población y planes de uso del suelo para mitigar sus efectos. Decenio Internacional para la Reducción de Desastres Naturales DIRND”. Perú. 50 Págs.

VALLMITJANA R. (s/f). Navegación pionera, Puerto San Carlos de Bariloche.

VAN DAELE M.; MOERNAUT J.; DOOM L.; BOES E.; FONTIJN K.; HEIRMAN K.; BRÜMMER R. 2015. A comparison of the sedimentary records of the 1960 and 2010 great Chilean earthquakes in 17 lakes: Implications for quantitative lacustrine palaeoseismology. Sedimentology, 62(5), 1466-1496.

VELASCO E.R. y LÓPEZ G.I. 2016. Marco conceptual para investigaciones tsunamigénicas: caso litoral Pacífico colombiano. Boletín de Geología, 38(4): 79-106. DOI: http://dx.doi.org/10.18273/revbol.v38n4-2016005

VELÁSQUEZ A.; MEYER H.; PERALTA H. 2002. Zonificación de amenazas por tsunami y licuación en el litoral de Nariño. Universidad del Valle, Observatorio Sismológico del Sur Occidente (OSSO). Santiago de Cali.

VILLAROSA G.; OUTES V.; GOMEZ E. A.; CHAPRON E.; ARIZTEGUI D. 2009. Origen del tsunami de mayo de 1960 en el lago Nahuel Huapi, Patagonia: aplicación de técnicas batimétricas y sísmicas de alta resolución. Revista de la Asociación Geológica Argentina. 65 (3): 593 - 597.

WAGNER T. P.; MCKEE C. O.; KUDUON J.; KOMBUA R. 2003. Landslide-induced wave in a small volcanic lake: Kasu Tephra Cone, Papua New Guinea. Int J Earth Sci (Geol Rundsch) 92:405-406. DOI 10.1007/s00531-003-0323-1

ZUIDAM R. A. Van 1986. Aerial photo-interpretation in terrain analysis and geomorphologic mapping (No. C 25102). Smits Publishers. The Hague. 441 Págs.

\section{Otras fuentes}

Google Earth. Versión 7.1.8.3036.

Diario Río Negro. 23 y 25 de mayo de 1960.

Fotos áreas INTA (1967) y Servicio Hidrológico Naval (1970).

INPRES. http://www.inpres.gov.ar/Ing_Sismorres/Reglamentos.html\#Zonificación Sísmica. Consultada el 23 de julio de 2015.

Rock-Color Chart with genuine Munsell color chips. 1991. The Geological Society of America. Séptima impresión.

Centro Sismológico Nacional. Universidad de Chile. http://evtdb.csn.uchile.cl/events. Consultada el 16 de agosto de 2017.

Earthquake Hazards Program. USGS (Servicio Geológico de los Estados Unidos). https://earthquake.usgs.gov/earthquakes/browse/. Consultada el 25 de agosto de 2017.

Ordenanza № 1541-CM-05. Municipalidad de San Carlos de Bariloche.

CÓDIGO DE PLANEAMIENTO URBANO aprobado por Ordenanza N 169-I-1979 Municipalidad de San Carlos de Bariloche. 


\section{CAPÍTULO VI}

\section{CONCLUSIONES}

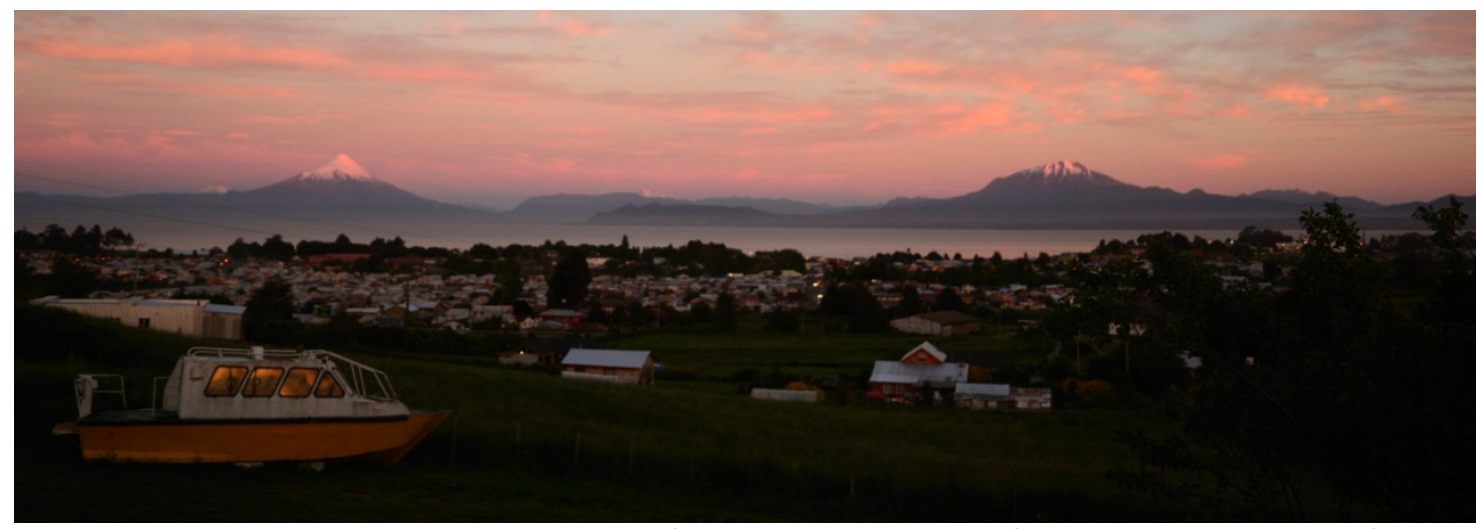

Vista panorámica del Lago Llanquihue, Chile. Los volcanes Osorno (izquierda) y Calbuco (derecha), representan dos grandes amenazas para la región del Nahuel Huapi. Llanquihue, 24 de Noviembre de 2016. Foto del autor. 
Al comienzo de este trabajo se analizaron las principales definiciones teóricas acerca de los riesgos en el marco de tendencias actuales para, de este modo, hallar aspectos que debieran tenerse en cuenta al momento de estudiar la vulnerabilidad en contexto de amenazas específicas, como la caída de ceniza volcánica y los tsunamis lacustres. A partir de ello, se reconoció la relevancia de nociones como exposición, donde la población afectable y sus características demográficas debieran estar presentes. Se le otorgó un lugar significativo a la incertidumbre y a la importancia de considerar el abordaje de los peligros y sus condicionantes naturales para, precisamente, reducir la incertidumbre científica en la materia.

Asimismo, se destacó el rol que adquirió la vulnerabilidad en el estudio de los riesgos y, sobre todo, sus diferentes visiones, las cuales condujeron a la adopción de una posición metodológica concreta, donde las condiciones socioeconómicas previas a un evento natural adquieren un rol significativo. Pero la discusión acerca de la vulnerabilidad no se agotó allí. El rol de las ciencias sociales en la abordaje de la vulnerabilidad y particularmente el caso de la geografía, tuvo su discusión donde se insistió fuertemente en que los esfuerzos debieran orientarse al aporte de la visión territorial de la problemática, es decir, la diferenciación y distribución espacial de los fenómenos sobre la superficie de la tierra. Esta mirada, sumada a la tendencia actual de la gestión local de los riesgos, condujo al interés metodológico de abordar ambas amenazas según los espacios urbanos que se sitúan a orillas del lago Nahuel Huapi, es decir, San Carlos de Bariloche y Dina Huapi por un lado y Villa La Angostura, por el otro.

El desarrollo histórico expuso cómo la región del Nahuel Huapi fue adquiriendo un perfil turístico, lo que le otorga una vulnerabilidad económica per se, por la sensibilidad que tiene esta actividad a eventos disruptivos como la caída de ceniza volcánica. La lejanía de la región a los principales centros poblados del país y la consecuente dependencia de los medios de trasportes aéreos y terrestres, sumado a la dependencia que numerosas producciones locales tienen del turismo para vender sus productos (chocolates, cervezas artesanales, productos regionales, entre otros) magnifican los impactos económicos de las erupciones volcánicas. Los aspectos demográficos permitieron también destacar el crecimiento de la población y su fuerte componente migratorio, variable sumamente importante en la exposición frente a fenómenos naturales en general, condición muy ligada a la hipótesis específica sobre caída de ceniza volcánica.

En primer lugar, sobresalen los factores naturales desencadenantes, en este caso, la caída de ceniza volcánica procedente de las erupciones explosivas de los volcanes andinos. 
Como se mostró a lo largo del trabajo, la región del Nahuel Huapi se encuentra altamente expuesta a la caída de ceniza volcánica, no sólo avalado por los recientes acontecimientos eruptivos sino también por los niveles de tefras preservados en los registros lacustres. Para ello, se extrajo un testigo sedimentario de la laguna El Trébol, donde se observaron las características sedimentológicas del mismo y los niveles de tefras preservados. A partir de este registro, se determinó la recurrencia de erupciones explosivas significativas que afectaron en la región del Nahuel Huapi representando el Cordón Caulle una de las mayores amenazas para la zona.

En segundo lugar, el otro aspecto relevante en este estudio lo constituye el análisis de la vulnerabilidad social. La erupción del Cordón Caulle en 2011, unos meses después de desarrollado el Censo de Población, Hogares y Viviendas 2010, permitió construir una metodología para evaluar la vulnerabilidad frente a la caída de ceniza volcánica y sus impactos específicos. Dicha erupción impactó fuertemente en Villa La Angostura, donde el relevamiento de impactos efectivos a través de los registros generados durante la emergencia permitió comparar y validar los resultados de distintas metodologías.

A partir de los impactos inherentes a una caída de ceniza volcánica, se procedió a analizar indicadores censales que permitan construir una metodología específica para evaluar la vulnerabilidad frente a la caída de material piroclástico. Como resultado, el material predominante de la cubierta exterior del techo, la procedencia del agua de beber y cocinar, las viviendas inconvenientes, el hacinamiento, la desocupación, la presencia de hogares con Jefe de hogar femenino, el analfabetismo y la leña y/o carbón como combustible usado principalmente para cocinar, emergieron como los indicadores censales apropiados para analizar la vulnerabilidad social.

A partir de esta instancia, y en función de la relevancia que debía adquirir cada indicador, apareció como necesario efectuar una ponderación de tales indicadores, ya sea a partir de un criterio cuantitativo como cualitativo. Esta selección de indicadores censales, sumada a la posibilidad de replicar la metodología en cualquier parte del territorio nacional, es uno de los aportes más significativos de esta tesis al estudio de la vulnerabilidad social frente a la caída de ceniza volcánica.

Una metodología cuantitativa, aplicada -el Proceso Analítico Jerárquico-, mostró que ciertos espacios urbanos presentan niveles de vulnerabilidad elevados, cuando se tata de áreas residenciales de elevado poder adquisitivo. Numerosos servicios básicos aún no se encuentran disponibles para todos los habitantes de Villa La Angostura, como las redes de 
agua potable, cloacal y de gas, lo que reduce las condiciones bienestar, que se reflejan en un aumento de la vulnerabilidad.

La otra metodología, de carácter cualitativo presentada en esta tesis, mostró que determinadas áreas urbanas presentan niveles elevados de vulnerabilidad, pese a que ciertos servicios esenciales como el acceso al agua potable están presentes. Frente a esto, y a partir de la sistematización de los registros, se reveló que hacia estás áreas se destinó gran parte de la ayuda en el momento de la emergencia volcánica.

Ambas metodologías se complementan para comprender la vulnerabilidad y su expresión espacial, sin reducir el análisis a un único mapa. Complementariamente, se pudo observar que amplios espacios urbanos, sobre todo al interior de San Carlos de Bariloche, son altamente vulnerables a la caída de material piroclástico, especialmente por elevado número de habitantes, su gran extensión territorial y las condiciones habitacionales que presentan, donde el material de los techos es uno de los factores específicos más críticos.

A medida que el proceso de elaboración de esta tesis corría, el análisis de la percepción del riesgo se presentaba cada vez más complejo, muy difícil de abordar: la experiencia del Cordón Caulle en 2011 tuvo tal significancia en las comunidades del lago Nahuel Huapi, que resulta muy difícil llegar a saber qué conocimientos poseían sobre este riesgo con anterioridad a este evento. A partir del intercambio con la población y organismos públicos a través de distintas actividades y visitas, se pudo observar que el aprendizaje en la población y organismos públicos ha sido significativo, sobre todo en Villa La Angostura, posicionándose como la comunidad que más atesoró la experiencia. Ello pudo observarse tanto en los cambios operados a partir de 2011, sobre todo en el suministro de agua potable, como así también en la respuesta verificada, durante la erupción del volcán Calbuco en abril de 2015.

A partir de esto se abre otra perspectiva: la vulnerabilidad se expresa tanto en los impactos registrados como así también en las mejoras materiales y de gestión que debieron emprenderse después de la erupción (por ejemplo, en servicios básicos), dado que se visualizaron problemáticas que pasaron a ser prioritarios en la agenda en la administración pública local. Quizás aún resta que los aprendizajes de las experiencias de Cordón Caulle se plasmen en protocolos de actuación integrados, tanto en las protecciones civiles como en los organismos encargados de los servicios básicos (electricidad, agua, cloacas). Ello conduciría a capitalizar al máximo los aprendizajes derivados de las experiencias anteriores (Cordón Caulle y Calbuco). 
A partir del intercambio con diferentes actores sociales e institucionales de Villa La Angostura (Protección Civil, educación, salud, obras públicas, bromatología) se pudo apreciar una escasa percepción de los riesgos volcánicos en las comunidades del Nahuel Huapi, no sólo por la alta población migrante que comúnmente no tiene presente los riesgos naturales, sino también por lo que manifestaron algunos entrevistados que presenciaron la erupción de 1960, quienes señalaron que en aquella época se tomaba todo con más naturalidad; lejos se estaba del caos que se vivió en 2011.

Si algo se puede destacar de las recientes erupciones (Chaitén, Cordón Caulle y Calbuco) es que la caída de cenizas adquirió un lugar significativo en los medios de comunicación así como también en la sociedad en general. Como se vio oportunamente, los impactos económicos trajeron enormes perjuicios a las localidades de la región del Nahuel Huapi, afectando de uno u otro modo a toda la población en su conjunto. A su vez, estos impactos se tornan cada vez más profundos en la medida en que los flujos aéreos y terrestres son cada vez mayores, la población crece continuamente y los espacios urbanos se expanden. Indudablemente, la percepción del riesgo cambió, su presencia se hizo más notoria, sobre todo a partir de la experiencia de 2011. Avanzar en la dirección de entender mejor la percepción del riesgo volcánico, mediada por dos erupciones, requiere de estudios complejos, acabados y multidisciplinarios (sociólogos, geógrafos, historiadores, entre otros) y es esto lo que condujo a una pequeña modificación de la hipótesis asociada a la caída de ceniza volcánica, la cual originalmente comprendía la percepción del riesgo, aunque sólo como un mero contexto de la vulnerabilidad social.

Lejos de significar un problema, ello condujo a una orientación de los esfuerzos hacia la construcción de una metodología lo más sólida posible para evaluar la vulnerabilidad frente a la caída de material piroclástico. Este enfoque no es frecuente de observar, dado que gran parte de los trabajos sobre vulnerabilidad se han orientado casi exclusivamente a los impactos de cenizas en la infraestructura (vulnerabilidad física), es decir, servicios de agua potable, comunicaciones, electricidad, entre otros, sin incorporar de manera concreta diferentes aspectos sociales que marcan de una manera significativa la vulnerabilidad, a la vez que también aportan información a los tomadores de decisiones (sitios con mayor vulnerabilidad social). En este contexto, esta propuesta es simplemente una flecha de lanza para iniciar la discusión en materia de vulnerabilidad frente a los riesgos volcánicos en el país.

Los efectos de la caída de ceniza volcánica no sólo se limitan al ámbito social. Como se ha visto, los niveles de tefra constituyen parte del material sedimentario del lecho lacustre 
y, por su baja cohesión, serían susceptibles de actuar como potenciales planos de deslizamiento.

Para estudiar los impactos posibles de un tsunami lacustre, deben considerarse el peligro y la vulnerabilidad asociada. En primer lugar, entre las distintas causas que inducen a los tsunamis se encuentran los sismos y, sobre todo, los deslizamientos subacuáticos. Para ello, a través de los relevamientos realizados mediante batimetrías de alta resolución, se visualizó la morfología del lecho lacustre, destacándose los sectores deslizados y sin deslizar. Los deslizamientos subacuáticos que se desarrollan en el lecho del lago Nahuel Huapi son capaces de movilizar un volumen de agua y sedimentos considerables y generar una ola de tipo tsunami, sobre todo en ambientes deltaicos.

El testigo extraído del Brazo Rincón, en proximidades del delta de los arroyos Pireco y Totoral, puso de manifiesto las relaciones entre procesos volcánicos, fluviales y lacustres, donde los flujos de densidad capaces de movilizar grandes volúmenes de agua y sedimentos se dan con gran frecuencia, procesos turbulentos que en ocasiones podrían desembocar en tsunamis lacustres. Vale recordar en este punto el evento reportado en este sitio en el año 2014.

Para abordar la vulnerabilidad social, el otro aspecto clave en este estudio, se identificaron y combinaron una serie de aspectos naturales y sociales. Precisamente, en este enfoque metodológico radica uno de los aportes de esta tesis doctoral para el estudio de impactos de olas extraordinarias. Entre ellos, se destacan, la densidad de población, la presencia de playas turísticas, los muelles y puertos como parte de la infraestructura fácilmente afectable, la accesibilidad, las pendientes costeras, la vegetación, los sectores deslizados y no deslizados del sustrato lacustre, las formas costeras (atenuantes y potenciadoras de los efectos de un tsunami) y la litología costera.

Luego de esto, se procedió a ponderar las variables seleccionadas aplicando el Proceso Analítico Jerárquico, para obtener los sectores costeros más vulnerables a los impactos de una ola de tipo tsunami. Esta combinación de factores a lo largo del período histórico de ocupación de los espacios costeros, ha ido creando una condición específica de peligrosidad natural y vulnerabilidad social muy visible en los ambientes costeros urbanizados en torno a la localidad de San Carlos de Bariloche y Villa La Angostura, con algunas zonas altamente vulnerables a los impactos de dichas olas.

El desafío a superar en materia de gestión de riesgos se encuentra en el aspecto político/administrativo. Por un lado, las múltiples jurisdicciones que conforman las poblaciones urbanas de la región del Nahuel Huapi dificultan la gestión integrada de riesgos, 
más aún cuando una de las localidades -Dina Huapi- no cuenta con su propio sistema de protección civil. Por otro lado, está latente el desafío de incluir en las legislaciones y planificaciones territoriales los riesgos naturales, sobre todo los que son menos conocidos, como los tratados en esta tesis. El ordenamiento territorial de las localidades costeras del lago Nahuel Huapi debiera contemplar los avances que se vienen registrando en materia de conocimientos de peligros naturales, incorporando limitaciones más estrictas a las construcciones urbanas así como también a la regulación de los materiales constructivos de las edificaciones propensas a ser dañados por el peso de la ceniza, como los techos de chapa de cartón.

Emerge así la necesidad de reforzar aspectos referidos a la multidisciplinariedad en materia de riesgos, teniendo como punto de partida y acuerdo generalizado que el riesgo es una construcción social. Este tipo de estudios conducen a destacar la importancia realizar trabajos conjuntos entre diferentes ciencias contemplando conjuntamente los aspectos físicos y sociales en la comprensión de los peligros, especialmente generando avances en materia de conocimientos volcánicos (trabajos de base volcanológica para determinar recurrencia, magnitud y tipos de eventos), limnogeológicos/limnogeomorfológicos (recurrencia, magnitud y tipos de fenómenos) y la vulnerabilidad social (indicadores, infraestructuras, localización). Sólo así podrá reducirse la incertidumbre científica.

La discusión acerca de las estrategias metodológicas para abordar la vulnerabilidad social frente a estos peligros naturales está recién iniciada. El ámbito de aplicación es grande, sobre todo en una región con gran crecimiento demográfico. Por este motivo, el camino por recorrer es aún muy extenso. 


\section{AGRADECIMIENTOS}

A mi familia y amigos.

A mis directores de Bariloche y la Plata.

A mis compañeros del Grupo de Estudios Ambientales.

A las numerosas personas que colaboraron aportando información valiosa.

Agradecimientos especiales:

Administración de Parques Nacionales (APN).

Aguas Rionegrinas.

Archivo Visual Patagónico.

Biblioteca Popular Sarmiento (San Carlos de Bariloche, Río Negro).

Camping Brazo Rincón.

Centro Regional Universitario Bariloche (CRUB), Universidad Nacional del Comahue (UNCo).

Club Náutico Bariloche.

Cooperativa de Electricidad Bariloche (CEB).

Delegación de Estadísticas y Censos (San Carlos de Bariloche, Río Negro).

Departamento Provincial de Aguas (DPA), provincia de Río Negro.

Diario Río Negro.

Dirección de Bromatología, Municipalidad de Villa La Angostura.

Dirección de Estadísticas y Censos (provincia de Río Negro).

Dirección Nacional de Protección Civil (DNPC), Regional Patagónica.

Dirección Provincial de Estadística y Censos (provincia de Neuquén).

Dr. Eduardo Gómez (IADO-CONICET/UNS).

Facultad de Humanidades y Ciencias de la Educación (FaHCE), Universidad Nacional de La Plata (UNLP).

Honorable Concejo Deliberante de Villa La Angostura.

Instituto de Investigaciones en Biodiversidad y Medioambiente (INIBIOMA)CONICET/UNCO.

Instituto Andino Patagónico de Investigaciones en Tecnologías Biológicas y Geoambientales (IPATEC) - CONICET/UNCo.

Instituto Argentino de Oceanografía (IADO) - CONICET/UNS.

Instituto Nacional de Estadísticas y Censos (INDEC).

Museo de la Patagonia "Francisco P. Moreno"

Oficina de Catastro, Municipalidad de Villa La Angostura.

Prefectura Naval Argentina (PNA). 
Protección Civil de San Carlos de Bariloche.

Protección Civil de Villa La Angostura.

Sanatorio San Carlos (Bariloche).

Secretaría de Turismo, Municipalidad de San Carlos de Bariloche.

Secretaría de Turismo, Municipalidad de Villa La Angostura.

Subsecretaria de Planeamiento Territorial, Municipalidad de San Carlos de Bariloche.

\section{Proyectos de investigación asociados al desarrollo de la Beca Interna Doctoral del CONICET}

"Volcanismo explosivo y fenómenos catastróficos asociados en Norpatagonia Andina: recurrencia y peligrosidad". MINCYT. PICT 2010-2046 Investigador Responsable: Gustavo Villarosa

"Deslizamientos subacuáticos en deltas lacustres en el contexto de la evaluación de peligrosidad de tsunamis: hacia una gestión del riesgo en localidades costeras de los grandes lagos patagónicos". Agencia Nacional de Promoción Científica y Tecnológica, PICT 2015 N¹322 (Plan Argentina Innovadora 2020). IR: Débora Beigt

"Susceptibilidad a deslizamientos en ambientes subácueos del lago Nahuel Huapi. Relación potencial con la ocurrencia de olas extraordinarias tipo tsunami" Agencia Nacional de Promoción Científica y Tecnológica, PICT 2010 Impacto Regional Nº636. IR: Débora Beigt

"Los registros sedimentarios lacustres como herramienta de evaluación de peligrosidad volcánica y de eventos asociados en Patagonia: la Erupción del Volcán Chaitén como caso de estudio". PIP-CONICET 2011-2013GI. Investigador Responsable: Gustavo Villarosa.

"Medioambiente y sociedad. Peligros naturales y vulnerabilidad en poblaciones de Patagonia Andina”. PIN I B191. Universidad Nacional del Comahue. Centro Regional Universitario Bariloche. Director: Gustavo Villarosa. Período: 2014-2017. Unidad Académica: CCT Comahue, CONICET-Universidad Nacional del Comahue.

\section{Trabajos científicos que se produjeron durante el proceso de formación doctoral Reuniones científicas}

MANZONI C.; DELMÉNICO A.; BEIGT D.; VILLAROSA G. 2013. Análisis preliminar de susceptibilidad frente a tsunamis lacustres en costas urbanizadas del lago Nahuel Huapi (Río Negro) en base a la interpretación de imágenes satelitales y fotos aéreas. En Libro de Resúmenes y Trabajos Completos $1^{\circ}$ Congreso Internacional sobre Riesgos de Desastres y Desarrollo Territorial Sostenible / Niz, Ortiz, Ramos y Carrizo (Eds.)-1a ed. Catamarca: Editorial Científica Universitaria de la Universidad Nacional de Catamarca. Año 2013. Págs. 428-429. 
DELMÉNICO A.; VILLAROSA G.; BEIGT D.; OUTES V. 2015. "Pensando el volcanismo en términos de vulnerabilidad: la construcción de escenarios como herramienta de gestión de riesgos frente a la caída de ceniza volcánica en Bariloche y Dina Huapi (Patagonia, Argentina)". En actas del Seminario Internacional "Ciencias Sociales y Riesgo de Desastres en América Latina: un encuentro inconcluso". Bs. As., 15-17 de Septiembre de 2015. En: http://www.pirna.com.ar/files/pirna/SICSYRD_PON_DELMENICO_Agustin.pdf

DELMÉNICO A. Una mirada desde la vulnerabilidad y el riesgo hacia el campo del volcanismo explosivo en Norpatagonia Andina. Trabajo presentado en la "Jornada del Doctorado en Geografía", (FaHCE/ UNLP). La Plata, 28 de octubre de 2016. 15 Págs.

DELMÉNICO A.; VILLAROSA G.; BEIGT D.; OUTES V.; ANDRADE M. I.; MANZONI C. Census indicators as a tool to assess social vulnerability to ashfall events in Argentina: the case of Villa La Angostura during 2011 Cordón Caulle eruption. Resumen publicado para presentación en formato póster en el Congreso "Cities on volcanoes". Puerto Varas, Chile, 20-25 de noviembre de 2016.

VILLAROSA G.; OUTES V.; DELMÉNICO A.; BEIGT D.; COTTET J.; TOYOS G.; HORWELL C. J.; DAMBY D. E.; NAJORKA J.; ARRETCHE M.; WILSON T.; STEWART C. Impacts after the 2015 Calbuco eruption in Argentina and their relation to tephra deposit characteristics and climatic variables. Resumen publicado para presentación en formato póster en el Congreso "Cities on volcanoes". Puerto Varas, Chile, 20-25 de noviembre de 2016.

\section{Revistas científicas}

PETRINOVIC I .A.; VILLAROSA G .; D'ELIA L .; GUZMÁN S.; PÁEZ G.N.; OUTES V.; MANZONI C.; DELMÉNICO A.; BALBIS C.; CARNIEL R.; HERNANDO I.R. (2014). La erupción del 22 de diciembre de 2012 del volcán Copahue, Neuquén, Argentina: caracterización del ciclo eruptivo y sus productos. Revista Asociación Geológica Argentina (RAGA), Vol. 71; pp. 161-173.

D’ELIA; PÁEZ; HERNANDO; PETRINOVIC; GUSTAVO VILLAROSA; BILMES; BODAÑO; GUZMÁN; BORZI; SERRA VARELA; MANZONI; OUTES; DELMÉNICO; BALBIS (2014). Erupciones históricas del Volcán Tromen: análisis geomorfológico y geocronológico en su sector noroeste. RAGA, 2014, Vol. 71; pp. 444-448.

DELMÉNICO A.; VILLAROSA G.; BEIGT D.; OUTES V.; ANDRADE M. I.; MANZONI C. Los indicadores censales como herramienta para evaluar la vulnerabilidad social frente a la caída de ceniza volcánica. El caso de Villa La Angostura (Argentina) durante la erupción del Cordón Caulle 2011. Revista Universitaria de Geografía de la Universidad Nacional del Sur. En prensa.

\section{Capítulos de libros}

VILLAROSA G.; OUTES V.; MANZONI C.; DELMÉNICO A.; BEIGT D.; RAFAELLE M. (2016). Volcanes: alertas, peligros, riesgos ¿cómo gestionarlos?. En GERVASONI y CORSO (Coor.), COMBO DE CIENCIA Y CAFÉ. Tinta Libre. Córdoba, Argentina.

OUTES, V.; VILLAROSA, G.; DELMÉNICO, A.; GÓMEZ LISSARRAGUE, M.; BEIGT, D.; MANZONI C.; ARRETCHE M. 2014. La erupción del Cordón Caulle 2011 en Villa La Angostura: una experiencia de cooperación entre los sistemas científico y de protección civil. 
En VIAND, J. y BRIONES, F. (Comp.). 2014. Riesgos al sur. Especial Desastres y Sociedad. La Red.

\section{Informes técnicos}

D’ELIA; PÁEZ; HERNANDO; PETRINOVIC; VILLAROSA; BILMES; BODAÑO; GUZMÁN; CARNIEL; MANZONI; OUTES; DELMÉNICO. 2014. "Análisis de Peligrosidad Volcánica en el Cinturón Volcánico Domuyo-Tromen. Norte de la Provincia de Neuquén". Informe CientíficoTécnico. Convenio CONICET-Legislatura de Neuquén (Informe II).

OUTES V.; VILLAROSA G.; BEIGT D.; DELMÉNICO A. Abril 2015. ERUPCIÓN DEL VOLCÁN CALBUCO 2015. Informe técnico. Inédito. 15 Págs. 